Florida International University FIU Digital Commons

3-24-2014

\title{
Speciation, Metabolism, Toxicity, and Protein- binding of Different Arsenic Species in Human Cells
}

Szabina A. Stice

Florida International University, szabinastice@hotmail.com

DOI: $10.25148 /$ etd.FI14040844

Follow this and additional works at: https://digitalcommons.fiu.edu/etd

Part of the Analytical Chemistry Commons, Medicinal-Pharmaceutical Chemistry Commons, and the Toxicology Commons

\section{Recommended Citation}

Stice, Szabina A., "Speciation, Metabolism, Toxicity, and Protein-binding of Different Arsenic Species in Human Cells" (2014). FIU Electronic Theses and Dissertations. 1203.

https://digitalcommons.fiu.edu/etd/1203 


\section{FLORIDA INTERNATIONAL UNIVERSITY}

Miami, Florida

\section{SPECIATION, METABOLISM, TOXICITY, AND PROTEIN-BINDING OF DIFFERENT ARSENIC SPECIES IN HUMAN CELLS}

A dissertation submitted in partial fulfillment of

the requirements for the degree of

DOCTOR OF PHILOSOPHY

in

CHEMISTRY

by

Szabina Stice

2014 
To: Dean Kenneth G. Furton

College of Arts and Sciences

This dissertation, written by Szabina Stice, and entitled Speciation, Metabolism, Toxicity, and Protein-binding of Different Arsenic Species in Human Cells, having been approved in respect to style and intellectual content, is referred to you for judgment.

We have read this dissertation and recommend that it be approved.

$\begin{array}{r}\hline \text { Joong Ho Moon } \\ \hline \text { Yuan Liu } \\ \hline \text { Barry Rosen } \\ \hline \text { Lawrence Boise } \\ \hline \text { Yong Cai, Major Professor }\end{array}$

Date of Defense: March 24, 2014

The dissertation of Szabina Stice is approved.

\begin{tabular}{r} 
Dean Kenneth G. Furton \\
College of Arts and Sciences \\
\hline Dean Lakshmi N. Reddi \\
University Graduate School
\end{tabular}

Florida International University, 2014 


\section{ACKNOWLEDGMENTS}

I would like to thank the Florida International University Minority Biomedical Research Support Research Initiative for Scientific Enhancement (FIU MBRS RISE) program, Dr Charles Bigger, Dr Robert Lickliter, and the MBRS staff for their support.

I would like to thank my advisor, Dr Yong Cai for his guidance, continuous support, and patience throughout my $\mathrm{PhD}$ studies.

I am very grateful for all the scientific discussions and guidance I have received from Guangliang Liu, PhD. I would also like to thank him for the countless hours he patiently helped me to figure out and fix the problems I had with the analytical instrumentation.

I would like to thank Shannon Matulis, $\mathrm{PhD}$ for all her help with the cancer cells and Dr Boise, Dr Liu, Dr Moon, and Dr Rosen for their help, guidance, and participation in my committee.

I would also like to thank my family and all the other people who helped and supported me at Florida International University throughout my studies including but not limited to Dr Lichter, Dr McCord, Dr O’Shea, Dr Kavallieratos, and Dr Mebel.

A part of chapter 3 was accepted for publication in the journal of Chemical Research in Toxicology. Adapted with permission from Yehiayan, L., Stice, S., Liu, G., Matulis, S., Boise, L., \& Cai, Y. (2014). Dimethylarsinothioyl glutathione as a metabolite in human multiple myeloma cell lines upon exposure to Darinaparsin. Chemical Research in Toxicology. Copyright (2014) American Chemical Society. 


\title{
ABSTRACT OF THE DISSERTATION \\ SPECIATION, METABOLISM, TOXICITY, AND PROTEIN-BINDING OF \\ DIFFERENT ARSENIC SPECIES IN HUMAN CELLS
}

\author{
by \\ Szabina Stice \\ Florida International University, 2014 \\ Miami, Florida \\ Professor Yong Cai, Major Professor
}

Despite of its known toxicity and potential to cause cancer, arsenic has been proven to be a very important tool for the treatment of various refractory neoplasms. One of the promising arsenic-containing chemotherapeutic agents in clinical trials is Darinaparsin (dimethylarsinous glutathione, $\mathrm{DMA}^{\mathrm{III}}(\mathrm{GS})$ ). In order to understand its toxicity and therapeutic efficacy, the metabolism of Darinaparsin in human cancer cells was evaluated. With the aim of detecting all potential intermediates and final products of the biotransformation of Darinaparsin and other arsenicals, an analytical method employing high performance liquid chromatography inductively coupled mass spectrometry (HPLCICP-MS) was developed. This method was shown to be capable of separating and detecting fourteen human arsenic metabolites in one chromatographic run. The developed analytical technique was used to evaluate the metabolism of Darinaparsin in human cancer cells. The major metabolites of Darinaparsin were identified as dimethylarsinic acid $\left(\mathrm{DMA}^{\mathrm{V}}\right), \mathrm{DMA}^{\mathrm{III}}(\mathrm{GS})$, and dimethylarsinothioyl glutathione (DMMTA $\left.{ }^{\mathrm{V}}(\mathrm{GS})\right)$. Moreover, the method was employed to study the conditions and mechanisms of formation of thiol-containing arsenic metabolites from $\mathrm{DMA}^{\mathrm{III}}(\mathrm{GS})$ and $\mathrm{DMA}^{\mathrm{V}}$ as the 
mechanisms of formation of these important As species were unknown. The arsenic sulfur compounds studied included but were not limited to the newly discovered human arsenic metabolite $\operatorname{DMMTA}^{\mathrm{V}}(\mathrm{GS})$ and the unusually highly toxic dimethylmonothioarsinic acid $\left(\mathrm{DMMTA}^{\mathrm{V}}\right)$. It was found that these species may form from hydrogen sulfide produced in enzymatic reactions or by utilizing the sulfur present in protein persulfides. Possible pathways of thiolated arsenical formation were proposed and supporting data for their existence provided. In addition to known mechanism of arsenic toxicity such as protein-binding and reactive oxygen formation, it was proposed that the utilization of thiols from protein persulfides during the formation of thiolated arsenicals may be an additional mechanism of toxicity. The toxicities of $\mathrm{DMA}^{\mathrm{V}}(\mathrm{GS})$, DMMTA $^{\mathrm{V}}$, and DMMTA ${ }^{\mathrm{V}}(\mathrm{GS})$ were evaluated in cancer cells, and the ability of these cells to take the compounds up were compared. When assessing the toxicity by exposing multiple myeloma cells to arsenicals externally, $\operatorname{DMMTA}^{\mathrm{V}}(\mathrm{GS})$ was much less toxic than $\mathrm{DMA}^{\mathrm{III}}(\mathrm{GS})$ and $\mathrm{DMMTA}^{\mathrm{V}}$, probably as a result of its very limited uptake (less than $10 \%$ and $16 \%$ of $\mathrm{DMA}^{\mathrm{III}}(\mathrm{GS})$ and $\mathrm{DMMTA}^{\mathrm{V}}$ respectively). 


\section{TABLE OF CONTENTS}

CHAPTER

PAGE

CHAPTER 1 Introduction...............................................................................

1.1 Arsenic in the Environment and its Effects on Human Health ........................... 2

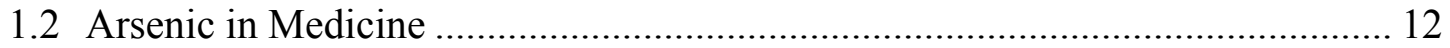

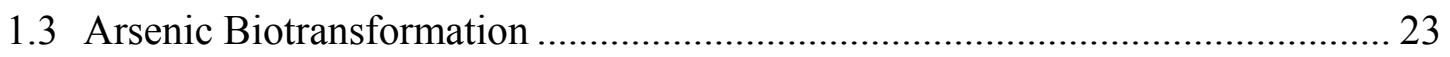

1.4 Arsenic Speciation in Biological Systems.................................................... 31

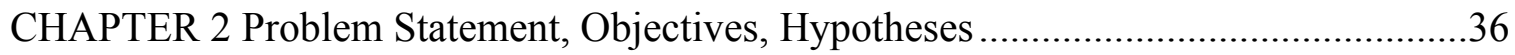

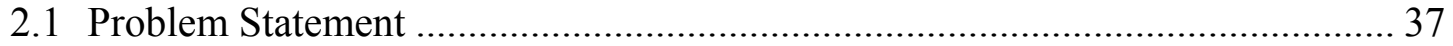

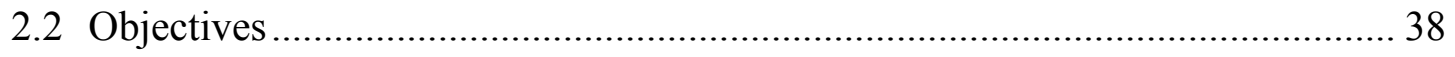

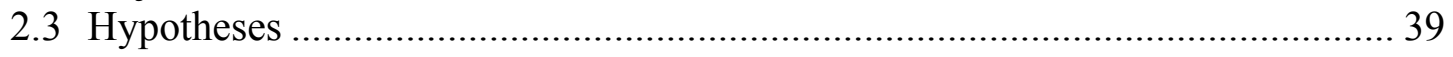

CHAPTER 3 Dimethylarsinothioyl Glutathione as a Metabolite in Human Multiple Myeloma Cell Lines upon Exposure to Darinaparsin: Formation, Toxicity, and Cellular Uptake

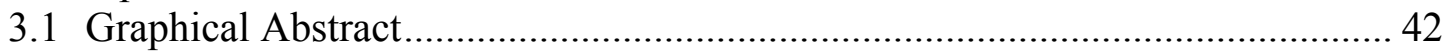

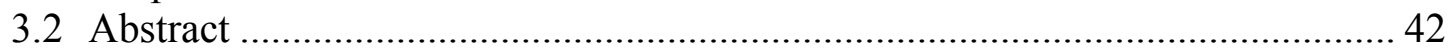

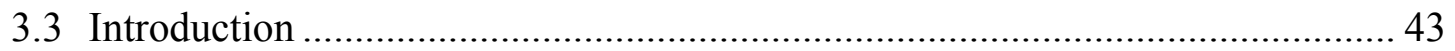

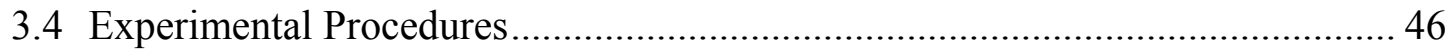

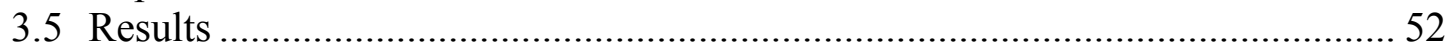

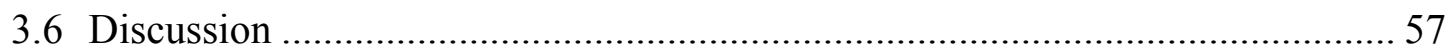

CHAPTER 4 Simultaneous Determination of Multiple Human Arsenic Metabolites Employing High Performance Liquid Chromatograph Inductively Coupled Plasma

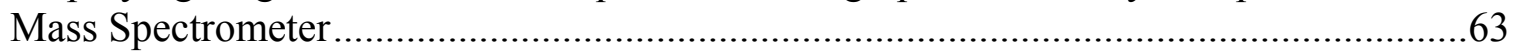

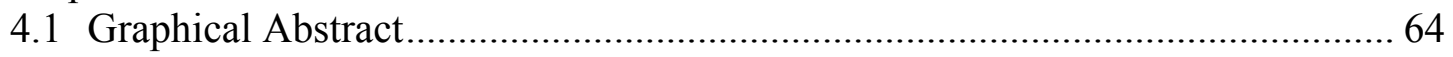

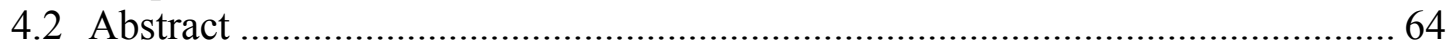

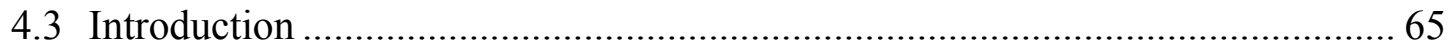

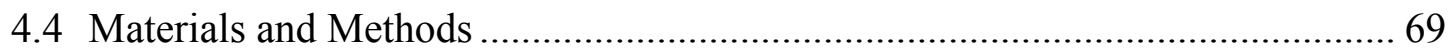

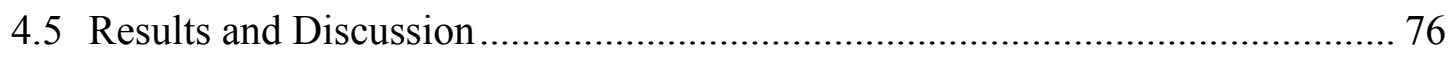

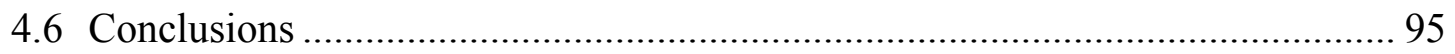

CHAPTER 5 Mechanistic Study on the Formation of Dimethylarsinothioyl Glutathione and Other Sulfur Containing Arsenic Metabolites...................................97

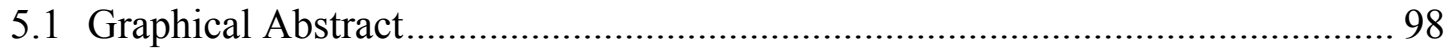

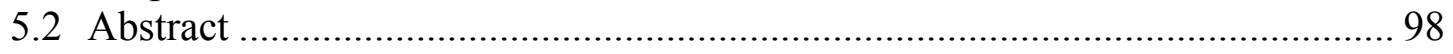

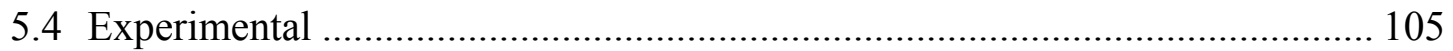

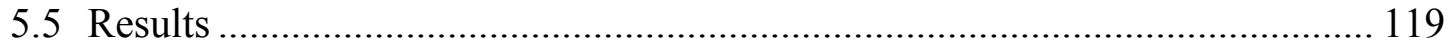

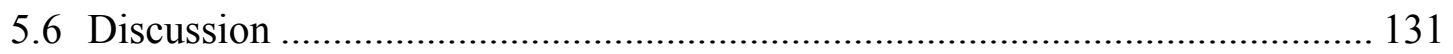


CHAPTER 6 Stabilization of Arsenic Metabolites in Biological Samples: The

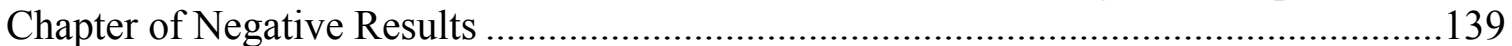

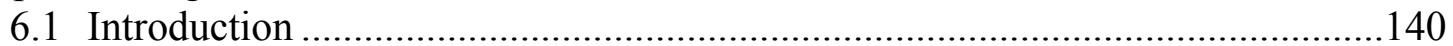

6.2 Experimental Procedures and Results.............................................................142

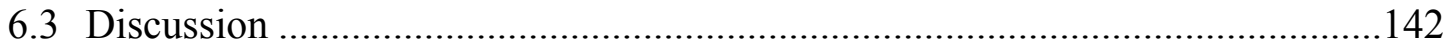

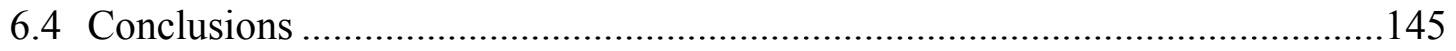

CHAPTER 7 Summary, Significance, and Future Research Directions .........................147

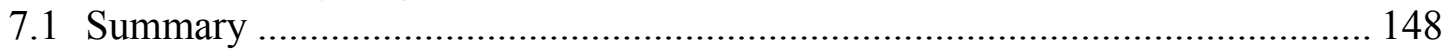

7.2 Significance and Implications of the Work Done ………….............................. 152

7.3 Future Research Directions ………………………...................................... 156

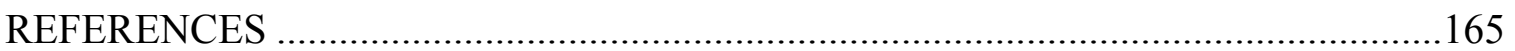

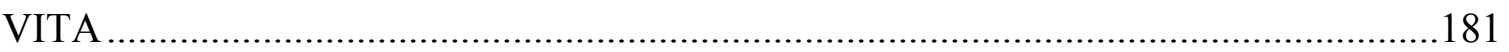




\section{LIST OF TABLES}

TABLE

PAGE

Table 1.1 Possible clinical manifestations of arsenicals in humans ............................... 7

Table 1.2 Arsenic species of interest in this study ............................................... 8

Table 1.2 Arsenic species of interest in this study (cont'd) ........................................ 9

Table 1.3 Binding affinities of trivalent arsenic species to hemoglobin........................ 10

Table 1.4 Arsenic-containing medicines............................................................... 13

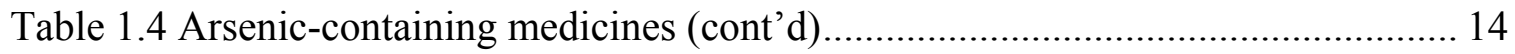

Table 3.1 Names, abbreviations, and structures of compounds of interest.................... 47

Table 3.2 ICP-MS and ESI-MS parameters employed.......................................... 49

Table 4.1 Thirteen arsenic species identified and separated by the developed method ... 68

Table 4.2 A Instrumental parameters after optimization ........................................ 80

Table 4.2 B Gradient elution program after optimization........................................ 80

Table 5.1 Infrared spectroscopy results for GYY4137 ........................................ 109

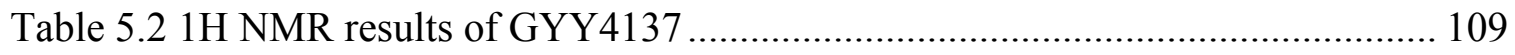

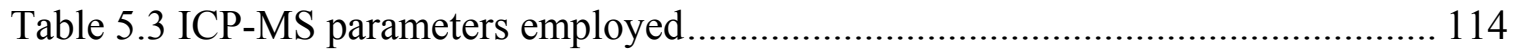

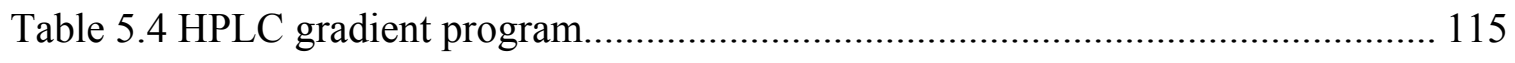

Table 5.5 Names, abbreviations, structures and peak numbers ............................... 120

Table 6.1 Agents explored for the stabilization of labile arsenicals .......................... 143 


\section{LIST OF FIGURES}

FIGURE

PAGE

Figure 1.1 Possible structures of Salvarsan ............................................................ 15

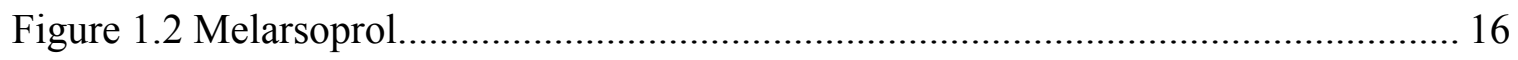

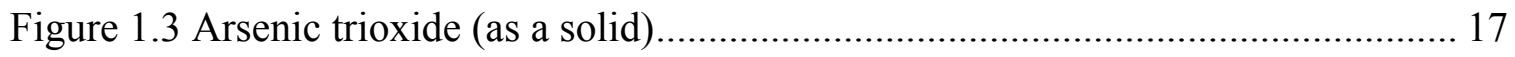

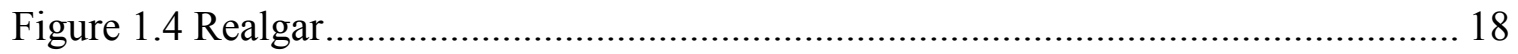

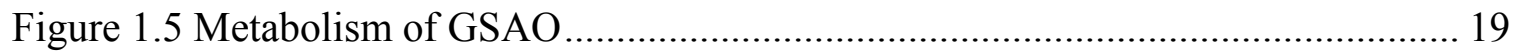

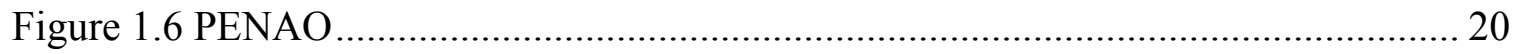

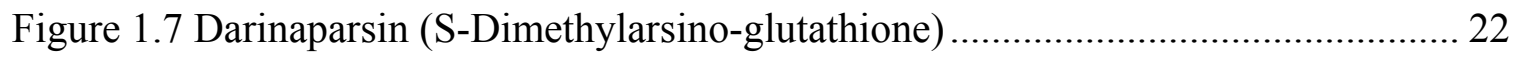

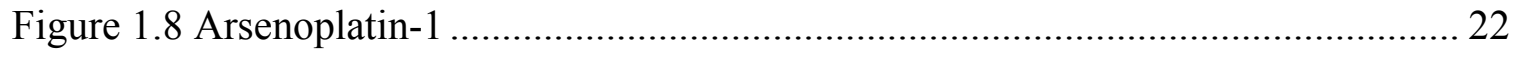

Figure 1.9 An early postulated scheme of metabolism (Challenger pathway) ................ 26

Figure 1.10 New metabolic pathway of arsenic proposed by Hayakawa ...................... 27

Figure 1.11 Proposed biotransformation pathway of iAs ${ }^{\mathrm{V}}$ by Naranmandura ................ 27

Figure 1.12 Proposed formation of thiolated arsenicals in rat hepatocytes by Suzuki ..... 28

Figure 1.13 Transformation of DMA ${ }^{\mathrm{III}}$ in rat RBCs proposed by Naranmandura et

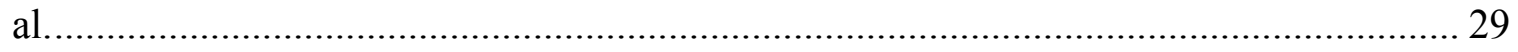

Figure 1.14 Arsenic cellular efflux pathways ........................................................ 31

Figure 3.1 HPLC-ICP-MS chromatograms of cell line and culture media both

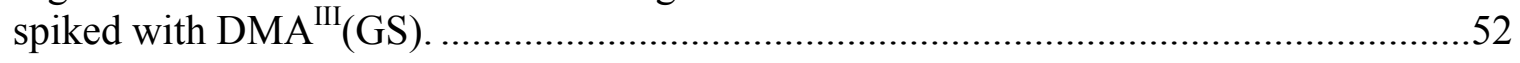

Figure 3.2 Typical ESI-MS chromatograms for (A) $\operatorname{DMMTA}^{\mathrm{V}}(\mathrm{GS})$ and (B)

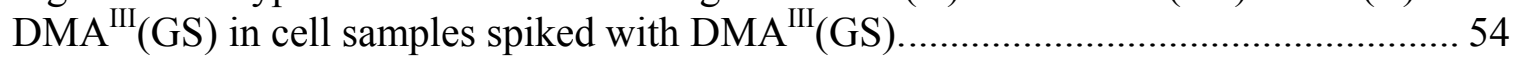

Figure $3.3 \mathrm{MS}^{2}$ and $\mathrm{MS}^{3}$ spectra for $\mathrm{m} / \mathrm{z}=444$ and $\mathrm{m} / \mathrm{z}=314.5$, respectively to confirm the structure of the new As metabolite $\left(\mathrm{DMMTA}^{\mathrm{V}}(\mathrm{GS})\right)$................................ 55

Figure 3.4 Comparison of toxicities of $\mathrm{DMA}^{\mathrm{III}}(\mathrm{GS}), \mathrm{DMMTA}^{\mathrm{V}}$, and

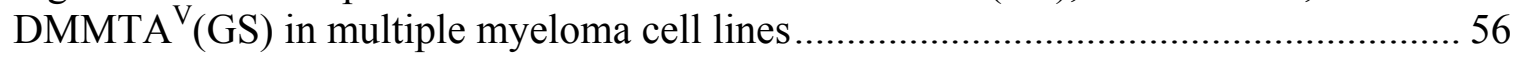

Figure 4.1 Typical chromatogram for the separation and analysis of arsenic compounds containing no glutathione using HPLC-ICP-MS. 79 
Figure 4.2 Demonstration of signal enhancement as a consequence of changes in nebulizer gas composition and flow rate for (A) $\mathrm{MMA}^{\mathrm{III}}(\mathrm{GS})_{2}$ eluting during high (20\%) v/v\% acetonitrile and (B) $\mathrm{As}^{\mathrm{V}}$ and $\mathrm{As}{ }^{\mathrm{III}}$ eluting during low (1\%) $\mathrm{v} / \mathrm{v} \%$ acetonitrile in the gradient program....

Figure 4.3 Baseline disturbance vs nebulizer flow rate and composition for blank injection.

Figure 4.4 The effect of nebulizer gas on instrumental response 86

Figure 4.5 Separation of arsenic metabolites demonstrated by (A) injection of glutathione complexes and $\mathrm{S}$ containing compounds and (B) overlay of the chromatograms for injection of sulfur-containing and non-sulfur-containing

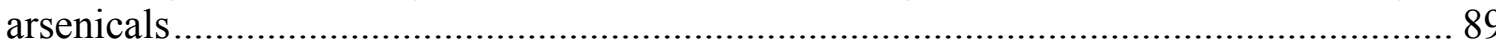

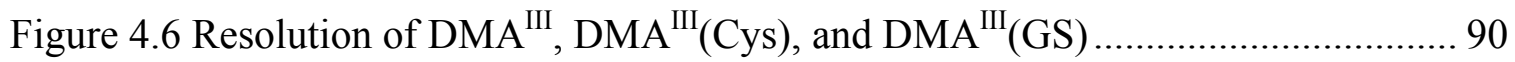

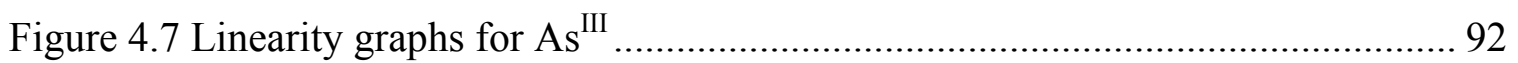

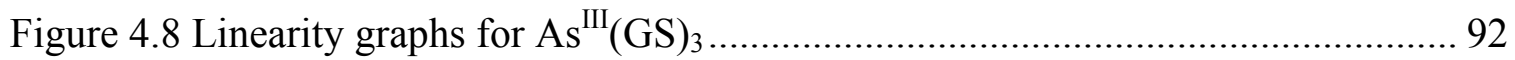

Figure 4.9. Results of human cells analysis using the developed method after

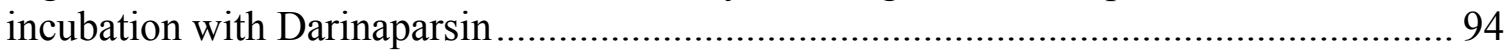

Figure 5.1 Proposed reaction involved in the production of $\mathrm{H}_{2} \mathrm{~S}$ from GYY4137 ........ 104

Figure 5.2 Reaction involved in the synthesis of GYY4137 .................................. 107

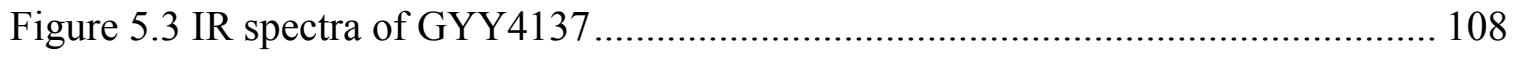

Figure 5.4 Reaction of Ellman's reagent with thiols ................................................. 110

Figure 5.5 The accumulated cconcentration of $\mathrm{H}_{2} \mathrm{~S}$ released over time at $\mathrm{pH} 7.4 \ldots \ldots . .111$

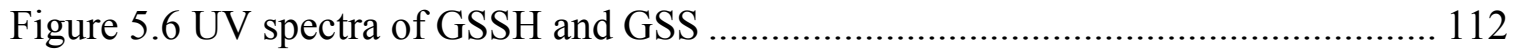

Figure 5.7 Proposed mechanism of formation of thiolated arsenicals ........................ 116

Figure 5.8 Reactions between DMA ${ }^{\mathrm{III}}(\mathrm{GS})$ and GYY4137, $\mathrm{NaHS}$, and $\mathrm{Na}_{2} \mathrm{~S}$ at (A)

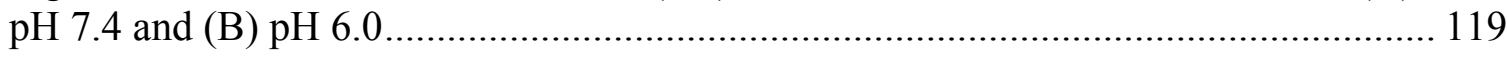

Figure 5.9. Reaction between $\mathrm{DMA}^{\mathrm{V}}$ and $\mathrm{GSSH}$ at $\mathrm{pH} 7.4$ in the presence and

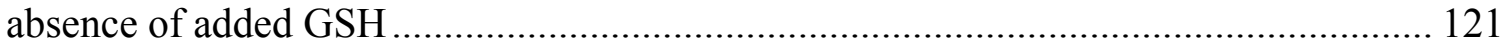

Figure 5.10 Formation of DMMTA ${ }^{\mathrm{V}}$ from $\mathrm{DMA}^{\mathrm{V}}$ at $\mathrm{pH} 7.4,6.0$ and 3.0 at As:S mol ratio of $1: 2$ over time 
Figure 5.11 Formation of DMMTA ${ }^{\mathrm{V}}$ from $\operatorname{DMA}^{\mathrm{III}}(\mathrm{GS})$ at $\mathrm{pH} 7.4,6.0$, and 3.0 with As:S mol ratios of 1:2 at different GSH concentrations ....

Figure 5.12 Formation of DMDTA ${ }^{\mathrm{V}}$ from $\mathrm{DMA}^{\mathrm{III}}(\mathrm{GS})$ at $\mathrm{pH} 7.4,6.0$, and 3.0 with As:S mol ratios of 1:2 at different GSH concentrations

Figure 5.13 Formation of $\mathrm{DMA}^{\mathrm{III}}(\mathrm{GS})$ from $\mathrm{DMA}^{\mathrm{III}}(\mathrm{GS})$ at $\mathrm{pH} 7.4,6.0$, and 3.0 with As:S mol ratios of 1:2 at different GSH concentrations

Figure 5.14 Formation of $\mathrm{DMA}^{\mathrm{III}}$ from $\mathrm{DMA}^{\mathrm{III}}(\mathrm{GS})$ at $\mathrm{pH} 7.4,6.0$, and 3.0 with As:S mol ratios of 1:2 at different GSH concentrations.

Figure 5.15 Formation of DMMTA ${ }^{\mathrm{V}}(\mathrm{GS})$ from $\mathrm{DMA}^{\mathrm{III}}(\mathrm{GS})$ at $\mathrm{pH} 7.4,6.0$, and 3.0 with As:S mol ratios of 1:2 at different GSH concentrations

Figure 5.16 Comparison of formation of DMMTA ${ }^{\mathrm{V}}$ from $\mathrm{DMA}^{\mathrm{V}}$ and $\mathrm{DMA}^{\mathrm{III}}(\mathrm{GS})$ at $\mathrm{pH}$ 3.0, 6.0, and 7.4. The mol ratio of As:S was 1:2. (No GSH was added.)

Figure 5.17 Overlay of chromatograms to show the presence of unknown peaks for chromatograms with $\mathrm{DMA}^{\mathrm{III}}(\mathrm{GS})$ as a starting material and the absence of these peaks for experiments where the starting compound was $\mathrm{DMA}^{\mathrm{V}}$.

Figure 5.18. (A) Overlay of chromatograms to show changes in peak distribution when a sample produced under anaerobic conditions is gradually exposed to air. To prepare the sample $\mathrm{DMA}^{\mathrm{III}}(\mathrm{GS})$ was reacted with $\mathrm{Na}_{2} \mathrm{~S}$ in the absence of oxygen, immediately analyzed and then exposed to air and re-analyzed periodically. Chromatograms B) and C) show how the unknown peaks changed in size over time once exposed to air

Figure 5.19 Distribution diagram for $\mathrm{H}_{2} \mathrm{~S}$

Figure 6.1 Stability of $\mathrm{DMA}^{\mathrm{III}}(\mathrm{GS})$ in the presence of NaDDC and/or GSH. The mol ratio of As:NaDDC was 1:2 and the samples were kept at $-4 \mathrm{C}^{\circ}$ in the freezer and were periodically reanalyzed to monitor $\mathrm{DMA}^{\mathrm{III}}(\mathrm{GS})$ stability. 


\section{ABBREVIATIONS}

\begin{tabular}{|c|c|}
\hline As & Arsenic \\
\hline $\mathrm{As}^{\mathrm{III}}$ & Arsenite \\
\hline $\mathrm{As}^{\mathrm{V}}$ & Arsenate \\
\hline $\mathrm{As}^{\mathrm{III}}(\mathrm{GS})_{3}$ & Arsino-glutathione \\
\hline $\mathrm{MMA}^{\mathrm{III}}$ & Monomethylarsonous acid \\
\hline $\mathrm{MMA}^{\mathrm{V}}$ & Monomethylarsonic acid \\
\hline $\mathrm{MMA}^{\mathrm{III}}(\mathrm{GS})_{2}$ & Monomethylarsino-glutathione \\
\hline MMMTA $^{\mathrm{V}}$ & Monomethylmonothioarsonic acid \\
\hline $\mathrm{DMA}^{\mathrm{III}}$ & Dimethylarsinous acid \\
\hline $\mathrm{DMA}^{\mathrm{V}}$ & Dimethylarsinic acid \\
\hline $\mathrm{DMA}^{\mathrm{III}}(\mathrm{Cys})$ & S-(Dimethylarsenic) cysteine \\
\hline $\mathrm{DMA}^{\mathrm{III}}(\mathrm{GS})$ or DAR & Dimethyarsinous glutathione, Darinaparsin, ZIO-101 \\
\hline $\operatorname{DMMTA}^{\mathrm{V}}(\mathrm{GS})$ & Dimethylarsinothioyl glutathione \\
\hline DMMTA $^{\mathrm{V}}$ & Dimethylmonothioarsinic acid \\
\hline DMDTA $^{\mathrm{V}}$ & Dimethyldithioarsinic acid \\
\hline DMMTA $^{\text {III }}$ & Dimethylmonothioarsinous acid \\
\hline TMAO & Trimethylarsine oxide \\
\hline AsB & Arsenobetaine \\
\hline $\mathrm{AsC}$ & Arsenocholine \\
\hline $\mathrm{As}_{2} \mathrm{O}_{3}$ or ATO & Arsenic trioxide, Trisenox \\
\hline $\mathrm{As}_{2} \mathrm{~S}_{3}$ & Oripment \\
\hline $\mathrm{AsS}$ or $\mathrm{As}_{4} \mathrm{O}_{4}$ or REA & Realgar \\
\hline
\end{tabular}




\begin{tabular}{|c|c|}
\hline GSAO & 4-(N-(S-glutathionylacetyl)amino)phenylarsonous acid \\
\hline PENEAO & 4-(N-(S-penicillaminylacetyl)amino) phenylarsonous acid \\
\hline GYY4137 & $\begin{array}{l}\text { Morpholin-4-ium 04-methoxphenyl (morpholino)- } \\
\text { phosphinodithionate }\end{array}$ \\
\hline $\mathrm{NH}_{2} \mathrm{OH} \cdot \mathrm{HCl}$ & Hydroxylamine hydrochloride \\
\hline DMSA & Meso-2,3-dimercaptosuccinic acid \\
\hline DMPS & 2,3-Dimercapto-1-propenesulfonic acid \\
\hline APDC & Pyrrolidine dithiocarbamate ammonium salt \\
\hline $\mathrm{NaDDC}$ & Sodium diethyldithiocarbamate \\
\hline TGA or MMA & Thioglycolic acid or mercaptoacetic acid \\
\hline DTPA & Diethylene triamine pentaacetic acid \\
\hline EDTA & Ethylenediaminetetraacetic acid \\
\hline $\mathrm{Ar}$ & Argon \\
\hline $\mathrm{O}_{2}$ & Oxygen \\
\hline $\mathrm{ACN}$ & Acetonitrile \\
\hline $\mathrm{CH}_{2} \mathrm{Cl}_{2}$ or $\mathrm{DCM}$ & Methylene chloride or dichloromethane \\
\hline DDIW & Double deionized water \\
\hline FA & Formic acid \\
\hline TFA & Trifluoro acetic acid \\
\hline $\mathrm{H}_{2} \mathrm{SO}_{4}$ & Sulfuric acid \\
\hline $\mathrm{HCl}$ & Hydrochloric acid \\
\hline $\mathrm{HNO}_{3}$ & Nitric acid \\
\hline $\mathrm{D}_{2} \mathrm{O}$ & Deuterated water or deuterium oxide \\
\hline
\end{tabular}




\begin{tabular}{|c|c|}
\hline $\mathrm{D}_{3} \mathrm{C}-\mathrm{OD}$ & Deuterated methanol or methanol-D4 \\
\hline LA & Lipoic acid \\
\hline NAC & $\mathrm{N}$-acetylcysteine \\
\hline Cys & Cysteine \\
\hline $\mathrm{Na}_{2} \mathrm{~S}$ & Sodium sulfide \\
\hline NaHS & Sodium hydrosulfide \\
\hline $\mathrm{H}_{2} \mathrm{~S}$ & Hydrogen sulfide \\
\hline $\mathrm{HS}^{-}$ & Bisulfide \\
\hline $\mathrm{S}^{2-}$ & Sulfide \\
\hline GSH & Reduced glutathione \\
\hline GSSG & Oxidized glutathione \\
\hline GSSH & Glutathione persulfide \\
\hline RSSH or R-S-S-H & Protein persulfide \\
\hline DTNB & 5,5'-dithiobis-2-nitrobenzoic acid or Ellman's reagent \\
\hline TNB & 5-thio-2-nitrobenzoate \\
\hline HEPES & 4-(2-hydroxyethyl)-1-piperazineethanesulfonic acid \\
\hline MES & 2-(N-morpholino)ethanesulfonic acid \\
\hline Tris & Tris(hydroxymethyl)aminomethane \\
\hline PBS & Phosphate buffer saline \\
\hline GST & Glutathione S-transferase \\
\hline GGT or $\gamma$-GT & $\gamma$-glutamyl transpeptidase \\
\hline SAM & S-adenosylmethionin \\
\hline Cyt 19 or As3MT & Arsenic methyltransferase \\
\hline
\end{tabular}




\begin{tabular}{|c|c|}
\hline ANT & Adenine nucleotide translocase \\
\hline CBS & Cystathionine beta synthase \\
\hline CSE & Cystathionine gamma lyase \\
\hline Trx-1 & Cytoplasmic thioredoxin-1 \\
\hline Trx-2 & Mitochondrial thioredoxin-1 \\
\hline PARP & Poly ADP ribose polymerase \\
\hline GLUT & Glucose transporter \\
\hline AQP-9 & Aquaglyceroporin-9 \\
\hline $\mathrm{ABC}$ & ATP-binding cassette (transporter) \\
\hline PGP & P-glycoprotein \\
\hline FDA & Food and Drug Administration \\
\hline IV & Intravenous or intravenously \\
\hline $\mathrm{RBC}$ & Red blood cells \\
\hline APL & Acute promyelotic leukemia \\
\hline RA-APL & Retinoic-acid acute promyelotic leukemia \\
\hline MM & Multiple myeloma \\
\hline ARDS & Acute respiratory distress syndrome \\
\hline DNA & Deoxyribonucleic acid \\
\hline RNA & Ribonucleic acid \\
\hline ROS & Reactive oxygen species \\
\hline HSAB & Hard and soft acids and bases theory \\
\hline $\mathrm{FW}$ & Formula weight \\
\hline $\mathrm{m}$ & Milli \\
\hline
\end{tabular}




\begin{tabular}{|c|c|}
\hline$\mu$ & Micro \\
\hline M & Molar or mega \\
\hline $\mathrm{L}$ & Liter \\
\hline $\mathrm{Da}$ & Dalton \\
\hline $\mathrm{Hz}$ & Hertz \\
\hline ppm & Parts per million \\
\hline ppb & Parts per billion \\
\hline $\mathrm{K}_{\mathrm{a}}$ & Acid dissociation constant \\
\hline $\mathrm{RPC}$ & Reverse phase chromatography \\
\hline LC & Liquid chromatography \\
\hline LOD or LD & Limit of detection or detection limit \\
\hline LOQ or LQ & Limit of quantitation or quantitation limit \\
\hline HPLC & High performance liquid chromatography \\
\hline GC & Gas chromatography \\
\hline Q & Quadruple mass analyzer \\
\hline $\mathrm{m} / \mathrm{z}$ & Mass to charge ratio \\
\hline ICP-MS & Inductively coupled plasma mass spectrometry \\
\hline DRC & Dynamic reaction cell \\
\hline ESI & Electrospray ionization \\
\hline $\mathrm{MS}^{2}$ or MS/MS & Tandem mass spectrometry \\
\hline TIC & Total ion chromatography \\
\hline SIM & Selected ion monitoring \\
\hline AFS & Atomic fluorescence spectrometer \\
\hline
\end{tabular}


AAS

NMR

IR

UV
Atomic absorption spectrometer

Nuclear magnetic resonance

Infrared spectroscopy

Ultraviolet spectroscopy 


\section{CHAPTER 1}

Introduction 


\subsection{Arsenic in the Environment and its Effects on Human Health}

\subsubsection{Abundance, Forms, and Distribution}

Arsenic (As) is a naturally occurring element that can be found in many forms such as elemental, inorganic, and organic in large quantities all over the world. It is mostly present in the trivalent or pentavalent forms when it combines with other elements of the periodic table. Arsenic is present in our oceans, meteorites, living organisms, and is also the $20^{\text {th }}$ most abundant element in the crust of the Earth. ${ }^{1}$ Arsenic compounds have diverse structures, chemical compositions, toxicities, and a broad range of applications. It forms ores with sulfide and metals such as copper, lead, nickel, and cobalt, just to name a few. Weathering of rocks converts arsenic sulfide to arsenic trioxide, the main form arsenic that enters and contaminates our rivers and groundwater or pollutes the air we breathe.

\subsubsection{Use and Source}

It is or was used at some point in history in animal feed (as an additive to promote growth and prevent infections of animals), ceramics, glass, computers, semiconductors, herbicides, insecticides, pesticides, rodenticides, metallurgy, wood preservatives, dyes, and for many other applications. ${ }^{1,2}$ Arsenic originating from these and other applications contribute to anthropogenic As pollution of the environment in addition to the naturally present As (naturogenic pollution).

\subsubsection{Human Exposure to Arsenic}

The major sources of arsenic for the general population are contaminated soil,

water, and food. ${ }^{1,2}$ It is found in appreciable concentrations in food (such as seafood and rice, a staple food crop and an efficient arsenic accumulator) as well as in drinking water 
from certain sources resulting in chronic arsenic toxicity in humans throughout the world. ${ }^{3}$ It has also been used as a homicidal and a suicidal agent since ancient times.

\subsubsection{Toxicity and Health Effects}

Arsenic compounds are known to be very toxic and carcinogenic. People exposed to arsenic compounds develop a wide range of health problems ranging from gastrointestinal disturbance to the development of various types of life threatening neoplasms such as kidney, liver, skin, and lung cancer. ${ }^{1,2,4-6}$ Table 1.1 gives a detailed list of the health consequences associated with acute, subacute, and chronic arsenic exposure in humans, while Table 1.2 contains the names, abbreviations, and structures of selected arsenic metabolites relevant to my research in mammals with an emphasis on humans.

Different arsenic compounds have different toxicities and the extent of toxicity is also animal species dependent. The order of toxicity, within the same species also depends on the type of cells involved. For example, on the basis of the estimated $\mathrm{IC}_{50}$ values, the increasing order of toxicity in human hepatocytes was $\mathrm{DMA}^{\mathrm{III}}(\mathrm{GS}) \approx$ $\mathrm{iAs}^{\mathrm{III}}<<\mathrm{MMA}^{\mathrm{III}}$, while in human keratinocytes it is iAs ${ }^{\mathrm{III}}<<\mathrm{DMA}^{\mathrm{III}}(\mathrm{GS})<\mathrm{MMA}^{\mathrm{III}}$, and in human bronchial cells it is $\mathrm{DMA}^{\mathrm{III}}(\mathrm{GS})<\mathrm{iAs}^{\mathrm{III}} \approx \mathrm{MMA}^{\mathrm{III}} .{ }^{7}$ Pentavalent arsenicals were found to possess relatively low toxicities in these cell types compared to the above trivalent species. Generally, trivalent arsenicals are much more toxic than their pentavalent counterparts. ${ }^{7,8}$ In addition, trivalent arsenicals are taken up more efficiently by organs/tissues or cells than that of pentavalent arsenicals. ${ }^{7,9}$ The reason for the much lower toxicity of pentavalent species compared to the trivalent compounds was partially attributed to the lower rate of accumulation of pentavalent species. ${ }^{7}$ Additionally, toxicity 
of these species is dependent on the extent of their methylation. When comparing arsenite $\left(\mathrm{As}^{\mathrm{III}}\right)$ and monomethylarsonous acid (MMA $\left.{ }^{\mathrm{III}}\right)$, the monomethylated arsenical has higher affinity for sulfur ligands (such as thiols in proteins and enzymes) than the nonmethylated As ${ }^{\mathrm{III}}$, thus exhibiting higher toxicity. ${ }^{7}$

Interestingly, while in general trivalent arsenic compounds are more toxic than their pentavalent counterparts, dimethylmonothioarsinic acid $\left(\mathrm{DMMTA}^{\mathrm{V}}\right)$ has been shown to be unusually highly toxic for a pentavalent species. ${ }^{10-13}$ According to Watanabe and Hirano, the toxicity of DMMTA ${ }^{\mathrm{V}}$ is comparable to that of MMA ${ }^{\mathrm{III}}$, while Bartel et al. reported lesser (approximately $1 / 2$ ) toxicity compared to MMA ${ }^{\text {III }}$ in human lung cells..$^{14,15}$ While the toxicity of DMMTA ${ }^{\mathrm{V}}$ was found to be similar to the even more toxic dimethylarsinous acid (DMA ${ }^{\mathrm{III}}$ ) in epidermoid carcinoma cells, in human lung adenocarcinoma epithelium cells it was found to be less cytotoxic than dimethylarsino glutathione $\left(\mathrm{DMA}^{\mathrm{III}}(\mathrm{GS})\right){ }^{13,}{ }^{16}$ Compared to dimethylarsinic acid $\left(\mathrm{DMA}^{\mathrm{V}}\right)$, the corresponding non-thiolated pentavalent species, $\mathrm{DMMTA}^{\mathrm{V}}$ was found to be about 10fold more cytotoxic in HepG2 cells derived from human hepatocarcinoma and approximately 80 times more toxic in epidermoid cells. ${ }^{11,13}$ Its toxicity can be attributed to the fact that DMMTA ${ }^{\mathrm{V}}$ is highly reactive with thiol compounds. This is unusual for a pentavalent arsenical.

The glutathione complexes, DMA ${ }^{\mathrm{III}}(\mathrm{GS})$ and monomethylarsinoglutathione $\left(\mathrm{MMA}^{\mathrm{III}}(\mathrm{GS})_{2}\right)$ may form in the body from $\mathrm{DMA}^{\mathrm{V}}$ and monomethylarsonic acid $\left(\mathrm{MMA}^{\mathrm{V}}\right)$ with the help of reduced glutathione. By reducing the pentavalent species into trivalent glutathione complexes, their cytolethality increases. They were shown to be toxic by dissociating into trivalent species and glutathione. ${ }^{17,}{ }^{18}$ On the other hand, GSH 
conjugation promotes the elimination of these species and flags them for removal from the cells, thus reducing intracellular arsenic concentrations.

\subsubsection{Mechanism of Arsenic Toxicity}

The varying toxicity of arsenic species is partly caused by the ability of these species to generate reactive oxygen species (ROS) initiating oxidative stress and by their differing ability to cause DNA methylation (both hypomethylation and hypermethylation via interaction with DNA methylating enzymes or by depleting SAM). ${ }^{19}$ Arsenic exposure produces superoxide $\left(\mathrm{O}^{2 \cdot}\right)$, singlet oxygen species, peroxy radical (ROO'), hydrogen peroxide $\left(\mathrm{H}_{2} \mathrm{O}_{2}\right)$, dimethylarsinicperoxyl radicals $\left[\left(\mathrm{CH}_{3}\right)_{2} \mathrm{AsOO}{ }^{*}\right)$, dimethylarsinic radical $\left.\left(\left(\mathrm{CH}_{3}\right)_{2} \mathrm{As}\right)^{\circ}\right)$ in addition to nitric oxide $\left(\mathrm{NO}^{\circ}\right){ }^{20,21}$ The manner in which arsenic-containing compounds generate ROS and cellular oxidative stress is quite complex. ${ }^{14}$ Arsenic can significantly oxidize cytoplasmic thioredoxin-1 (Trx-1) and mitochondrial thioredoxin-2 (Trx-2). ${ }^{22}$ Thioredoxins act as antioxidants by facilitating the reduction of proteins. The oxidation of thioredoxins by arsenic may lead to the generation of ROS.

The difference in toxicity of different arsenic species and in general their toxicity along with their biological actions can also be attributed to the fact that trivalent arsenicals can bind to the thiol (-SH) groups of proteins and enzymes resulting in the disruption of their functions. ${ }^{23}$

While trivalent arsenicals can easily bind to thiol groups of biomolecules, thus disrupt their functions, pentavalent arsenical only do so to a much smaller extent. This observation can be partially explained with the help of the hard and soft acids and bases theory (HSAB). According to HSAB, the small species with high charge states (mainly 
for acids) that are weakly polarizable are designated as hard and the large low charge states that are strongly polarizable are labelled as soft. Soft acids are said to react faster and form stronger bonds with soft bases, while hard acids react faster and form stronger bonds with hard bases. Thiolates are categorized as soft bases. While both $\mathrm{As}^{3+}$ and $\mathrm{As}^{5+}$ are categorized as acids, $\mathrm{As}^{3+}$ is much softer than $\mathrm{As}^{5+}$, thus $\mathrm{As}^{3+}$ has higher affinity for the thiol groups of proteins and enzymes than $\mathrm{As}^{5+}$. The different binding affinity of the diverse arsenic species to various biomolecules may be responsible for the higher concentration (accumulation) of toxic arsenic species in certain cell types. The binding can be through different number of binding sites depending on the arsenic species involved in the process. 
Table 1.1 Possible clinical manifestations of arsenicals in humans ${ }^{1,2,4-6}$

\begin{tabular}{|c|c|c|c|}
\hline Signs and Symptoms of & Acute Toxicity & Subacute Toxicity & Chronic Toxicity \\
\hline Gastrointestinal & $\begin{array}{c}\text { Nausea, vomiting, diarrhea, } \\
\text { hepatitis, pancreatitis }\end{array}$ & $\begin{array}{l}\text { Anorexia, weight loss, nausea, } \\
\text { vomiting, diarrhea }\end{array}$ & $\begin{array}{l}\text { Nausea, vomiting and diarrhea, } \\
\text { hepatomegaly, diabetes mellitus }\end{array}$ \\
\hline $\begin{array}{l}\text { Cardiovascular, } \\
\text { cerebrovascular and } \\
\text { other vascular }\end{array}$ & $\begin{array}{c}\text { Sinus tachycardia, } \\
\text { orthostatic hypotension, } \\
\text { myocardial dysfunction }\end{array}$ & $\begin{array}{l}\text { Ventricular tachycardia (torsades } \\
\text { de pointes) }\end{array}$ & $\begin{array}{l}\text { Cerebrovascular disease, } \\
\text { Raynaud phenomenon }\end{array}$ \\
\hline Neurological & $\begin{array}{l}\text { Acute encephalopathy, } \\
\text { fainting, delirium, coma, } \\
\text { seizure, nerve paralysis, } \\
\text { nerve palsy }\end{array}$ & $\begin{array}{l}\text { Headache, confusion, decreased } \\
\text { memory, personality change, } \\
\text { irritability, numbness, pain on } \\
\text { touching, paralysis mimicking } \\
\text { Guillain-Barré Syndrome }\end{array}$ & $\begin{array}{c}\text { Encephalopathy, peripheral } \\
\text { neuropathy }\end{array}$ \\
\hline Respiratory & $\begin{array}{c}\text { Pulmonary edema, } \mathrm{ARDS}^{\mathrm{a}}, \\
\text { respiratory failure }\end{array}$ & Cough, crackles & $\begin{array}{l}\text { Restrictive and/or obstructive } \\
\text { lung disease }\end{array}$ \\
\hline Renal & Acute renal failure & Renal failure & Cancer \\
\hline Dermatologic & Exfoliative dermatitis & $\begin{array}{c}\text { Dermatologic lesions, contact } \\
\text { dermatitis }\end{array}$ & $\begin{array}{c}\text { Dermatologic lesions, } \\
\text { hyperpigmentation }\end{array}$ \\
\hline Hematological & Hemolytic anemia & Leukopenia ${ }^{\mathrm{d}}$, anemia & Aplastic anemia \\
\hline Muscular & Rhabdomyolysis $^{\mathrm{b}}$ & & \\
\hline Others including cancer & & Mees' lines & $\begin{array}{c}\text { Squamous and basal cell } \\
\text { carcinomas, hepatic } \\
\text { angiosarcoma, adenocarcinoma } \\
\text { and oat cell carcinoma (lung } \\
\text { cancers), bladder carcinoma }\end{array}$ \\
\hline
\end{tabular}

${ }^{\mathrm{e}} \mathrm{ARDS}$ stands for acute respiratory distress syndrome

${ }^{\mathrm{b}} \mathrm{Rhabdomyolysis}$ is the quick breakdown of muscular tissue and may lead to kidney failure

${ }^{\mathrm{c}}$ Guillain-Barré Syndrome is a disorder affecting the peripheral nervous system and is characterized with ascending paralysis. It can cause breathing problems and disrupt the autonomous nervous system.

${ }^{\mathrm{d}}$ Leukopenia is the decrease of white blood cells

${ }^{\mathrm{e}}$ Raynaud phenomenon is the discoloration of finger and occasionally other body parts 
Table 1.2 Arsenic species of interest in this study

\begin{tabular}{|c|c|c|c|}
\hline \multicolumn{2}{|l|}{ Most common } & \multirow{2}{*}{ Structure } & \multirow{2}{*}{$\begin{array}{l}\text { Occurrence in } \\
\text { humans }\end{array}$} \\
\hline Names & Abbreviations & & \\
\hline Arsenite, Arsenious acid & $\mathrm{As}^{\mathrm{III}}$ & $\left.\right|_{\mathrm{OH}} ^{\mathrm{HO}-\mathrm{As}-\mathrm{OH}}$ & $\begin{array}{c}\text { Urine }^{24-28} \\
\text { Fingernail }^{26} \\
\text { Blood plasma }^{29}\end{array}$ \\
\hline Arsino-glutathione & $\begin{array}{l}\mathrm{As}^{\mathrm{III}}(\mathrm{GS})_{3} \\
\mathrm{ATG}\end{array}$ & $\left.\right|_{\mathrm{GS}} ^{\mathrm{GS}-\mathrm{As}-\mathrm{SG}}$ & $\begin{array}{l}\text { Not yet reported, } \\
\text { only in mammals } \\
31\end{array}$ \\
\hline Arsenate, Arsenic acid & $\mathrm{As}^{\mathrm{V}}$ & 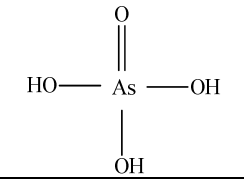 & $\begin{array}{c}\text { Urine }^{24-28} \\
\text { Fingernail }^{26} \\
\text { Blood plasma }^{26,29}\end{array}$ \\
\hline $\begin{array}{l}\text { Monomethylarsonous acid, } \\
\text { Methylarsonous acid, } \\
\text { Methylarsonite }\end{array}$ & $\begin{array}{l}\text { MMA }^{\mathrm{III}} \\
\text { MAs }^{\mathrm{III}}\end{array}$ & $\left.\right|_{\mathrm{OH}} ^{\mathrm{CH}_{3}-\mathrm{As}-\mathrm{OH}}$ & $\begin{array}{c}\text { Urine }^{24-28,32} \\
\text { Hepatocytes }^{33}\end{array}$ \\
\hline $\begin{array}{l}\text { Monomethylarsino- } \\
\text { glutathione, } \\
\text { Monomethylarsonic } \\
\text { diglutathione }\end{array}$ & $\begin{array}{l}\mathrm{MMA}^{\mathrm{III}}(\mathrm{GS})_{2} \\
\mathrm{MADG}\end{array}$ & 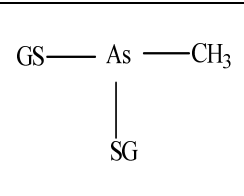 & $\begin{array}{l}\text { Not yet reported, } \\
\text { only in mammals } \\
31\end{array}$ \\
\hline $\begin{array}{l}\text { Monomethylarsonic acid, } \\
\text { Methylarsonic acid }\end{array}$ & $\begin{array}{l}\mathrm{MMA}_{\mathrm{MAs}}^{\mathrm{V}} \\
\text { MA }\end{array}$ & $\prod_{\mathrm{OH}}^{\mathrm{O}} \mathrm{CH}_{3}-\mathrm{As}$ & $\begin{array}{c}\text { Urine }^{24-28} \\
\text { Fingernail }^{26} \\
\text { Blood plasma }^{26,29} \\
\text { Hepatocytes }^{33}\end{array}$ \\
\hline $\begin{array}{l}\text { Dimethylarsinous acid, } \\
\text { Dimethylarsinite }\end{array}$ & $\begin{array}{l}\text { DMA }^{\mathrm{III}} \\
\text { DMAs }^{\mathrm{III}}\end{array}$ & $\left.\right|_{\mathrm{OH}} ^{\mathrm{CH}_{3}-\mathrm{As}-\mathrm{CH}_{3}}$ & $\begin{array}{c}\text { Urine }^{24-28,32} \\
\text { Fingernail }^{26} \\
\text { Hepatocytes }^{33}\end{array}$ \\
\hline $\begin{array}{l}\text { S-(Dimethylarsenic) } \\
\text { Cysteine }\end{array}$ & $\mathrm{DMA}^{\mathrm{III}} \mathrm{Cys}$ & $\left.\right|_{\mathrm{Cys}} ^{\mathrm{CH}_{3}-\mathrm{As}-\mathrm{CH}_{3}}$ & Not reported \\
\hline $\begin{array}{l}\text { Dimethylarsinous } \\
\text { glutathione, Dimethylarsinic } \\
\text { glutathione, } \\
\text { Dimethylarsino-glutathione, } \\
\text { Darinaparsin, ZIO-101, DAR } \\
\end{array}$ & $\begin{array}{c}\mathrm{DMA}^{\mathrm{III}}(\mathrm{GS}) \\
\text { DAR } \\
\text { DMAG } \\
\text { DMAs }^{\mathrm{III}} \mathrm{GS}\end{array}$ & 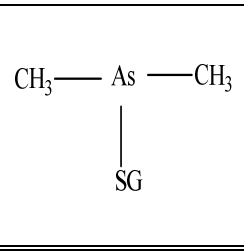 & $\begin{array}{l}\text { Human multiple } \\
\text { myeloma cells }\end{array}$ \\
\hline
\end{tabular}


Table 1.2 Arsenic species of interest in this study (cont'd)

\begin{tabular}{|c|c|c|c|c|}
\hline \multicolumn{3}{|c|}{ Most common } & \multirow{2}{*}{ Structure } & \multirow{2}{*}{$\begin{array}{l}\text { Occurrence in } \\
\text { humans }\end{array}$} \\
\hline Names & Abbre & iations & & \\
\hline $\begin{array}{l}\text { Dimethylmonothioarsinous } \\
\text { acid }\end{array}$ & \multicolumn{2}{|c|}{ DMMTA $^{\text {III }}$} & $\mathrm{CH}_{3}-\mathrm{As}-\mathrm{CH}_{3}$ & Not reported \\
\hline $\begin{array}{l}\text { Dimethylarsinic acid, } \\
\text { Dimethylarsinate }\end{array}$ & \multicolumn{2}{|c|}{$\begin{array}{l}\text { DMA }^{\mathrm{V}} \\
\text { DMAs }^{\mathrm{V}}\end{array}$} & & $\begin{array}{c}\text { Urine }^{24-28} \\
\text { Fingernail }^{26} \\
\text { Blood plasma }^{26,29} \\
\text { Hepatocytes }^{33}\end{array}$ \\
\hline $\begin{array}{l}\text { Dimethylmonothioarsinic } \\
\text { acid, } \\
\text { Dimethylarsinothioic acid, } \\
\text { Thio-dimethylarsinate }\end{array}$ & \multicolumn{2}{|c|}{$\begin{array}{l}\text { DMMTA }^{\mathrm{V}} \\
\text { Thio-DMA }^{\text {DMAS }}\end{array}$} & $-\mathrm{CH}_{3}$ & $\begin{array}{c}\text { Urine }^{11} \\
\text { Red blood cells }\end{array}$ \\
\hline $\begin{array}{l}\text { Dimethyldithioarsinic acid } \\
\text { Dimethylarsinodithioic acid }\end{array}$ & \multicolumn{2}{|c|}{ DMDTA $^{\mathrm{V}}$} & & $\begin{array}{l}\text { Not yet reported, } \\
\text { only in mammals }\end{array}$ \\
\hline $\begin{array}{l}\text { Dimethylarsinothioyl } \\
\text { glutathione }\end{array}$ & \multicolumn{2}{|c|}{$\begin{array}{c}\text { DMMTA }^{\mathrm{V}}-\mathrm{GS} \\
\text { DMATG }^{\mathrm{D}} \\
\text { DMAS }^{\mathrm{V}}-\mathrm{GS} \\
\text { DMMTA }^{\mathrm{V}}(\mathrm{GS})\end{array}$} & & $\begin{array}{l}\text { Human multiple } \\
\text { myeloma cells } \\
\text { and lymphoma cells }\end{array}$ \\
\hline Trimethylarsine oxide & \multicolumn{2}{|c|}{$\begin{array}{l}\text { TMAs }^{\mathrm{V} O} \\
\text { TMAO }\end{array}$} & & \\
\hline Arsenobetaine & AsB & & & $\begin{array}{l}\text { Urine, Red Blood } \\
\text { Cells, Blood } \\
\text { plasma }\end{array}$ \\
\hline Arsenocholine & $\mathrm{AsC}$ & & & \\
\hline
\end{tabular}


Table 1.3 Binding affinities of trivalent arsenic species to hemoglobin

\begin{tabular}{|c|c|c|c||}
\hline \hline Name of arsenic compound & $\mathrm{As}^{\text {III }}$ & MMA $^{\text {III }}$ & DMA $^{\text {III }}$ \\
\hline Number of binding sites & 3 & 2 & 1 \\
\hline Ability to bind human hemoglobin & lowest & medium & highest \\
\hline
\end{tabular}

As mentioned above, arsenic compounds (including thioarsenicals) can inhibit important enzymes by binding to them. The affinity of binding depends on the arsenic species and the biomolecule involved. Important enzymes that are inhibited by arsenic include, but are not limited to glutathione reductase, glutathione peroxidase, thioredoxin reductase, thioredoxin peroxidase, lipoamide dehydrogenase, Arg-tRNA protein transferase, and pyruvate dehydrogenase. ${ }^{40-50}$ In addition, arsenic binds to protein disulfide isomerase, an enzyme catalyzing protein folding, and peroxiredoxin 1/enhancer protein, an antioxidant enzyme that plays a role in cell proliferation (hence it may have a role in cancer progression). ${ }^{23}$ Furthermore, certain arsenic species may disrupt the functions of DNA repair proteins and enzymes such as PARP (Poly ADP ribose polymerase) which binds arsenic and xeroderma pigmentosum protein A (a DNA repair enzyme). ${ }^{19}, 39$ Additionally, arsenic interacts with the mitochondrial transmembrane protein complex called the mitochondrial membrane transition pore complex resulting in the induction of apoptosis. ${ }^{51,52}$ Arsenic also affects the cell cycle through the stabilization of microtubules. ${ }^{52-56}$ As a result of this stabilizing effect, the cell cycle may be halted during mitosis.

In order for arsenic to directly inhibit an enzyme by binding to it, it either has to bind and thus block the active sites of proteins or has to bind to the protein in a manner that the binding will cause a conformational change in the protein that also affects the 
binding site and therefore inhibiting the active site from binding other molecules. ${ }^{57}$ Protein binding may also be a detoxification process in some species (for example in monkeys) ${ }^{58,59}$ The bonding of As to thiols of enzymes may not always be responsible for the inhibition of those enzymes; instead, ROS can cause oxidative damage to proteins rendering them unable to perform their enzymatic functions. ${ }^{60}$

\subsubsection{Treatments of Arsenic Toxicity}

The treatment of chronic arsenic toxicity includes, but is not limited to removing the source of arsenic from the patients' lives and the administration of chelation therapy with Dimercaprol (BAL), Succimer, or Dimaval (DMPS) all of which have vicinal dithiol moieties. ${ }^{2}{ }^{61}$ Also, newer alternative chelation agents are in development, along with the usage of combination therapy. Combination therapy employs structurally different chelating agents simultaneously, one of which is lipophilic and the other one is lipophobic, to more efficiently remove arsenic from different tissue compartments than single agent therapy and to reduce the toxicity of the chelating agent itself. The lipophilic chelating agent can remove the intracellular As, while the lipophobic chelating agent can remove the extracellular As. ${ }^{62}$ Supplementing antioxidants to chelation therapy was shown to be beneficial in increasing the mobilization of some toxic metals and lessen the effects of oxidative stress caused by the presence of these noxious compounds. As oxidative stress is one of the main contributing mechanisms of metal toxicity, thus it makes sense to try to co-administer antioxidants, such as $\mathrm{N}$-acetylcysteine (NAC), lipoic acid (LA), melatonin, ascorbic acid (vitamin C), or gossypin with primary chelation therapy as they have shown great potential in improving clinical recoveries in 
animals. ${ }^{62}$ Moreover, some of the potential antioxidants are capable of interfering with the absorption of arsenic, such as lipoic acid, thus reduce arsenic burden.

\subsection{Arsenic in Medicine}

\subsubsection{Past}

Numerous arsenic compounds have been used for over two thousand years for medicinal purposes and some are still in use today (Table 1.4). In ancient China and India different arsenic compounds have been employed to treat all kinds of diseases. ${ }^{63,64}$ Hippocrates, the ancient Greek physician and the father of western medicine, used orpiment $\left(\mathrm{As}_{2} \mathrm{~S}_{3}\right)$ and realgar (arsenic sulfide: $\mathrm{As}_{4} \mathrm{~S}_{4}$ or $\left.\mathrm{AsS}\right)$ to treat ulcers although by now it has been confirmed that these arsenic compounds are human carcinogens. ${ }^{63-67}$ During history, arsenic compounds were used to treat numerous diseases and conditions ranging from respiratory diseases to head lice to the plague. ${ }^{63,64,68}$ It was also observed that the spread of use of arsenic to control rat populations, an important vector of the plague, coincided with the decrease in the spread of this deadly disease. ${ }^{69}$ Fowler's solution, which contains $1 \%$ potassium arsenite, was utilized as a treatment for malaria, trypanosomiasis, leukemia and asthma along with other diseases from the 1700's to the mid 1900's., 4, 64 Donovan's solution (containing iodomercury and triiodoarsane) and Valagin's solution (arsenic trichloride) were employed to treat a range of ills from rheumatism to tuberculosis along with others. ${ }^{68,70,71}$ Salvarsan (Arsphenamine) and Neosalvarsan, both of which are organoarsenic compounds from the laboratory of the famous Paul Erlich, had been used in the $20^{\text {th }}$ century to treat trypanosomiasis and syphilis until they got replaced by penicillin., ${ }^{2,4,68,71,72}$ The active ingredients of both of 
these drugs are produgs and are activated in the body during metabolism. Early on, it was noticed that arsenic is effective to treat chronic myelogenous leukemia, a cancer of the white blood cells. ${ }^{63,72}$ As a consequence of the toxicity, carcinogenicity and teratogenicity of these compounds they fell out of favor for a while. Side effects of certain arsenic compounds include but are not limited to cirrhosis of the liver and the development of different types of cancers.

\subsubsection{Present and Future}

Despite of their known toxicity and potential to cause cancer, several arsenic compounds have been recently rediscovered and put to use again in order to manage and treat different conditions that may not respond to other agents or stopped responding to them. In 2013, there were 129 clinical trials involving As registered with the Food and Drug Administration (FDA). ${ }^{51}$ Most trials involved Trisenox (arsenic trioxide, $\mathrm{As}_{2} \mathrm{O}_{3}$ ), Darinaparsin (Dimethylarsinous glutathione, DMA $\left.{ }^{\mathrm{III}}(\mathrm{GS})\right)$, and GSAO (4-(N-(Sglutathionylacetyl)amino)phenylarsonous acid). Most trials investigated these and other arsenicals for the treatment of hematological cancers such as leukemias (75) and lymphomas (11) and solid tumors (25). Interestingly, one of the trials involved arsenic trioxide for the treatment of lupus, a systemic autoimmune disease, while the rest of the trials focused on chronic arsenic exposure due to anthropogenic and naturogenic sources.

Table 1.4 Arsenic-containing medicines

\begin{tabular}{|c|c|}
\hline Name & Chemical Composition and/or Structure \\
\hline Oripment & $\mathrm{As}_{2} \mathrm{~S}_{3}$ \\
\hline Realgar (REA, arsenic sulfide) & $\mathrm{As}_{4} \mathrm{~S}_{4}$ or $\mathrm{AsS}$ \\
\hline Fowler's solution $^{\mathrm{a}}$ & $\mathrm{KAsO}_{2}$ \\
\hline Donovan's solution $^{\mathrm{a}}$ (arsenic triiodide) & $\mathrm{AsI}_{3}$ \\
\hline Valagin's solution $^{\mathrm{AsCl}}{ }_{3}$ \\
\hline
\end{tabular}


Table 1.4 Arsenic-containing medicines (cont'd)

\begin{tabular}{|c|c|}
\hline Name & Chemical Composition and/or Structure \\
\hline \multicolumn{2}{|l|}{ Arsenoplatin-1 } \\
\hline \multicolumn{2}{|l|}{ Trisenox (ATO, arsenic trioxide) } \\
\hline \multicolumn{2}{|l|}{$\begin{array}{l}\text { Darinaparsin (DAR, dimethylarsino } \\
\left.\text { glutathione, } \mathrm{DMA}^{\mathrm{III}}(\mathrm{GS})\right)\end{array}$} \\
\hline \multicolumn{2}{|l|}{ Salvarsan (Arsphenamine, Ehrlich 606) } \\
\hline \multicolumn{2}{|l|}{$\begin{array}{l}\text { Melarsoprol (Mel B, Arsobal, Melarsen } \\
\text { Oxide-BAL) }\end{array}$} \\
\hline \multicolumn{2}{|l|}{ Neosalvarsan (Neoarsphenamine, 914) } \\
\hline $\begin{array}{c}\text { GSAO } \\
\text { (4-(N-(S- } \\
\text { glutathionylacetyl)amino)phenylarsonous } \\
\text { acid) }\end{array}$ & \\
\hline PENEAO & \\
\hline
\end{tabular}

${ }^{\mathrm{a}}$ Active arsenic-containing ingredient

${ }^{b}$ Other structures have been proposed as well 


\subsubsection{Salvarsan and Melarsoprol}

Salvarsan (Arsphenamine, Ehrlich 606) was used to cure syphilis and trypanosomiasis (sleeping disease) a parasitic infection (Fig. 1.1) ${ }^{73}$ Melarsoprol (Mel B, Arsobal, Melarsen Oxide-BAL) is now in use to treat East African (first-line of therapy) and West African (second-line of therapy) trypanosomiasis, a type of parasitic infection. ${ }^{74}$ Melarsoprol (Fig. 1.2), a derivative of mersalyl oxide, exerts its antiparasitic effects by lowering the amount of the reducing agent trypanothione which subsequently leads to the lysis of the parasite. ${ }^{2,61}$ It is extremely toxic, both to the parasite and the host, but is still in use as there is no better drug for the treatment of East African (Rhodesian) trypanosomiasis. Melarsoprol causes abdominal pain, vomiting, joint pain (arthralgia), and cerebral edema in addition to other signs and symptoms of toxicity that may result in the death of the patient. ${ }^{61}$ Recently it has been observed that the parasite may be developing resistance to the above therapeutic agent.
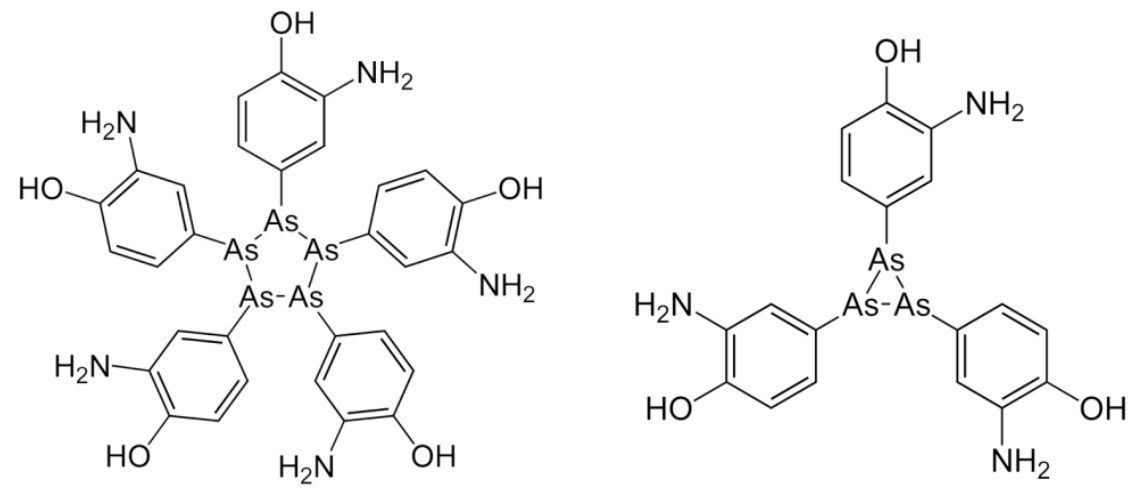<smiles>Nc1cc(C=Nc2ccc(O)c(N)c2)ccc1O</smiles>

Figure 1.1 Possible structures of Salvarsan ${ }^{75}$ 


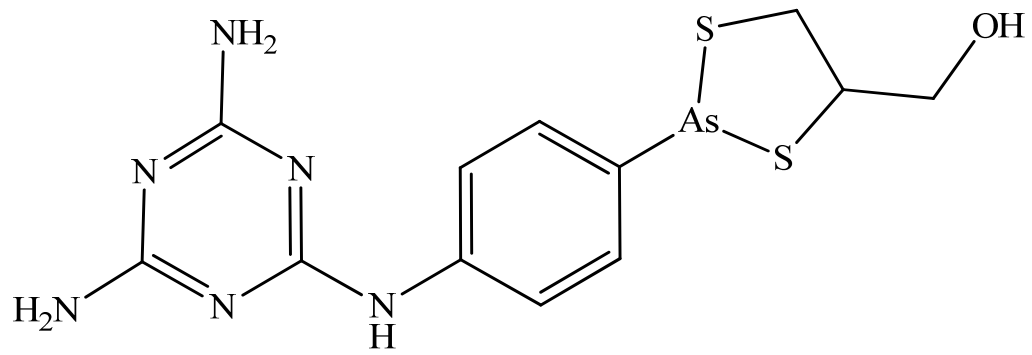

Figure 1.2 Melarsoprol

\subsubsection{Arsenic Trioxide}

Arsenic Trioxide $\left(\mathrm{As}_{2} \mathrm{O}_{3}\right)$ (ATO, Trisenox, Fig. 1.3), an inorganic arsenic compound, was first reported to be effective against chronic myelogenous leukemia in 1878 and for a while it experienced popularity. ${ }^{63,72}$ However its usage then sharply declined as a result of the high incidence of chronic arsenic toxicity in patients and was replaced by cytotoxic chemotherapy and radiation therapy. Recently, arsenic trioxide given in the IV form was rediscovered for the treatment of acute promyelotic leukemia (APL) for both newly diagnosed and relapsed APL. ${ }^{63}$ Most importantly, it was shown to be effective for refractory disease when the illness was already unresponsive to traditional therapy. Trisenox finally received approval from the U. S. FDA in 2000 to treat APL. Moreover, the oral formulation that has been developed was found to have very high bioavailability (up to $95 \%$ of an equivalent dose of intravenous ATO) and can be self-administered in outpatient settings. ${ }^{51,76}$

The side-effects of the ATO treatment include fatigue, fluid retention, weight gain, arrhythmia etc., and may lead to the development of APL differentiation syndrome which can be fatal. ${ }^{61,77,78}$ Retinoic-acid-Acute Promyelocytic Leukemia (RA- 
APL) or simply APL differentiation syndrome is characterized by the presence of skin rash, fluid retention, weight gain, shortness of breath (dyspnea), fever, pulmonary infiltrates in addition other symptoms. ${ }^{61,78}$ The drug is cardio and neuro-toxic. ${ }^{4,5,79,80}$ Compared to IV ATO therapy, oral ATO has slower absorption resulting in reduced peak arsenic plasma concentration, which was found to be associated with lower levels of cardiotoxicity. ${ }^{76,81}$

ATO induces apoptosis (cell death) and cell differentiation, inhibits proliferation and angiogenesis. ${ }^{2,61,63,64}$ During treatment with ATO, highly reactive oxygen species (ROS) form that can damage cells and lead to cell death.

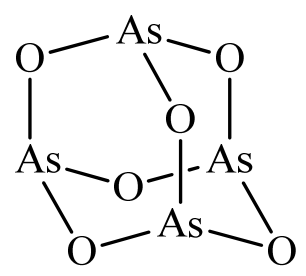

Figure 1.3 Arsenic trioxide (as a solid)

Recently, arsenic trioxide has been encapsulated inside nanoscale liposomes, called nanobins. ${ }^{51,82-86}$ The nanobin formulation is stable in plasma and longcirculating, and the lipid bilayer surrounding the arsenic attenuates cytotoxicity3-4-fold and allows for controlled release. Moreover, anticancer efficacy of ATO is increased in this formulation as the nanobins reduce the clearance rate of arsenic (over 300 fold) and significantly increase the exposure of the neoplasm to the drug. ${ }^{51}$

\subsubsection{Realgar}

Realgar (REA), an inorganic arsenical that was used to treat ulcers, convulsion, schistosomiasis (a parasitic disease), and inflammation, is currently being 
reexamined for the treatment of hematological malignant diseases because of it is less toxic than arsenic trioxide (Fig. 1.4) ${ }^{63,87}$ It is also in clinical trials for the treatment of certain solid tumors. While it was shown to be effective against hematological malignant diseases, it is presently unclear if it will be suitable for the treatment of solid malignant tumors. It is cytotoxic towards the malignant cells and induces cell apoptosis, but was observed to exert only a very small effect on healthy human cells and as such it is better tolerated than ATO therapy. ${ }^{64,87}$ Unfortunately, it has low solubility and bioavailability, but efforts are underway to overcome this obstacle with the development of realgar nanoparticles called nanorealgar. ${ }^{51,64}$

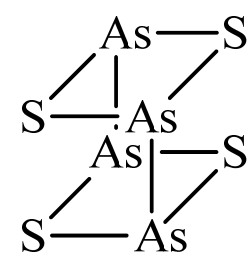

Figure 1.4 Realgar

1.2.2.4 GSAO (4-(N-(S-glutathionylacetyl)amino)phenylarsonous acid) and PENEAO (4-(N-(S-penicillaminylacetyl)amino) phenylarsonous acid)

These two compounds are potential anti-cancer drugs in the cases where tumor metastasis relies heavily on neovascularization (they have a very high potential as an anti-angiogenic therapeutic agents). ${ }^{88-90}$ Both GSAO (Fig. 1.5) and PENAO (Fig. 1.6) are or will soon be (respectively) in trials in patients with solid tumors refractory (resistant) to standard therapy. As hematological cancers do not rely on new blood vessel formation for proliferation, it is only suitable for use against solid tumors. As phase I clinical trials have not been completed, their side effects and toxicities in 
humans are largely unknown. Their mechanism of action is similar; they both react with cysteine residues of the mitochondrial membrane protein ANT (adenine nucleotide translocase) and thus inactivate the transporter and cause proliferation arrest and cancer cell death. ${ }^{88,90}$ The metabolism of GSAO is depicted in Figure 1.4. ${ }^{88,90}$ During its biotransformation, first GCAO forms on the cell surface and then it enters the cell in this form via an organic ion transporter. Once inside the cells, it further metabolizes to CAO. It is actually CAO that will react with ANT thus is responsible for its pharmacological effects, meaning that GSAO is only a pro-drug. On the other hand, PENAO is a cysteine mimetic of CAO and not a pro-drug, meaning that PENAO itself is responsible for inhibiting ANT and not one of its metabolites. 4-(N-(S-penicillaminylacetyl)amino) phenylarsonous acid accumulates much faster in cells and is a stronger anti-proliferative agent.

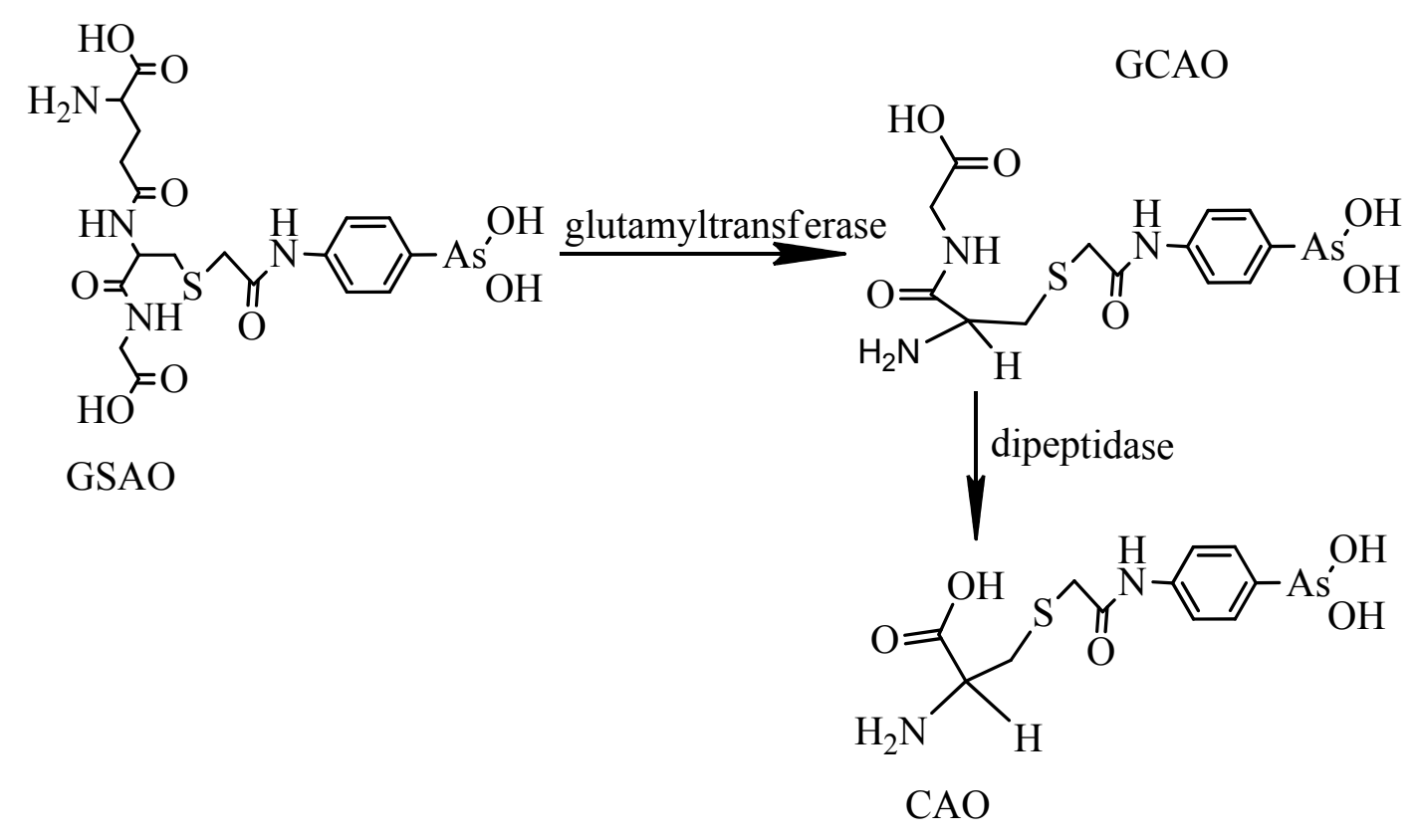

Figure 1.5 Metabolism of GSAO ${ }^{90}$ 


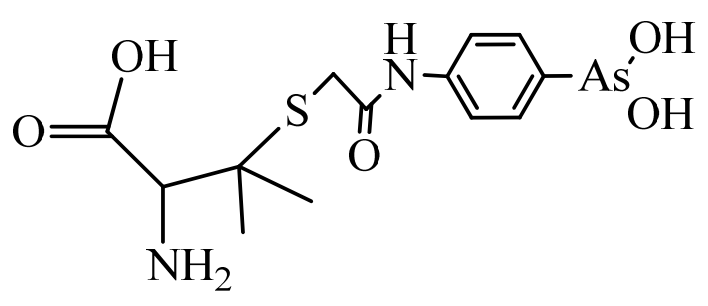

Figure 1.6 PENAO

\subsubsection{Darinaparsin}

Darinaparsin (S-Dimethylarsino-glutathione, ZIO 101, DAR, $\mathrm{DMA}^{\mathrm{III}}(\mathrm{GS})$ ) (Fig. 1.7), an organo-arsenic compound to be discussed here and under investigation in our lab, is currently in clinical trials for hematological cancers and refractory solid tumors. ${ }^{79,91}$ The drug targets the pathways needed for cell survival, induces mitochondrial damage, antiangiogenic (angiogenesis inhibitor) and causes apoptosis. It has a different mode of action from ATO and is also less toxic. While the modulation of glutathione (GSH) levels affects the cytotoxicity of ATO, it does not affect the cytotoxicity of DAR. Furthermore, Darinaparsin seems to be more effective than ATO despite of its lesser toxicity even at higher concentrations. ${ }^{79}$ It may also be used as an alternative for ATO-resistant hematological malignancies as cross-resistance between these two drugs does not necessarily develop. ${ }^{91}$ Arsenic trioxide and Darinaparsin are uptaken by different transport mechanisms, illicit somewhat differing protective responses, and they are metabolized by cells differently. ${ }^{79,91,92}$ Darinaparsin was initially administered in IV (intravenous) form (no first-pass metabolism), but it is currently being evaluated as an orally administered medication. Current results show activity but as with all orally taken medications, first-pass metabolism could potentially limit its bioavailability. Data available at present suggest adequate bioavailability. ${ }^{93}$ 
As mentioned previously, the uptake of DAR is different from ATO. While the presence of exogenous GSH was shown not to affect the uptake of arsenic trioxide, it did prevent Darinaparsin uptake by the cells. DMA ${ }^{\mathrm{III}}(\mathrm{GS})$ has been postulated to enter the cells in the form of DMA ${ }^{\mathrm{III}}$ (dimethylarsinous acid) at low concentrations of exogenous glutathione or in the absence of it. Newer research indicates that DMA ${ }^{\mathrm{III}}(\mathrm{GS})$ may be processed by the enzyme $\gamma$-glutamyl transpeptidase $(\gamma-\mathrm{GT})$ on the cell surface to S-(dimethylarsenic) cysteine $\left(\mathrm{DMA}^{\mathrm{III}}(\mathrm{Cys})\right)$ prior to transport into the cells. ${ }^{94}$ This proposal is supported by the fact that the inhibition of $\gamma$-GT significantly inhibits the uptake and decreases the toxicity of DMA ${ }^{\mathrm{III}}(\mathrm{GS})$, but not has no effect on the uptake and toxicity of DMA ${ }^{\mathrm{III}}(\mathrm{Cys})$. Thiol-containing compounds such as glutathione and cysteine can decrease or inhibit the intracellular accumulation of both $\mathrm{DMA}^{\mathrm{III}}(\mathrm{GS})$ and $\mathrm{DMA}^{\mathrm{III}}$ (Cys) to the same extent by probably modulating the import of these two arsenical into the cell. ${ }^{94} \mathrm{DMA}^{\mathrm{III}}(\mathrm{Cys})$ was shown to be uptaken by multiple cystine/cysteine importers, while no transporter has been yet identified that could transport DMA ${ }^{\mathrm{III}}(\mathrm{GS})$ as is.

The metabolites found inside $\mathrm{DMA}^{\mathrm{III}}(\mathrm{GS})$ treated cells include $\mathrm{DMA}^{\mathrm{III}}(\mathrm{GS})$ (which may re-form by the reaction of $\mathrm{DMA}^{\mathrm{III}}$ or $\mathrm{DMA}^{\mathrm{III}}(\mathrm{Cys})$ with intracellular GSH), $\mathrm{DMA}^{\mathrm{V}}$, and $\mathrm{DMMTA}^{\mathrm{V}}(\mathrm{GS})$. To understand the mechanism of action and the overall potency of this chemotherapeutic agent along with the toxicities of Darinaparsin and its metabolites, it is necessary to determine with certainty what form of Darinaparsin enters cells, how it is metabolized, and evaluate the toxicity of all of its metabolites. 
<smiles>C[As](C)SCC(NC(=O)CCC(N)C(=O)O)C(=O)NCC(=O)O</smiles>

Figure 1.7 Darinaparsin (S-Dimethylarsino-glutathione)

\subsubsection{Design of New As-containing Anticancer Agents}

Platinum-based antineoplastic drugs (platins) are chemotherapeutic agents used to treat cancer. They are coordination complexes of platinum. While they are very effective to treat various cancers, platins exhibit neurotoxicity. Platinum (cisplatin) and arsenic trioxide has been recently combined into one molecular compound called arsenoplatin-1 (Fig. 1.8) in the hopes of developing a therapeutic agent that is more suitable to treat refractory malignancies. ${ }^{95}$ Arsenoplatin-1was found to be more cytotoxic in certain cancer lines than cisplatin. Moreover, in cisplatin resistant cells it was two times more cytotoxic than cisplatin itself and the development of cross resistance between the two drugs has not been observed. ${ }^{51}$ The development and the in vitro investigation of arsenoplatin compounds is an on ongoing project.

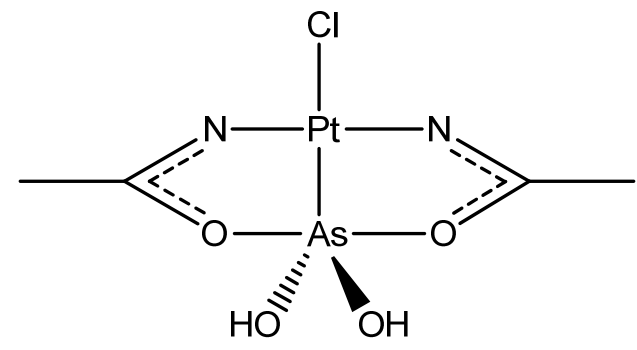

Figure 1.8 Arsenoplatin-1 


\subsection{Arsenic Biotransformation}

The metabolism of these arsenic-containing medicinal preparations and environmental pollutants plays a key role in determining the potency and toxicity of these compounds. Once inside a living organism, arsenic compounds get distributed and metabolized in a process that is highly animal, plant, and chemical species dependent. ${ }^{96}$, 97

\subsubsection{Arsenic Uptake}

Trivalent arsenicals are taken up more efficiently by organs/tissues or cells than pentavalent arsenicals. ${ }^{7,9}$ The reason for the much lower toxicity of pentavalent species compared to the trivalent compounds was partially attributed to the lower rate of accumulation of these species. ${ }^{7}$ Uptake of inorganic arsenite (iAs ${ }^{\mathrm{III}}$ ) in cells is facilitated by membrane transporter proteins, in particular aquaglyceroporin-9 (AQP-9) while inorganic arsenate $\left(\mathrm{iAs}^{\mathrm{V}}\right)$ is thought to enter the cells with the help of phosphate transporters. $^{14,98-100}$ Aquaglyceroporin-9 is most highly expressed in acute promyelotic leukemia (APL) cells, correlating to higher arsenic uptake and sensitivity to arsenic treatment in this malignant cell type. ${ }^{101}$ As mentioned above, newer research indicates that $\mathrm{DMA}^{\mathrm{III}}(\mathrm{GS})$ may be processed by $\gamma$-GT on the cell surface to $\mathrm{DMA}^{\mathrm{III}}(\mathrm{Cys})$ prior to transport into the cells. ${ }^{94}$

\subsubsection{Arsenic Distribution, Metabolism, and Transport}

The distribution of the different metabolites depends on many factors, such as the arsenic species administered, the plant or animal species involved, the type of cells within the same organism, the availability of reducing agents such as glutathione (GSH) 
and other thiol $(-\mathrm{SH})$ containing biomolecules, the presence of arsenic methylating enzymes, and the $\mathrm{pH}$ of the matrix. ${ }^{9,} 102$

During the detoxification of $\mathrm{iAs}^{\mathrm{III}}$, the compound is biomethylated to monoand dimethylated (in some cases trimethylated) arsenicals of varying toxicity. Some of these metabolites will be less while others will be more toxic than iAs ${ }^{\mathrm{III}}$. Pentavalent methylated arsenicals are less toxic than inorganic iAs ${ }^{\mathrm{III}}$. However this is generally not the case for the trivalent methylated species which are highly cytotoxic and genotoxic. ${ }^{7}$ Hence, the methylation of arsenic is a bioactivation pathway rather than a mode of detoxification. The toxic trivalent methylated species are easily oxidized to the less cytotoxic pentavalent species at low glutathione (and other reducing agent) concentrations.

According to the early postulated scheme of metabolism, called the reductive/oxidative methylation pathway, during the detoxification of iAs $^{\mathrm{V}}$ (Fig. 1.9), it is first reduced to the more toxic $\mathrm{iAs}^{\mathrm{III}}$, and then methylated and oxidized to $\mathrm{MMA}^{\mathrm{V}}$ simultaneously. ${ }^{98,} 103$ Then $\mathrm{MMA}^{\mathrm{V}}$ gets reduced to $\mathrm{MMA}^{\mathrm{III}}$ and during oxidative methylation it is transformed into $\mathrm{DMA}^{\mathrm{V}}$, which is then reduced to $\mathrm{DMA}^{\mathrm{III}}$. In certain species, but not in humans, during oxidative methylation $\mathrm{DMA}^{\mathrm{V}}$ then can be converted into trimethylarsine oxide $\left(\mathrm{TMAO}^{\mathrm{V}}\right)$. Numerous evidence pointed to the flaws of this early proposed oxidation methylation pathway of arsenic biotransformation and suggested this pathway to be unreasonable and that it should be reconsidered. ${ }^{98}$

On the basis of observations, it was proposed that the pentavalent methylated species, $\mathrm{MMA}^{\mathrm{V}}$ and $\mathrm{DMA}^{\mathrm{V}}$ form from the oxidation of $\mathrm{MMA}^{\mathrm{III}}$ and $\mathrm{DMA}^{\mathrm{III}}$, and not the other way around. Moreover, the involvement of As-glutathione complexes in the 
biotransformation of arsenic was finally recognized as a necessary component. Sadenosylmethionine (SAM) was found to act as the methyl donor in the reaction and Cyt 19 (As3MT, arsenic methyltransferase) was recognized as the catalyst. Glutathione and possibly other thiols were suggested to act as reducing agents. ${ }^{98,} 104$ According to this pathway, proposed by Hayakawa (Fig. 1.10), instead of the oxidative methylation of $\mathrm{iAs}^{\mathrm{III}}$ and $\mathrm{MMA}^{\mathrm{III}}$ to $\mathrm{MMA}^{\mathrm{V}}$ and $\mathrm{DMA}^{\mathrm{V}}$ respectively, the oxidative methylation is via arsenic triglutathione $\left(\mathrm{As}(\mathrm{GS})_{3}\right)$, monomethylarsenic diglutathione $\left(\mathrm{MMA}(\mathrm{GS})_{2}\right)$, and dimethylarsenic glutathione (DMA $\left.{ }^{\mathrm{III}}(\mathrm{GS})\right)$ to $\mathrm{MMA}^{\mathrm{V}}$ and $\mathrm{DMA}^{\mathrm{V}}$.

Kala et al. suggested that the formation of these arsenic-GSH complexes may play an important role in the transportation of arsenic and its methylated derivatives. ${ }^{105}$ They estimated that $60-70 \%$ of the urinary As metabolite may be present as GSHconjugate in mice, but it is catabolized by the enzyme $\gamma$-glutamyl transpeptidase and 80 $90 \%$ of the total arsenic excreted in the bile is also GSH conjugated. ${ }^{31,}{ }^{105}$ Arsenicglutathione conjugates were observed to be the transported forms and account for the majority of excreted arsenic. ${ }^{100}$ As the addition of GSH to a molecule during metabolism is said to provide a molecular 'flag' that promotes the removal of the xenobiotic from cells, this is not surprising. ${ }^{106}$ However, others theorize that the trivalent species are mostly protein-bound and are not present as GSH-conjugates, and possess higher affinities to bind to proteins than to glutathione. ${ }^{1,107-109}$

A third possible pathway was proposed by Naranmandura (Fig.1.11), who theorizes that as arsenic compounds have a higher affinity for the thiol groups of proteins than glutathione, an such during methylation the trivalent arsenicals are attached to the thiols of proteins and are not glutathione conjugated..$^{98}$ In addition to the above mentioned 
arsenic metabolites, thiolated species may also form during the biotransformation of arsenic. The most often seen thiolated arsenical is dimethylmonothioarsinic acid $\left(\right.$ DMMTA $\left.^{\mathrm{V}}\right)$, which was reported to form from DMA ${ }^{\mathrm{III}}$ in thiol-rich rat liver cells in addition to the less frequently observed dimethyldithioarsinic acid (DMDTA $\left.{ }^{\mathrm{V}}\right) \cdot{ }^{110}$ Suzuki proposed that these species must form from DMA ${ }^{\mathrm{III}}$ and cannot form from DMA ${ }^{\mathrm{V}}$, the reduction of $\mathrm{DMA}^{\mathrm{V}}$ to $\mathrm{DMA}^{\mathrm{III}}$ is required for the reaction to take place. ${ }^{110}$ The proposed pathway of thiolated arsenical formation by Suzuki is depicted in Figure 1.12.

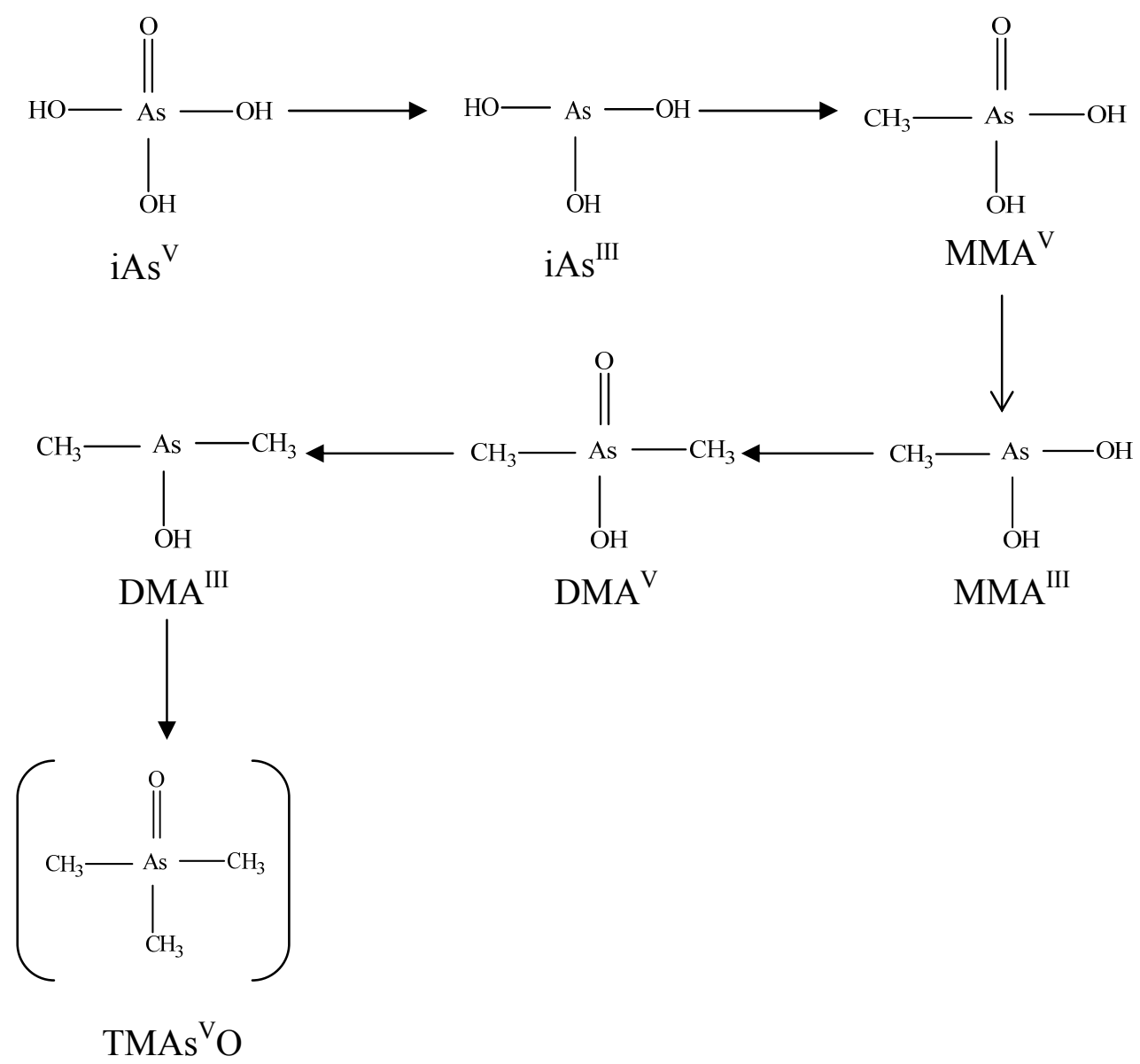

Figure 1.9 An early postulated scheme of metabolism (Challenger pathway) 


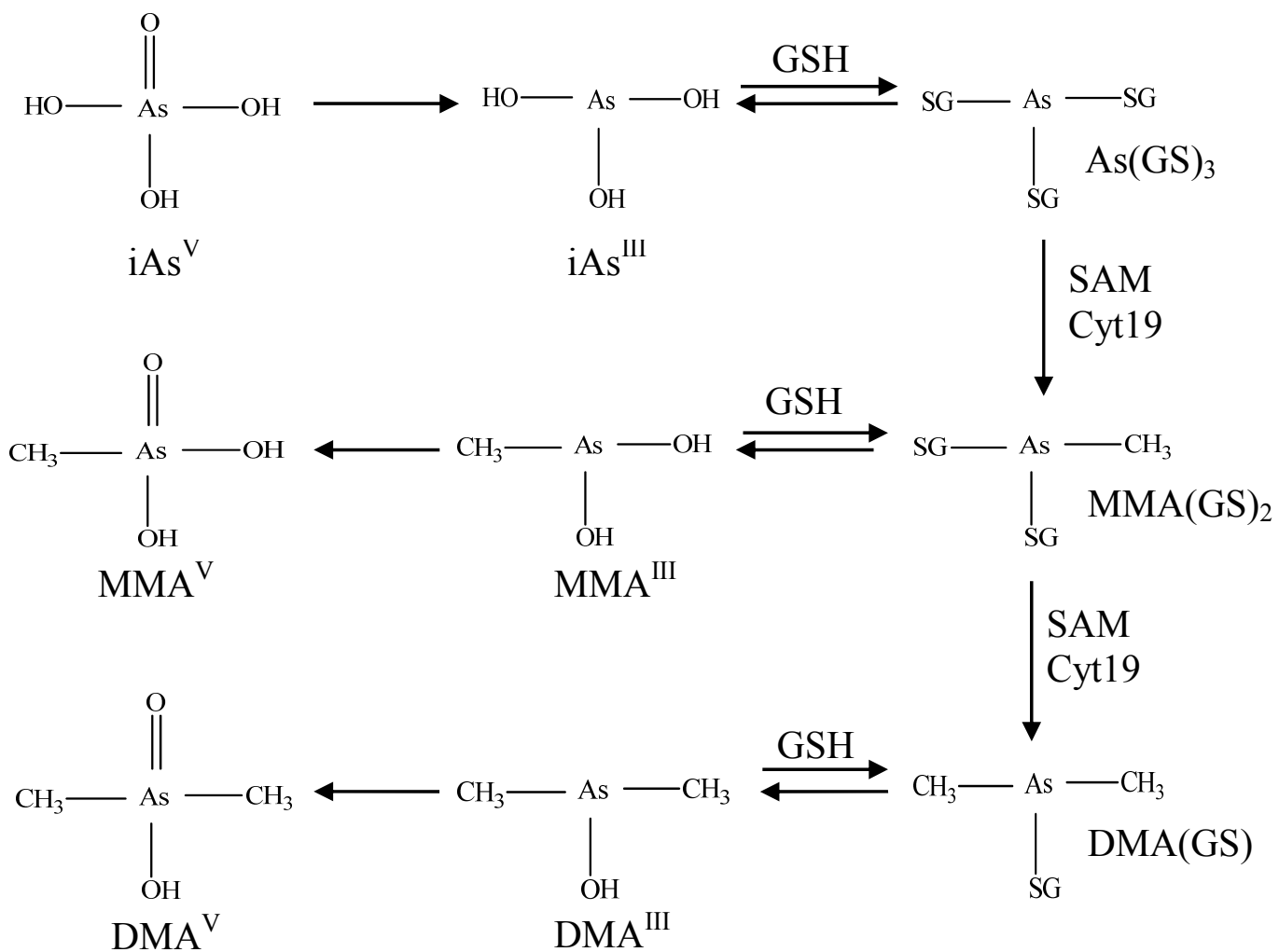

Figure 1.10 New metabolic pathway of arsenic proposed by Hayakawa

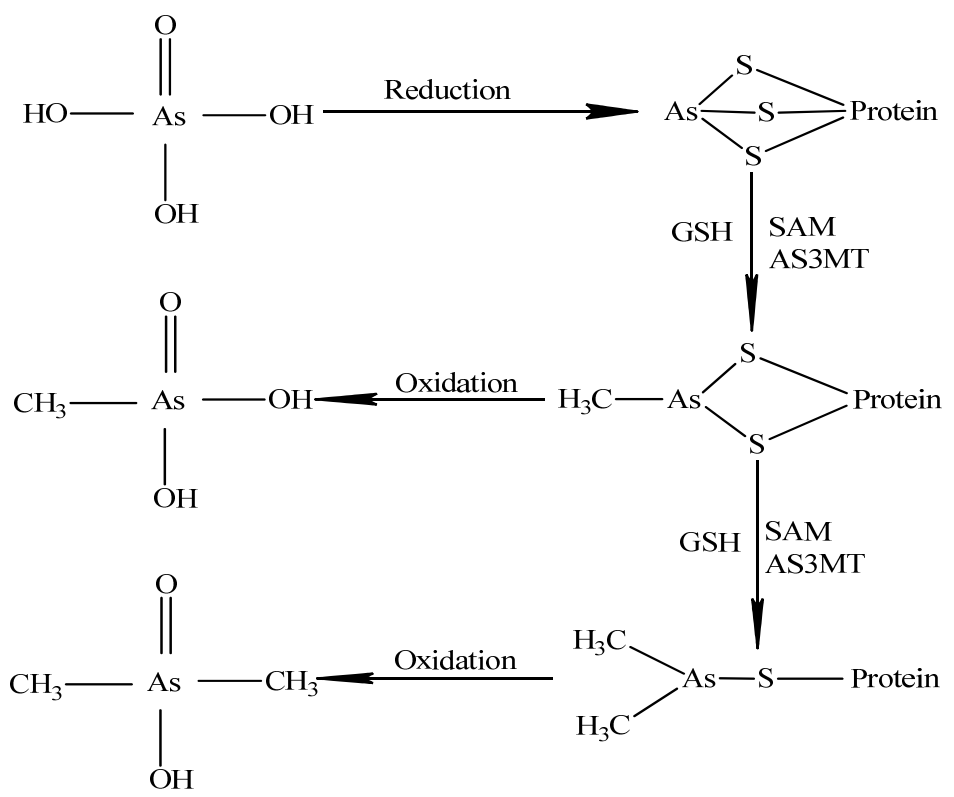

Figure 1.11 Proposed biotransformation pathway of $\mathrm{iAs}^{\mathrm{V}}$ by Naranmandura 


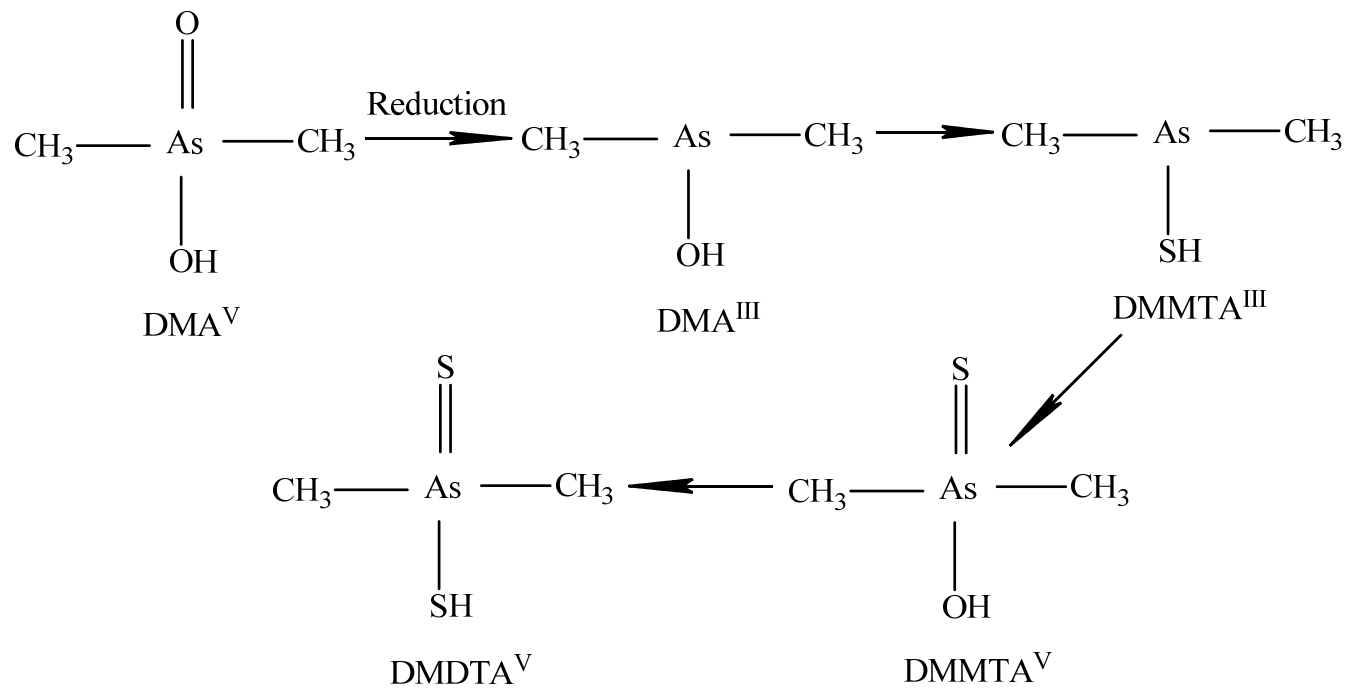

Figure 1.12 Proposed formation of thiolated arsenicals in rat hepatocytes by Suzuki

Naranmandura et al. also proposed a possible pathway for the formation of thiolated arsenicals (Fig. 1.13) but in rat red blood cells (RBC). ${ }^{11}$ According to this scheme, the formation of DMMTA ${ }^{\mathrm{V}}$ is via the formation of DMMTA ${ }^{\mathrm{III}}$ from DMA ${ }^{\mathrm{III}}$. He also did not suggest that DMMTA ${ }^{\mathrm{V}}$ can directly form from DMA ${ }^{\mathrm{V}}$, nor could he prove that the intermediate is DMMTA ${ }^{\mathrm{III}}$. Additionally, he suggested that DMDTA ${ }^{\mathrm{V}}$ may partially form utilizing $\mathrm{HS}^{-}$liberated from the enzymatic hydrolysis of DMMTA ${ }^{\mathrm{V}}$. The enzyme responsible for the hydrolysis was not identified. It is important to note here, that the exact form of sulfur $\left(\mathrm{S}^{2-}, \mathrm{HS}^{-}\right.$, or $\mathrm{H}_{2} \mathrm{~S}$ ) or the source of it (from enzymatic reactions that produce $\mathrm{H}_{2} \mathrm{~S}$ or from the sulfane sulfur of biomolecules or from other sources) have not yet been identified. 


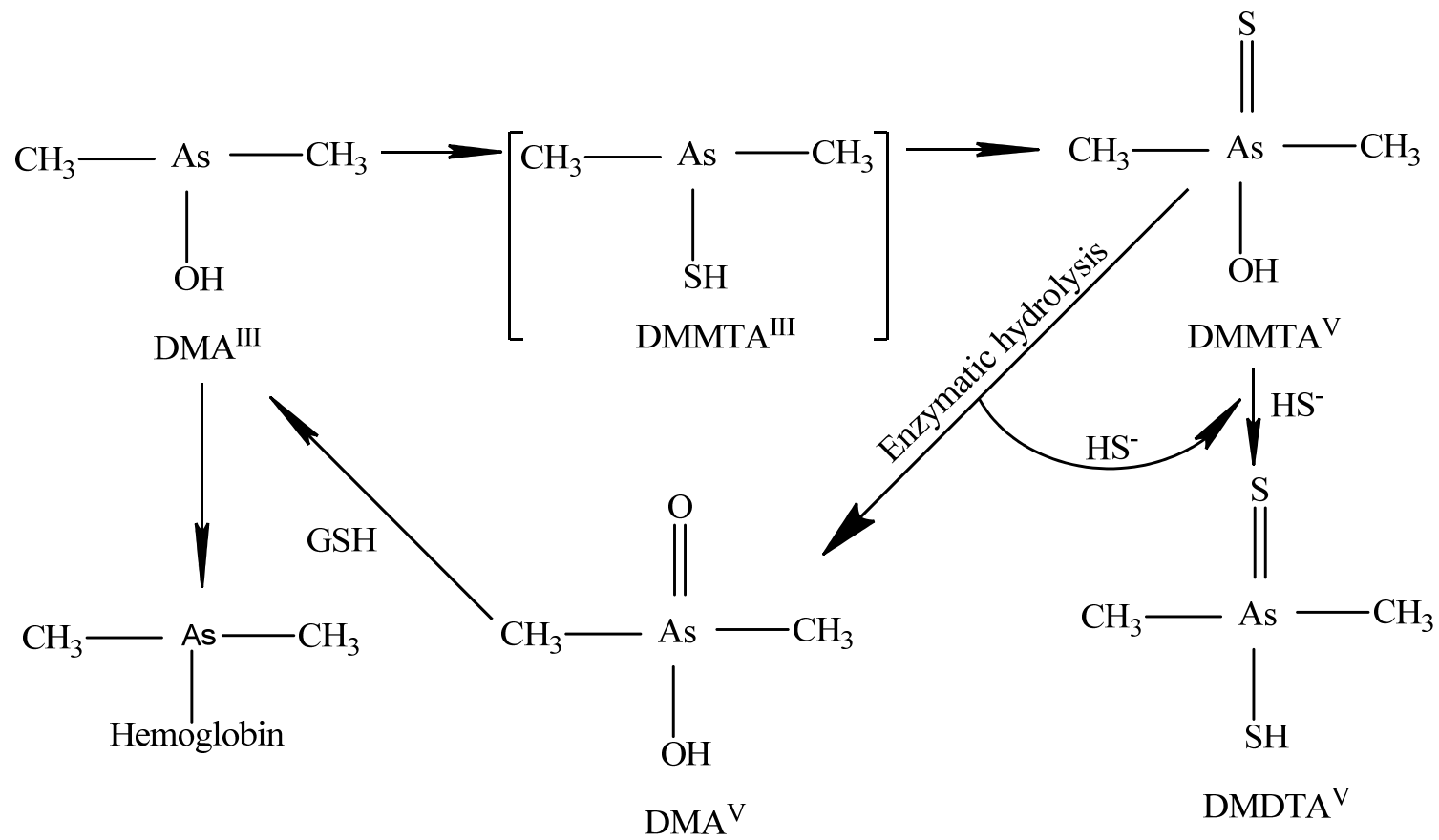

Figure 1.13 Transformation of DMA ${ }^{\mathrm{III}}$ in rat RBCs proposed by Naranmandura et al.

In our lab the metabolism of Darinaparsin $\left(\mathrm{DMA}^{\mathrm{III}}(\mathrm{GS})\right)$ was studied. It was found that $\mathrm{DMA}^{\mathrm{III}}(\mathrm{GS})$ metabolizes to $\mathrm{DMA}^{\mathrm{V}}$, dimethylarsinothioyl glutathione $\left(\operatorname{DMMTA}^{\mathrm{V}}(\mathrm{GS})\right)$, and $\mathrm{DMA}^{\mathrm{III}}(\mathrm{GS}){ }^{34}$ Dimethylarsenothioyl glutathione has not been identified in humans ever before. The only reported presence of this metabolite of unknown toxicity was in cabbage prior to this finding. ${ }^{112}$

\subsubsection{Retention and elimination}

Currently no studies exist for organic As retention in humans. Arsenic retention in the body can best be monitored via the analysis of hair, fingernails, and toenails. ${ }^{113}$ After the extensive metabolism of arsenic in the liver and other cells, arsenicals are transported out of the cells. Different transporters are responsible for the cellular efflux of these species and some of the transporters responsible for a few of the 
arsenic metabolites, such as DMA ${ }^{\mathrm{III}}(\mathrm{GS})$ and $\mathrm{DMMTA}^{\mathrm{V}}(\mathrm{GS})$, are still not known. ${ }^{14,100} \mathrm{~A}$ summary of these cellular efflux pathways are depicted in Figure 1.14. For the transport of $\mathrm{As}(\mathrm{GS})_{3}$ and $\mathrm{MMA}(\mathrm{GS})_{2}$ transporters MRP1 and MRP2 are responsible. These two transporters belong to the of ATP-binding cassette $(\mathrm{ABC})$ transporters, namely to $\mathrm{ABCC}$ subfamily and are responsible for the efflux of these two arsenical from the liver into the bile (MRP2) and the blood (MRP1). ${ }^{14,} 100$ Additionally, multidrug resistant Pglycoproteins (PGPs) that are also ATP-binding cassette transporters are also responsible for the efflux of glutathione conjugated arsenicals into the extracellular space. ${ }^{99} \mathrm{As}^{\mathrm{III}}$, $\mathrm{MMA}^{\mathrm{III}}, \mathrm{MMA}^{\mathrm{V}}$, and $\mathrm{DMA}^{\mathrm{V}}$ are effluxed using the membrane protein family aquaporin isozymes 9 (AQP9) that facilitate the movement of solutes down their concentration gradient. ${ }^{99,}{ }^{100}$ Moreover, glucose transporters, especially GLUT2, facilitate the transport of $\mathrm{As}^{\mathrm{III}}$ and $\mathrm{MMA}^{\mathrm{III}}$ across the cellular membrane. ${ }^{99}$ Once exported from hepatocytes to the bile, these compounds are excreted into the intestines. Some of these may end up in the feces and eliminated, or reabsorbed unchanged, while others either may get further metabolized by intestinal bacteria to MMMTA ${ }^{\mathrm{V}}$, DMMTA ${ }^{\mathrm{V}}$, and $\mathrm{DMDTA}^{\mathrm{V}}$ and then excreted or reabsorbed from the intestines into the body. ${ }^{10,}{ }^{14,}{ }^{114}$ Additionally, large amounts of arsenic metabolites are excreted into the urine. As mentioned before, it is estimated that in mice $60-70 \%$ of urinary arsenic metabolites are present as glutathione complexes originally, but get further metabolized by $\gamma$-glutamyl transpeptidase (GGT), the enzyme responsible for the catabolism of glutathione-conjugates. ${ }^{31}$ 


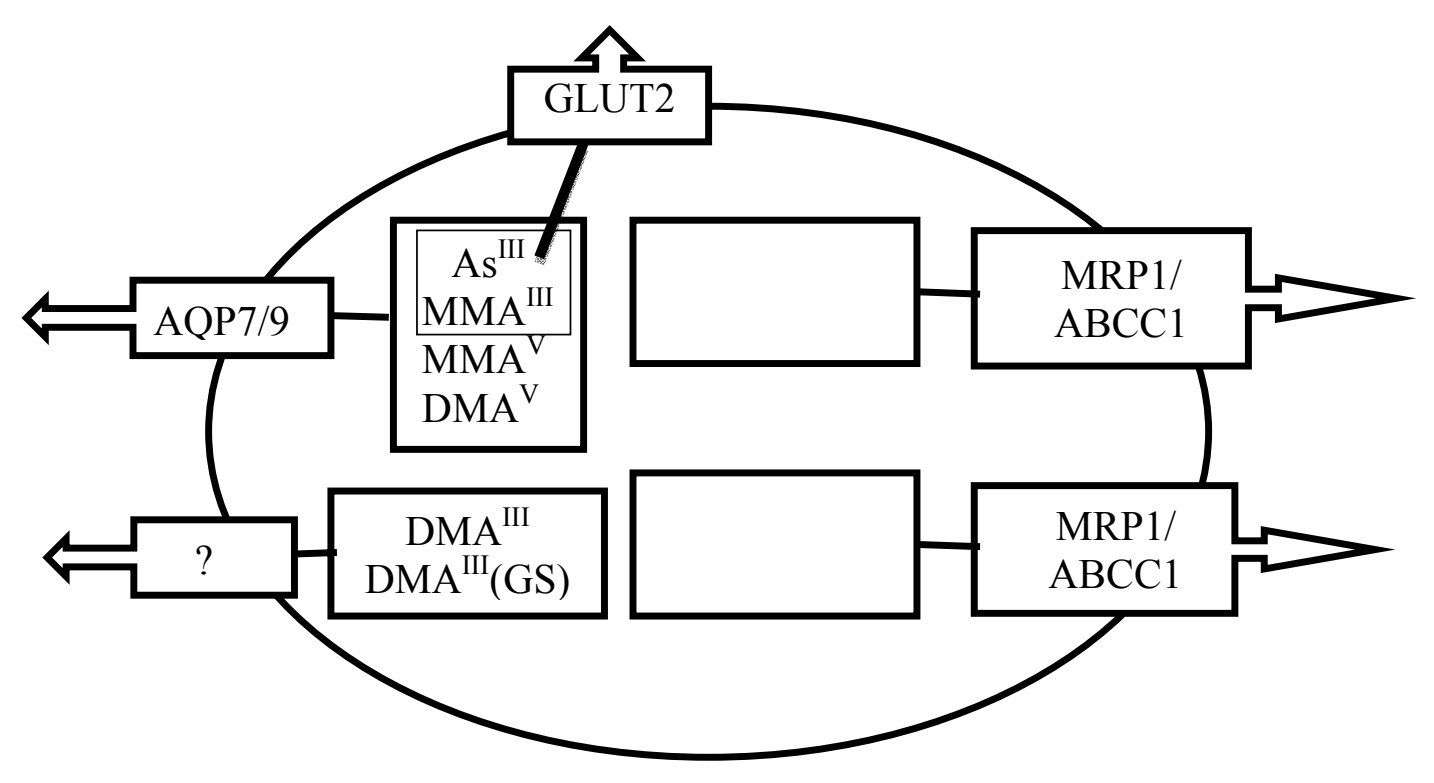

Figure 1.14 Arsenic cellular efflux pathways

\subsection{Arsenic Speciation in Biological Systems}

To understand the metabolism, toxicity, and the therapeutic efficacy of arsenicals, an appropriate analytical technique is needed that can conserve species identities during storage, extraction (sample preparation), separation, and detection to enable us to correctly identify and quantify all arsenic species present in biological systems.

\subsubsection{Sample Preparation and Extraction}

Trivalent arsenic metabolites $\mathrm{As}^{\mathrm{III}}$, $\mathrm{MMA}^{\mathrm{III}}$, and $\mathrm{DMA}^{\mathrm{III}}$ are unstable and highly prone to oxidation to their pentavalent counterparts, especially DMA ${ }^{\mathrm{III}} .115,116$ Moreover, glutathione conjugates $\left(\mathrm{As}^{\mathrm{III}}(\mathrm{GS})_{3}, \quad \mathrm{MMA}^{\mathrm{III}}(\mathrm{GS})_{2}, \quad \mathrm{DMA}^{\mathrm{III}}(\mathrm{GS}), \quad\right.$ and $\left.\operatorname{DMMTA}^{\mathrm{V}}(\mathrm{GS})\right)$ easily hydrolyze and are oxidized if the native reducing environment of the cells is not maintained (as in the cases of all reported methods). ${ }^{117}$ Consequently, if samples are not stored properly or if the reducing environment of the sample (most 
importantly its glutathione concentration) is not maintained during sample preparation, the identities of species will be altered and a misleading metabolic speciation profile will be obtained resulting in incorrect assessment of toxicity and mechanism of action of therapeutic arsenical preparations. Additionally, species stability is $\mathrm{pH}$ dependent thus the $\mathrm{pH}$ of the sample should be maintained during sample preparation or disturbed minimally. Ultrasonic bath and probe (Sonic Dismembrator) along with vortexing were evaluated for extraction efficiency of arsenic from cancer cells. ${ }^{117}$ The ultrasonic probe was found to be the fastest and most efficient extraction method. Using the sonicator probe double deionized water (DDIW), $0.1 \%$ trifluoroacetic acid (TFA), and DDIW/methanol $(50 / 50 \mathrm{v} / \mathrm{v})$ mix were used as extraction solvent and their ability to maintain species identities over time were evaluated and compared to pepsin, trypsin, and protease. It was found that DDIW in combination with the sonicator probe yielded similar stability results with trypsin and pepsin, while the other extraction solvents were able to preserve species identities to a lesser extent. ${ }^{117}$

\subsubsection{Separation of Species}

Currently existing arsenic speciation techniques usually employ high performance liquid chromatography (HPLC) separation on reverse phase (RP) or ion exchange column for the analysis of biological samples. In reverse phase chromatography (RPC) separation is achieved employing a solid hydrophobic stationary phase and a polar liquid mobile phase. The hydrophobic molecules in the mobile phase have a higher affinity for the stationary phase thus they are retained longer. In ion-exchange chromatography the analytes are retained on the column on the basis of ionic interactions. The stationary phase has ionic functional groups that interact with the analyte ions of 
opposite charge. Ion exchange chromatography is further divided into cation and anion exchange chromatography. In cation exchange chromatography positively charged ions are retained as the stationary phase possesses negatively charged functional groups. In anion exchange chromatography negatively charged ions are retained as the stationary phase displays positively charged functional groups.

Unfortunately, currently available techniques have shortcomings and cannot meet the need of "full-spectrum" analysis of As metabolites. First, standard ion chromatography was found to destroy glutathione complexes of As in both our and others' labs, failing to detect As-GSH complexes. ${ }^{117,}{ }^{118}$ As these glutathione complexes are thought to be necessary intermediates for arsenic methylation, their unequivocal identification is important to depict the pathways of arsenic metabolism. Second, many current As speciation methods are unable to detect sulfur-containing arsenicals such as DMMTA $^{\mathrm{V}}$, DMDTA ${ }^{\mathrm{V}}$, and $\operatorname{DMMTA}^{\mathrm{V}}(\mathrm{GS})$, and in particular cannot simultaneously determine methylated species (trivalent and pentavalent) and sulfur-containing arsenicals. It is necessary to identify sulfur-containing arsenicals as these As species may play an important role in As metabolism, toxicity, and anticancer activity. Finally, current analytical methods usually are able to separate a limited number of arsenic species only and co-elution of species occurs during analysis. For example, many of the methods employing anion exchange columns could not distinguish $\mathrm{MMA}^{\mathrm{III}}$ from $\mathrm{MMA}^{\mathrm{V}}$ and $\mathrm{DMA}^{\mathrm{III}}$ from DMA $\mathrm{D}^{\mathrm{V}}$, providing incomplete and misleading arsenic speciation profile. As a result of the inadequacy of the currently available methods to accurately evaluate the metabolism of Darinaparsin and other arsenic arsenicals in biological samples, I developed an analytical method that addresses most of the shortcomings of currently 
available speciation methods. The objective of that study was to develop an analytical method using that is capable of performing a "full-spectrum" analysis of As metabolites. The method was aimed to simultaneously determine the arsenic species of traditional interest (e.g. inorganic $\mathrm{As}^{\mathrm{V}}$ and $\mathrm{As}^{\mathrm{III}}$ and organic $\mathrm{DMA}^{\mathrm{V}}$ and $\mathrm{MMA}^{\mathrm{V}}$ ), the highly toxic trivalent methylated As recently reported (DMA ${ }^{\mathrm{III}}$ and $\mathrm{MMA}^{\mathrm{III}}$ ), and the newly discovered sulfur-containing As metabolites (e.g., DMMTA ${ }^{\mathrm{III}}, \mathrm{DMMTA}^{\mathrm{V}}, \mathrm{DMDTA}^{\mathrm{V}}$, and $\left.\operatorname{DMMTA}^{\mathrm{V}}(\mathrm{GS})\right)$ in addition to the glutathione and cysteine complexes $\left(\mathrm{As}^{\mathrm{III}}(\mathrm{GS})_{3}\right.$, $\left.\mathrm{MMA}^{\mathrm{III}}(\mathrm{GS})_{2}, \mathrm{DMA}^{\mathrm{III}}(\mathrm{GS})\right)$, and $\mathrm{DMA}^{\mathrm{III}}(\mathrm{Cys})$. These results are presented in this dissertation.

\subsubsection{Detection Techniques}

The separation techniques mentioned above are usually coupled to an element specific detector such as inductively coupled plasma mass spectrometer (ICP-MS), atomic fluorescence spectrometer (AFS), or atomic absorption spectrometer (AAS) for the detection of species. ${ }^{119-123}$ Unfortunately, these detectors are only element specific and cannot reveal the true identity of the species or detect co-elution as the only information they are able to provide is the presence of arsenic. To monitor co-elution of species and identify arsenic compounds, electrospray ionization mass spectroscopy (ESI MS) is employed. Unfortunately, the technique has its own shortcomings. Some of the arsenic species either have very low ionization efficiently and such they are not detected or only detected at higher concentration levels. Moreover, a few of the trivalent species may oxidize during the electrospray to their pentavalent counterparts (especially DMA ${ }^{\mathrm{III}}$ to $\mathrm{DMA}^{\mathrm{V}}$ ) thus giving way to misidentification of species. Furthermore, when an unknown species is found on the HPLC-ICP-MS chromatograms, in order to identify it, 
the exact same method must be run on an HPLC-ESI-MS/MS system to determine the structure of the unknown at the retention time determined on the ICP system. Unfortunately, the ICP and the ESI ionization techniques are very different. While ICP does not tolerate the presence of large amounts of organic solvents and plasma instability and consequently extinction occurs, the presence of large amounts of organic solvent in the mobile phase is required for adequate and efficient ionization in ESI. As a result, it is very difficult to develop a method that can be used both on the ESI and the ICP. During method development, I aimed to develop a separation technique that could be coupled with both ICP and ESI detection technique to achieve the unequivocal identification of all species. 


\section{CHAPTER 2}

Problem Statement, Objectives and Hypotheses 


\subsection{Problem Statement}

Arsenic compounds are extensively metabolized in the human body. Deciphering the exact mechanism of metabolism and identifying and quantifying all metabolites produced during the biotransformation of arsenicals contribute significantly to our understanding of their toxicities, and in the case of arsenic containing therapeutics their mechanism of antineoplastic action. To accomplish this, an analytical method capable of conserving all species identities during sample preparation, separation, and detection was needed. In addition, the separation technique had to able to resolve all species that may be present in order to accurately assess the quantities and the identities of all species. Presently available analytical techniques are not capable to conserve, resolve, and detect all possible human arsenic metabolites from biological samples. Consequently, the development of an analytical method overcoming the shortcomings of the currently available methods was necessary.

Moreover, the lack of a good separation method also hindered the deciphering of the exact mechanisms of metabolism of Darinaparsin (a promising new chemotherapeutic agent), the mechanism of formations of the newly discovered human metabolite $\operatorname{DMMTA}^{\mathrm{V}}(\mathrm{GS})$, and the thiolated arsenicals DMMTA ${ }^{\mathrm{III}}, \mathrm{DMMTA}^{\mathrm{V}}$, and DMDTA ${ }^{\mathrm{V}}$. Additionally, the source of sulfur used for the formation of these species (DMMTA ${ }^{\text {III }}$, DMMTA $^{\mathrm{V}}, \mathrm{DMDTA}^{\mathrm{V}}$, and $\operatorname{DMMTA}^{\mathrm{V}}(\mathrm{GS})$ ) (either generated by enzymatic reactions producing $\mathrm{H}_{2} \mathrm{~S}$ or from sulfane sulfur containing biomolecules) has not yet been

deciphered. Furthermore, the form of sulfur $\left(\mathrm{S}^{2-}, \mathrm{HS}^{-}\right.$, and/or $\left.\mathrm{H}_{2} \mathrm{~S}\right)$ that is involved in the formation of the thiolated arsenicals has not been determined either. 
One of the main obstacles to decipher the mechanism of formation of thiolated arsenic species was the unavailability of a method describing the synthesis of DMMTA ${ }^{\text {III }}$, a potential precursor of $\mathrm{DMMTA}^{\mathrm{V}}$ synthesis from $\mathrm{DMA}^{\mathrm{III}}$ and $\mathrm{DMA}^{\mathrm{III}}(\mathrm{GS})$, in addition to the lack of a good analytical separation method to identify all species formed in the reaction of arsenicals and sulfur donors.

While the toxicity and the ability of cells to take many arsenic compounds up have already been evaluated, the uptake and toxicity of the newly discovered arsenic metabolite DMMTA ${ }^{\mathrm{V}}(\mathrm{GS})$ have not yet been assessed. It is also not known, if the formation of $\mathrm{DMMTA}^{\mathrm{V}}(\mathrm{GS})$ during Darinaparsin metabolism is a detoxification process or it is still a highly toxic metabolite. Thus the assessment of toxicity and the cancer cells' ability to take DMMTA ${ }^{\mathrm{V}}$ up needed to be evaluated.

\subsection{Objectives}

The present work emphasized on the analytical method development for speciation of a large number of possible and confirmed human arsenic metabolites from biological samples. Once the method was successfully developed, it was employed to determine the arsenicals formed in cancer cell lines upon exposure to Darinaparsin and to propose the mechanism of metabolism of Darinaparsin in above cells. Additionally, the method was applied to decipher the mechanism and conditions of formation of thiolated arsenicals DMMTA $^{\mathrm{III}}$, DMMTA ${ }^{\mathrm{V}}, \mathrm{DMDTA}^{\mathrm{V}}$, and $\operatorname{DMMTA}^{\mathrm{V}}(\mathrm{GS})$ from both trivalent $\left(\mathrm{DMA}^{\mathrm{III}}(\mathrm{GS})\right)$ and pentavalent $\left(\mathrm{DMA}^{\mathrm{V}}\right)$ arsenicals and the source and the form of sulfur utilized for the formation of the above species. It was also pertinent to evaluate the uptake and the toxicity of the newly discovered human metabolite $\operatorname{DMMTA}^{\mathrm{V}}(\mathrm{GS})$. 
The following objectives were established:

1. Development of efficient and selective speciation method for the simultaneous separation and detection of the known and suspected human arsenic metabolites from biological samples that is suitable with both ICP-MS and ESI-MS as detectors.

2. Application of the newly developed analytical method to decipher the mechanism of metabolism of Darinaparsin by incubating the cancer cells with Darinaparsin and then analyzing the samples to determine the intermediates and the final metabolites of the biotransformation of this chemotherapeutic agent.

3. Application of newly developed method to decipher the mechanism of formation of thiolated arsenic metabolites DMMTA ${ }^{\mathrm{III}}$ (and resolve its synthesis), DMMTA ${ }^{\mathrm{V}}$, DMDTA $^{\mathrm{V}}$, and DMMTA ${ }^{\mathrm{V}}(\mathrm{GS})$ from both trivalent and pentavalent arsenicals, and to find the source and the form of sulfur utilized for their formation in biological systems.

4. To evaluate the toxicity of DMMTA $^{\mathrm{V}}(\mathrm{GS})$ and the ability of cells to take it up and to understand its role in the metabolism of Darinaparsin.

\subsection{Hypotheses}

The objectives were guided by the following hypotheses:

1. Stabilities and the adequate separation of trivalent arsenicals, thiolated arsenicals, and arsenic glutathione complexes during speciation analysis are dependent on the experimental conditions employed for sample preparation and separation.

2. The proper speciation technique, once developed, will enable me to detect all possible metabolites and intermediates of metabolism of Darinaparsin from biological samples and will aid in understanding the mechanism of formation of 
the thiolated arsenicals including the newly discovered metabolite $\operatorname{DMMTA}^{\mathrm{V}}(\mathrm{GS})$.

3. The formation of $\operatorname{DMMTA}^{\mathrm{V}}(\mathrm{GS})$ is a detoxification process thus it is less toxic than the parent compound $\mathrm{DMA}^{\mathrm{III}}(\mathrm{GS})$. The ability of cells to take $\operatorname{DMMTA}^{\mathrm{V}}(\mathrm{GS})$ up as is (without prior hydrolysis to DMMTA ${ }^{\mathrm{V}}$ ) may be limited, just like the uptake of $\mathrm{DMA}^{\mathrm{III}}(\mathrm{GS})$ in the presence of stabilizing GSH in the extracellular space. Moreover, in cells, $\operatorname{DMMTA}^{\mathrm{V}}(\mathrm{GS})$ is probably mainly formed in enzymatic reactions under physiological conditions.

4. It is most likely that the forms of sulfur utilized for thiolated arsenical formation are $\mathrm{HS}^{-}$and $\mathrm{H}_{2} \mathrm{~S}$ as these two are the mayor forms of hydrogen sulfide present at physiological $\mathrm{pH}$. The $\mathrm{HS}^{-}$and $\mathrm{H}_{2} \mathrm{~S}$ may come from both enzymatically generated processes and/or from sulfane sulfur-containing biomolecules. 


\section{CHAPTER 3}

Dimethylarsinothioyl Glutathione as a Metabolite in Human Multiple Myeloma Cell Lines upon Exposure to Darinaparsin: Formation, Toxicity, and Cellular Uptake

Part of this chapter was accepted for publication in the journal of Chemical Research in Toxicology. Adapted with permission from Yehiayan, L., Stice, S., Liu, G., Matulis, S., Boise, L., \& Cai, Y. (2014). Dimethylarsinothioyl glutathione as a metabolite in human multiple myeloma cell lines upon exposure to Darinaparsin. Chemical Research in Toxicology. Copyright (2014) American Chemical Society. 


\subsection{Graphical Abstract}

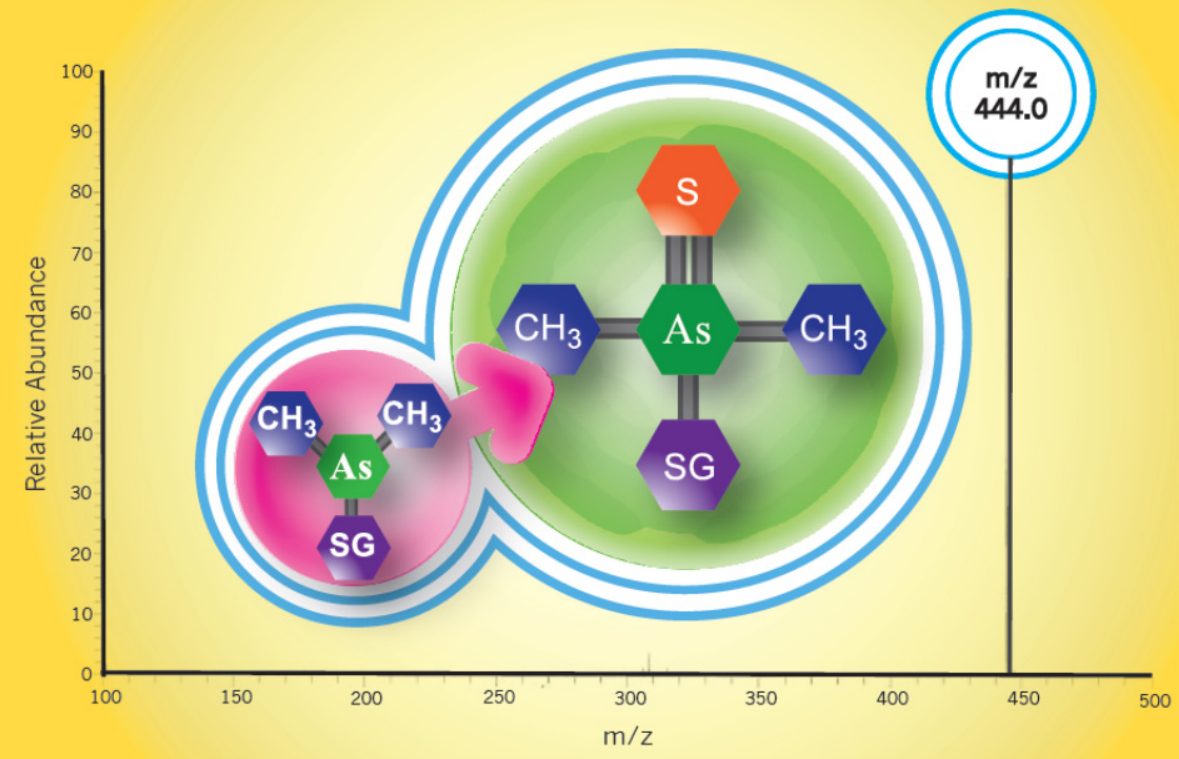

\subsection{Abstract}

Dimethylarsinothioyl glutathione $\left(\operatorname{DMMTA}^{\mathrm{V}}(\mathrm{GS})\right)$ was first identified as a metabolite in the cellular extracts of dimethylarsinous glutathione (Darinaparsin, $\left.\mathrm{DMA}^{\mathrm{III}}(\mathrm{GS})\right)$ treated human multiple myeloma and lymphoma cell lines in our laboratory. Formation studies in $\mathrm{DMA}^{\mathrm{III}}(\mathrm{GS})$ spiked cells revealed the dependence of $\operatorname{DMMTA}^{\mathrm{V}}(\mathrm{GS})$ formation on the depletion of DMA ${ }^{\mathrm{III}}(\mathrm{GS})$, while presence of $5 \mathrm{mM}$ glutathione (GSH) prevented its formation. ${ }^{34}$ Dimethylarsinothioyl glutathione was observed to form under acidic and neutral $\mathrm{pH}$ conditions $(\mathrm{pH}$ 3.0-7.4). Liquid chromatography electrospray ionization mass spectrometry (LC-ESI-MS) in the MS and tandem MS modes $\left(\mathrm{MS}^{2}\right.$ and $\left.\mathrm{MS}^{3}\right)$ revealed molecular ion peaks at $\mathrm{m} / \mathrm{z}=443.9,466.0$, corresponding to $\left[\mathrm{DMMTA}^{\mathrm{V}}(\mathrm{GS})+\mathrm{H}\right]^{+}$and $\left[\mathrm{DMMTA}^{\mathrm{V}}(\mathrm{GS})+\mathrm{Na}\right]^{+}, 314.8$ for the loss of glutamic acid, 231.1 resulting from the loss of glycine and $-\mathrm{C}_{2} \mathrm{H}_{7} \mathrm{AsS}, 176.9$ 
corresponding to cysteine and glycine adduct (loss of glutamic acid and $-\mathrm{C}_{2} \mathrm{H}_{7} \mathrm{AsS}$ ), and 137.1 for $\left[\mathrm{C}_{2} \mathrm{H}_{6} \mathrm{AsS}\right]^{+}$respectively. Both co-elution and increase in the peak area were observed upon spiking the cell extracts with a standard of $\operatorname{DMMTA}^{\mathrm{V}}(\mathrm{GS})$. Heat deactivation of the enzymes in the cells prevented the formation of $\operatorname{DMMTA}^{\mathrm{V}}(\mathrm{GS})$ arousing the possibility of its enzymatic formation. ${ }^{34}$ As some of the pentavalent thiolated arsenic metabolites are just as or almost as toxic as their trivalent non-thiol counterparts (dimethylmonothioarsinic acid $\left(\mathrm{DMMTA}^{\mathrm{V}}\right)$ and dimethylarsinous acid $\left(\mathrm{DMA}^{\mathrm{III}}\right)$ ) the toxicity of $\operatorname{DMMTA}^{\mathrm{V}}(\mathrm{GS})$, thus its role in detoxification of $\mathrm{DMA}^{\mathrm{III}}(\mathrm{GS})$, and the ability of multiple myeloma cell lines to take it up were evaluated in addition to DMMTA ${ }^{\mathrm{V}}$ and $\mathrm{DMA}^{\mathrm{III}}(\mathrm{GS})$. Dimethylarsinothioyl glutathione was found to be much less toxic than $\mathrm{DMA}^{\mathrm{III}}(\mathrm{GS})$ and DMMTA ${ }^{\mathrm{V}}$, probably as a result of its very limited uptake (less than $10 \%$ and $16 \%$ of $\mathrm{DMA}^{\mathrm{III}}(\mathrm{GS})$ and $\mathrm{DMMTA}^{\mathrm{V}}$ respectively).

\subsection{Introduction}

Arsenic (As) is a worldwide contaminant with widespread human health effects. Aside from carcinogenesis, As is known to cause pulmonary, neurological, cardiovascular and hematological disorders, keratosis, hyperpigmentation and black foot disease. ${ }^{1}{ }^{124}$ Paradoxically, As has been used for medicinal purposes since ancient Greece. ${ }^{63}$ Darinaparsin (dimethylarsinous glutathione, $\mathrm{DMA}^{\mathrm{III}}(\mathrm{GS})$ ) is a novel organic arsenical that shows promising anticancer activity (structures and names of As species of interest are shown in Table 3.1). ${ }^{125-127}$ A series of in vitro and in vivo studies in toxicity and potency suggest Darinaparsin employs a mechanism of action that is different from that of arsenic trioxide (ATO). Darinaparsin seems to be more effective than ATO despite 
of its lower toxicity even at higher concentrations. It may also be used as an alternative for ATO-resistant hematological malignancies as cross-resistance between these two drugs does not appear to develop. ${ }^{91,127-129}$ While Darinaparsin shows clinical promise, the underlying mechanisms by which it metabolizes and exerts its apoptotic effects have yet to be fully understood.

Since arsenic toxicity is species dependent, it is essential to obtain speciation information at the cellular and molecular level to identify active arsenic metabolites responsible for its toxicity or therapeutic efficacy. Arsenic taken up by cells can be metabolized into various species via different processes. Glutathione conjugates of arsenite $\left(\mathrm{As}^{\mathrm{III}}\right)$, monomethylarsonous acid $\left(\mathrm{MMA}^{\mathrm{III}}\right)$ and dimethylarsinous acid $\left(\mathrm{DMA}^{\mathrm{III}}\right)$ have been reported as As metabolites in mammals and they are more toxic than their pentavalent counterparts as a result of their high affinity to sulfhydryl groups on biomolecules. ${ }^{8,17,18,104,130,131}$ Recently, it was shown that in fact S-adenosylmethionine (SAM), the enzyme responsible for the methylation of arsenite, prefers the glutathionylated arsenicals (arsino-glutathione $\left(\mathrm{As}(\mathrm{GS})_{3}\right)$ and monomethylarsinoglutathione $\left(\mathrm{MMA}(\mathrm{GS})_{2}\right)$ ) as substrates for methylation compared to As ${ }^{\mathrm{III}}$ and $\mathrm{MMA}^{\mathrm{III}}{ }^{132}$ Arsino-glutathione and monomethylarsino-glutathione have been identified in rat bile and urine following intravenous injection, while DMA ${ }^{\mathrm{III}}(\mathrm{GS})$ was not. $^{30,31}$

Latest studies reported the existence of toxic sulfur-containing pentavalent As species. Dimethylmonothioarsinic acid $\left(\mathrm{DMMTA}^{\mathrm{V}}\right)$, a thiolated pentavalent sulfurcontaining derivative of dimethylarsinic acid $\left(\mathrm{DMA}^{\mathrm{V}}\right)$, has been shown to be toxic toward human epidermoid carcinoma A431 and bladder carcinoma EJ1 cells. ${ }^{13,133}$ This As species and dimethyldithioarsinic acid $\left(\right.$ DMDTA $\left.^{\mathrm{V}}\right)$ have been identified in urine, liver 
and kidney homogenates, plasma and red blood cells. ${ }^{11,35,36,110}$ The identification of these new thiolated species has provided new information on the metabolic pathways of $\mathrm{DMA}^{\mathrm{III}}$ and $\mathrm{DMA}^{\mathrm{III}}(\mathrm{GS})$. Suzuki et al. have proposed that after the decomposition of $\mathrm{DMA}^{\mathrm{III}}(\mathrm{GS})$ to $\mathrm{DMA}^{\mathrm{III}}$ in the absence of excess glutathione (GSH), dimethylmonothioarsinous acid $\left(\mathrm{DMMTA}^{\mathrm{III}}\right)$ is formed through nucleophilic attack by a sulfide ion. Dimethylmonothioarsinous acid is further oxidized to DMMTA ${ }^{\mathrm{V}}$, which has the potential for further thiolation to DMDTA ${ }^{\mathrm{V}} \cdot{ }^{110,111}$ Dimethylmonothioarsinic acid has also been identified to be bound to rat hemoglobin, suggesting the possibility for pentavalent As interaction with sulfhydryls on proteins and peptides. ${ }^{35}$ Furthermore, Raab et al. have identified dimethylarsinothioyl glutathione complex (DMMTA ${ }^{\mathrm{V}}(\mathrm{GS})$ ), a pentavalent thioarsenical bound to GSH, in Brassica oleracea extracts after subjecting the roots to $\mathrm{DMA}^{\mathrm{V}}$ for 24 hours. ${ }^{112}$ Hirano et al. reported the presence of an unknown As species in the culture media containing rat endothelial cells and human leukemia cells exposed to $\mathrm{DMA}^{\mathrm{III}}(\mathrm{GS})$, however, they were unable to identify the species. ${ }^{131}$

During previous studies to decipher the metabolism of $\mathrm{DMA}^{\mathrm{III}}(\mathrm{GS})$ in human cancer cells in our laboratory, an unidentified arsenic metabolite was observed in addition to $\mathrm{DMA}^{\mathrm{III}}(\mathrm{GS}), \mathrm{DMA}^{\mathrm{III}}$, and DMA ${ }^{\mathrm{V}} \cdot{ }^{117}$ The elucidation of chemical structure of this new arsenic metabolite present in the extracts of multiple myeloma cell lines incubated with $\mathrm{DMA}^{\mathrm{III}}(\mathrm{GS})$ was performed. The molecular weight and structure information of this new metabolite was gained using liquid chromatography electrospray mass spectrometry (LCESI-MS) performed in the tandem MS mode. The new arsenic metabolite was identified as DMMTA ${ }^{\mathrm{V}}(\mathrm{GS})$, dimethylarsinothioyl glutathione. ${ }^{34}$ The identity of $\operatorname{DMMTA}^{\mathrm{V}}(\mathrm{GS})$ was further confirmed by spiking the cell extract with the synthesized standard of 
$\operatorname{DMMTA}^{\mathrm{V}}(\mathrm{GS})$. Experiments were performed to determine the range of $\mathrm{pH}$ at which this compound forms. I proposed the possible pathways that may be involved in the formation of $\operatorname{DMMTA}^{\mathrm{V}}(\mathrm{GS})$ in the tested cells. As some of the pentavalent thiolated arsenic metabolites are just as or almost as toxic as their trivalent non-thiol counterparts (dimethylmonothioarsinic acid $\left(\mathrm{DMMTA}^{\mathrm{V}}\right)$ and dimethylarsinous acid $\left(\mathrm{DMA}^{\mathrm{III}}\right)$ ) the toxicity of DMMTA ${ }^{\mathrm{V}}(\mathrm{GS})$, thus its role in detoxification of $\mathrm{DMA}^{\mathrm{III}}(\mathrm{GS})$, and the ability of multiple myeloma cell lines to take $\operatorname{DMMTA}^{\mathrm{V}}(\mathrm{GS})$ up were evaluated in addition to DMMTA $^{\mathrm{V}}$ and DMA ${ }^{\mathrm{III}}(\mathrm{GS})$. Dimethylarsinothioyl glutathione was found to be much less toxic than $\mathrm{DMA}^{\mathrm{III}}(\mathrm{GS})$ and DMMTA ${ }^{\mathrm{V}}$, probably as a result of its very limited uptake (less than $10 \%$ and $16 \%$ of $\mathrm{DMA}^{\mathrm{III}}(\mathrm{GS})$ and $\mathrm{DMMTA}^{\mathrm{V}}$ respectively).

\subsection{Experimental Procedures}

Caution: The arsenic species included in this study are toxic and are potential human carcinogens; therefore, they should be handled with great care.

\subsubsection{Reagents and Standards}

All reagents used were of analytical grade or better. Argon (Ar) purged double deionized water (DDIW) was used throughout the experiments. Acetonitrile and pepsin were purchased from Thermo Fisher Scientific, USA. Reduced L-glutathione (GSH) was purchased from Sigma-Aldrich, USA. Sodium chloride $(\mathrm{NaCl})$, sodium phosphate, dibasic $\left(\mathrm{Na}_{2} \mathrm{HPO}_{4} \cdot 7 \mathrm{H}_{2} \mathrm{O}\right)$, potassium chloride $(\mathrm{KCl})$, potassium dihydrogen phosphate $\left(\mathrm{KH}_{2} \mathrm{PO} 4\right)$ used to prepare phosphate buffer saline (PBS) and phosphate buffer, ammonium hydroxide $\left(\mathrm{NH}_{4} \mathrm{OH}\right)$, potassium hydroxide $(\mathrm{KOH})$, and nitric acid $\left(\mathrm{HNO}_{3}\right)$ used for $\mathrm{pH}$ adjustments were also purchased from Thermo Fisher Scientific, USA. 
Table 3.1 Names, abbreviations, and structures of compounds of interest

\begin{tabular}{|c|c|c|}
\hline \multicolumn{2}{|c|}{ Most common } & \multirow{2}{*}{ Structure } \\
\hline Names & Abbreviations & \\
\hline Arsenate, Arsenic acid & $\mathrm{As}^{\mathrm{V}}$ & $\mathrm{HO}-\mathrm{As}_{1}-\mathrm{OH}$ \\
\hline $\begin{array}{l}\text { Dimethyldithioarsinic acid } \\
\text { Dimethylarsinodithioic acid }\end{array}$ & DMDTA $^{\mathrm{V}}$ & $\mathrm{CH}_{3}-\mathrm{As}-\mathrm{CH}_{3}$ \\
\hline Arsenite, Arsenious acid & $\mathrm{As}^{\mathrm{III}}$ & $\mathrm{HO}=\mathrm{As}-\mathrm{OH}$ \\
\hline $\begin{array}{l}\text { Monomethylarsonic acid, } \\
\text { Methylarsonic acid }\end{array}$ & $\begin{array}{l}\text { MMAV V }^{\mathrm{V}} \\
\mathrm{MAs}^{\mathrm{N}}\end{array}$ & $\mathrm{CH}_{3}-\mathrm{As}_{\mathrm{O}}-\mathrm{OH}$ \\
\hline $\begin{array}{l}\text { Monomethylarsonous acid, } \\
\text { Methylarsonous acid, } \\
\text { Methylarsonite }\end{array}$ & $\begin{array}{l}\text { MMA }^{\text {III }} \\
\text { MAs }^{\text {III }}\end{array}$ & $\mathrm{CH}_{3}-\mathrm{As}-\mathrm{OH}$ \\
\hline $\begin{array}{l}\text { Dimethylmonothioarsinic acid, } \\
\text { Dimethylarsinothioic acid, } \\
\text { Thio-dimethylarsinate }\end{array}$ & $\begin{array}{l}\text { DMMTA } \\
\text { Thio-DMA } \\
\text { DMAS }^{\mathrm{DM}}\end{array}$ & $\prod_{\mathrm{OH}}^{\mathrm{S}}-\mathrm{CH}_{3}-\mathrm{CH}_{3}$ \\
\hline $\begin{array}{l}\text { Dimethylarsinic acid, } \\
\text { Dimethylarsinate }\end{array}$ & $\begin{array}{l}\mathrm{DMA}^{\mathrm{V}} \\
\mathrm{DMAs}^{\mathrm{V}}\end{array}$ & $\mathrm{CH}_{3}-\mathrm{As}^{\mathrm{As}}-\mathrm{CH}_{3}$ \\
\hline Arsino-glutathione & $\begin{array}{c}\mathrm{As}^{\mathrm{III}}(\mathrm{GS})_{3} \\
\mathrm{ATG}\end{array}$ & $\left.\right|_{\mathrm{GS}} ^{\mathrm{OS}-\mathrm{OH}}=\mathrm{SG}$ \\
\hline Dimethylarsinothioyl glutathione & $\begin{array}{c}\text { DMMTA }^{\mathrm{V}}-\mathrm{GS} \\
\text { DMATG } \\
\text { DMAS }^{\mathrm{V}}-\mathrm{GS} \\
\text { DMMTA }^{\mathrm{V}}(\mathrm{GS})\end{array}$ & 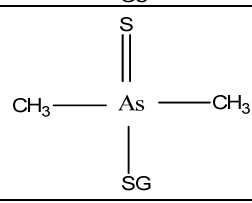 \\
\hline $\begin{array}{l}\text { Monomethylarsino-glutathione, } \\
\text { Monomethylarsonic diglutathione }\end{array}$ & $\begin{array}{c}\mathrm{MMA}^{\mathrm{III}}(\mathrm{GS})_{2} \\
\mathrm{MADG}\end{array}$ & $\left.\right|_{S G} ^{\mathrm{As}-\mathrm{CH}_{3}}$ \\
\hline $\begin{array}{l}\text { Dimethylarsinous acid, } \\
\text { Dimethylarsinite }\end{array}$ & $\begin{array}{l}\text { DMA }^{\text {III }} \\
\text { DMAs }^{\text {III }}\end{array}$ & $\left.\right|_{\mathrm{OH}} ^{\mathrm{CH}_{3}-\mathrm{As}-\mathrm{CH}_{3}}$ \\
\hline $\begin{array}{l}\text { Dimethylarsinous glutathione, } \\
\text { Darinaparsin, Dimethylarsinic, } \\
\text { glutathione, DAR, } \\
\text { Dimethylarsino-glutathione, }\end{array}$ & $\begin{array}{l}\text { DMA }^{\mathrm{III}}(\mathrm{GS}) \\
\text { DAR, DMAG } \\
\text { DMAs }^{\mathrm{III}} \mathrm{GS}\end{array}$ & $\left.\right|_{\mathrm{SG}} ^{\mathrm{CH}_{3}-\mathrm{As}-\mathrm{CH}_{3}}$ \\
\hline
\end{tabular}


Formic acid and acetic acid used to prepare formate and acetate buffers were purchased from Acros Organics and Thermo Fisher Scientific, USA, respectively. DMA $^{\text {III }}$ was synthesized in our lab following procedures previously reported. ${ }^{134}$ DMA $^{\text {III }}(\mathrm{GS})$ was obtained from Ziopharm Oncology, Boston, MA.

\subsubsection{Syntheses of DMMTA ${ }^{\mathrm{V}}$ and $\operatorname{DMMTA}^{\mathrm{V}}(\mathrm{GS})$}

The syntheses of DMMTA ${ }^{\mathrm{V}}$ and $\operatorname{DMMTA}^{\mathrm{V}}(\mathrm{GS})$ were performed following previously reported methods. ${ }^{110,112}$ Briefly, for DMMTA ${ }^{\mathrm{V}}$ synthesis, $\mathrm{DMA}^{\mathrm{V}}, \mathrm{Na}_{2} \mathrm{~S}$ and $\mathrm{H}_{2} \mathrm{SO}_{4}$ were mixed in mole ratios of 1:1.6:1.6 in water for 24 hours. For DMMTA ${ }^{\mathrm{V}}(\mathrm{GS})$ synthesis, GSH was added in excess ( 3 times of the molar concentration of DMA ${ }^{\mathrm{v}}$ ) to the standard mixture of DMMTA ${ }^{\mathrm{V}}$. No attempts were made to isolate the products, however, their formation was monitored on ESI-MS by monitoring m/z 155 and m/z 444 for $\left[\mathrm{DMMTA}^{\mathrm{V}}+\mathrm{H}\right]^{+}$and $\left[\operatorname{DMMTA}^{\mathrm{V}}(\mathrm{GS})+\mathrm{H}\right]^{+}$, respectively.

\subsubsection{Instrumentation and Chromatographic Conditions}

A Perkin Elmer Series 200 HPLC system was coupled to a Perkin Elmer DRC-e ICP-MS to monitor As and S. A Thermo Finnigan Surveyor HPLC system equipped with a peltier-controlled autosampler and column compartment was used with an LCQ Deca XP MAX (Thermo Finnigan, USA) electrospray mass spectrometer to gain molecular weight information. Separation was achieved on a Waters Spherisorb $\mathrm{C}_{8}$ column ( $150 \times 4.6 \mathrm{~mm}$ in dimension and 5 micron particle size) following a previously published method ${ }^{134}$. Briefly, the mobile phase consisted of $0.1 \%$ formic acid and acetonitrile in linear gradient mode at a flow rate of $1 \mathrm{~mL} \mathrm{~min}^{-1}$. The sample injection volume was $50 \mu \mathrm{L}$ with ICP-MS and $25 \mu \mathrm{L}$ with ESI-MS as detectors. The column effluent was split into 2 parts, one going to the detector and the other going to waste. 
The ICP-MS was equipped with a cyclonic spray chamber and a Meinhard nebulizer and was employed both in standard and DRC modes. In standard mode, m/z 75 for As and $\mathrm{m} / \mathrm{z} 77$ for $\mathrm{ArCl}$ interference were monitored. Data were collected and processed using Chromera software version 1.2 (Perkin Elmer, USA).

The ESI-MS was used in the positive ionization mode and the total ion chromatogram (TIC) was acquired for $\mathrm{m} / \mathrm{z}=100-1050$ with results being reported in the single ion mode (SIM). The instrument was also operated in tandem MS mode. Data were collected and treated using Xcaliar software (Thermo, USA). The instrument was optimized using the flow injection mode with a $5 \mu \mathrm{g} \mathrm{mL}^{-1}$ standard of caffeine. Instrumental parameters employed during analysis are listed in Table 3.2.

Table 3.2 ICP-MS and ESI-MS parameters employed

\begin{tabular}{|l|c|}
\hline ICP-MS (DRC) & Value \\
\hline Rf power (W) & 1350 \\
\hline Plasma gas flow rate (L/min.) & 15.00 \\
\hline Auxiliary gas flow rate (L/min.) & 1.20 \\
\hline Nebulizer gas flow rate (L/min.) & $0.96-1.04$ \\
\hline Oxygen gas flow rate (L/min.) & 1 \\
\hline Lens voltage (V) & 8 \\
\hline Acquisition time (min.) & 15 \\
\hline Dwell time (ms) & 600 \\
\hline RPQ & 0.45 \\
\hline ESI-MS & \\
\hline ISpray Voltage (kV) & 5 \\
\hline Sheath gas (arb) & 30 \\
\hline Capillary Voltage (V) & 25 \\
\hline Temperature ( ${ }^{\circ}$ C) & 260 \\
\hline Tube lens offset (V) & 10 \\
\hline Acquisition time (min.) & 15 \\
\hline Normalized collision energy & 25 \\
\hline Activation Q & 0.25 \\
\hline Isolation width & 1 \\
\hline \hline
\end{tabular}




\subsubsection{Cell Lines}

8226/S multiple myeloma and DAUDI lymphoma cell lines were purchased from the American Type Culture Collection (ATCC, Manassas, VA), while KMS11 myeloma cell line was provided by Dr. P. Leif Bergsagel (Mayo Clinic, Scottsdale, AZ). The MM1S myeloma cell line was provided by Dr. Steven Rosen (Northwestern University). The cells were maintained at $37^{\circ} \mathrm{C}$ in a humidified atmosphere with $5 \% \mathrm{CO}_{2}$ on RPMI-1640 media, supplemented with $100 \mathrm{U} \mathrm{mL}^{-1}$ of penicillin, $100 \mu \mathrm{g} \mathrm{mL}^{-1}$ of streptomycin, 10\% heat inactivated fetal bovine serum and $2 \mathrm{mM}$ L-glutamine (all culture reagents from Cellgro, MediaTech, Herndon, VA).

The cells were cultured at a concentration of $2.5 \times 10^{5}$ cells $\mathrm{mL}^{-1}$ and then harvested by centrifugation at $1000 \mathrm{rpm}$ for 5 minutes, washed with PBS once, spun down again, then the pellets were frozen in liquid nitrogen and stored at $-20{ }^{\circ} \mathrm{C}$ for analysis and incubation experiments. Each cell pellet contained 5.0 x $10^{6}$ cell counts.

\subsubsection{Incubation Experiments}

The following incubation experiments with $\mathrm{DMA}^{\mathrm{III}}(\mathrm{GS})$ were conducted at room temperature after the cell pellets thawed: 1) To confirm the formation and identity of the unknown arsenical in multiple myeloma (MM) cell lines and examine if $\operatorname{DMMTA}^{\mathrm{V}}(\mathrm{GS})$ can also form in lymphoma cell lines, MM and lymphoma cells were incubated with $0.26 \mathrm{mM} \mathrm{DMA}^{\mathrm{III}}(\mathrm{GS})$ in double deionized water for 10 minutes and then analyzed for speciation on the HPLC-ICP-MS and HPLC-ESI-MS ${ }^{3}$; 2) To determine the range of $\mathrm{pH}$ where this metabolite can form (either enzymatically or non-enzymatically), $\mathrm{DMA}^{\mathrm{III}}(\mathrm{GS})$ was prepared in $\mathrm{pH} 3.0$ (formate), 3.5 (formate), 5.0 (acetate) and 7.4 (phosphate) buffers and added into the cells. Immediately after the addition of 
$\mathrm{DMA}^{\mathrm{III}}(\mathrm{GS})$, the cells were broken up with a membrane sonicator and let stand for 10 minutes prior to analysis.

\subsubsection{Extraction Procedure and As Speciation Analysis}

For As speciation analysis, cells were extracted following a procedure reported previously. ${ }^{115}$ To break up cell walls and to extract As, a sonic dismembrator (Fisher Scientific, Model 100) operated at power level 2 was employed. To the cells placed in $2 \mathrm{~mL}$ centrifuge tubes and dipped in ice, $1.5 \mathrm{~mL}$ of DDIW was added prior to sonication. Following sonication, the samples were filtered through a 0.2 micron sterile nylon syringe filter (Whatman, USA) before HPLC-ICP-MS and HPLC-ESI-MS analysis. Samples were prepared and analyzed in duplicate.

\subsubsection{Uptake and Toxicity Experiments of DMMTA ${ }^{\mathrm{V}}(\mathrm{GS})$}

Separate experiments were conducted to preliminarily evaluate the toxicity of $\operatorname{DMMTA}^{\mathrm{V}}(\mathrm{GS})$ and its uptake by cell viability measurements and cell total As analysis respectively. The chemically synthesized $\operatorname{DMMTA}^{\mathrm{V}}(\mathrm{GS})$ was prepared at $0,1,3,5,10$, and $20 \mu \mathrm{M}$ concentrations and the MM cells were exposed to these solutions for 24 hours before viability test and total As analysis. For the purpose of comparison, DMA ${ }^{\mathrm{III}}(\mathrm{GS})$ and DMMTA ${ }^{\mathrm{V}}$ were also used in these experiments at the same concentration levels. Cell viability was measured by Annexin V-FITC and PI staining. Data were acquired on a BD FACS Canto II flow cytometer (Becton Dickinson, San Jose, CA) and analyzed using BD FACS Diva software (Becton Dickinson). The cells were then washed with PBS, pelleted for total As analysis, and kept frozen until analysis. Prior to speciation and total As measurement, the frozen samples were defrosted, lysed, and homogenized by using a sonic dismembrator after adding $500 \mu \mathrm{L}$ of double deionized water. Following 
homogenization, the sample was digested with $500 \mu \mathrm{L}$ of concentrated nitric acid for 2 hours followed by $250 \mu \mathrm{L}$ of $30 \%$ hydrogen peroxide for another two hours, diluted, and analyzed on ICP-MS for total intracellular As.

\subsection{Results}

3.5.1 Formation of the newly observed $\operatorname{DMMTA}^{\mathrm{V}}(\mathrm{GS})$

I conformed $\mathrm{DMMTA}^{\mathrm{V}}(\mathrm{GS}), \mathrm{DMA}^{\mathrm{III}}(\mathrm{GS}), \mathrm{DMA}^{\mathrm{III}}$, and $\mathrm{DMA}^{\mathrm{V}}$ to be the products of $\mathrm{DMA}^{\mathrm{III}}(\mathrm{GS})$ metabolism in multiple myeloma cell lines (Fig 3.1). Additionally, the same metabolites were observed for the first time in lymphoma cells treated with DMA ${ }^{\mathrm{III}}(\mathrm{GS})$ on the HPLC-ICP-MS speciation chromatograms. The majority of $\mathrm{DMA}^{\mathrm{III}}(\mathrm{GS})$ that was spiked into the culture media (used as control) was oxidized to DMA $^{\mathrm{V}}$.

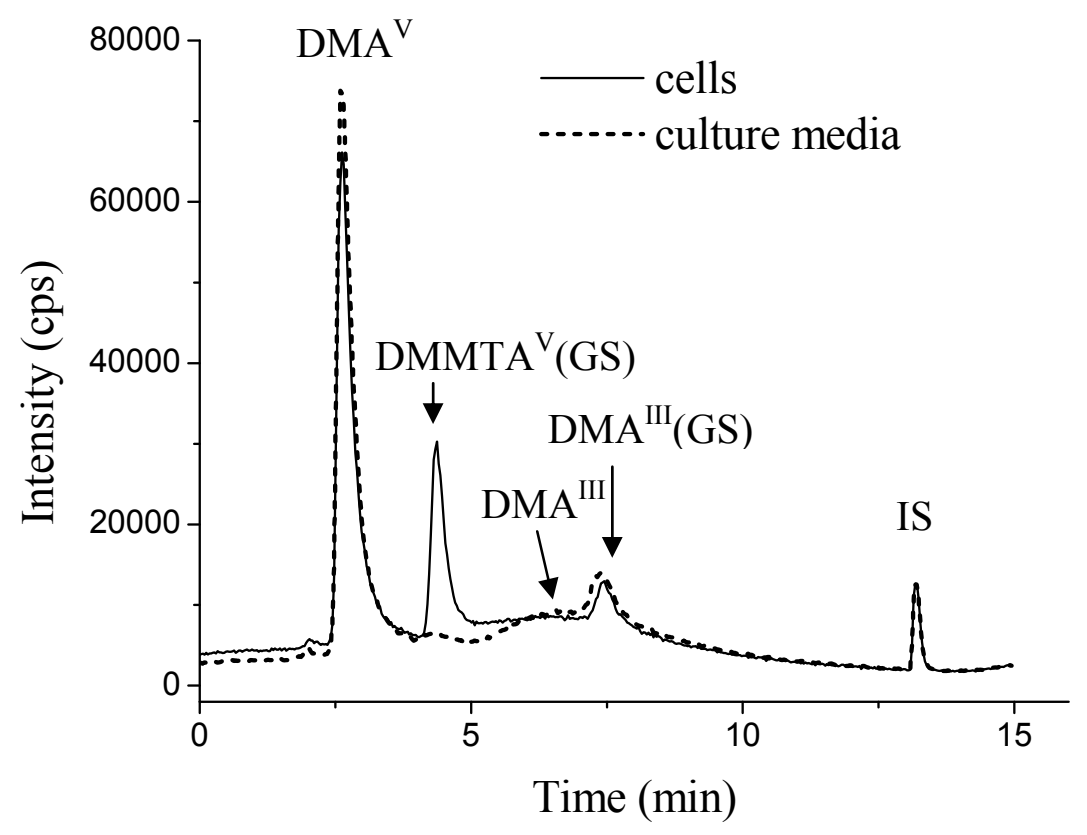

Figure 3.1 HPLC-ICP-MS chromatograms of cell line and culture media both spiked with $\mathrm{DMA}^{\mathrm{III}}(\mathrm{GS}) . \mathrm{As}^{\mathrm{V}}$ was used as internal standard (IS). 


\subsubsection{Confirmation of Identity of DMMTA ${ }^{\mathrm{V}}(\mathrm{GS})$}

Using LC-MS in the electrospray mode I confirmed the structure of the unknown arsenical. Figure 3.2 A and B show the chromatograms acquired in total ion monitoring mode and processed to the responses of peaks at $\mathrm{m} / \mathrm{z} 444$ and 412 , respectively. The mass spectra (Fig. 3.2 C and D) corresponding to peaks DMMTA ${ }^{\mathrm{V}}(\mathrm{GS}$ ) and $\mathrm{DMA}^{\mathrm{III}}(\mathrm{GS})$ in Fig. $3.2 \mathrm{~B}$ revealed molecular ions at $\mathrm{m} / \mathrm{z}=444$ and $\mathrm{m} / \mathrm{z}=412$. The ion at $\mathrm{m} / \mathrm{z}=412$ was the protonated form of $\mathrm{DMA}^{\mathrm{III}}(\mathrm{GS})$ that was spiked to the cellular matrix. The ion at $\mathrm{m} / \mathrm{z}=444$ was from $\operatorname{DMMTA}^{\mathrm{V}}(\mathrm{GS})$, a dimethylated pentavalent arsenical conjugated with glutathione. The unequivocal identification of this molecular ion was accomplished with the assistance of the results by Raab et al. who identified DMMTA $^{\mathrm{V}}(\mathrm{GS})$ in Brassica oleracea extracts after subjecting the roots to DMA ${ }^{\mathrm{V}}$ for 24 hours. ${ }^{112}$ The LC-MS analysis in the tandem mass mode performed for DMA ${ }^{\mathrm{III}}(\mathrm{GS})$ and $\operatorname{DMMTA}^{\mathrm{V}}(\mathrm{GS})$ spiked cell samples (Fig. 3.3) revealed fragments at $\mathrm{m} / \mathrm{z}=314.8,231.1$, 176.9 and 137.1. Peak at $\mathrm{m} / \mathrm{z}=314.8$ corresponds to the loss of glutamic acid, 231.1 results from the combined loss of glycine and the loss of $-\mathrm{C}_{2} \mathrm{H}_{7} \mathrm{AsS}$, and $\mathrm{m} / \mathrm{z} 176.9$ corresponds to an adduct of cysteine and glycine. The presence of glutamic acid, glycine and cysteine in the $\mathrm{MS}^{2}$ and $\mathrm{MS}^{3}$ fragments confirmed the presence of GSH. Peak at $\mathrm{m} / \mathrm{z}$ $=137.1$ observed in the $\mathrm{MS}^{2}$ spectra matches with $\mathrm{DMMTA}^{\mathrm{V}}$ with the loss of $-\mathrm{OH}$ from the molecule $\left(\left[\left(\mathrm{CH}_{3}\right)_{2} \mathrm{AsS}\right]^{+}\right)$. On the basis of these spectral information, it was concluded that the $\mathrm{S}$ on the cysteine group of GSH was bound to $\mathrm{DMMTA}^{\mathrm{V}}$ by replacing the $-\mathrm{OH}$ in the molecule. The lack of $\mathrm{DMMTA}^{\mathrm{V}}$ molecular ion peak at $\mathrm{m} / \mathrm{z}=155$ could be a consequence of the fast transformation of $\mathrm{DMMTA}^{\mathrm{V}}$ to $\mathrm{DMMTA}^{\mathrm{V}}(\mathrm{GS})$ or the limited sensitivity of the mass spectrometer. 

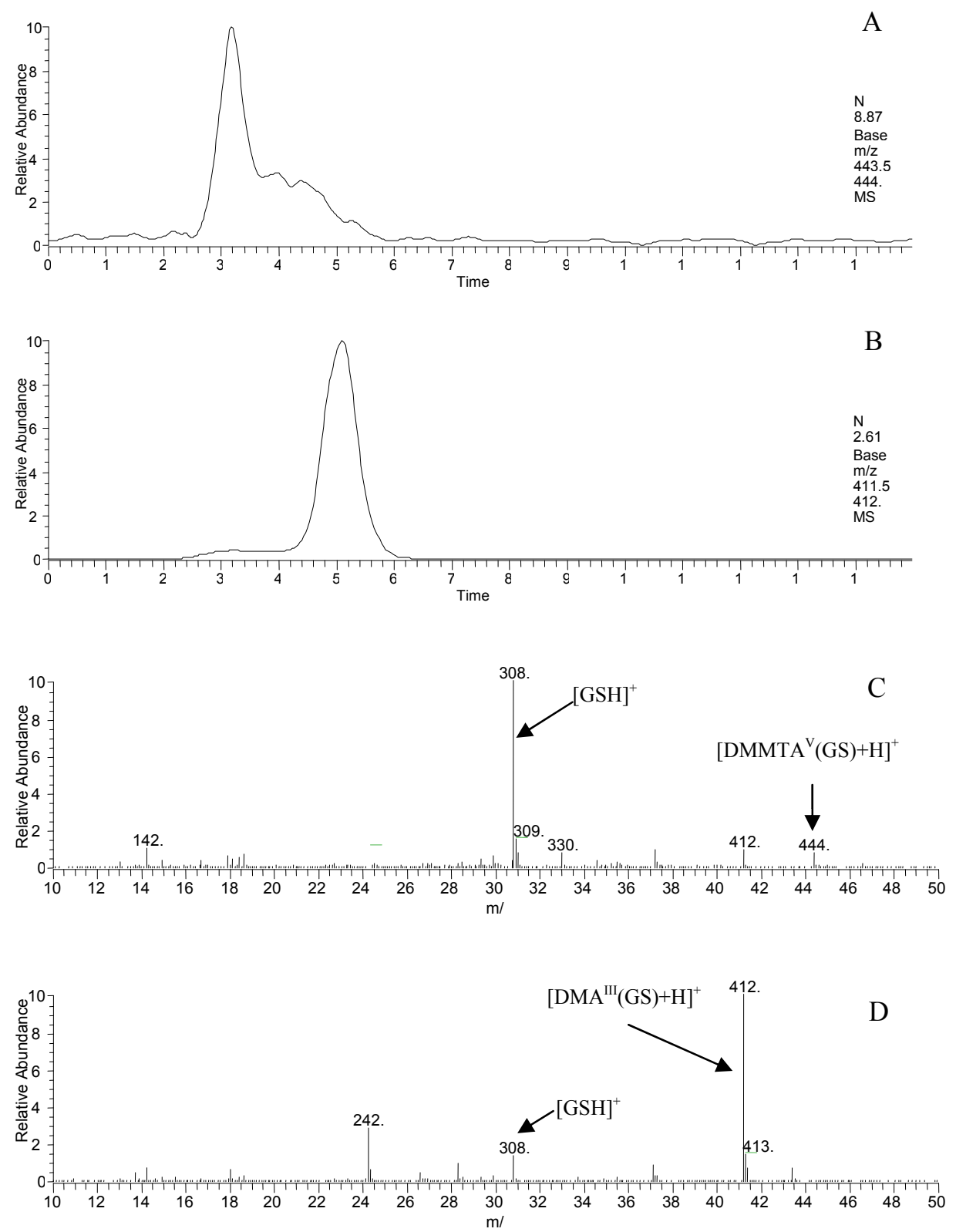

Figure 3.2 Typical ESI-MS chromatograms for (A) DMMTA ${ }^{\mathrm{V}}(\mathrm{GS})$ and (B) $\mathrm{DMA}^{\mathrm{III}}(\mathrm{GS})$ in cell samples spiked with $\mathrm{DMA}^{\mathrm{III}}(\mathrm{GS})$. The chromatograms were acquired in total ion monitoring mode and processed to show peaks at 444 and $412 \mathrm{~m} / \mathrm{z}$, respectively. Molecular ion peaks corresponding to (C) $\operatorname{DMMTA}^{\mathrm{V}}(\mathrm{GS})$ and (D) $\mathrm{DMA}^{\mathrm{III}}(\mathrm{GS})$ are shown. 

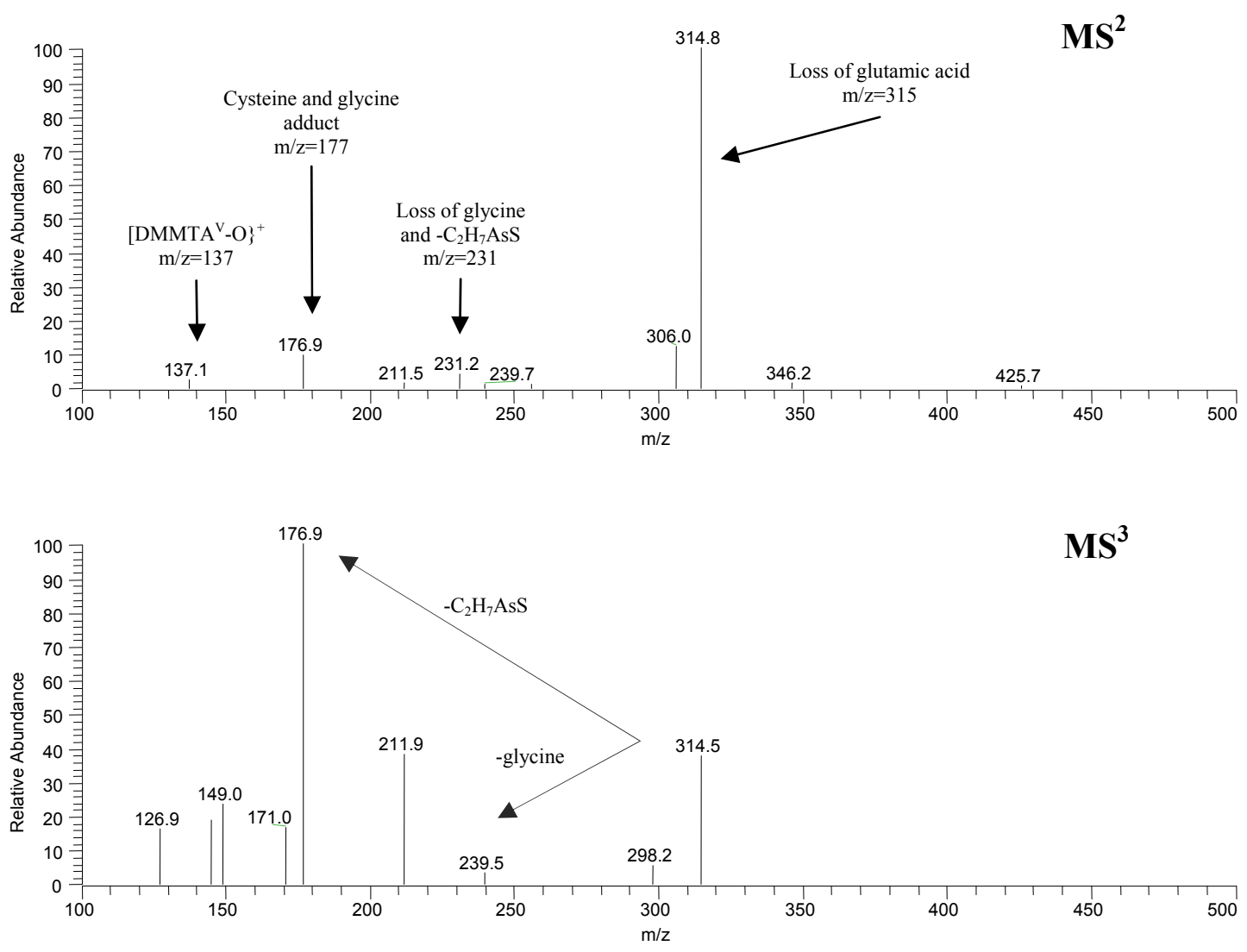

Figure $3.3 \mathrm{MS}^{2}$ and $\mathrm{MS}^{3}$ spectra for $\mathrm{m} / \mathrm{z}=444$ and $\mathrm{m} / \mathrm{z}=314.5$, respectively to confirm the structure of the new As metabolite $\left(\operatorname{DMMTA}^{\mathrm{V}}(\mathrm{GS})\right)$.

\subsection{3 pH Dependence of DMMTA ${ }^{\mathrm{V}}(\mathrm{GS})$ Formation}

During incubation experiments under different $\mathrm{pH}$ values, the appearance of DMMTA $^{\mathrm{V}}(\mathrm{GS})$ was monitored and confirmed with HPLC-ICP-MS and HPLC-ESI$\mathrm{MS} / \mathrm{MS}$, indicating that this metabolite could be formed in the tested $\mathrm{pH}$ range of 3.0 to 7.4 .

\subsubsection{Uptake and Toxicity Studies}

Uptake studies showed that $\operatorname{DMMTA}^{\mathrm{V}}(\mathrm{GS})$ is not efficiently taken up by the 
cells. Compared to $\mathrm{DMA}^{\mathrm{III}}(\mathrm{GS})$ treated at the same concentration level, the total amount of intracellular arsenic of the DMMTA ${ }^{\mathrm{V}}(\mathrm{GS})$ treated cells was only $9.5 \%$ of that of Darinaparsin. Dimethylmonothioarsinous acid $\left(\mathrm{DMMTA}^{\mathrm{V}}\right)$, the precursor of $\operatorname{DMMTA}^{\mathrm{V}}(\mathrm{GS})$, was more efficiently taken up than DMMTA $(\mathrm{GS})$, but its intracellular concentration was only $58.4 \%$ of that of Darinaparsin.

Cell viability studies revealed that of the three compounds examined, Darinaparsin was the most toxic to multiple myeloma cells, followed by DMMTA ${ }^{\mathrm{V}}$ being less toxic than Darinaparsin, and $\operatorname{DMMTA}^{\mathrm{V}}(\mathrm{GS})$ being least toxic. Figure 3.4 below displays the \% apoptosis dose curves for DMA ${ }^{\mathrm{III}}(\mathrm{GS}), \operatorname{DMMTA}^{\mathrm{V}}(\mathrm{GS})$, and DMMTA ${ }^{\mathrm{V}}$.

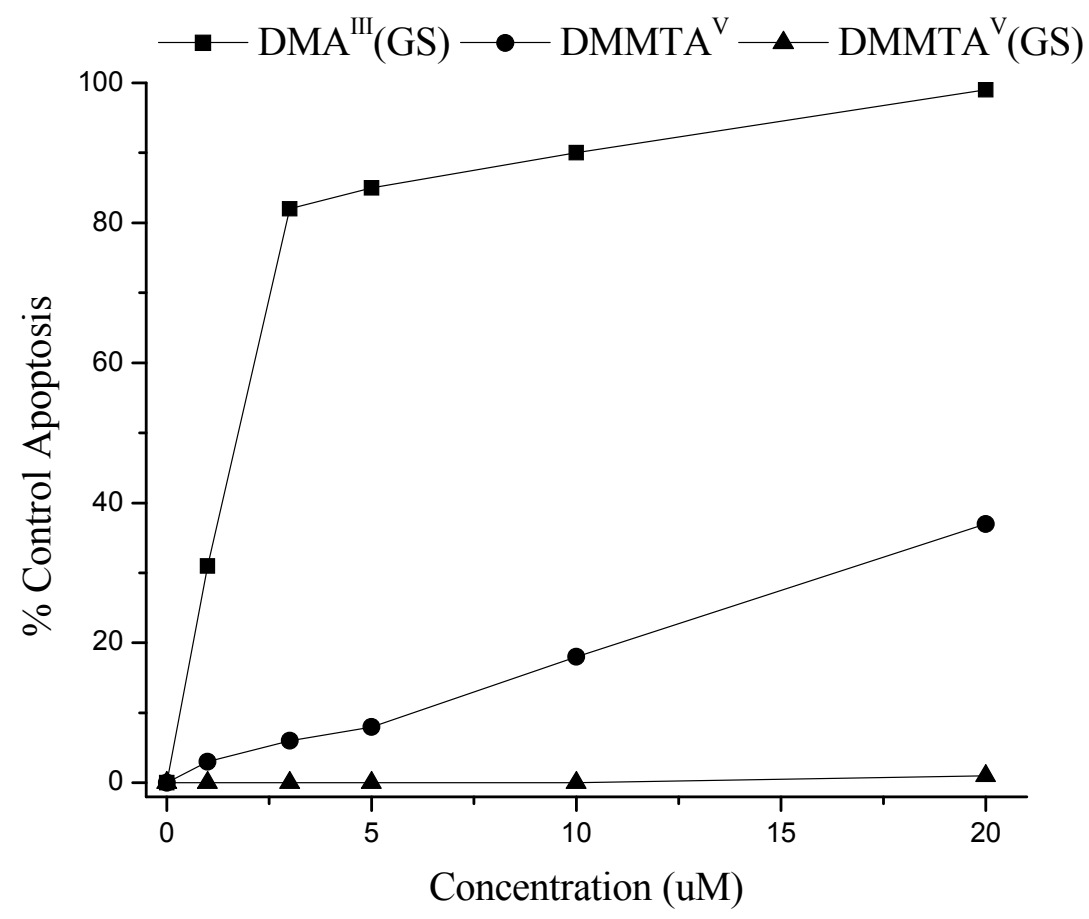

Figure 3.4 Comparison of toxicities of $\mathrm{DMA}^{\mathrm{III}}(\mathrm{GS})$, DMMTA ${ }^{\mathrm{V}}$, and $\mathrm{DMMTA}^{\mathrm{V}}(\mathrm{GS})$ in multiple myeloma cell lines 


\subsection{Discussion}

The presence of the newly observed human metabolite $\operatorname{DMMTA}^{\mathrm{V}}(\mathrm{GS})$ was confirmed in multiple myeloma cell lines and seen for the first time in lymphoma cell lines. Dimethylarsinothioyl glutathione appeared only on the chromatogram obtained in the presence of cell lines but not in culture media, indicating that the formation of this arsenical was resulting from the presence of both cellular material and DMA ${ }^{\mathrm{III}}(\mathrm{GS})$, while culture media played no role in its formation. It should be noted that for the HPLCESI-MS experiments I incubated cells at $0.26 \mathrm{mM} \mathrm{DMA}^{\mathrm{III}}(\mathrm{GS})$ concentration level to ensure adequate sensitivity on the HPLC-ESI-MS. The cells probably cannot tolerate this As concentrations for an extended time period (as shown in the cell viability tests). However, most of the changes in As speciation profile (relative species distribution) occurred within 15 minutes. The rapid increasing and levelling off of $\operatorname{DMMTA}^{\mathrm{V}}(\mathrm{GS})$ concentrations at the beginning of the incubation experiments, when the cells were likely alive, suggest that its formation is still related to cellular metabolic processes.

The LC-MS and tandem MS in the electrospray mode were performed to confirm the structure of DMMTA ${ }^{\mathrm{V}}(\mathrm{GS})$. On the basis of the $\mathrm{m} / \mathrm{z}=444$ and the fragmentation pattern, species identity of the newly observed dimethylarsinothioyl glutathione $\left(\operatorname{DMMTA}^{\mathrm{V}}(\mathrm{GS})\right)$, a dimethylated pentavalent arsenical conjugated with glutathione, was reconfirmed. The identification of this molecular ion was accomplished with the assistance of the results by Raab et al. who identified DMMTA $^{\mathrm{V}}(\mathrm{GS})$ in Brassica oleracea extracts after subjecting the roots to $\mathrm{DMA}^{\mathrm{V}}$ for 24 hours. ${ }^{112}$ To further confirm the identity of the new metabolite, fragmentation pattern was analyzed. Peak at $\mathrm{m} / \mathrm{z}=$ 314.8 corresponds to the loss of glutamic acid from the molecule of $\operatorname{DMMTA}^{\mathrm{V}}(\mathrm{GS})$, 
231.1 results from the combined loss of glycine and the loss of $-\mathrm{C}_{2} \mathrm{H}_{7} \mathrm{AsS}$, and m/z 176.9 corresponds to an adduct of cysteine and glycine. The presence of glutamic acid, glycine and cysteine in the $\mathrm{MS}^{2}$ and $\mathrm{MS}^{3}$ fragments confirmed the presence of GSH. Peak at $\mathrm{m} / \mathrm{z}$ $=137.1$ observed in the $\mathrm{MS}^{2}$ spectra matches with $\mathrm{DMMTA}^{\mathrm{V}}$ with the loss of $-\mathrm{OH}$ from the molecule $\left(\left[\left(\mathrm{CH}_{3}\right)_{2} \mathrm{AsS}\right]^{+}\right)$. On the basis of these spectral information, it was concluded that the $\mathrm{S}$ on the cysteine group of glutathione was bound to DMMTA ${ }^{\mathrm{V}}$ by replacing the $\mathrm{OH}$ in the molecule. No $\mathrm{m} / \mathrm{z}=155$ corresponding to the protonated molecular ion peak for DMMTA ${ }^{\mathrm{V}}$ was observed. The lack of this peak could be resulting from the fast transformation of DMMTA ${ }^{\mathrm{V}}$ to $\mathrm{DMMTA}^{\mathrm{V}}(\mathrm{GS})$ or from the limited sensitivity of the mass spectrometer. Additional support for the identification of $\operatorname{DMMTA}^{\mathrm{V}}(\mathrm{GS})$ came from the overlap in retention times of the unknown peak with the synthesized $\operatorname{DMMTA}^{\mathrm{V}}(\mathrm{GS})$ standard when it was spiked to the samples. ${ }^{34}$

Formation experiments demonstrated that $\operatorname{DMMTA}^{\mathrm{V}}(\mathrm{GS})$ could be formed and detected at the $\mathrm{pH}$ range of 3.0-7.4. At physiological $\mathrm{pH}$, the formation of $\operatorname{DMMTA}^{\mathrm{V}}(\mathrm{GS})$ was probably as a result of enzymatic processes, as prior experiments using heat deactivated cells indicated that the formation of $\operatorname{DMMTA}^{\mathrm{V}}(\mathrm{GS})$ under physiological conditions ( $\mathrm{pH}$ 7.4) is probably enzymatically catalyzed, as evidenced by the absence of the unknown metabolite in heat deactivated cells. ${ }^{34}$ At other $\mathrm{pH}$ values, the formation of the metabolite could be attributed to non-enzymatic chemical processes, in particular for lower pHs (e.g., pH 3) where the enzymes were not active. Previous studies have shown that DMMTA ${ }^{\mathrm{V}}(\mathrm{GS})$ can be readily formed through chemical reactions under acidic conditions in the absence of cellular material. ${ }^{12,} 135$ 
Identification of DMMTA ${ }^{\mathrm{V}}(\mathrm{GS})$ in human multiple myeloma and lymphoma cell lines upon exposure to DMA ${ }^{\mathrm{III}}(\mathrm{GS})$ in this study reveals that the thiolated As species could be important metabolites of DMA ${ }^{\mathrm{III}}(\mathrm{GS})$ and influence the efficacy and toxicity of therapeutic arsenicals. As previous studies have identified DMDTA ${ }^{\mathrm{V}}, \mathrm{DMMTA}^{\mathrm{V}}$, and $\operatorname{DMMTA}^{\mathrm{V}}(\mathrm{GS})$ in biological systems exposed to other As species, it appears that thiolated arsenicals could play an important role in the metabolic transformation of As and its toxicity in general. In summarizing our current and previous, and others' work, ${ }^{34,}$ 91, 115, 117 a conceptual model is proposed to illustrate the possible pathways for the formation of DMMTA ${ }^{\mathrm{V}}(\mathrm{GS})$ (Fig. 3.5).

Darinaparsin $\left(\mathrm{DMA}^{\mathrm{III}}(\mathrm{GS})\right)$ is a trivalent dimethylarsenic conjugated to GSH. Trivalent arsenicals, particularly dimethylated forms, whether or not conjugated with GSH, are highly unstable, subject to rapid oxidation, decomposition, and metabolic transformation. ${ }^{34,115,117}$ Inside DMA ${ }^{\mathrm{III}}(\mathrm{GS})$-treated cells, DMA ${ }^{\mathrm{III}}$, DMA ${ }^{\mathrm{III}}(\mathrm{GS}), \mathrm{DMA}^{\mathrm{V}}$, and $\operatorname{DMMTA}^{\mathrm{V}}(\mathrm{GS})$ could be detected. As shown in figure 3.5, the formation of $\operatorname{DMMTA}^{\mathrm{V}}(\mathrm{GS})$ could be resulting from the nucleophilic attack of sulfide on DMA ${ }^{\mathrm{V}}$ (pathway 1 in Fig. 3.5) after which DMMTA ${ }^{\mathrm{V}}$ is formed and then conjugated with GSH to form $\operatorname{DMMTA}^{\mathrm{V}}(\mathrm{GS})$. Another possible pathway of $\mathrm{DMMTA}^{\mathrm{V}}(\mathrm{GS})$ formation could be through dimethylmonothioarsinous acid (DMMTA ${ }^{\mathrm{III}}$ ), which could be formed through nucleophilic attack of sulfide on $\mathrm{DMA}^{\mathrm{III}}$ or $\mathrm{DMA}^{\mathrm{III}}(\mathrm{GS})$ (pathway 2 in Fig. 3.5), as proposed by Suzuki and co-workers. ${ }^{35,110,111}$ Dimethylmonothioarsinous acid could be then transformed oxidatively into DMMTA ${ }^{\mathrm{V}}$, but the question about how DMMTA ${ }^{\mathrm{III}}$ is transformed into DMMTA ${ }^{\mathrm{V}}$ is still unanswered. It is possible that the transformation of DMMTA $^{\mathrm{III}}$ to DMMTA ${ }^{\mathrm{V}}$ involves a series of reactions including DMA ${ }^{\mathrm{III}}$ attack on 
DMMTA $^{\text {III }}$ dimer, nucleophilic attack of sulfide, and disproportionation as shown in figure 3.5, but further studies are needed to elucidate these pathways.

Once DMMTA ${ }^{\mathrm{V}}$ is formed, transformation of DMMTA ${ }^{\mathrm{V}}$ to DMMTA $^{\mathrm{V}}(\mathrm{GS})$ could readily occur, as evidenced by the experimental results of Raab et al., Suzuki et al., and our previous studies. ${ }^{34,112,135}$ The transformation of DMMTA ${ }^{\mathrm{V}}$ to $\operatorname{DMMTA}^{\mathrm{V}}(\mathrm{GS})$ was also supported by an ab initio calculation employing methanethiol $\left(\mathrm{CH}_{3} \mathrm{SH}\right)$ as a model compound. ${ }^{135}$ The reaction leading to the formation of the conjugate DMMTA ${ }^{\mathrm{V}}\left(\mathrm{SCH}_{3}\right)$ was exothermic $(\Delta \mathrm{H}=-4.85 \mathrm{kcal} / \mathrm{mol})$, indicating the formation of $\operatorname{DMMTA}^{\mathrm{V}}(\mathrm{GS})$ could be a favourable pathway in the presence of DMMTA ${ }^{\mathrm{V}}$ and GSH. Dimethylarsinothioyl glutathione formation did not occur in the trials with heat-deactivated cell lines. ${ }^{34}$ The involvement of cells in the formation of $\operatorname{DMMTA}^{\mathrm{V}}(\mathrm{GS})$ suggests that the pathways of $\operatorname{DMMTA}^{\mathrm{V}}(\mathrm{GS})$ formation illustrated in figure 3.5 could be catalysed enzymatically (at least for some steps). As DMMTA ${ }^{\mathrm{V}}(\mathrm{GS})$ can be readily formed as shown in previous theoretical calculations and in experiments by mixing DMMTA ${ }^{\mathrm{V}}$ and GSH in water or under acidic conditions, one might infer that the last step, conjugation of DMMTA ${ }^{\mathrm{V}}$ with GSH, is non-enzymatic. ${ }^{12,135}$ However, the theoretical calculations cannot fully consider the $\mathrm{pH}$ effect. Also, limited study shows that the formation of $\operatorname{DMMTA}^{\mathrm{V}}(\mathrm{GS})$ is $\mathrm{pH}$ dependent, and does not occur above $\mathrm{pH} 7 .{ }^{135}$ Therefore, at physiological $\mathrm{pH}$, it is still possible that the conjugation of GSH to DMMTA ${ }^{\mathrm{v}}$ is enzymatic.

Uptake studies revealed the limited cellular uptake of $\operatorname{DMMTA}^{\mathrm{V}}(\mathrm{GS})$ in multiple myeloma cell lines; only less than $10 \%$ and $16 \%$ of the uptakes of $\mathrm{DMA}^{\mathrm{III}}(\mathrm{GS})$ and DMMTA $^{\mathrm{V}}$, respectively. A previous study in our lab revealed that $\mathrm{DMA}^{\mathrm{III}}(\mathrm{GS})$ cannot enter the cells in the presence of $5 \mathrm{mM} \mathrm{GSH}$ in the extracellular space, while in the 
absence of GSH DMA ${ }^{\mathrm{III}}(\mathrm{GS})$ is taken up very efficiently. ${ }^{34}$ Initially it was proposed that the reason for this is that the hydrolysis of $\mathrm{DMA}^{\mathrm{III}}(\mathrm{GS})$ to $\mathrm{DMA}^{\mathrm{III}}$ may be required prior to uptake and the cells may not be able to take $\mathrm{DMA}^{\mathrm{III}}(\mathrm{GS})$ up efficiently in the conjugated form. ${ }^{34}$ Recently it was proposed that $\mathrm{DMA}^{\mathrm{III}}(\mathrm{GS})$ may be metabolized to S(dimethylarsenic)cysteine (DMA $\left.{ }^{\text {III }}(\mathrm{Cys})\right)$ on the cell surface with the help of $\gamma$-glutamyltranspeptidase $(\gamma-\mathrm{GT})$ and cysteinylglycine dipeptidase prior to uptake by cystine/cysteine transporters. ${ }^{94}$ It was theorized that in the presence of excess extracellular GSH, the GSH could compete for cystine transporters, thus reducing the uptake of $\mathrm{DMA}^{\mathrm{III}}(\mathrm{GS})$ in the form of $\mathrm{DMA}^{\mathrm{III}}(\mathrm{Cys})$. Additionally, excess GSH could compete with DMA ${ }^{\mathrm{III}}(\mathrm{GS})$ for catabolism by $\gamma$-GT and cysteinylglycine dipeptidase and decrease the transformation of DMA ${ }^{\mathrm{III}}(\mathrm{GS})$ into the transportable form of DMA ${ }^{\mathrm{III}}(\mathrm{Cys})$ thus further reducing the uptake of DMA ${ }^{\mathrm{III}}(\mathrm{GS})$.

On the basis of the above information, I suspect there may be multiple reasons for the very low uptake of $\operatorname{DMMTA}^{\mathrm{V}}(\mathrm{GS})$. On the one hand, it may be necessary for $\operatorname{DMMTA}^{\mathrm{V}}(\mathrm{GS})$ to first hydrolyze into the transportable form of DMMTA ${ }^{\mathrm{V}}$ and GSH before entering the cells. As DMMTA ${ }^{\mathrm{V}}(\mathrm{GS})$ was synthesized in the presence of excess GSH in solution (no pure solid standard is available or methods for its synthesis reported), its hydrolysis to DMMTA ${ }^{\mathrm{V}}$ could occur only to a limited degree, hence the low uptake of the compound. On the other hand, it is possible that DMMTA ${ }^{\mathrm{V}}(\mathrm{GS})$ could also be potentially catabolized by $\gamma$-GT and cysteinylglycine dipeptidase to DMMTA ${ }^{\mathrm{V}}(\mathrm{Cys})$ and transported by the same cystine/cysteine transporters but the excess GSH may compete with $\operatorname{DMMTA}^{\mathrm{V}}(\mathrm{Cys})$ for catabolism by $\gamma$-GT and cysteinylglycine dipeptidase for uptake by these transporters hence decreasing the uptake of DMMTA ${ }^{\mathrm{V}}(\mathrm{Cys})$ in the 
presence of excess GSH. Moreover, it is also plausible that $\operatorname{DMMTA}^{\mathrm{V}}(\mathrm{GS})$ is efficiently uptaken as is, but at the same time it is also quickly effluxed out of the cells, resulting in the low total As levels observed with DMMTA ${ }^{\mathrm{V}}(\mathrm{GS})$ treated cells.

Cell viability test showed that $\operatorname{DMMTA}^{\mathrm{V}}(\mathrm{GS})$ was the least toxic species among $\operatorname{DMA}^{\mathrm{III}}(\mathrm{GS}), \mathrm{DMMTA}^{\mathrm{V}}(\mathrm{GS})$, and DMMTA ${ }^{\mathrm{V}}$. The main reason for its low toxicity can be attributed to the inability of the cells to take $\operatorname{DMMTA}^{\mathrm{V}}(\mathrm{GS})$ up in the presence of excess GSH. I evaluated the toxicity of this compound by exposing the cells to DMMTA ${ }^{\mathrm{V}}(\mathrm{GS})$ externally, hence the observed low toxicity resulting from very limited uptake, which might not be able to reflect the actual toxicity of this compound. However, during the metabolism of $\mathrm{DMA}^{\mathrm{III}}(\mathrm{GS})$, this species forms inside the cells along with other metabolites, and could exhibit a higher toxicity.

In summary, this study confirms the presence of $\operatorname{DMMTA}^{\mathrm{V}}(\mathrm{GS})$ in multiple myeloma cell lines and presents the first observation of this metabolite in human lymphoma cell line treated with DMA ${ }^{\mathrm{III}}(\mathrm{GS})$. It is important to note that $\operatorname{DMMTA}^{\mathrm{V}}(\mathrm{GS})$ can be rapidly formed and is relatively stable under physiological conditions in the presence of cells. The identification of this glutathione bound pentavalent As species in human cells in this study and previous studies in our lab for the first time in humans has important implications on the interactions between As taken up by organisms and thiolrich biomolecules, and the role S compounds play in As metabolism. ${ }^{112}$ The presumption that trivalent arsenicals can bind to thiols in biological systems, whereas pentavalent arsenicals cannot form thiol conjugates needs to be revisited. ${ }^{31,} 39$ This finding is particularly important in studying the medicinal and toxicological effects of As since the identified species is a metabolite of $\mathrm{DMA}^{\mathrm{III}}(\mathrm{GS})$, a drug in study for chemotherapy. ${ }^{91}$ 


\section{CHAPTER 4}

Simultaneous Determination of Multiple Human Arsenic Metabolites Employing High

Performance Liquid Chromatograph Inductively Coupled Plasma Mass Spectrometer

Part of this chapter has been submitted to the journal of Analytical and Bioanalytical Chemistry for publication. 


\subsection{Graphical Abstract}

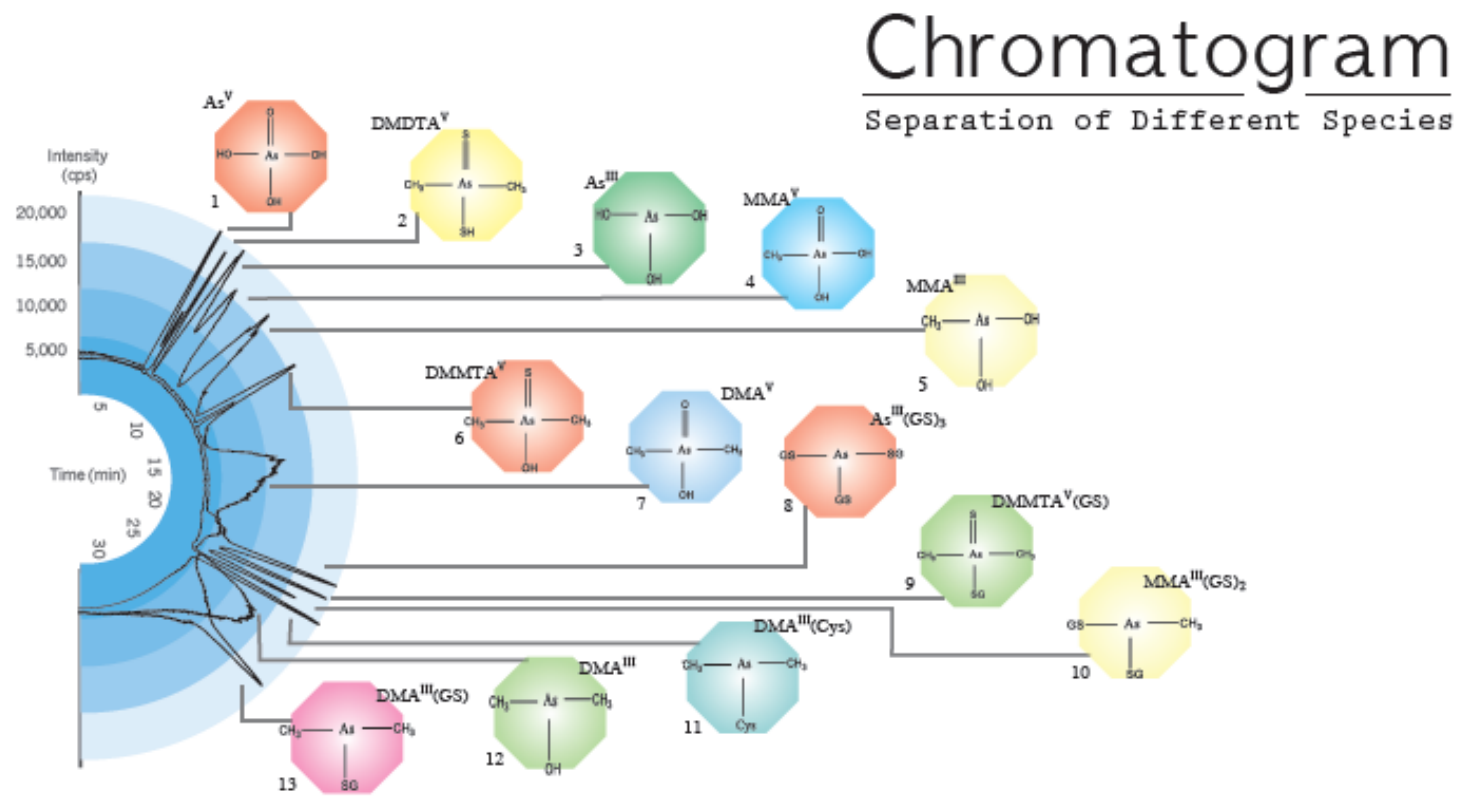

\subsection{Abstract}

During the metabolism of different arsenic-containing compounds in humans, a variety of metabolites are produced with significantly varying toxicities. Currently available analytical methods can only detect a limited number of human metabolites in biological samples during one run owing it to their diverse characteristics. In addition, with most detection techniques co-elution of species is unnoticeable leading to inaccurate metabolic profiles and assessment of toxicity. I developed a high performance liquid chromatography inductively coupled mass spectrometry (HPLC-ICP-MS) method that can identify thirteen common arsenic metabolites potentially present in humans in one chromatographic run to ensure that no co-elution of these species occur. The 13 species separated by the method are arsenite $\left(\mathrm{As}^{\mathrm{III}}\right)$, arsino-glutathione $\left(\mathrm{As}^{\mathrm{III}}(\mathrm{GS})_{3}\right)$, arsenate $\left(\mathrm{As}^{\mathrm{V}}\right)$, monomethylarsonous acid $\left(\mathrm{MMA}^{\mathrm{III}}\right)$, monomethylarsino-glutathione 
$\left(\mathrm{MMA}^{\mathrm{III}}(\mathrm{GS})_{2}\right)$, monomethylarsonic acid $\left(\mathrm{MMA}^{\mathrm{V}}\right)$, dimethylarsinous acid (DMA ${ }^{\mathrm{III}}$ (from DMA $\left.\left.^{\mathrm{III}} \mathrm{I}\right)\right), \quad$ S-(dimethylarsinic)cysteine $\quad\left(\mathrm{DMA}^{\mathrm{III}}(\mathrm{Cys})\right), \quad$ dimethylarsino-glutathione $\left(\mathrm{DMA}^{\mathrm{III}}(\mathrm{GS})\right)$, dimethylarsinic acid $\left(\mathrm{DMA}^{\mathrm{V}}\right)$, dimethylmonothioarsinic acid (DMMTA $\left.{ }^{\mathrm{V}}\right)$, dimethyldithioarsinic acid (DMDTA $\left.{ }^{\mathrm{V}}\right)$, and dimethylarsinothioyl glutathione $\left(\operatorname{DMMTA}^{\mathrm{V}}(\mathrm{GS})\right)$ ). I applied this method to the analysis of cancer cells that were treated with Darinaparsin (dimethylarsino-glutathione, DMA ${ }^{\mathrm{III}}(\mathrm{GS})$ ), a novel chemotherapeutic agent for refractory malignancies, and compared the metabolic profile obtained with results using a previously developed method.

\subsection{Introduction}

Arsenic (As), through naturally occurring from the Earth's crust to groundwater and anthropogenic activities such as nonferrous metal mining and smelting, coal combustion, and pesticide application, has resulted in the contamination of water, soil, and food around the world. ${ }^{1,2,69,136}$. The chronic toxicity of As exposure through drinking water and food (e.g., rice) poses serious health risks to millions of people. ${ }^{3,137-140}$ Toxic effects of As include diabetes, anemia, diarrhea, and more importantly, the development of different types of cancers such as carcinomas of the skin, lung, bladder, kidney, and liver. $141-143$

Despite of its known toxicity and potential to cause cancer, arsenic has been historically used for medicinal purposes to treat such diseases as ulcers, head lice, and plague. $^{63,72,144,145}$ Although the current use of medical As has been limited as a consequence of its high toxicity and carcinogenicity, some arsenic compounds have been recently rediscovered for the treatment of certain cancers. ${ }^{63,72,146}$ For example, arsenic 
trioxide $\left(\mathrm{As}_{2} \mathrm{O}_{3}\right.$, ATO, Trisenox) was revived for the treatment of both newly diagnosed and relapsed acute promyelotic leukemia (APL). ${ }^{72,} 147$ S-Dimethylarsino-glutathione (DMA ${ }^{\mathrm{III}}(\mathrm{GS})$, Darinaparsin, DAR) has been in clinical trials for hematological cancers and refractory solid tumors. $79,91,126,148$

Both the toxicity and anticancer activity of As are partially determined by the metabolism of As in human body. Arsenic metabolism is rather complicated, as the metabolic profile depends on the arsenic species introduced, the route of administration, and the type of cells involved in As elimination. A wide variety of As species, including methylated arsenicals such as $\mathrm{DMA}^{\mathrm{V}}, \mathrm{MMA}^{\mathrm{V}}, \mathrm{DMA}^{\mathrm{III}}, \mathrm{MMA}^{\mathrm{III}}$, and As-glutathione (GSH) conjugates, have been observed during As metabolism (see Table 4.1 for the names, structures, and abbreviations of all thirteen arsenicals included in this study). In particular, a new type of arsenicals, sulfur-containing As compounds including DMMTA $^{\mathrm{V}}, \mathrm{DMDTA}^{\mathrm{V}}$, and $\operatorname{DMMTA}^{\mathrm{V}}(\mathrm{GS})$, have been recently detected in humans and/or mammals. ${ }^{11,12,34-36}$ Although efforts have been made to reveal the pathways of As metabolism, much remains unclear about how some of these As species are formed and what role these arsenicals play in the toxicity and therapeutic efficacy of As. ${ }^{98,104}$

In order to understand the metabolic pathways of As, the mode of action of As toxicity, and the mechanisms underlying As chemotherapy, we must have an analytical method that is capable of unequivocally identifying these arsenicals formed during the metabolism of environmental As exposure or therapeutic As administration. Speciation analysis of arsenic metabolites is important, because each arsenic species possesses varying toxicities. For example, $\mathrm{MMA}^{\mathrm{III}}$ and $\mathrm{DMA}^{\mathrm{III}}$ were shown to be more genotoxic than iAs ${ }^{\mathrm{III}}$ and more potent inhibitors of enzymes while thio-DMA ${ }^{\mathrm{V}}$ is more cytotoxic 
than DMA ${ }^{\mathrm{V}} .{ }^{8,11,18,96}$ Generally trivalent arsenicals are much more toxic than pentavalent ones. In addition, trivalent arsenicals are taken up more efficiently by cells than pentavalent ones.

Currently existing arsenic speciation techniques usually employ high performance liquid chromatography (HPLC) separation on reverse phase or ion exchange column, coupled to an element specific detector such as inductively coupled plasma mass spectrometer (ICP-MS), atomic fluorescence spectrometer (AFS), or atomic absorption spectrometer (AAS). ${ }^{119-123}$ Unfortunately, currently available techniques have shortcomings and cannot meet the need of "full-spectrum" analysis of As metabolites. First, standard ion chromatography was found to destroy glutathione complexes of As in both our and others' labs, failing to detect As-GSH complexes. ${ }^{117,118}$ As these glutathione complexes are thought to be necessary intermediates for arsenic methylation, their unequivocal identification is important to depict the pathways of arsenic metabolism. Second, many current As speciation methods are unable to detect sulfur-containing arsenicals such as DMMTA ${ }^{\mathrm{V}}$, DMDTA ${ }^{\mathrm{V}}$, and $\operatorname{DMMTA}^{\mathrm{V}}(\mathrm{GS})$, and in particular cannot simultaneously determine methylated species (trivalent and pentavalent) and sulfurcontaining arsenicals. It is necessary to identify sulfur-containing arsenicals as these As species may play an important role in As metabolism, toxicity, and anticancer activity. Finally, current analytical methods usually are able to separate a limited number of arsenic species and co-elution of species occurs during analysis. For example, many of the methods employing anion exchange columns could not distinguish MMA ${ }^{\mathrm{III}}$ from $\mathrm{MMA}^{\mathrm{V}}$ and $\mathrm{DMA}^{\mathrm{III}}$ from DMA ${ }^{\mathrm{V}}$, providing incomplete information on the profile of As metabolism. 
Table 4.1 Thirteen arsenic species identified and separated by the developed method

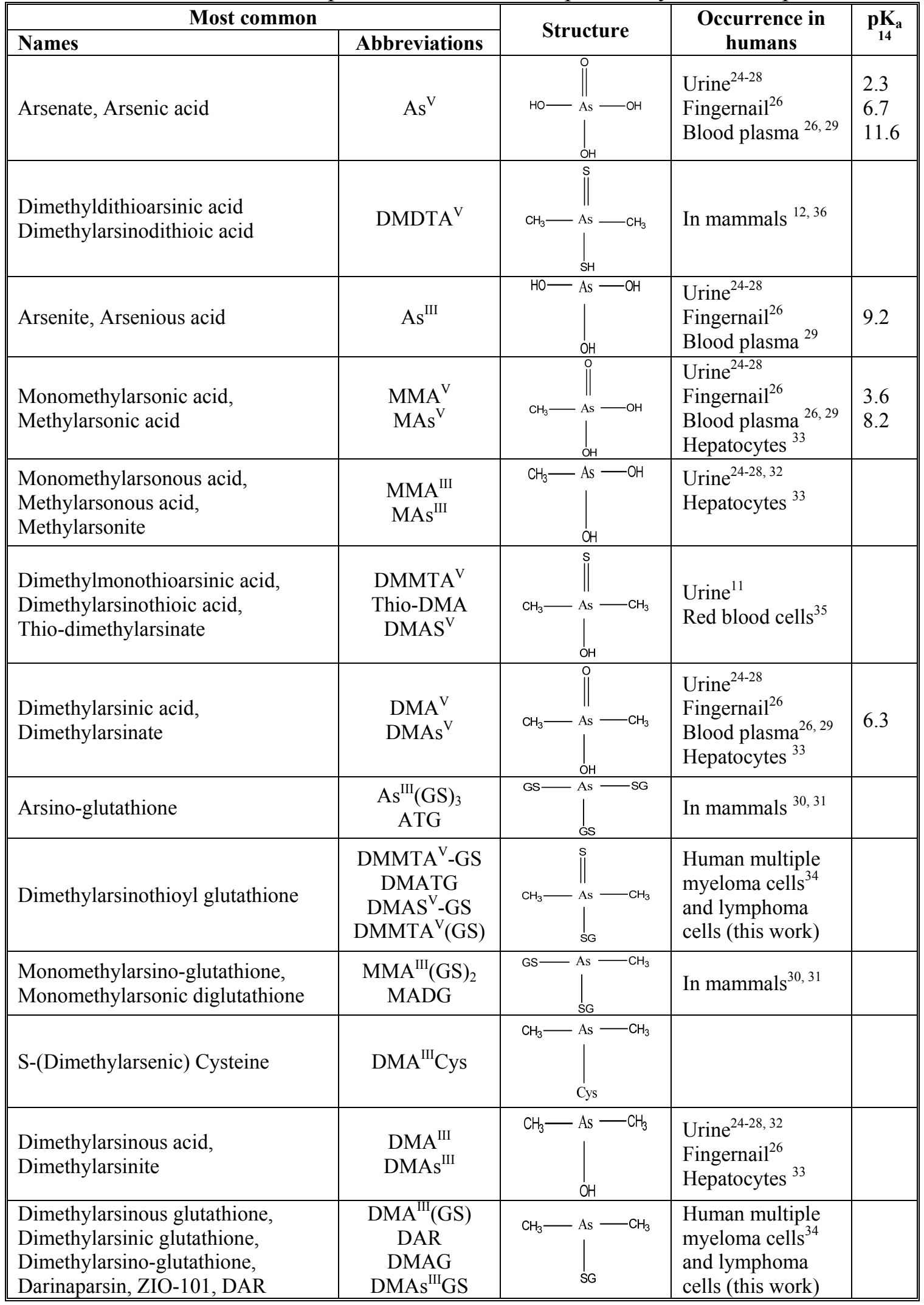


The objective of this study was to develop an analytical method using HPLC-ICP-MS that is capable of performing a "full-spectrum" analysis of As metabolites. The method was aimed to simultaneously determine the arsenic species of traditional interest (e.g. inorganic $\mathrm{As}^{\mathrm{V}}$ and $\mathrm{As}^{\mathrm{III}}$ and organic $\mathrm{DMA}^{\mathrm{V}}$ and $\mathrm{MMA}^{\mathrm{V}}$ ), the highly toxic trivalent methylated As recently reported (DMA ${ }^{\mathrm{III}}$ and $\mathrm{MMA}^{\mathrm{III}}$ ), and the newly discovered sulfurcontaining As metabolites (e.g., DMMTA ${ }^{\mathrm{V}}$, DMDTA ${ }^{\mathrm{V}}$, and $\operatorname{DMMTA}^{\mathrm{V}}(\mathrm{GS})$ ). Thirteen (13) possible human arsenic metabolites, which represent most of the As species reported so far during As metabolism, were included in this study. A variety of chemical and instrumental parameters were optimized for the method, with a focus on the key parameters influencing separation and detection of these arsenicals, such as mobile phase (composition and gradient program) and nebulizer gas (composition and flow rate). The developed method was applied to the analysis of human cancer cells that were incubated with Darinaparsin for the determination of arsenic speciation profile during the metabolism of this anticancer drug.

\subsection{Materials and Methods}

\subsubsection{Reagents}

Argon (Ar) purged double deionized water (DDIW) (18.2 M $\mathrm{M}$ Barnstead Nanopure Diamond) was used throughout the experiments. Acetonitrile and methanol were purchased from Thermo Fisher Scientific. Ammonium hydroxide $\left(\mathrm{NH}_{4} \mathrm{OH}\right)$, sodium hydroxide $(\mathrm{NaOH})$, potassium hydroxide $(\mathrm{KOH})$, phosphoric acid $\left(\mathrm{H}_{3} \mathrm{PO}_{4}\right)$, hydrochloric acid $(\mathrm{HCl})$, and nitric acid $\left(\mathrm{HNO}_{3}\right)$ used for $\mathrm{pH}$ adjustments were also purchased from Thermo Fisher Scientific. Isopropyl alcohol was obtained from Fluka. Glycine, L- 
glutathione reduced, and trifluoroacetic acid (TFA) were purchased from Sigma-Aldrich, USA. Trifluoroacetic acid and anhydrous citric acid were bought from Acros Organics. Formic acid and acetic acid used to prepare formate and acetate buffers were purchased from Acros Organics and Thermo Fisher Scientific, USA, respectively. Sulfur dioxide gas used for the synthesis of $\mathrm{MMA}^{\mathrm{III}} \mathrm{I}_{2}$ and DMA ${ }^{\mathrm{III}} \mathrm{I}$ was acquired from Specialty Gasses of America. Sodium metaarsenite (98\%), sodium arsenate (99\%), and cacodylic acid (98\%) were from Aldrich. Monosodium acid methane arsonate sesquihydrate was obtained from Chem Service, PA, USA. Solid DMA ${ }^{\mathrm{III}}(\mathrm{GS})$, obtained from Ziopharm Oncology, USA, was prepared in solution in our lab along with other arsenic standards used. All reagents used were of analytical grade or better.

\subsubsection{Arsenical Standards Synthesized in House}

As a consequence of the lack of availability, the following arsenical standards were synthesized in the laboratory: $\mathrm{MMA}^{\mathrm{III}} \mathrm{I}_{2}, \mathrm{DMA}^{\mathrm{III} I} \mathrm{DMA}{ }^{\mathrm{III}}(\mathrm{Cys}), \mathrm{As}^{\mathrm{III}}(\mathrm{GS})_{3}$, $\operatorname{MMA}^{\mathrm{III}}(\mathrm{GS})_{2}, \mathrm{DMA}^{\mathrm{III}}(\mathrm{GS}), \mathrm{DMMTA}^{\mathrm{V}}$, DMDTA ${ }^{\mathrm{V}}$, and $\operatorname{DMMTA}^{\mathrm{V}}(\mathrm{GS})$. The synthesis of these arsenicals was on the basis of the previously reported procedures with some modifications if necessary, and the identity and purity (if it was possible to purify the arsenicals using currently available procedures) of the synthesized As standards were verified with NMR, HPLC-ESI-MS, and/or HPLC-ICP-MS.

$\mathrm{MMA}^{\mathrm{III}} \mathrm{I}_{2}$ was synthesized following reported methods with minor

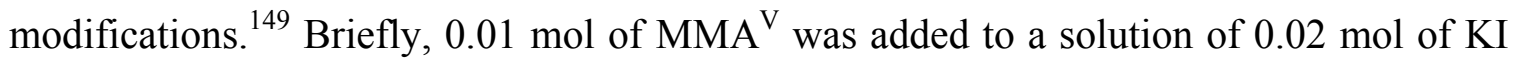
in $10.0 \mathrm{~mL}$ of double deionized water (DDIW). Concentrated $\mathrm{HCl}(3.0 \mathrm{~mL})$ was added to the reaction mixture in small portions over a period of 15 minutes and the reaction mixture was stirred under a stream of sulfur dioxide gas for a period of 3 hours. The 
yellow precipitate was collected, washed with ice cold water and dried over phosphorous pentoxide. The product was extracted with anhydrous diethylether. Evaporation of the extract gave $\mathrm{MMA}^{\mathrm{III}} \mathrm{I}_{2}$ as a yellow powder. The product was stored in argon purged glass vials at $-11^{\circ} \mathrm{C}$. H-NMR was employed to confirm the formation of the desired product. After reduction of $\mathrm{MMA}^{\mathrm{V}}$, the chemical shift changed from $1.68 \mathrm{ppm}$ to $1.24 \mathrm{ppm}$. This value is in very good agreement with the previously reported values in the literature (1.24 and $1.34 \mathrm{ppm}$ ) and confirms the formation of MMA ${ }^{\mathrm{III}} \mathrm{I}_{2} \cdot{ }^{41,107,150}$ The purity of MMA ${ }^{\mathrm{III}}$ was found to be near $100 \%$ using HPLC-ICP-MS.

DMA $^{\mathrm{III}}$ I was synthesized following reported methods with minor modifications. ${ }^{110}$ Briefly, 0.016 mol of $\mathrm{DMA}^{\mathrm{V}}$ was added to a solution of $0.05 \mathrm{~mol}$ of KI in $10.0 \mathrm{~mL}$ DDIW water. The reaction mixture was placed in an ice-bath and subsequently saturated with sulfur dioxide and then $10.0 \mathrm{~mL}$ of $6 \mathrm{M} \mathrm{HCl}$ was slowly added over a period of 1 hour. The yellow oil product, $\mathrm{DMA}^{\mathrm{III}} \mathrm{I}$, was isolated, dried over calcium chloride and distilled at reduced pressure. The receiving flask was submerged in ice. The product was stored in argon purged glass vials at $-11^{\circ} \mathrm{C}$. HNMR was employed to confirm the formation of the desired product. After reduction of $\mathrm{DMA}^{\mathrm{V}}$, the chemical shift changed from $1.50 \mathrm{ppm}$ to $1.26 \mathrm{ppm}$. This value is in perfect agreement with the previously reported chemical shift value in the literature $(1.26 \mathrm{ppm})$ and confirms the formation of DMA ${ }^{\mathrm{III}}{ }^{151}$

$\mathrm{DMA}^{\mathrm{III}}(\mathrm{Cys})$ was synthesized by reducing $\mathrm{DMA}^{\mathrm{V}}$ with L-cysteine according to previously reported methods with slight modifications (prepared at room temperature and no heating was employed). ${ }^{107}$ Formation of $\mathrm{DMA}^{\mathrm{III}}$ (Cys) was confirmed by monitoring the retention time shift from $\mathrm{DMA}^{\mathrm{V}}$ towards to that of DMA ${ }^{\mathrm{III}} \mathrm{I}$. 
$\mathrm{As}^{\mathrm{III}}(\mathrm{GS})_{3}$ was prepared by mixing $\mathrm{As}^{\mathrm{V}}$ with GSH in the molar ratio of 1:9 and in some cases by reacting $\mathrm{As}^{\mathrm{III}}$ with GSH in the ratio of 1:6. Formation and purity of the compound was confirmed by HPLC-ICP-MS. If the purity was not found to be $100 \%$ on the HPLC-ICP-MS, three additional mol equivalents of GSH was added to the solution. The HPLC-ESI-MS was employed in the positive mode for the unequivocal identification of the product. The $\mathrm{m} / \mathrm{z}$ value of synthesized compound was found to be $994[\mathrm{M}+\mathrm{H}]^{+}$, confirming the formation of $\mathrm{As}^{\mathrm{III}}(\mathrm{GS})_{3}$.

$\mathrm{MMA}^{\mathrm{III}}(\mathrm{GS})_{2}$ was prepared by mixing MMA ${ }^{\mathrm{V}}$ with GSH in the molar ratio of 1:6. Formation and purity of the compound was confirmed by HPLC-ICP-MS. If the purity was not found to be $100 \%$ on the HPLC-ICP-MS, the molar ratio of MMA ${ }^{\mathrm{V}}$ to GSH was increased to 1:8. The HPLC-ESI-MS was employed in the positive mode for the unequivocal identification of the product. The $\mathrm{m} / \mathrm{z}$ value of synthesized compound was found to be $703[\mathrm{M}+\mathrm{H}]^{+}$confirming the formation of $\mathrm{MMA}^{\mathrm{III}}(\mathrm{GS})_{2}$.

$\mathrm{DMA}^{\mathrm{III}}(\mathrm{GS})$ was prepared by mixing $\mathrm{DMA}^{\mathrm{V}}$ with GSH in the molar ratio of 1:9 under acidic conditions. Formation of the compound was confirmed by HPLC-ICPMS by comparing its retention time with solid standard received from Ziopharm Oncology, Boston, MA. Additionally, the HPLC-ESI-MS was employed in the positive mode for the unequivocal identification of the product. The $\mathrm{m} / \mathrm{z}$ value of synthesized compound was found to be $412[\mathrm{M}+\mathrm{H}]^{+}$, confirming the formation of DMA ${ }^{\mathrm{III}}(\mathrm{GS})$.

DMMTA $^{\mathrm{V}}$ was prepared by reacting DMA ${ }^{\mathrm{V}}$ with sodium sulfide $\left(\mathrm{Na}_{2} \mathrm{~S}\right)$ and sulfuric acid $\left(\mathrm{H}_{2} \mathrm{SO}_{4}\right)$ in DDIW according to previously reported method with slight modification. ${ }^{10}$ Unlike the reference, I did not purify DMMTA ${ }^{\mathrm{V}}$ by extracting it into diethyl ether at the end. The mol ratio of As: $\mathrm{Na}_{2} \mathrm{~S}: \mathrm{H}_{2} \mathrm{SO}_{4}$ was 1:1.6:1.6. DMMTA ${ }^{\mathrm{V}}$ was 
aliquoted and stored in argon purged glass vials at $-11^{\circ} \mathrm{C}$. Formation of DMMTA ${ }^{\mathrm{V}}$ was confirmed with the help of HPLC-ESI-MS in the positive mode. A peak with an $\mathrm{m} / \mathrm{z}$ value of 155 was obtained confirming species identity.

DMDTA $^{\mathrm{V}}$ was prepared by stepwise addition of concentrated $\mathrm{H}_{2} \mathrm{SO}_{4}$ to an aqueous solution of $\mathrm{DMA}^{\mathrm{V}}$ and $\mathrm{Na}_{2} \mathrm{~S}$ at the final molar ratio of $\mathrm{DMA}^{\mathrm{V}}: \mathrm{Na}_{2} \mathrm{~S}: \mathrm{H}_{2} \mathrm{SO}_{4}$ was 1:7.5:7.5. The reaction solution was allowed to stand for 1 day. ${ }^{107}$

$\operatorname{DMMTA}^{\mathrm{V}}(\mathrm{GS})$ was prepared by adding GSH to DMMTA ${ }^{\mathrm{V}}$ in the molar ratio of 9:1 respectfully. Formation and purity of the compound was confirmed by HPLC-ICPMS. If needed, more GSH was added to the solution. The HPLC-ESI-MS was employed in the positive mode for the unequivocal identification of the product. The $\mathrm{m} / \mathrm{z}$ value of synthesized compound was found to be $444[\mathrm{M}+\mathrm{H}]^{+}$confirming the formation of $\operatorname{DMMTA}^{\mathrm{V}}(\mathrm{GS})$

\subsubsection{Instrumentation}

Proton NMR spectra for the confirmation of $\mathrm{MMA}^{\mathrm{III}} \mathrm{I}_{2}$ and $\mathrm{DMA}^{\mathrm{III}} \mathrm{I}$ synthesis was performed at $25^{\circ} \mathrm{C}$ on a Bruker $400 \mathrm{FT}$ NMR spectrometer operating at a proton frequency of $400 \mathrm{MHz}$. Samples were dissolved in $\mathrm{D}_{2} \mathrm{O}$, except for the oily $\mathrm{DMA}^{\mathrm{III} I}$ which was dissolved in a mixture of $\mathrm{D}_{2} \mathrm{O}$ and $\mathrm{D}_{3} \mathrm{C}-\mathrm{OD}$ to increase its solubility. The samples were transferred to the NMR tubes and capped with rubber septa immediately. NMR spectra were collected within half an hour of sample preparation. Chemical shift values were referenced to the residual HDO signal at $4.70 \mathrm{ppm}$.

A Thermo Finnigan Surveyor HPLC system equipped with an autosampler and column compartment was coupled with an LCQ Deca XP MAX (Thermo Finnigan, USA) MS. Data was collected and treated using Xcalibar software (Thermo, USA). The 
instrumental parameters were optimized using the flow injection mode with a $5 \mu \mathrm{g} \mathrm{mL} \mathrm{L}^{-1}$ caffeine standard.

A Perkin Elmer Series 200 HPLC system equipped with a temperature controlled column compartment was coupled to a Perkin Elmer Elan DRC-e ICP-MS. The ICP-MS was equipped with a cyclonic spray chamber and a Meinhard nebulizer and was used in the standard mode. The ICP-MS signal at $\mathrm{m} / \mathrm{z} 75$ for ${ }^{75} \mathrm{As}$ was monitored. Data was collected and processed using Elan v. 3.4 and Chromera v. 1.2 software (Perkin Elmer, USA).

\subsubsection{Optimization of HPLC and ICP-MS Parameters}

To develop an HPLC-ICP-MS method for speciation of various As metabolites, experiments were performed to optimize a variety of parameters, including HPLC column type and dimension, column temperature, mobile phase (composition, $\mathrm{pH}$, and gradient program), and ICP-MS parameters such as nebulizer gas, RF power, analog stage, and lens voltages. It was observed that HPLC mobile phase and ICP-MS nebulizer gas were the two key factors influencing the separation and detection of the As compounds of interest. Therefore the experiments were focused on these two parameters to find the most optimal conditions for the separation and detection of all arsenic species of interest.

The optimization of mobile phase included selection of aqueous buffer and organic solvent and the gradient elution program. Considering the $\mathrm{pK}_{\mathrm{a}}$ values of arsenicals, a number of buffers, including but not limited to trifluoroacetate (TFA, $\mathrm{pK}_{\mathrm{a}}=$ $0.5)$, formate $\left(\mathrm{pK}_{\mathrm{a}}=3.8\right)$, and acetate $\left(\mathrm{pK}_{\mathrm{a}}=4.8\right)$, were tested. The commonly used organic solvents, such as acetonitrile, methanol, and isopropyl alcohol, were tested for 
separation of the As species of interest. The gradient elution program was optimized by changing the $\mathrm{v} / \mathrm{v} \%$ of the selected organic component from $0-20 \%$.

Nebulizer gas was optimized for its composition and flow rate to investigate its effect on detection of the arsenic metabolites selected in this study. In order to address the issue of plasma instability and instrument contamination, which was caused by high v/v \% of organic solvent used here (see Results and Discussion), oxygen was added through a T-connector to the nebulizer Ar gas. The flow rate of Ar for nebulization was further optimized to investigate its effect on separation of arsenic compounds and instrumental sensitivity, by varying the flow rate from 0.80 to $1.04 \mathrm{~L} / \mathrm{min}$.

\subsubsection{Linearity, Limit of Detection (LOD), and Limit of Quantitation (LOQ)}

Even at low $\mathrm{v} / \mathrm{v} \%$, the organic portion of the mobile phase significantly changes the ionization characteristics in the plasma and thus the sensitivity of the method for the same species. Consequently, the linearity, LOQ and LOD of the method were demonstrated using two compounds, one (As $\left.{ }^{\mathrm{III}}\right)$ eluting during very low (1\%) acetonitrile $(\mathrm{ACN})$ concentrations and one $\left(\mathrm{As}^{\mathrm{III}}(\mathrm{GS})_{3}\right)$ eluting during very high $(>15 \%)$ acetonitrile concentration. Linearity, LOQ, and LOD studies were performed under the optimized instrumental conditions.

4.4.6 Application of Method for the Determination of Metabolites of DMA ${ }^{\mathrm{III}}(\mathrm{GS})$ in Human Cells

The developed method was used to analyze the metabolites of $\operatorname{DMA}^{\mathrm{III}}(\mathrm{GS})$ in 8226/S multiple myeloma cell line (ATCC, Manassas, VA). The cells were maintained at $37{ }^{\circ} \mathrm{C}$ in a humidified atmosphere with $5 \% \mathrm{CO}_{2}$ on RPMI-1640 media, supplemented with $100 \mathrm{U} \mathrm{mL}^{-1}$ of penicillin, $100 \mu \mathrm{g} \mathrm{mL}^{-1}$ of streptomycin, $10 \%$ heat inactivated fetal 
bovine serum and $2 \mathrm{mM}$ L-glutamine (all culture reagents from Cellgro, MediaTech, Herndon, VA). Following incubation the cells were harvested by centrifugation at 1000 rpm for 5 minutes, washed with PBS once, spun down again, then the pellets were frozen in liquid nitrogen and stored at $-11{ }^{\circ} \mathrm{C}$. Each cell pellet contained $5.0 \times 10^{6}$ cell counts. For the As exposure experiment, the cell pellets were thawed, spiked with $0.26 \mathrm{mM}$ $\mathrm{DMA}^{\mathrm{III}}(\mathrm{GS})$ in double deionized water (DDIW) and left for 10 minutes. The cells were then broken up with a sonication probe, and the sample was filtered through a $0.2 \mu \mathrm{m}$ NYLON syringe filter into an HPLC vial and analyzed. Unspiked cells used as control were prepared in the same way, but without spiking the cells with DMA ${ }^{\mathrm{III}}(\mathrm{GS})$.

\subsection{Results and Discussion}

\subsubsection{HPLC Column}

Since a number of As metabolites could exist in human cells and some of which (e.g., trivalent arsenicals) are redox sensitive, an efficient separation is required for their determination to maintain integrity of the analytes. I first compared three HPLC columns, namely ion exchange, $\mathrm{C}_{18}$, and $\mathrm{C}_{8}$, and found that $\mathrm{C}_{8}$ column was the most promising for further optimization to achieve better separation of a variety of arsenicals. I then performed further experiments to optimize the $\mathrm{C}_{8}$ column-based HPLC-ICP-MS method, focusing on mobile phase and nebulizer gas as I observed they are critical in the performance of the method. In addition, as I observed that lower temperatures help preserve the oxidation state of trivalent arsenic species and prevent the degradation of As-glutathione complexes, concurring with previous studies ${ }^{118}$, I conducted all the experiments with the column kept at $10^{\circ} \mathrm{C}$. 


\subsubsection{Mobile Phase}

It was observed that a mixture of aqueous buffer and organic solvent was needed for the separation of the arsenic species of interest. For aqueous mobile phase, a number of buffers were evaluated, particularly such volatile buffers as trifluoroacetate $\left(\mathrm{TFA}, \mathrm{pK}_{\mathrm{a}}=0.5\right)$, formate $\left(\mathrm{pK}_{\mathrm{a}}=3.8\right)$, and acetate $\left(\mathrm{pK}_{\mathrm{a}}=4.8\right){ }^{152}$ The selection of these buffers was primarily on the basis of $\mathrm{pH}$. Ideally, the $\mathrm{pH}$ of the mobile phase should be chosen to be at least two units away from the analyte $\mathrm{pK}_{\mathrm{a}}$ values in order to have all the analytes present in their neutral or fully ionized forms. ${ }^{152}$ Considering that the species to be separated have a wide range of $\mathrm{pK}_{\mathrm{a}}$ values (including unknown $\mathrm{pK}$ a for some species) and that many of these species are more stable at lower $\mathrm{pH}$ values, the final $\mathrm{pH}$ range studied was set from 1.5 to 4.6 on the basis of the available $\mathrm{pK}_{\mathrm{a}}$ values and stability

experiments. ${ }^{118}$ In addition to $\mathrm{pH}$, volatility was considered a factor for selection of aqueous mobile phase. This was because it would be ideal if the separation method could be used not only in HPLC-ICP-MS, but also in HPLC-ESI-MS. In this case, if an unknown peak appears or the identity of a peak is questionable solely on the basis of retention time, HPLC-ESI-MS can be used for the unequivocal identification of the species in question. A comparison of the above 3 mobile phases yielded that the best separation can be achieved using $0.05 \%$ TFA as the aqueous mobile phase (data not shown).

For organic solvents in the mobile phase, acetonitrile, methanol, and isopropyl alcohol were considered. It was found that the ICP did not tolerate isopropyl alcohol well even at low concentrations, and isopropyl alcohol was not used after the initial trials. Methanol, though evaluated extensively to be used for separation, was not selected as our 
research group previously observed the decreased stability of certain arsenic species in methanol. ${ }^{117}$ Acetonitrile was eventually selected as the organic part of the mobile phase, as it has higher eluotropic strength when used at the same volume percentage compared to methanol, achieving adequate separation within reasonable time. An additional benefit of acetonitrile addition to the mobile phase was the enhanced signal on ICP-MS detection (data not shown). This was not surprising, as it is known that the presence of organic solvents at $1-5 \mathrm{v} / \mathrm{v} \%$ would cause signal enhancement of arsenic and other elements with higher ionization potentials as a result of the modification of equilibrium in the plasma. ${ }^{153}$ This is the consequence of the modification of equilibrium in the plasma. The degree of ionization of carbon is significantly larger than that of Ar under standard conditions. As the $\mathrm{C}^{+}$has an ionization energy $\left(\mathrm{E}_{\mathrm{i}}\right)$ of $11.26 \mathrm{eV}$, the transfer of electrons to elements with lower $\mathrm{E}_{\mathrm{i}}$ (such as ${ }^{75} \mathrm{As}$ which has an $\mathrm{E}_{\mathrm{i}}$ of $9.81 \mathrm{eV}$ ), thus their ionization improves considerably, hence the signal enhancement.

After selection of aqueous and organic mobile phases, the gradient program was optimized by modifying the $\mathrm{v} / \mathrm{v} \%$ of the organic component, as the $\mathrm{v} / \mathrm{v} \%$ of organic solvent is the principal factor that governs the retention of analytes in reversed-phase LC separations. It was found that the $\mathrm{v} / \mathrm{v} \%$ needed to be gradually increased and a relative large amount of organic solvent $(20 \% \mathrm{v} / \mathrm{v})$ at the late stage of separation was necessary to achieve the most optimal separation of all species within reasonable time. Figure 4.1 illustrates the separation of major arsenic compounds (excluding arsenic-glutathione complexes) under the optimized HPLC gradient program and other conditions (Tables 4.2 $\mathrm{A}$ and $\mathrm{B})$. The total run time was set to $30 \mathrm{~min}$, although the retention time of the last peak was around $23.4 \mathrm{~min}$. The extra run time (between 26 to $30 \mathrm{~min}$ ) can be used for the 
post column injection of a stable internal standard (e.g., $\mathrm{As}^{\mathrm{V}}$ ), if required, to correct for instrumental drifts occurring during the day. During the last ten minutes of the gradient program, the $\mathrm{v} / \mathrm{v} \%$ of acetonitrile was decreased to $5 \%$ from $20 \%$ in the previous step. This change of $\mathrm{ACN} v / \mathrm{v} \%$ not only had no significant effect on the retention time and the resolution of the peaks eluted during this period, but also provided a way to reduce the usage of organic solvent and to protect the stability of plasma. If the run was finished with $20 \%$ acetonitrile in the mobile phase at $0.5 \mathrm{~mL} / \mathrm{min}$ without the decrease in $\mathrm{ACN} \mathrm{v} / \mathrm{v}$ $\%$, the plasma would be frequently extinguished once the equilibration stage began when the mobile phase changed to $1 \% \mathrm{v} / \mathrm{v}$ acetonitrile at $1 \mathrm{~mL} / \mathrm{min}$.

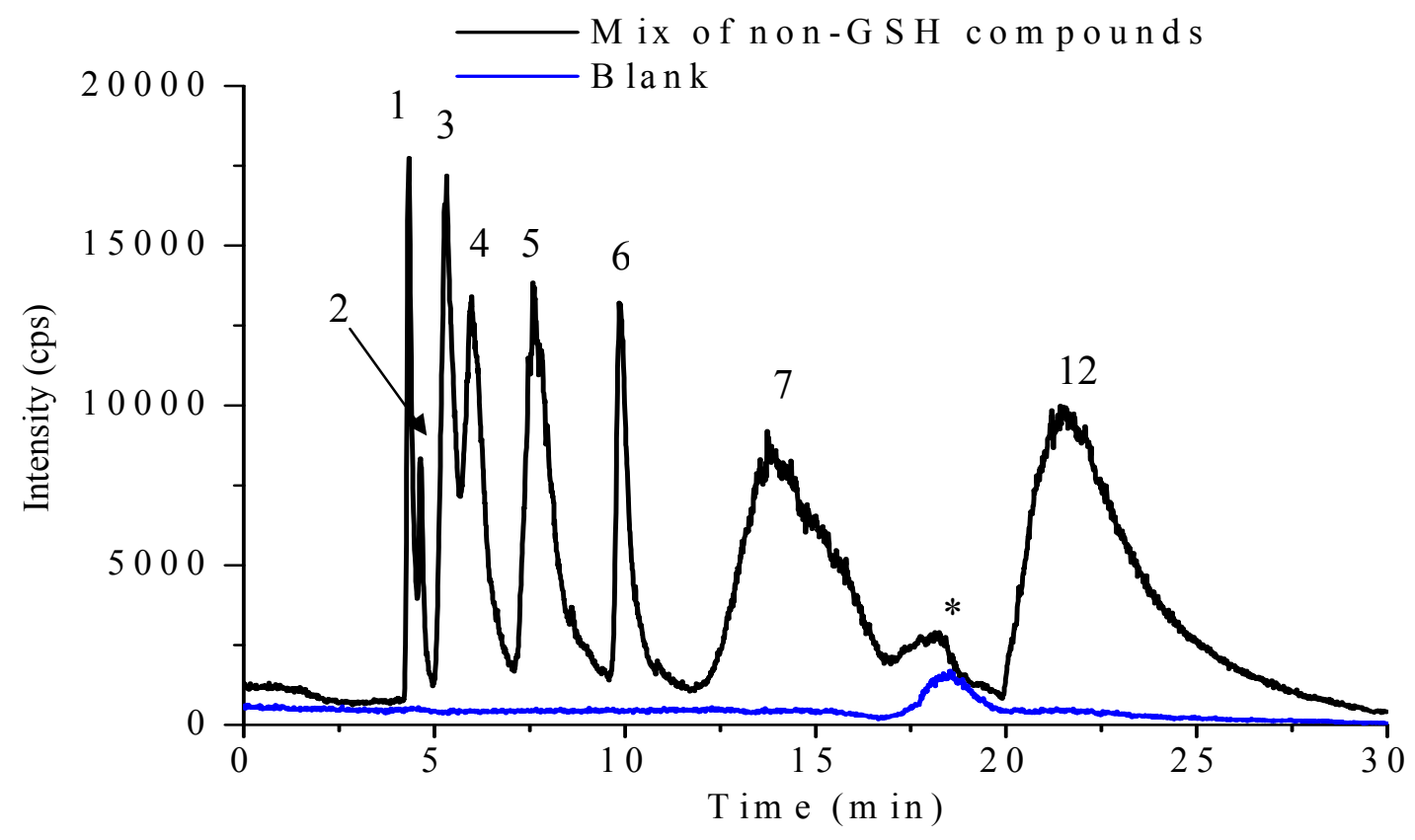

Figure 4.1 Typical chromatogram for the separation and analysis of arsenic compounds containing no glutathione using HPLC-ICP-MS. The compounds separated are as

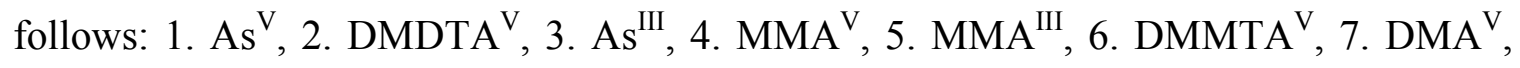


12. $\mathrm{DMA}^{\mathrm{III}}$, * Baseline disturbance originating from high concentration of acetonitrile in the gradient program.

Table 4.2 A Instrumental parameters after optimization

\begin{tabular}{|c|c|c|}
\hline \multirow{13}{*}{ 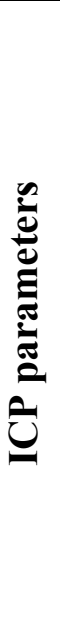 } & Parameter (unit) & Typical values \\
\hline & ICP-MS Nebulizer Ar Gas Flow (L/min) & $0.84-0.90$ \\
\hline & Nebulizer Oxygen Gas Flow (L/min) & 0.2 \\
\hline & Auxiliary Gas Flow (L/min) & 1 \\
\hline & Plasma Gas Flow (L/min) & 15 \\
\hline & Lens voltage & 9 \\
\hline & ICP RF Power (W) & 1350 \\
\hline & Analog Stage Voltage & -1525 \\
\hline & Pulse Stage Voltage & 950 \\
\hline & Quadrupole Rod Offset Std (QRO) & -2 \\
\hline & Cell Rod Offset Std (CRO) & -7 \\
\hline & Discriminator Threshold & 40 \\
\hline & Cell Path Voltage Std (CPV) & -20 \\
\hline \multirow{5}{*}{ 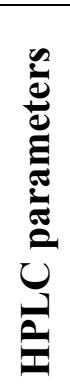 } & Column & $\begin{array}{l}\text { Waters Spherisorb } 5 \\
\mu \mathrm{m} \mathrm{C} 8,4.0 \times 250 \mathrm{~mm}\end{array}$ \\
\hline & Column temperature & $10^{\circ} \mathrm{C}$ \\
\hline & Mobile phase temperature & $\begin{array}{l}\text { Cooled in ice bath } \\
\text { during analysis }\end{array}$ \\
\hline & Sample temperature & Room temperature \\
\hline & Mobile phase (MP) & $\begin{array}{l}\text { MP A: } 0.05 \% \text { TFA } \\
\text { MP B: Acetonitrile }\end{array}$ \\
\hline
\end{tabular}

Table 4.2 B Gradient elution program after optimization

\begin{tabular}{|c|c|c|c|c|c|c||}
\hline Step & Step type & $\begin{array}{c}\text { Step time } \\
\text { (min) }\end{array}$ & $\begin{array}{c}\text { Flow } \\
\text { (mL/min) }\end{array}$ & $\mathbf{0 . 0 5 \%}$ TFA & ACN \% & Curve \\
\hline 0 & Equilibration & 6.0 & 1.0 & 99 & 1 & N/A \\
\hline 1 & Run & 5.5 & 0.4 & 99 & 1 & 0.0 \\
\hline 2 & Run & 3.5 & 0.5 & 87 & 13 & 1.0 \\
\hline 3 & Run & 11.0 & 0.5 & 80 & 20 & 0.0 \\
\hline 4 & Run & 10.0 & 0.5 & 95 & 5 & 0.0 \\
\hline
\end{tabular}




\subsubsection{Nebulizer gas}

From the optimization of mobile phase, it was seen that high acetonitrile composition (up to $20 \% \mathrm{v} / \mathrm{v}$ ) was needed for the separation of arsenic species. The usage of high fraction of organic solvent in the mobile phase caused several problems. First, high fraction of ACN extinguished the plasma frequently during the run, interrupting sample analysis. Second, as a consequence of the high organic composition in the mobile phase, carbon built up quickly on the ICP sampling interface and torch, necessitating the frequent cleanup or replacement of the torch, the injector, and the cones. Finally, high $\mathrm{ACN} v / \mathrm{v} \%$ in mobile phase produced severe baseline disturbance during gradient elution and caused appearance of a ghost peak, interfering with detection of arsenic species. In order to solve these problems, I did further optimization on the method and found that nebulizer gas was the critical factor. I then optimized nebulizer gas, including composition and flow rate, to solve these problems.

For nebulizer gas composition, I introduced a small amount of oxygen to the nebulizer gas flow, aiming to burn the carbon from organic solvent to avoid carbon deposition on ICP hardware. A T-connector was employed to add $0.2 \mathrm{~L} / \mathrm{min}$ oxygen gas to the Ar nebulizer flow exiting from the ICP and going to the nebulizer. Prior to analysis, the flow rates of Ar and oxygen were separately measured and the flow of the two gasses added up was verified before the gases entered the nebulizer. The highest manufacturer recommended flow rate of $0.2 \mathrm{~mL} / \mathrm{min}$ of $\mathrm{O}_{2}$ was used to achieve maximum protection for the instrument from carbon buildup. The approach was found to be successful and I managed to keep our equipment protected from carbon build up for a long time (e.g., months) and from the extinguishing the plasma. 

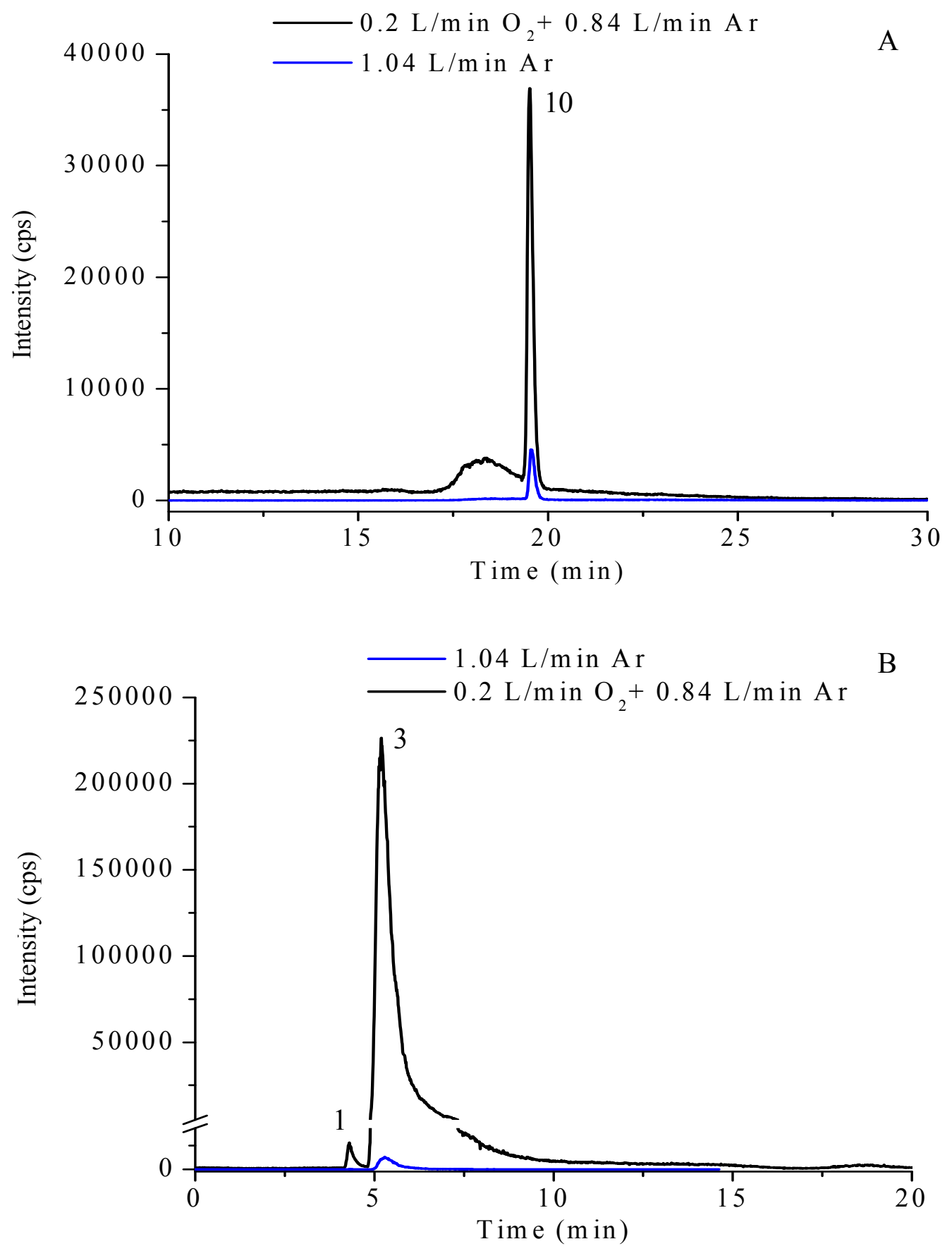

Figure 4.2 Demonstration of signal enhancement as a consequence changes in nebulizer gas composition and flow rate for (A) $\mathrm{MMA}^{\mathrm{III}}(\mathrm{GS})_{2}$ eluting during high $(20 \%) \mathrm{v} / \mathrm{v} \%$ acetonitrile and (B) $\mathrm{As}^{\mathrm{V}}$ and $\mathrm{As}^{\mathrm{III}}$ eluting during low (1\%) $\mathrm{v} / \mathrm{v} \%$ acetonitrile in the gradient program. 
During the experiments of introducing oxygen into the nebulizer gas flow, it was observed that the intensity of the ICP-MS signal was enhanced when the nebulizer gas was composed of $\mathrm{O} 2$ and $\mathrm{Ar}$ than $\mathrm{Ar}$ alone, with the total flow rate being the same (Fig. 4.2). For example, the signal for $\mathrm{MMA}^{\mathrm{III}}(\mathrm{GS})_{2}$, which was eluted at high $\mathrm{ACN} \mathrm{v} / \mathrm{v} \%$, increased by a factor of about 7 when the nebulizer gas was composed of $0.2 \mathrm{~L} / \mathrm{min}$ of $\mathrm{O}_{2}$ and $0.84 \mathrm{~L} / \mathrm{min}$ of Ar, compared to $1.04 \mathrm{~L} / \mathrm{min}$ of Ar. Similarly, under the same experimental conditions, the signals for $\mathrm{As}^{\mathrm{V}}$ and $\mathrm{As}{ }^{\mathrm{III}}$, which were eluted at low $\mathrm{ACN} \mathrm{v} / \mathrm{v}$ $\%$, increased when the mixture of $\mathrm{O}_{2} \mathrm{Ar}$ was used as nebulizer gas. This signal increase could be a consequence of the introduction of $\mathrm{O}_{2}$ and/or the difference in Ar flow rates $\left(0.84 \mathrm{~L} / \mathrm{min}\right.$ when $\mathrm{O}_{2}$ was added versus $1.04 \mathrm{~L} / \mathrm{min}$ with Ar only). From Fig. 4.2, it was also observed that the baseline disturbance from high $\mathrm{ACN} v / \mathrm{v} \%$ in the mobile phase was more severe at a lower flow of $\operatorname{Ar}(0.84 \mathrm{~L} / \mathrm{min})$, compared to a higher flow of $\mathrm{Ar}$ $(1.04 \mathrm{~L} / \mathrm{min})$. It seems possible that a lower flow of Ar enhanced the instrumental signal and at the same time increased baseline disturbance. Further experiments were conducted to examine the effect of Ar flow rate on baseline disturbance and on instrumental signal.

Blanks without As compounds were used to check the baseline disturbance during gradient elution under different flow rates of nebulizer Ar gas. It was found that the baseline disturbance producing the ghost peak can be substantially decreased by increasing slightly the Ar nebulizer flow (Fig. 4.3). Increasing the Ar flow from 0.80 to $0.90 \mathrm{~L} / \mathrm{min}$ could reduce the baseline disturbance to an acceptable level. It appears that $\mathrm{O}_{2}$ had no influence on baseline disturbance, as indicated by the similarity of baseline signals with or without $\mathrm{O}_{2}$ present in the nebulizer gas when Ar was $0.8 \mathrm{~L} / \mathrm{min}$. 
Arsenic standards were run to assess the effect of Ar flow rate on instrumental signal. It was observed that increasing the nebulizer Ar gas flow decreased the sensitivity of the instrument for arsenic detection. Figure $4.4 \mathrm{~A}$ demonstrates an example of the negative effects of Ar flow increase on the response of the instrument, with DMA ${ }^{\mathrm{III}}(\mathrm{Cys})$ being detected on ICP-MS. The instrumental intensity for $\mathrm{DMA}^{\mathrm{III}}(\mathrm{Cys})$ decreased by a factor of 2 when the Ar flow increased from 0.80 to $0.90 \mathrm{~L} / \mathrm{min}$ with $\mathrm{O}_{2}$ present in the nebulizer gas at $0.20 \mathrm{~L} / \mathrm{min}$. Again, the influence of Ar gas flow on baseline disturbance was observed, as $0.90 \mathrm{~L} / \mathrm{min}$ of Ar produced significantly lower baseline disturbance, compared to $0.80 \mathrm{~L} / \mathrm{min}$ of Ar.

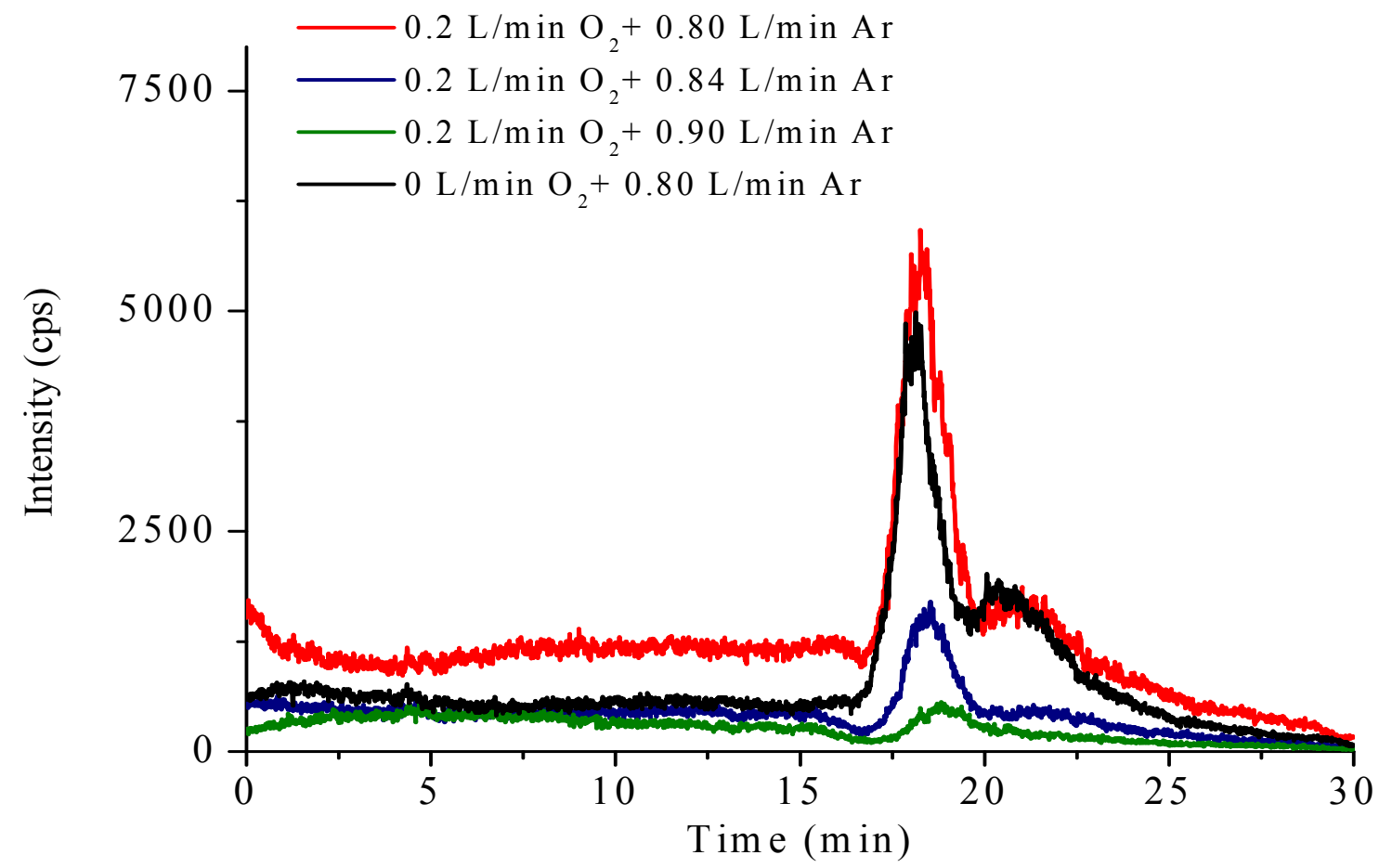

Figure 4.3 Baseline disturbance vs nebulizer flow rate and composition for blank injection. 
To exclude the possibility that the decreased instrumental response was the consequence of the overall increase of nebulizer gas flow $\left(\mathrm{Ar}+\mathrm{O}_{2}\right)$, experiments were conducted to examine the ICP-MS signal for DMA ${ }^{\mathrm{III}}$ (Cys) at a fixed Ar flow rate with and without the addition of $\mathrm{O}_{2}$. It was observed that the ICP-MS signals were fairly similar when $0.2 \mathrm{~L} / \mathrm{min}$ of $\mathrm{O}_{2}$ was added to $0.86 \mathrm{~L} / \mathrm{min}$ of $\mathrm{Ar}$ (making up a total flow of 1.06 L/min), compared to $0.86 \mathrm{~L} / \mathrm{min}$ of Ar being used as nebulizer gas (Fig. $4.4 \mathrm{~B}$ ). This result suggests that the increase in nebulizer gas flow as a consequence of $\mathrm{O}_{2}$ addition did not affect instrumental response. Additionally, others reported for some elements such as tellurium (Te) with similar behavior to $\mathrm{As}^{3+}$ in ICP-MS, the addition of $\mathrm{O}_{2}$ to the outer gas (nebulizer gas flow) had no effect on analyte sensitivity except when mixed in with the plasma gas. ${ }^{154}$

From figure 4.4 B, it was also seen that the increase in nebulizer gas flow as a consequence of $\mathrm{O}_{2}$ addition did not affect baseline disturbance. These results confirmed that it is Ar flow rate that influences the instrumental response and baseline disturbance. Through the optimization of nebulizer gas, it was found that increasing Ar flow rate reduced baseline disturbance, but at the same time decreased instrumental response. Therefore, the nebulizer Ar flow rate (in addition to other instrumental parameters) should be carefully optimized prior to analysis, to achieve adequate sensitivity while minimizing the interference from baseline disturbance. The typical Ar flow rates used in our experiments were about $0.84-0.90 \mathrm{~L} / \mathrm{min}$ (Table 4.2). As for $\mathrm{O}_{2}$, it was observed that $\mathrm{O}_{2}$ protected the instrument from carbon buildup and from plasma extinguishing, but did not affect signal intensity. 

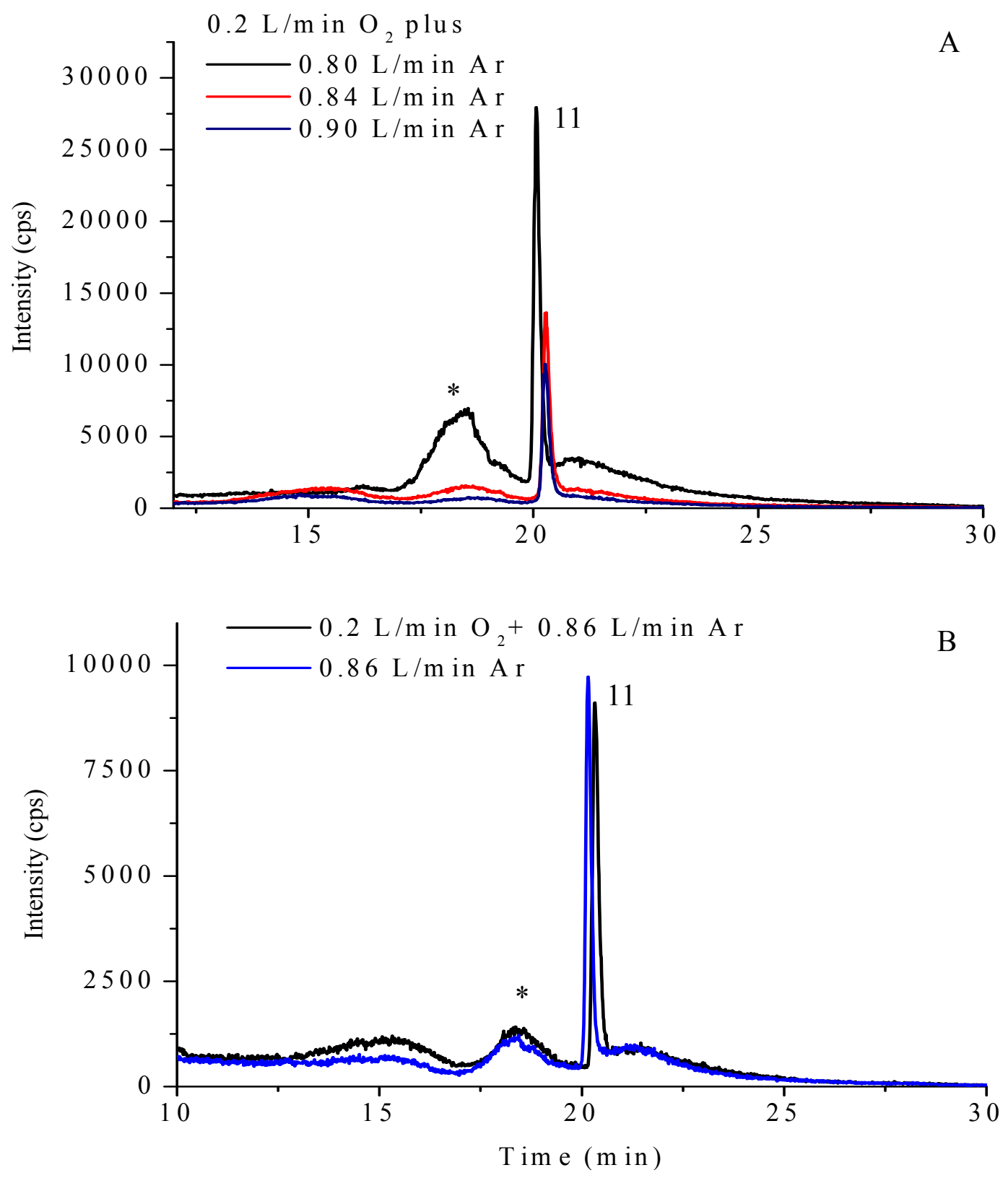

Figure 4.4 The effect of nebulizer gas on instrumental response demonstrated by (A) decreased sensitivity for $\mathrm{DMA}^{\mathrm{III}}(\mathrm{Cys})$ detection with increasing Ar flow rate and (B) similar responses of $\mathrm{DMA}^{\mathrm{III}}(\mathrm{Cys})$ at the same Ar flow rate regardless of the presence of oxygen. The effect of Ar flow rate on baseline disturbance is also observable in the figure. 


\subsubsection{Analysis of As-GSH complexes}

As-GSH complexes represent an important type of intermediates during As metabolism in human body, and thus the developed method was also intended for analysis of As-GSH complexes. For analysis of As-GSH complexes, the first consideration was about the standards. The As-GSH complexes standards were prepared by mixing As standard solutions (As ${ }^{\mathrm{III}}, \mathrm{MMA}^{\mathrm{III}}$, DMA ${ }^{\mathrm{III}}$, and $\mathrm{DMMTA}^{\mathrm{V}}$ ) with excess GSH, and thus the standards of As-GSH complexes, e.g., As ${ }^{\mathrm{III}}(\mathrm{GS})_{3}, \mathrm{MMA}^{\mathrm{III}}(\mathrm{GS})_{2}$, $\mathrm{DMA}^{\mathrm{III}}(\mathrm{GS})$, and DMMTA ${ }^{\mathrm{V}}(\mathrm{GS})$ were always present in excess GSH. The standard solution of As-GSH complexes could not be mixed with the non-GSH complexed As standards, because, once mixed, the non-GSH complexed arsenicals (free $\mathrm{As}^{\mathrm{III}}$, MMA ${ }^{\mathrm{III}}$, $\mathrm{DMA}^{\mathrm{III}}$, and DMMTA ${ }^{\mathrm{V}}$ ) would be complexed by GSH from the solution of As-GSH complexes. Therefore I prepared two sets of standards, one for As-GSH complexes and the other for non-GSH complexed arsenicals, and these two types of As standards need to be injected separately. For samples, when GSH and non-GSH complexed arsenicals are present in a sample, equilibrium will be established between the GSH complexes and their non-GSH counterparts depending on the reduced GSH concentration in the sample. When injected, the relative amounts of each arsenic species can be determined on the basis of the two sets of As standards.

Figure 4.5 A shows a typical chromatogram with good separation for As-GSH complexes, $\mathrm{As}^{\mathrm{III}}(\mathrm{GS})_{3}, \operatorname{DMMTA}^{\mathrm{V}}(\mathrm{GS}), \mathrm{MMA}^{\mathrm{III}}(\mathrm{GS})_{2}$, and $\mathrm{DMA}^{\mathrm{III}}(\mathrm{GS})$, as well as thiolcontaining arsenicals, DMDTA ${ }^{\mathrm{V}}$ and $\mathrm{DMMTA}^{\mathrm{V}}$. An overlay of the chromatograms for non-GSH complexes As standards and As-GSH complexes shows the separation of major As metabolites of interest (Fig. 4.5 B), suggesting that the developed method is indeed 
able to detect both sulfur-containing and non-sulfur-containing arsenicals if they are both present in the sample.

It should be pointed out that the DMA ${ }^{\mathrm{III}}$ peak (\#12 in the chromatogram, Fig. 4.6) corresponded to the injection of DMA ${ }^{\mathrm{III} I}$ synthesized in our laboratory, which could be hydrolyzed to $\mathrm{DMA}^{\mathrm{III}}(\mathrm{OH})$ upon dilution in aqueous solutions. It was found that, when a high concentration of $\mathrm{DMA}^{\mathrm{III}}(\mathrm{GS})$ (\#13 in the chromatogram, Fig. 4.6) was injected, during the run it partially dissociated to DMA ${ }^{\mathrm{III}}$, as shown by the fronting peak of $\mathrm{DMA}^{\mathrm{III}}(\mathrm{GS})$ in Figure 4.6. The decomposition of $\mathrm{DMA}^{\mathrm{III}}(\mathrm{GS})$ to $\mathrm{DMA}^{\mathrm{III}}$ during analysis, along with the lack of availability of pure DMA ${ }^{\mathrm{III}}$ standard and DMA ${ }^{\mathrm{III}}$ being extremely prone to oxidation during storage and sample preparation, make it nearly impossible to accurately determine the native $\mathrm{DMA}^{\mathrm{III}}$ concentration in the sample. As the preparation of $\mathrm{DMA}^{\mathrm{III}} \mathrm{I}$ is rather difficult, $\mathrm{DMA}^{\mathrm{III}}(\mathrm{Cys})$ and $\mathrm{DMA}^{\mathrm{III}}(\mathrm{GS})$ have been used as standards for DMA ${ }^{\mathrm{III}}$ in a number of studies, which further complicated the issue of DMA $^{\text {III }}$ identification and detection. By using the developed method here, I observed that DMA $^{\mathrm{III} I}$ (probably should be labeled as DMA ${ }^{\mathrm{III}}$ as this species usually refers to the nonconjugated form), $\mathrm{DMA}^{\mathrm{III}}(\mathrm{Cys})$, and $\mathrm{DMA}^{\mathrm{III}}(\mathrm{GS})$ gave three completely different peaks, with a very broad peak for DMA ${ }^{\mathrm{III}}$ and two sharp peaks for $\mathrm{DMA}^{\mathrm{III}}(\mathrm{Cys})$ and $\mathrm{DMA}^{\mathrm{III}}(\mathrm{GS})$ (Fig. 4.6). Therefore, $\mathrm{DMA}^{\mathrm{III}}(\mathrm{GS}), \mathrm{DMA}^{\mathrm{III}}(\mathrm{Cys})$, and $\mathrm{DMA}^{\mathrm{III}}$ (non-conjugated form) should be treated as three different As species and caution should be exercised to avoid confusion. I further demonstrated that the developed method was able to separate all these three forms of the trivalent dimethylated arsenical (Fig. 4.6), if they are present as As metabolites in the sample. 

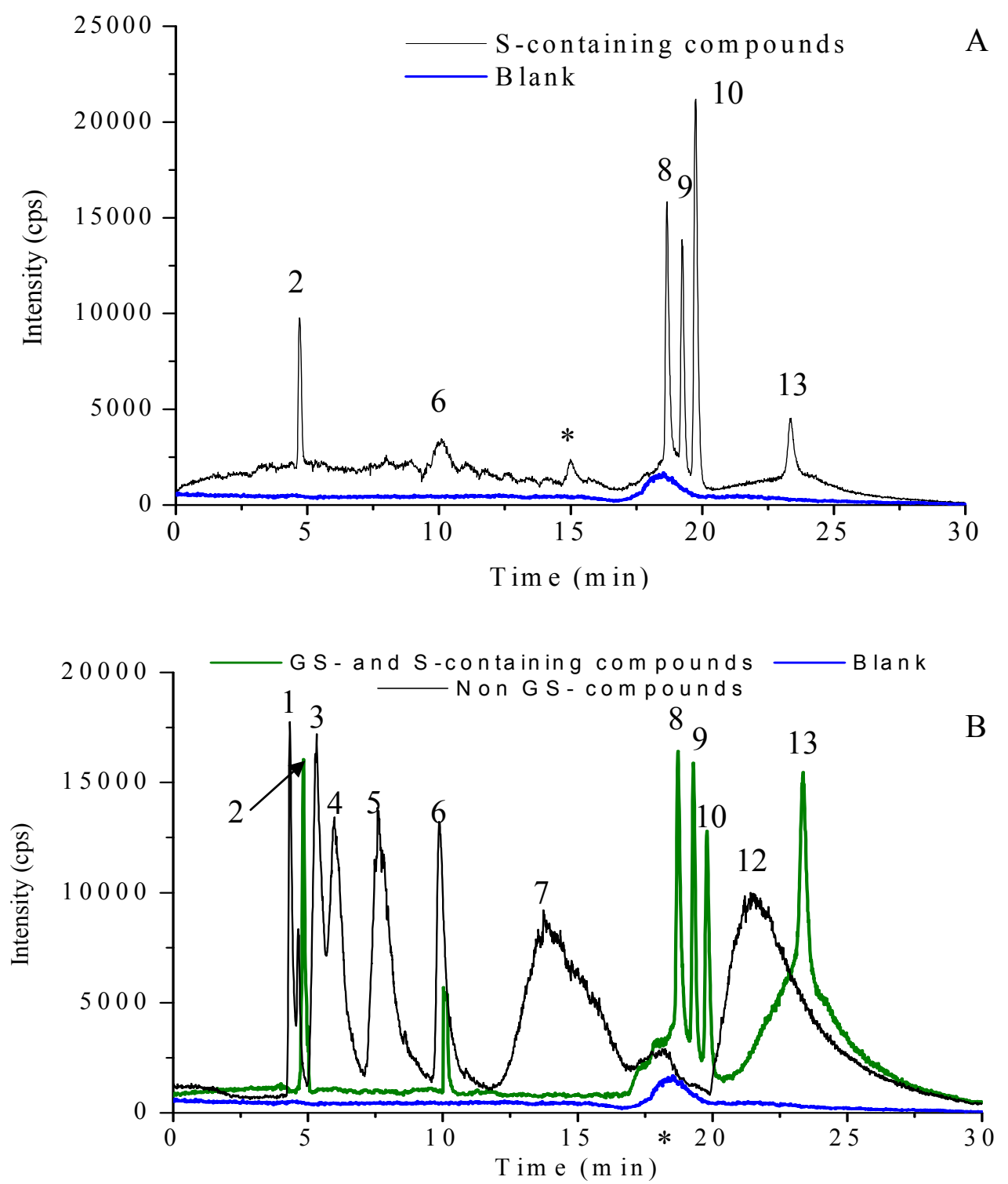

Figure 4.5 Separation of arsenic metabolites demonstrated by (A) injection of glutathione complexes and S containing compounds and (B) overlay of the chromatograms for injection of sulfur-containing and non-sulfur-containing arsenicals. The compounds separated are as follows: 1. As ${ }^{\mathrm{V}}, 2 . \mathrm{DMDTA}^{\mathrm{V}}, 3 . \mathrm{As}^{\mathrm{III}}, 4 . \mathrm{MMA}^{\mathrm{V}}, 5 . \mathrm{MMA}^{\mathrm{III}}, 6$. DMMTA $^{\mathrm{V}}$, 7. $\mathrm{DMA}^{\mathrm{V}}$, 8. $\mathrm{As}^{\mathrm{III}}(\mathrm{GS})_{3}$, 9. $\mathrm{DMMTA}^{\mathrm{V}}(\mathrm{GS}), 10 . \mathrm{MMA}^{\mathrm{III}}(\mathrm{GS})_{2}$, 12. DMA ${ }^{\mathrm{III}}$, 13. DMA ${ }^{\mathrm{III}}(\mathrm{GS}),{ }^{*}$ Baseline disturbance originating from high concentration acetonitrile gradient program. 

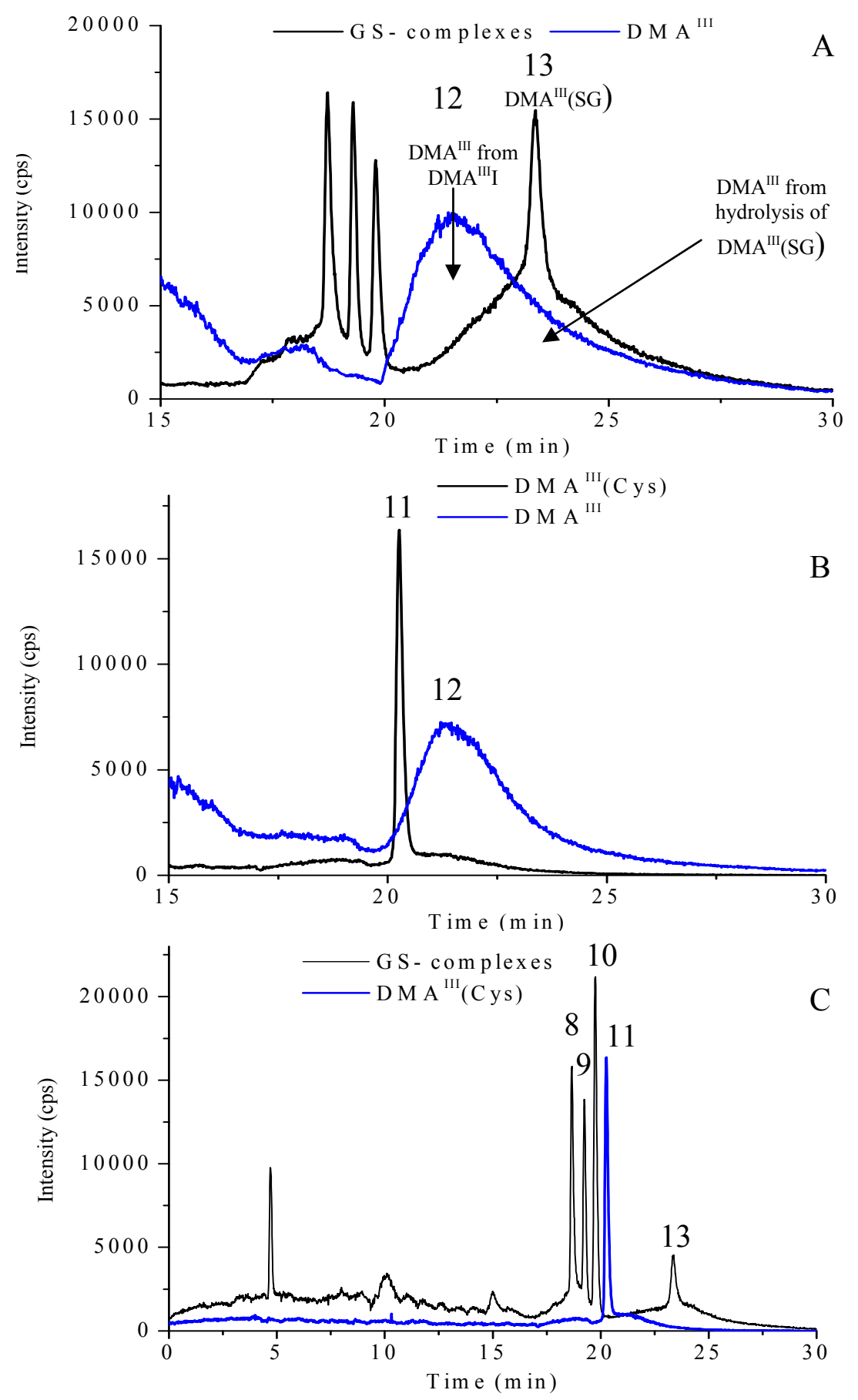

Figure 4.6 Resolution of $\mathrm{DMA}^{\mathrm{III}}$, $\mathrm{DMA}^{\mathrm{III}}(\mathrm{Cys})$, and $\mathrm{DMA}^{\mathrm{III}}(\mathrm{GS})$ demonstrated by (A) generation of $\mathrm{DMA}^{\mathrm{III}}$ during high concentration of $\mathrm{DMA}^{\mathrm{III}}(\mathrm{GS})$ injection, (B) separation of $\mathrm{DMA}^{\mathrm{III}}(\mathrm{Cys})(\# 11)$ and $\mathrm{DMA}^{\mathrm{III}} \mathrm{I}(\# 12)$, and (C) separation of $\mathrm{DMA}^{\mathrm{III}}(\mathrm{Cys})$ from AsGSH complexes. 


\subsubsection{Linearity, LOQ and LOD}

Linearity, LOQ, and LOD were determined using $\mathrm{As}^{\mathrm{III}}$ and $\mathrm{As}^{\mathrm{III}}(\mathrm{GS})_{3}$ under the optimized conditions, with a nebulizer flow consisting of $0.2 \mathrm{~L} / \mathrm{min} \mathrm{O}_{2}$ and 0.84 $\mathrm{L} / \mathrm{min}$ Ar giving a total flow of $1.04 \mathrm{~L} / \mathrm{min}$. Because $\mathrm{As}^{\mathrm{III}}$ and $\mathrm{As}^{\mathrm{III}}(\mathrm{GS})_{3}$ were two peaks eluted at low and relatively high acetonitrile $\mathrm{v} / \mathrm{v} \%$, respectively, the results obtained for these two species are indicative of the method performance for all As species. The method was found to be linear between the tested range of 1.25 to $2500 \mathrm{ppb}$ for both $\mathrm{As}$ III (Fig. 4.7) and $\mathrm{As}^{\mathrm{III}}(\mathrm{GS})_{3}$ (Fig. 4.8) with $\mathrm{r}^{2}>0.999$. Limit of detections of $\mathrm{As}^{\mathrm{III}}$ and $\mathrm{As}^{\mathrm{III}}(\mathrm{GS})_{3}$ were experimentally determined to be $1.25 \mathrm{ppb}$ with an average of signal to noise ratio $(\mathrm{S} / \mathrm{N})$ of 3 for three injections for both compounds. The limits of quantitation for $\mathrm{As}^{\mathrm{III}}$ and $\mathrm{As}^{\mathrm{III}}(\mathrm{GS})_{3}$ were experimentally found to be $2.5 \mathrm{ppb}$ for each. Though the average $\mathrm{S} / \mathrm{N}$ for three injections was only 6 for $\mathrm{As}^{\mathrm{III}}$ and 8 for $\mathrm{As}^{\mathrm{III}}(\mathrm{GS})_{3}$ (less than the customary 10), the percent relative standard deviation of the peak areas was only 4.2 for $\mathrm{As}^{\mathrm{III}}$ and 7.0 for $\mathrm{As}^{\mathrm{III}}(\mathrm{GS})_{3}$ at this concentration level, thus the LOQ concentration was set to be $2.5 \mathrm{ppb}$ for both compounds. Though the linearity ranges and the detection limits were not determined for each compound, I expect similar results for other As species. Additionally, depending on the age and condition of the ICP-MS, the type of spray chamber used, the sampling interface, and other parameters, the sensitivity of the instrument varies, thus the LOD and LOQ may vary in different laboratories and should be determined in each laboratory. 


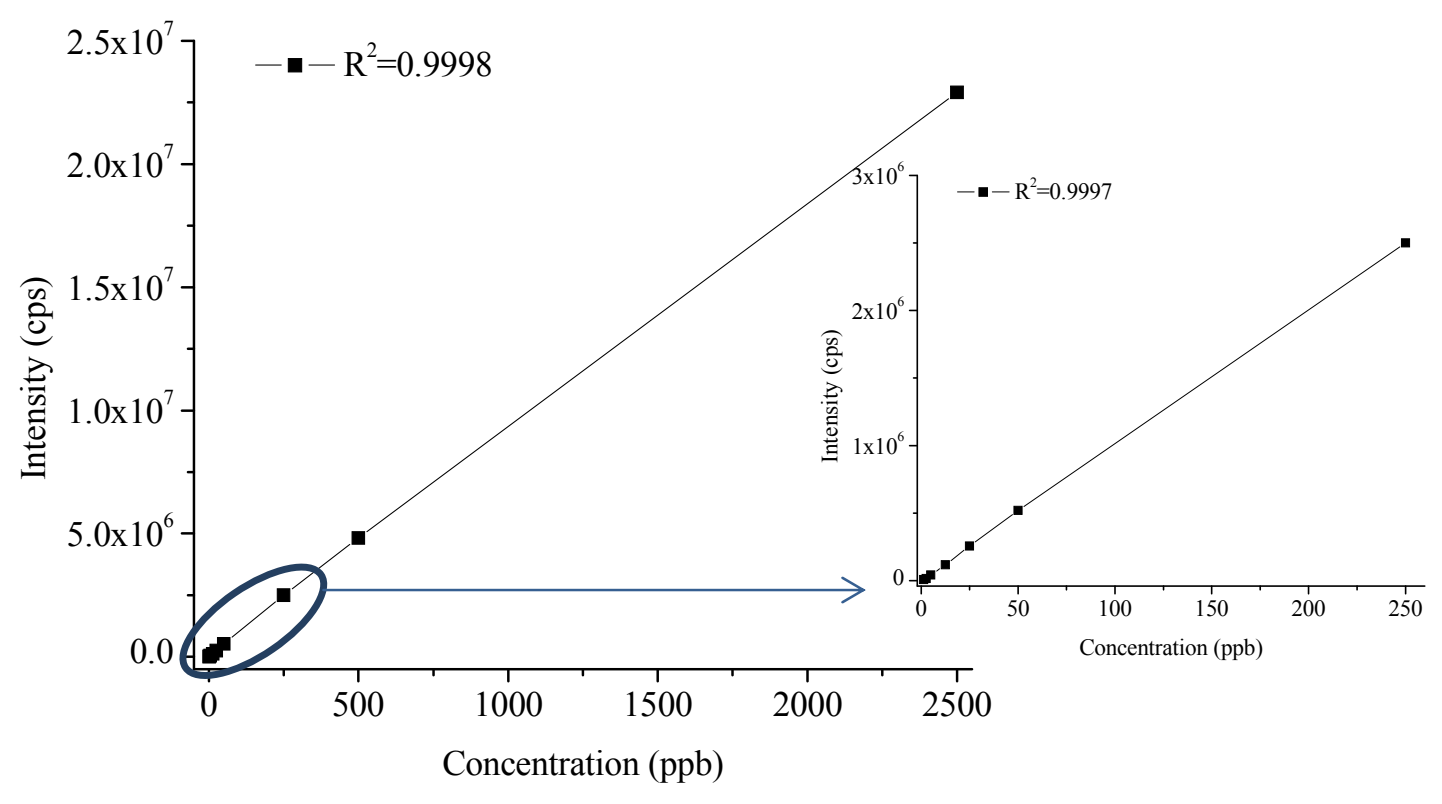

Figure 4.7 Linearity graphs for As ${ }^{\mathrm{III}}$

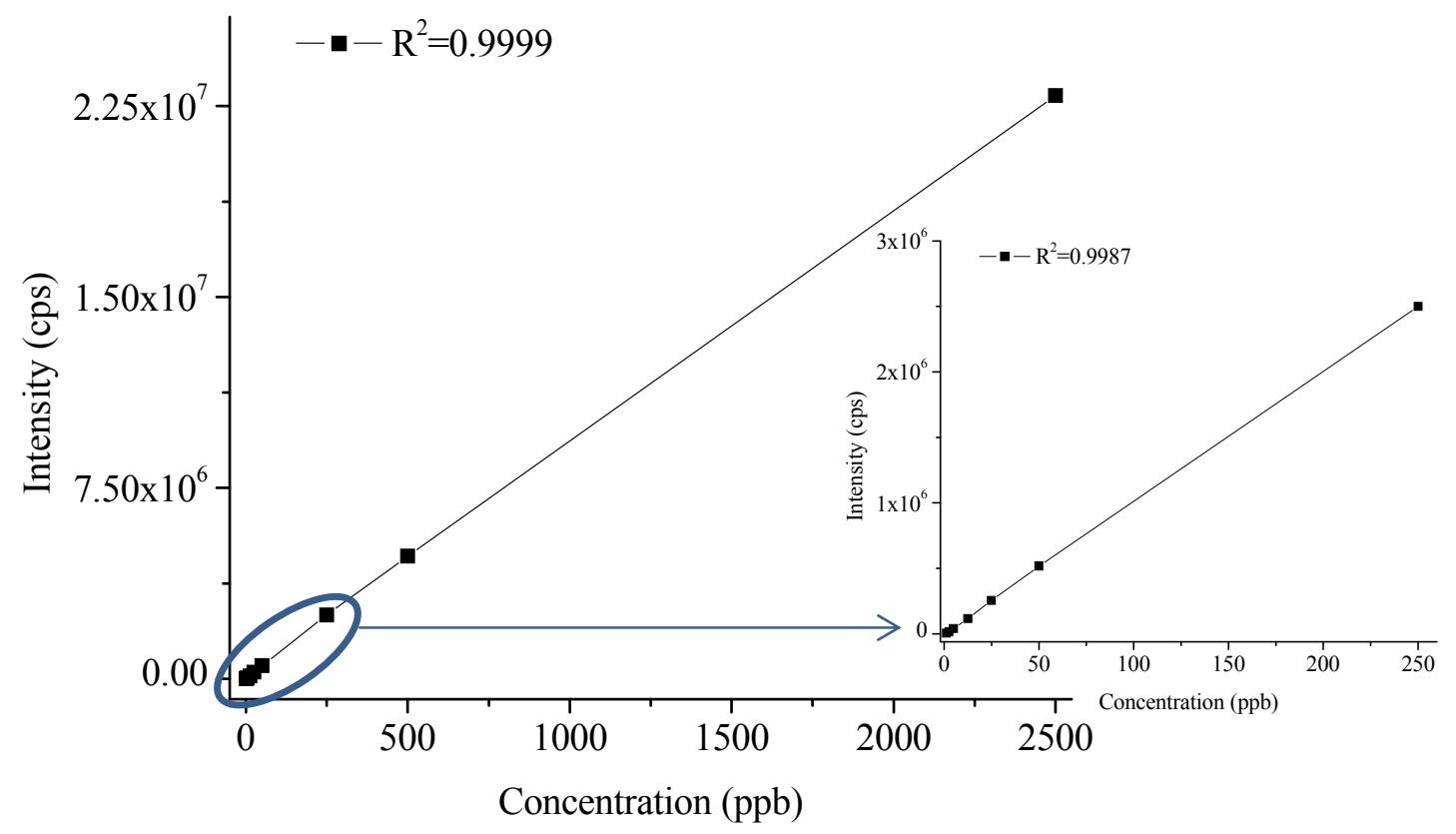

Figure 4.8 Linearity graphs for $\mathrm{As}^{\mathrm{III}}(\mathrm{GS})_{3}$ 


\subsubsection{Application of Method}

The analysis of the $8226 / \mathrm{S}$ multiple myeloma cells exposed to $\mathrm{DMA}^{\mathrm{III}}(\mathrm{GS})$ using the developed method revealed the presence of several As species (Fig. 4.9). In addition to the parent $\mathrm{DMA}^{\mathrm{III}}(\mathrm{GS})$, its dissociation product $\mathrm{DMA}^{\mathrm{III}}$ and its oxidation product $\mathrm{DMA}^{\mathrm{V}}$ were detected. The thiol-containing arsenical $\mathrm{DMMTA}^{\mathrm{V}}$ was detected, and more importantly its GSH conjugate, $\operatorname{DMMTA}^{\mathrm{V}}(\mathrm{GS})$, was found to be the major species of $\mathrm{DMA}^{\mathrm{III}}(\mathrm{GS})$ metabolism in the cells. These results suggest that thiolcontaining arsenicals may play an important role in the metabolism of $\mathrm{DMA}^{\mathrm{III}}(\mathrm{GS})$ and these thiolated arsenicals could be eventually related to the anticancer activity of $\mathrm{DMA}^{\mathrm{III}}(\mathrm{GS})$. The simultaneous determination of thiol-containing and non-thiolcontaining arsenicals (e.g., DMMTA ${ }^{\mathrm{V}}(\mathrm{GS}), \mathrm{DMMTA}^{\mathrm{V}}$, and $\mathrm{DMA}^{\mathrm{III}}$ ) demonstrates the robustness of the developed method, as a combination of two HPLC-ICP-MS methods had to be used to run the same sample twice for the separation of the metabolites of interest in our previous studies. Even running both previous methods (on two different columns) could not separate all possible As intermediates during Darinaparsin metabolism, as the missing of $\mathrm{DMMTA}^{\mathrm{V}}$ in the previous studies indicates. It was also observed that the method developed had better resolution of As species separation. 


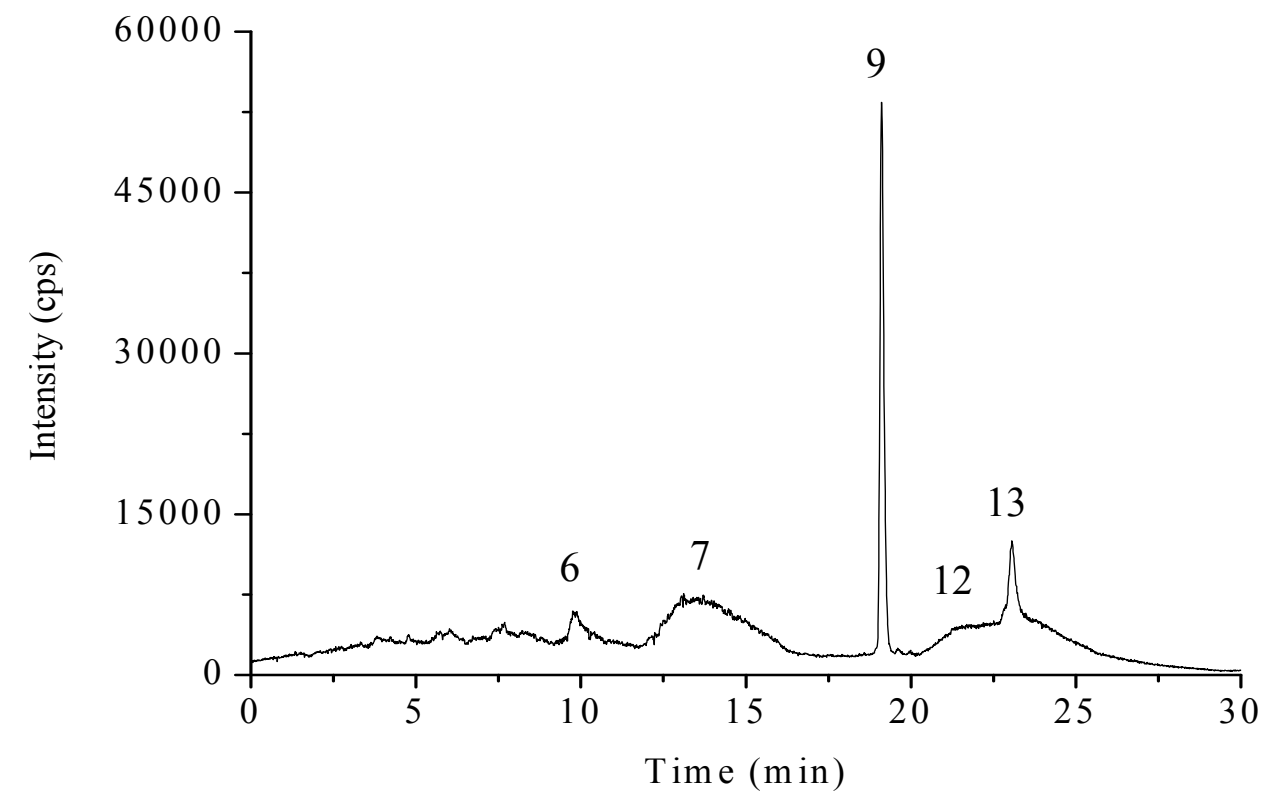

Figure 4.9. Results of human cells analysis using the developed method after incubation with Darinaparsin. The compounds separated are as follows: 6. DMMTA ${ }^{\mathrm{V}}, 7 . \mathrm{DMA}^{\mathrm{V}}, 9$. $\operatorname{DMMTA}^{\mathrm{V}}(\mathrm{GS})$, 12. DMA ${ }^{\mathrm{III}}, 13 . \mathrm{DMA}^{\mathrm{III}}(\mathrm{GS})$

\subsubsection{Potentials and Problems}

The HPLC separation method developed in this study can be used for ICP-MS (as reported here) or ESI-MS detection, as the mobile phases used in the HPLC separation are compatible with ESI-MS. It is possible to use the separation method on ESI-MS for the identification of unknown arsenic species, with the flow rate of mobile phase being adjusted to $0.5 \mathrm{~mL} / \mathrm{min}$ during equilibration and the equilibration time being extended as a result of the reduced flow rate. Fortunately, these changes during equilibration stage will not affect chromatographic separation of arsenic species. This dual suitability of the separation method for both ICP-MS and ESI-MS can help us in the unequivocal identification of arsenic species. It should be noted that not all arsenic 
species could be easily detected on ESI-MS, as some arsenic species do not have high ionization efficiency and/or could get oxidized during the electrospray ionization stage.

When identifying and quantifying arsenic metabolites, the unavailability of some species as stable high purity standards poses a significant problem. $\mathrm{As}^{\mathrm{III}}, \mathrm{As}^{\mathrm{V}}$, $\mathrm{MMA}^{\mathrm{III}}, \mathrm{MMA}^{\mathrm{V}}, \mathrm{DMA}^{\mathrm{V}}, \mathrm{As}^{\mathrm{III}}(\mathrm{GS})_{3}$ (in solution), $\mathrm{MMA}^{\mathrm{III}}(\mathrm{GS})_{2}$ (in solution), $\mathrm{DMA}^{\mathrm{III}}(\mathrm{Cys})$ (in solution), DMA ${ }^{\mathrm{III}}(\mathrm{GS})$, can be purchased or synthesized as high purity standards, but DMDTA ${ }^{\mathrm{V}}, \mathrm{DMMTA}^{\mathrm{V}}, \mathrm{DMA}^{\mathrm{III}}$, and DMMTA ${ }^{\mathrm{V}}(\mathrm{GS})$ cannot, making the quantification of these species difficult. For example, DMA ${ }^{\mathrm{III}}$ has the high capacity of being oxidized to $\mathrm{DMA}^{\mathrm{V}}$ without the presence of relatively high concentrations of GSH or when exposed to oxygen, so it is difficult to accurately quantify this species. However, it is also difficult to detect $\mathrm{DMA}^{\mathrm{III}}$ in the presence of GSH, as in this case DMA ${ }^{\mathrm{III}}$ is present in the form of $\mathrm{DMA}^{\mathrm{III}}(\mathrm{GS})$ and not as free $\mathrm{DMA}^{\mathrm{III}}$.

\subsection{Conclusions}

An HPLC-ICP-MS method was developed and optimized in an attempt to analyze for the above mentioned thirteen confirmed and plausible human arsenic metabolites and intermediates of As metabolism in one chromatographic run. Results showed that while it is difficult to separate all these species as a consequence of their very different chemical properties, it is indeed achievable. The HPLC-ICP-MS technique described here is applicable to (or suitable for) the analysis of these arsenic metabolites from cells as demonstrated with the incubation experiments of human cancer cells with DMA ${ }^{\mathrm{III}}(\mathrm{GS})$.

While ICP-MS is supposed to be element specific, significant baseline disturbance was observed resulting from the high acetonitrile $\mathrm{v} / \mathrm{v} \%$ present in the gradient elution 
program. Adjustment of Ar nebulizer flow rate could reduce the problem. Under optimum conditions the detection limits were experimentally shown to be $1.25 \mathrm{ppb}$ and the quantitation limit $2.5 \mathrm{ppb}$. The method was found to be linear between the tested ranges of 1.25 to $2500 \mathrm{ppb}$. This method is also suitable for use on HPLC-ESI-MS for the identification of unknown arsenic metabolites. 


\section{CHAPTER 5}

Mechanistic Study on the Formation of Dimethylarsinothioyl Glutathione and Other Sulfur Containing Arsenic Metabolites

Part of this chapter has been submitted to Chemical Research in Toxicology for publication. 


\subsection{Graphical Abstract}

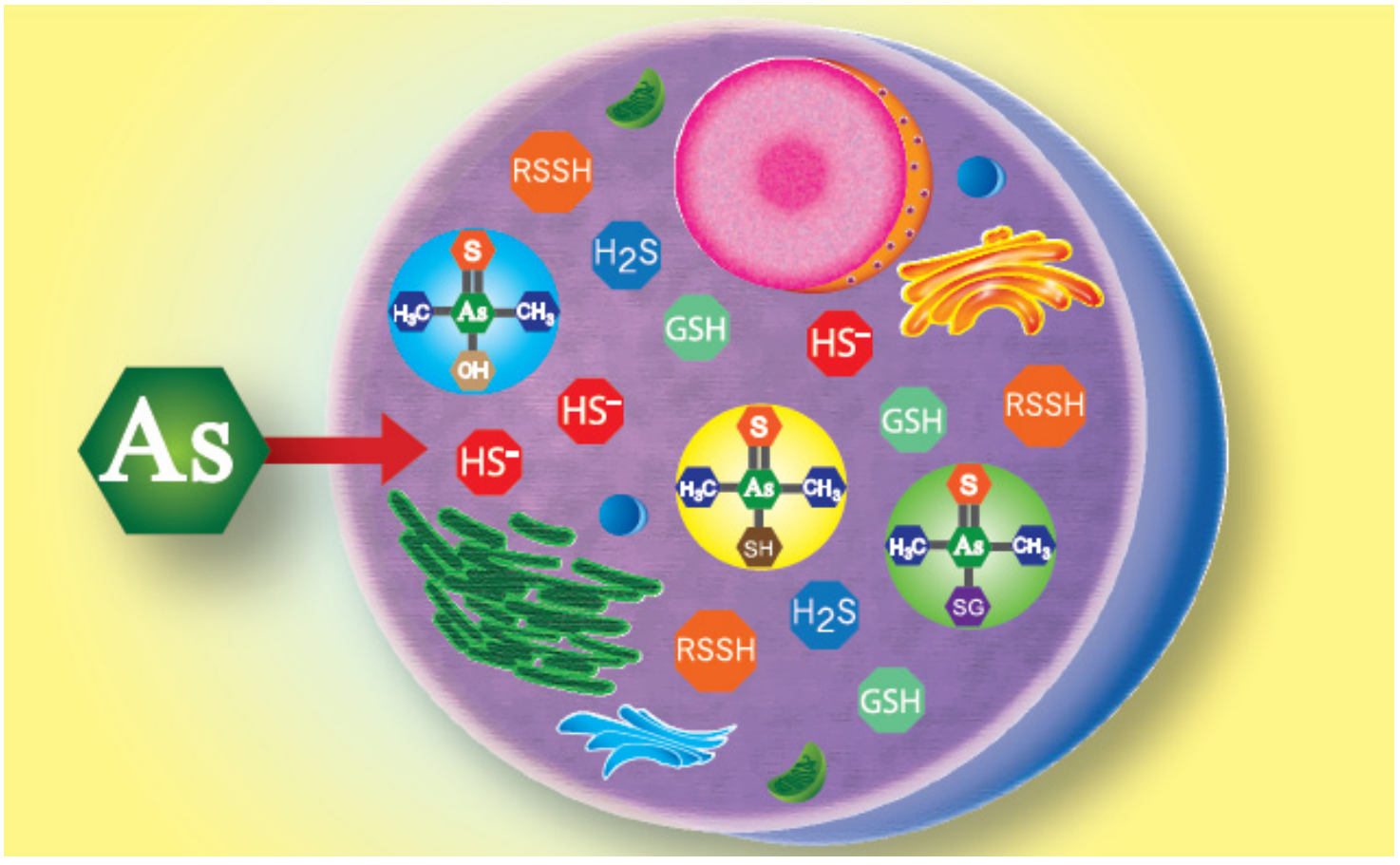

\subsection{Abstract}

While in general arsenic (As) compounds are highly toxic carcinogens, they may also possess strong and unique antineoplastic properties. The toxicity and the potential beneficial therapeutic efficacy of arsenicals depend on the form of arsenical present and their metabolism. Arsenic-containing chemicals are extensively metabolized in mammals. During biotransformation metabolites with toxicity higher than the parent compound may form. While generally pentavalent arsenic xenobiotics are less toxic than trivalent ones, pentavalent thiolated arsenic metabolites may possess unusually high toxicity. Until now, the mechanism and the conditions of the formation of these noxious sulfur-containing arsenicals have not yet been fully deciphered. Moreover, the source of sulfur and the form of sulfur utilized in these reactions have been highly debated. In the course of my 
research I investigated the possible mechanisms and conditions of formation of these noxious species. I found that under physiological conditions $(\mathrm{pH}$ and glutathione concentrations (GSH)) both dimethylmonothioarsinic acid $\left(\right.$ DMMTA $\left.^{\mathrm{V}}\right)$ and dimethyldithioarsinic acid $\left(\mathrm{DMDTA}^{\mathrm{V}}\right)$ easily form from dimethylarsinic acid $\left(\mathrm{DMA}^{\mathrm{V}}\right)$ and dimethylarsinous glutathione (DMA ${ }^{\mathrm{III}}(\mathrm{GS})$, Darinaparsin), the chemotherapeutic agent under investigation in our lab. I have found that there are different pathways through which DMMTA ${ }^{\mathrm{V}}$ may form. The conditions of formation of the newly discovered human metabolite of $\mathrm{DMA}^{\mathrm{III}}(\mathrm{GS})$ dimethylarsinothioyl glutathione $\left(\operatorname{DMMTA}^{\mathrm{V}}(\mathrm{GS})\right)$ were determined as well. It was observed that under physiological $\mathrm{pH}$ and GSH concentrations $\operatorname{DMMTA}^{\mathrm{V}}(\mathrm{GS})$ only forms to a very minimal extent nonenzymatically. Attempts to find the enzyme that may catalyze its formation were carried out. Additionally, the form $\left(\mathrm{H}_{2} \mathrm{~S}, \mathrm{HS}^{-}\right.$, or $\left.\mathrm{S}^{2-}\right)$ and the source of sulfur $\left(\mathrm{H}_{2} \mathrm{~S}\left(3 / 4^{\text {th }}\right.\right.$ present as $\mathrm{HS}^{-}$at $\mathrm{pH}$ 7.4) produced as a byproduct of metabolism or liberated from protein persulfides (R-S-S-H)) utilized for these reactions were studied.

\subsection{Introduction}

The metabolic pathways involved in the biotransformation of arsenic compounds are still highly debated though this knowledge is necessary to understand the mechanisms of arsenic toxicity and the therapeutic efficacy of As-containing medicinal preparations. The most common mammalian arsenic metabolites reported are arsenite $\left(A s^{\mathrm{III}}\right)$, arsenate $\left(\mathrm{As}^{\mathrm{V}}\right)$, monomethylarsonous acid $\left(\mathrm{MMA}^{\mathrm{III}}\right)$, monomethylarsonic acid $\left(\mathrm{MMA}^{\mathrm{V}}\right)$, dimethylarsinous acid (DMA ${ }^{\mathrm{III}}$ ), and dimethylarsinic acid (DMA $\left.{ }^{\mathrm{V}}\right)$. Additionally, sulfurcontaining pentavalent arsenic metabolites such as monomethylmonothioarsonic acid 
$\left(\right.$ MMMTA $\left.^{\mathrm{V}}\right)$, dimethylmonothioarsinic acid $\left(\mathrm{DMMTA}^{\mathrm{V}}\right)$, and dimethyldithioarsinic acid $\left(\right.$ DMDTA $^{\mathrm{V}}$ ) were also detected. ${ }^{10,11,14,25,35,36,114,155}$ Interestingly, while in general trivalent arsenic compounds are more toxic than their pentavalent counterparts, DMMTA $^{\mathrm{V}}$ has been shown to be unusually highly toxic for a pentavalent species. ${ }^{10-13,98}$ According to Watanabe, the toxicity of DMMTA ${ }^{\mathrm{V}}$ is comparable to that of MMA ${ }^{\mathrm{III}}$, whereas Bartel et al. reported lesser (approximately $1 / 2$ ) toxicity compared to MMA ${ }^{\mathrm{III}}$ in human lung cells. ${ }^{14,15}$ While its toxicity was found to be similar to DMA ${ }^{\mathrm{III}}$, which is even more toxic than $\mathrm{MMA}^{\mathrm{III}}$, in epidermoid carcinoma cells, DMMTA ${ }^{\mathrm{V}}$ was found to be less cytotoxic than dimethylarsinous glutathione $\left(\mathrm{DMA}^{\mathrm{III}}(\mathrm{GS})\right)$ in human lung adenocarcinoma epithelium cells. ${ }^{13,16}$ Compared to $\mathrm{DMA}^{\mathrm{V}}$, the corresponding nonthiolated pentavalent species, DMMTA ${ }^{\mathrm{V}}$ was found to be about 10 -fold more cytotoxic in HepG2 cells derived from human hepatocarcinoma and approximately 80 times more toxic in epidermoid cells. ${ }^{11,13}$

Dimethylmonothioarsinic acid $\left(\mathrm{DMMTA}^{\mathrm{v}}\right)$ is highly reactive with thiol compounds, which is very unusual for a pentavalent arsenical. Up until now, the form and the source of sulfur utilized for the formation of DMMTA ${ }^{\mathrm{V}}$ and $\mathrm{DMDTA}^{\mathrm{V}}$ in human and animal cells remain unclear. One possible source of sulfide is hydrogen sulfide enzymatically generated in the body with the help of cystathionine beta synthase (CBS) and cystathionine gamma lyase (CSE) from the metabolism of cysteine and homocysteine along with other enzymatic processes. ${ }^{156-159}$ The true concentration level of $\mathrm{H}_{2} \mathrm{~S}$ in cells is highly debated and varies over a $10^{5}$-fold concentration range in different reports; therefore its importance for the production of $\mathrm{DMMTA}^{\mathrm{V}}$ and other sulfur-containing compounds cannot be accurately estimated. ${ }^{158,159}$ In red blood cells it was proposed that 
the source of sulfur may be sulfane sulfur. ${ }^{35,107}$ Sulfane sulfur has the ability to reversibly attach to other sulfur atoms and it is attached to proteins as persulfide (R-S-S-H) or trisulfide. ${ }^{160}$ According to Mueller, it is protein persulfide groups rather than the noxious bisulfide that is the major source of sulfide for the biosynthesis of many biomolecules. ${ }^{161}$ Moreover, it is estimated that the formation of persulfides in cells is prevalent; approximately $10-25 \%$ of many hepatic proteins are sulfhydrated under physiological conditions and sulfhydration appears to be a common physiologic posttranslational modification of proteins. ${ }^{162,163}$ Consequently, it is very plausible that the sulfur may come from persulfides of biomolecules in the presence of reducing agents, such as GSH, that can liberate $\mathrm{HS}^{-}$from protein persulfides.

Trivalent arsenic-glutathione complexes such as $\mathrm{As}(\mathrm{GS})_{3}, \mathrm{MMA}(\mathrm{GS})_{2}$, and DMA(GS) have also been reported to be the products of As biotransformation. ${ }^{34,100}$ The existence of these complexes are not surprising knowing that trivalent arsenic species have high affinity for thiols and the thiol-containing GSH can be present in high concentrations, up to $10 \mathrm{mM}$, in the cells. Conjugation of GSH decreases sensitivity to these compounds and promotes their efflux from the cells. According to estimates, a very high percentage of trivalent arsenic species are bound to glutathione inside the cells. ${ }^{31,100}$ Kala et al. estimated that $60-70 \%$ of As may be present as GSH-conjugate $\left(\mathrm{As}(\mathrm{GS})_{3}\right.$ and $\left.\operatorname{MMA}(\mathrm{GS})_{2}\right)$ in the kidneys of mice, but it is catabolized by the enzyme $\gamma$-glutamyl transpeptidase in the microvilli of the proximal tubules of the kidney. ${ }^{31}$ Moreover, 80 $90 \%$ of the total arsenic excreted in the bile is also GSH conjugated. ${ }^{105}$ On the basis of observations, As-glutathione conjugates are the transported forms and account for the majority of excreted arsenic. ${ }^{100}$ This is not surprising as the addition of GSH to a 
molecule during metabolism is said to provide a molecular 'flag' that promotes the removal of the xenobiotic from cells. ${ }^{106}$ However, others theorize that the trivalent species are mostly protein-bound and are not present as GSH-conjugates and possess higher affinities to bind to proteins than to glutathione. ${ }^{1,107-109}$

For the first time in human cancer cell lines, our laboratory have reported the presence of dimethylarsinothioyl glutathione $\left(\operatorname{DMMTA}^{\mathrm{V}}(\mathrm{GS})\right)$ as a metabolite of dimethylarsino glutathione (Darinaparsin, ZIO-101, DAR, DMA $\left.{ }^{\mathrm{III}}(\mathrm{GS})\right){ }^{34}$ This compound has only been seen in cabbage before. ${ }^{112}$ The toxicity of this compound, thus its role in the detoxification of $\mathrm{DMA}^{\mathrm{III}}(\mathrm{GS})$, and the ability of multiple myeloma cell lines to take DMMTA ${ }^{\mathrm{V}}(\mathrm{GS})$ up was evaluated. DMMTA ${ }^{\mathrm{V}}(\mathrm{GS})$ was found to be much less toxic than DMA ${ }^{\mathrm{III}}(\mathrm{GS})$ and DMMTA ${ }^{\mathrm{V}}$, probably as a consequence of its very limited uptake (less than $10 \%$ and $16 \%$ of $\mathrm{DMA}^{\mathrm{III}}(\mathrm{GS})$ and DMMTA ${ }^{\mathrm{V}}$ respectively).

The precursor of $\operatorname{DMMTA}^{\mathrm{V}}(\mathrm{GS})$ is thought to be DMMTA ${ }^{\mathrm{V}}$. Theoretical calculations indicate that the conjugation of DMMTA ${ }^{\mathrm{V}}$ with GSH is exothermal, though these calculations did not take the effect of $\mathrm{pH}$ into calculation and used methanethiol $\left(\mathrm{CH}_{3} \mathrm{SH}\right)$ instead of GSH to shorten calculation time. ${ }^{135}$ Previous formation studies conducted in our lab in human cancer cells showed the presence of this metabolite even at $\mathrm{pH} 7.4$ and its stability upon extraction between $\mathrm{pH} 3$ to $7.4 .{ }^{34}$ Heat deactivation of the enzymes prevented its formation indicating the possibility that at $\mathrm{pH} 7.4$ (under physiological $\mathrm{pH}$ ) it forms in an enzymatic reaction. According to Suzuki above $\mathrm{pH} 7$, in the presence of glutathione, no $\operatorname{DMMTA}^{\mathrm{V}}(\mathrm{GS})$ forms from $\mathrm{DMMTA}^{\mathrm{V}}$ in the absence of cellular material. ${ }^{135}$ As our previous results showed the formation of substantial amounts of this metabolite within ten minutes in the presence of cells, it further indicates that it is 
probably mostly produced in enzymatic reactions. It is also possible that $\operatorname{DMMTA}^{\mathrm{V}}(\mathrm{GS})$ forms in acidic organelles in intact cells. The enzyme suspected to help its formation is glutathione S-transferase (GST). GSTs form three superfamilies: the cytosolic, mitochondrial, and microsomal GSTs that are further divided into classes on the basis of their structures. Glutathione transferases have the ability to inactivate toxic compounds thus play important roles in the detoxification of noxious chemicals that are cytotoxic and genotoxic. Moreover, glutathione conjugation flags the molecule for removal. While the ability of GSTs to aid in the removal of toxic chemicals is beneficial to the organism, in cancer therapy in the tumor cells, it is a potential problem to the host. Tumors may overexpress GSTs and increase their ability to conjugate GST significantly resulting in acquired resistance to chemotherapeutic agents. ${ }^{164}$ On the other hand, while xenobiotics may initially be detoxified by conjugation with GSH with the help of GSTs, the initial toxic compound can be regenerated spontaneously. I examined if human microsomal and cytosolic GSTs may catalyze the formation of $\operatorname{DMMTA}^{\mathrm{V}}(\mathrm{GS})$, but did not look at mitochondrial GSTs or other enzymes or proteins at this time. Human cytosolic class pi GST, widely distributed in tissues, was tested individually to examine if it can catalyze the conjugation of GSH to DMMTA ${ }^{\mathrm{V}}$.

Moreover, I conducted experiments to determine the conditions of formation and the mechanism of formation of DMMTA ${ }^{\mathrm{V}}$, DMDTA ${ }^{\mathrm{V}}, \mathrm{DMA}^{\mathrm{III}}, \mathrm{DMA}^{\mathrm{III}}(\mathrm{GS})$, and $\operatorname{DMMTA}^{\mathrm{V}}(\mathrm{GS})$ from DMA ${ }^{\mathrm{V}}$ and DMA ${ }^{\mathrm{III}}(\mathrm{GS})$, the form $\left(\mathrm{H}_{2} \mathrm{~S}, \mathrm{HS}^{-}\right.$, or $\left.\mathrm{S}^{2-}\right)$ and the source of sulfur involved in the generation of thioarsenicals (sulfane sulfur (protein persulfides in particular) or $\mathrm{H}_{2} \mathrm{~S}$ produced during metabolism). Previous studies investigating $\mathrm{H}_{2} \mathrm{~S}$ reactions with dimethylated arsenicals used directly bubbling gaseous $\mathrm{H}_{2} \mathrm{~S}$ or addition of 
sodium sulfide (or sodium hydrosulfide) as a means of producing $\mathrm{H}_{2} \mathrm{~S}$. These methods will produce $\mathrm{H}_{2} \mathrm{~S}$ in a large, rapid bolus and thus it remains a question as to how well this simulates the physiological condition with regards to the kinetics and concentrations of $\mathrm{H}_{2} \mathrm{~S}$ release. The resulting $\mathrm{pH}$ in the cases of sodium (hydro)sulfide and hydrogen sulfide cannot mimic physiological condition. In this study, I used a recently reported slowreleasing $\mathrm{H}_{2} \mathrm{~S}$ donor, GYY4137 (morpholin-4-ium 4 methoxphenyl (morpholino) phosphinodithionate) which has been shown to slowly release $\mathrm{H}_{2} \mathrm{~S}$ both in vitro and in vivo to produce $\mathrm{H}_{2} \mathrm{~S}$ creating a reaction environment milder and more closely relevant to physiological conditions. ${ }^{165}$ The reaction producing hydrogen sulfide from GYY4137 is depicted in Figure 5.1. In order to investigate the ability of arsenic to react with protein persulfides to form thiolated arsenicals, I employed glutathione persulfide (GSSH) as a simple model molecule for protein persulfides.

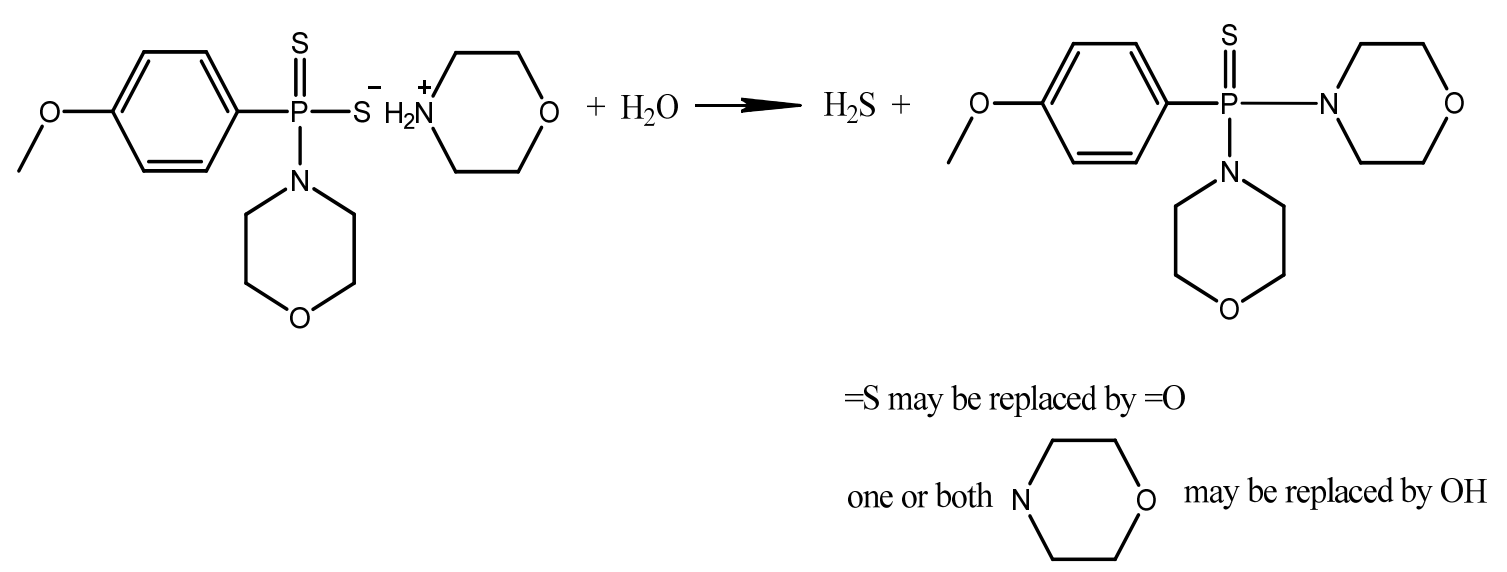

Figure 5.1 Proposed reaction involved in the production of $\mathrm{H}_{2} \mathrm{~S}$ from GYY4137 


\subsection{Experimental}

Caution: The arsenic species included in this study are toxic and are potential human carcinogens; therefore, they should be handled with great care.

\subsubsection{Reagents and Standards}

All reagents used were of analytical grade or better. Argon (Ar) purged double deionized water (DDIW) (18 M $\Omega$ Barnstead Nanopure Diamond) was used throughout the experiments. Acetonitrile a component of the mobile phase, potassium dihydrogen phosphate $\left(\mathrm{KH}_{2} \mathrm{PO}_{4}\right)$ used to prepare potassium phosphate buffer ( $\mathrm{pH} 6.5,7.0$ and 7.4), ammonium hydroxide $\left(\mathrm{NH}_{4} \mathrm{OH}\right)$, potassium hydroxide $(\mathrm{KOH})$, and nitric acid $\left(\mathrm{HNO}_{3}\right)$ used for $\mathrm{pH}$ adjustments were purchased from Thermo Fisher Scientific, USA. Sulfuric acid used for the synthesis of DMMTA ${ }^{\mathrm{V}}$, along with tris(2-Carboxyethyl)-Phosphine Hydrochloride (TCEP-HCl), dithiothreitol (DTT), and morpholine were also acquired from Fisher Scientific, USA. 4-(2-hydroxyethyl)-1-piperazineethanesulfonic acid (HEPES), 2-(N-morpholino)ethanesulfonic acid (MES), and ethylenediaminetetraacetic acid (EDTA) used for buffer preparation were all purchased from Sigma-Aldrich, USA along with L-glutathione reduced (GSH), cysteine, Glutathione S-Transferase from human placenta (catalog \# G8642), trifluoroacetic acid (TFA) used in aqueous mobile phase component, cacodylic acid $\left(\mathrm{DMA}^{\mathrm{V}}\right)$, 5,5'-dithiobis-2-nitrobenzoic acid (Ellman's reagent, DTNB), 2,4-bis(4-methoxyphenyl)-2,4-dithioxo-1,3,2,4-dithiadiphosphetane (Lawesson's reagent), anhydrous sodium sulfide, and sodium hydrosulfide hydrate. Lglutathione oxidized (98\%, GSSG) and formic acid (FA) used to prepare formate buffer $\left(\mathrm{pH}\right.$ 3.0) were purchased from Acros Organics. Deuterium oxide $\left(\mathrm{D}_{2} \mathrm{O}\right)$ and methanol-D4 used for NMR studies were acquired from Cambridge Isotope laboratories, Inc. 
Darinaparsin $\left(\mathrm{DMA}^{\mathrm{III}}(\mathrm{GS})\right)$ was obtained from Ziopharm Oncology, Boston, MA. Purified human pi GST was provided by Dr Barry Rosen's lab, Florida International University, FL. The protein sequence of the $24 \mathrm{KDa}$ enzyme was GQLPKFQDGDLTLYQSNTILRHLGRTLGLYGKDQQEAALVDMVNDGVED LRCKYISLIYTNYEAGKDDYVKALPGQLKPFETLLSQNQGGKTFIVGDQISFADY NLLDLLLIHEVLAPGCLDAFPLLSAYVGRLSARPKLKAFLASPEYVNLPINGNGK Q HHHHHH.

\subsubsection{Synthesis and Identification of DMMTA ${ }^{\mathrm{V}}$}

Dimethylmonothioarsinic acid $\left(\mathrm{DMMTA}^{\mathrm{v}}\right)$ was prepared by reacting $\mathrm{DMA}^{\mathrm{V}}$ with sodium sulfide $\left(\mathrm{Na}_{2} \mathrm{~S}\right)$ and sulfuric acid $\left(\mathrm{H}_{2} \mathrm{SO}_{4}\right)$ in DDIW according to previously reported method with slight modification. ${ }^{10}$ Unlike the reference, I did not purify DMMTA $^{\mathrm{V}}$ by extracting it into diethyl ether at the end. The mol ratio of As: $\mathrm{Na}_{2} \mathrm{~S}: \mathrm{H}_{2} \mathrm{SO}_{4}$ was 1:1.6:1.6. DMMTA ${ }^{\mathrm{V}}$ was aliquoted and stored in argon purged HPLC glass vials at $11^{\circ} \mathrm{C}$. Formation of DMMTA ${ }^{\mathrm{V}}$ was confirmed with the help of high performance liquid chromatography electrospray ionization mass spectrometry (HPLC-ESI-MS) in the positive mode. A peak with an $\mathrm{m} / \mathrm{z}$ value of 155 , corresponding to the protonated form of DMMTA $^{\mathrm{V}}$, was obtained confirming species identity.

5.4.3 Synthesis, Identification, and Activity Assessment of GYY4137 (a Slow Hydrogen Sulfide $\left(\mathrm{H}_{2} \mathrm{~S}\right)$ Releaser)

Synthesis of GYY4137 (FW 376.47) was conducted at room temperature following reported procedures with modifications. ${ }^{165}$ Briefly, morpholine $(20 \mathrm{mmol})$ in methylene chloride $\left(\mathrm{CH}_{2} \mathrm{Cl}_{2}, 36 \mathrm{~mL}\right)$ was added dropwise to a $\mathrm{CH}_{2} \mathrm{Cl}_{2}$ solution $(12 \mathrm{~mL})$ 
of 4 mmol 2,4-bis(4-methoxyphenyl)-2,4-dithioxo-1,3,2,4-dithiadiphosphetane (Lawesson's reagent). The reaction is depicted in Figure 5.2. The mixture was then stirred for 2 hours at room temperature. The precipitate formed was filtered and washed several times with $\mathrm{CH}_{2} \mathrm{Cl}_{2}$, to obtain a white solid that was dried under vacuum.

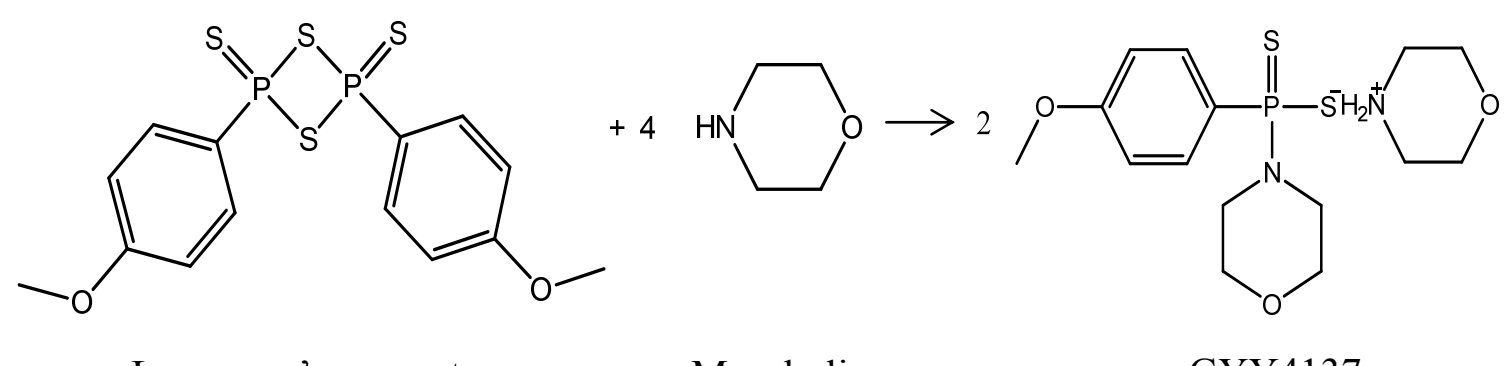

Lawesson's reagent

Morpholine

GYY4137

Figure 5.2 Reaction involved in the synthesis of GYY4137

1H NMR, IR, and melting point determination were used to identify and characterize GYY4137 and were compared to those found in the literature. $161-164^{\circ} \mathrm{C}$ (performed in triplicate) were obtained during melting point determination that corresponded with the previously reported 160 to $164^{\circ} \mathrm{C}$. Formerly, the IR data of GYY4137 found in the literature merely consisted of three wavenumber values and no assignment of these numbers to corresponding functional groups was carried out. I obtained the full IR spectrum and attempted to assign the wavenumbers to functional groups to confirm the formation of GYY4137. The IR spectrum is presented in Figure 5.3 and IR data interpretation in Table 5.1. The data confirmed the successful synthesis of GYY4137. The H-NMR chemical shift values of GYY4137 found in the literature were reported in acetone-D6. When I first tried to obtain the NMR spectra I have noticed that GYY4137 had an extremely low solubility in this solvent and the resulting spectra were 
very poor in quality. As a result, I used a solution of $\mathrm{D}_{2} \mathrm{O}$ : Acetone-D6 1:4 v/v mix to obtain the NMR characteristics of my compound. The sample was analyzed within five minutes of preparation to retard the formation of $\mathrm{H}_{2} \mathrm{~S}$ and other degradation products. The chemical shift values were referenced to acetone-D6. The values obtained by us corresponded well to the chemical shift values reported in the literature and to those predicted by MestReNova software further confirming the identity of GYY4137. This data is presented in Table 5.2.

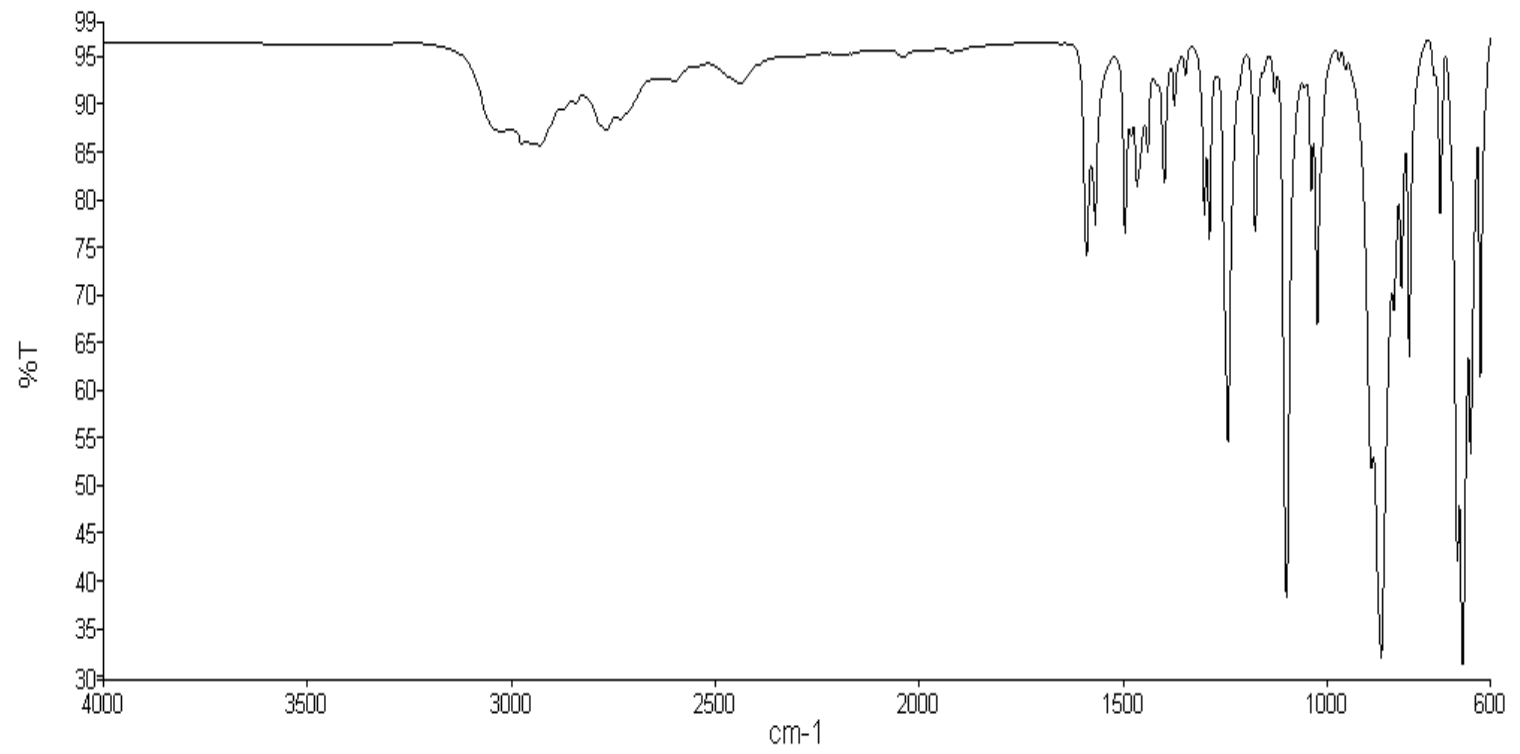

Figure 5.3 IR spectra of GYY4137 
Table 5.1 Infrared spectroscopy results for GYY4137

\begin{tabular}{|c|c|c|}
\hline Literature* & Our & \multirow{3}{*}{$I^{* * *}$} \\
\hline \multicolumn{2}{|c|}{ values $\left(\mathrm{cm}^{-1}\right)$} & \\
\hline film & neat powder & \\
\hline NR & $\begin{array}{l}3200-2600 \\
\text { (very broad) }\end{array}$ & May indicate N-H stretch \\
\hline $3019^{*}$ & 3030 & Indicates $\mathrm{sp}^{3} \mathrm{C}-\mathrm{H}$ stretch \\
\hline \multirow{5}{*}{ NR } & 2932 (very broad) & Indicates $\mathrm{sp}^{3} \mathrm{C}-\mathrm{H}$ stretch \\
\hline & $2768 \& 2440$ & May indicate $\mathrm{S}$ and/or $\mathrm{P}(?)$ \\
\hline & $\begin{array}{l}1590 \& 1568 \\
\& 1496\end{array}$ & $\begin{array}{l}\text { Aromatic } \mathrm{C}=\mathrm{C} \text { stretch is in the } 1600 \text { to } 1475 \\
\text { region and N-H bend above } 1550\end{array}$ \\
\hline & 1466 & $-\mathrm{CH}_{2}$ - bend \\
\hline & 1399 & $-\mathrm{CH}_{3}$ - bend \\
\hline $1215^{*}$ & 1243 & Aromatic C-O stretch (Phenyl-O-alkyl) \\
\hline \multirow{4}{*}{ NR } & 1177 & Not assigned \\
\hline & 1099 (strong) & $\mathrm{C}-\mathrm{O}$ and/or $\mathrm{C}-\mathrm{N}$ stretch \\
\hline & 1024 & Phenyl-O-alkyl \\
\hline & 867 (strong band) & Para substituted aromatic ring \\
\hline $756^{*}$ & 799 & $\begin{array}{l}=\mathrm{C}-\mathrm{H} \text { aromatics or N-H } \\
\text { (out-of-plane bend for both) }\end{array}$ \\
\hline NR & 668 (strong) & $\mathrm{N}-\mathrm{H}$ oop \\
\hline
\end{tabular}

NR: Not Reported

*Peaks were not assigned to corresponding functional groups in the literature

**Peaks assigned in our lab

Table 5.2 1H NMR results of GYY4137

\begin{tabular}{|c|c|c|c|}
\hline 1H NMR & Literature $\delta$ & $\begin{array}{l}\text { Predicted by } \\
\text { MestReNova }\end{array}$ & Our results \\
\hline $\mathrm{s}, \mathrm{NH}_{2}$ & & 9.69 & 5.60 \\
\hline $\mathrm{m}, 2 \mathrm{H}$, aromatic $\mathrm{CH}$ & 8.03 to 8.11 & 7.25 & 7.82 to 8.00 \\
\hline $\mathrm{m}, 2 \mathrm{H}$, aromatic $\mathrm{CH}$ & 6.88 to 6.90 & 6.90 & 6.70 to 6.78 \\
\hline \multirow[t]{2}{*}{$\mathrm{m}, 4 \mathrm{H}, \mathrm{CH}$} & 3.94 & 4.26 & 3.95 to 3.97 \\
\hline & & & 3.90 \\
\hline $\mathrm{s}, \mathrm{CH}_{3}$ & 3.82 & 3.80 & 3.78 \\
\hline $\mathrm{m}, 4 \mathrm{H}, \mathrm{CH}$ & 3.50 to 3.53 & 3.50 & 3.40 to 3.43 \\
\hline $\mathrm{m}, 4 \mathrm{H}, \mathrm{CH}$ & 3.36 to 3.40 & 3.07 & \\
\hline $\mathrm{Dd}$ & 2.87 to 2.92 & & \\
\hline $\mathrm{m}, 4 \mathrm{H}, \mathrm{CH}$ & 2.04 to 2.09 & & \\
\hline
\end{tabular}

NR: Not Reported 
The ability of GYY4137 to release hydrogen sulfide and its time profile were determined after confirming the identity of the synthesized product. Ellman's reagent (5,5'-dithiobis-2-nitrobenzoic acid or DTNB) was employed to asses $\mathrm{H}_{2} \mathrm{~S}$ release from GYY4137. It has two electron-deficient phenyl groups linked by a disulfide bond. The disulfide readily undergoes a transsulfuration reaction or reduction by a sulfhydryl group and in the process may release a conjugate and intense yellow 5-thio-2-nitrobenzoate (TNB) with a strong absorption at $412 \mathrm{~nm}$. The reaction is presented in Figure 5.4.

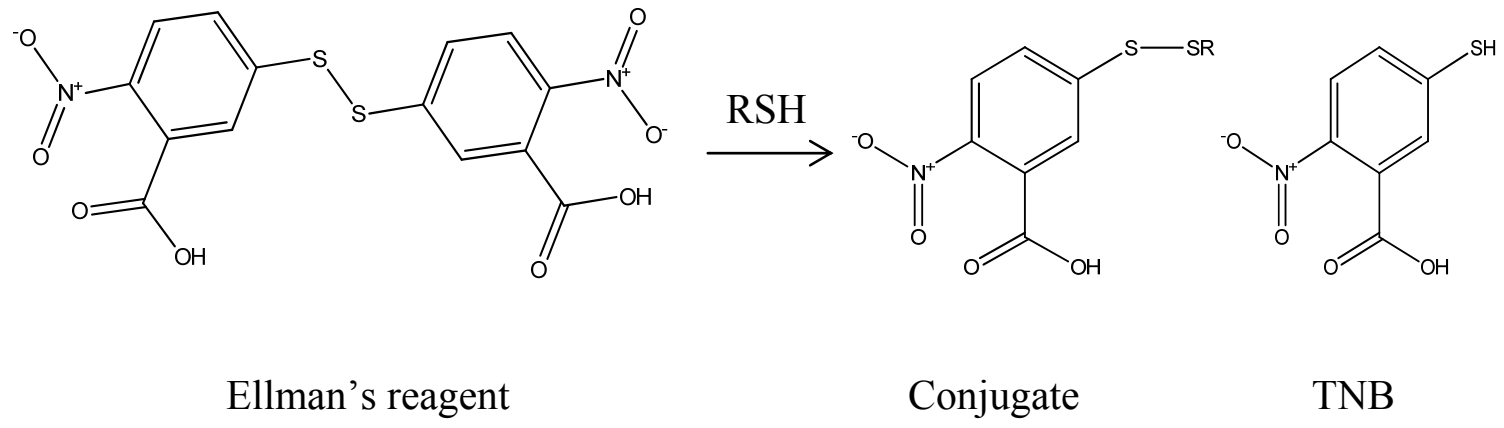

Figure 5.4 Reaction of Ellman's reagent with thiols

Reduced glutathione (GSH) and cysteine (Cys) were used to establish calibration curves in order to quantitate the amount of hydrogen sulfide released from GYY4137 over time. In the literature, sodium hydrosulfide hydrate $\left(\mathrm{NaHS}^{\circ} \times \mathrm{H}_{2} \mathrm{O}\right)$ is usually employed to establish the calibration curve for $\mathrm{H}_{2} \mathrm{~S}$. The problem with this compound is that it contains an unknown amount of water, hygroscopic and over time absorbs more moisture and such requires a lengthy iodometric titration process to establish its $\mathrm{HS}^{-}$concentration before use. Thus I decided to employ GSH and Cys instead to construct the calibration curves used for quantitation. The UV absorbance of 
the standards was measured at $412 \mathrm{~nm}$, and the calibration curves were constructed. A solution of GYY4137 was prepared with a known theoretical concentration. The absorbance of the solution was measured over three hours and the amount of hydrogen sulfide quantified over time. The time profile of $\mathrm{H}_{2} \mathrm{~S}$ release at $\mathrm{pH} 7.4$ is depicted in Figure 5.5. Most of the $\mathrm{H}_{2} \mathrm{~S}$ was found to be released in about 30 minutes, which result is in close agreement with those obtained by Li et al. ${ }^{165}$ The total time required to release all $\mathrm{H}_{2} \mathrm{~S}$ took almost 3 hours. On the basis of the theoretical concentration of GYY4137 and the amount of hydrogen sulfide released from this solution it was determined that most of the GYY4137 expected to be released, were released. (On the basis of the Cys and GSH calibration curves, 98 and $91 \%$ of the theoretical amount of $\mathrm{H}_{2} \mathrm{~S}$ were released respectively.)

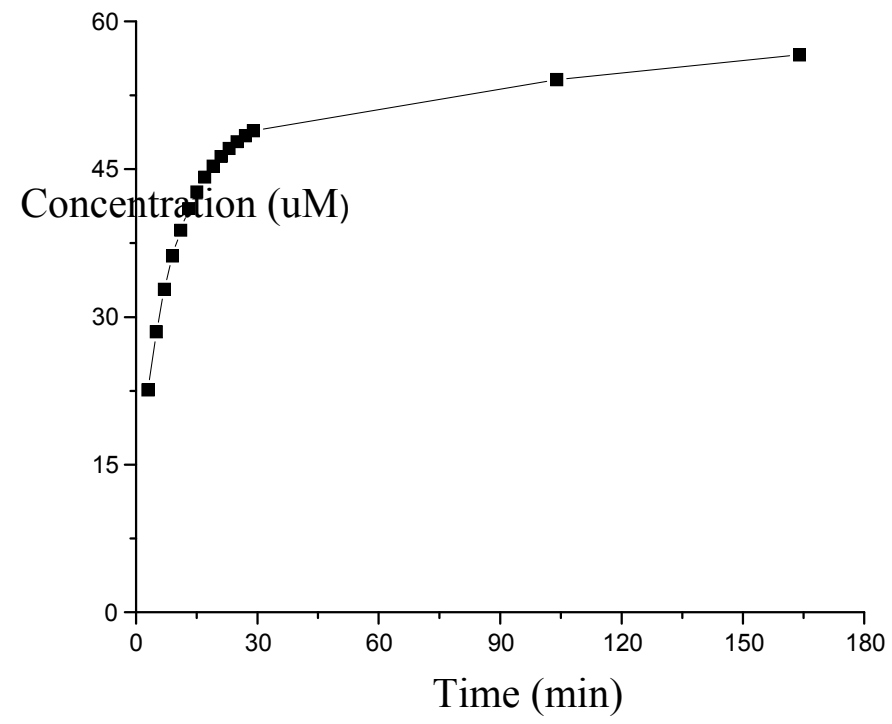

Figure 5.5 The accumulated cconcentration of $\mathrm{H}_{2} \mathrm{~S}$ released over time at $\mathrm{pH} 7.4$ 


\subsubsection{Synthesis and identification of glutathione persulfide (GSSH)}

Glutathione persulfide was synthesized according to a previously reported method. ${ }^{166}$ Briefly, sodium sulfide and oxidized glutathione were mixed in a 1 to $1 \mathrm{~mol}$ ratio in $50 \mathrm{mM} \mathrm{pH} 7.4$ HEPES buffer and placed in a $37^{\circ} \mathrm{C}$ water bath for 15 minutes. The solution was used immediately after the 15 -minute incubation period. The formation of GSSH was confirmed using UV/Visible spectroscopy. Immediately after preparation, the UV spectrum of GSSH was acquired (Fig. 5.6).

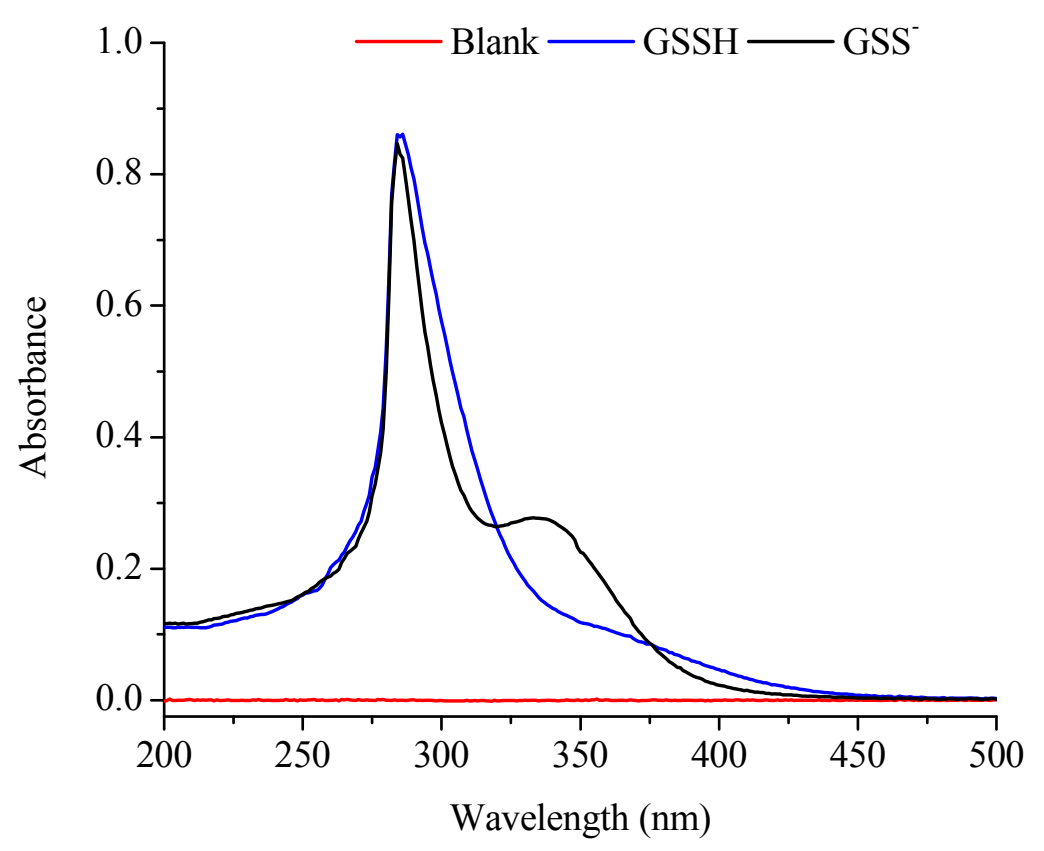

Figure 5.6 UV spectra of GSSH and GSS ${ }^{-}$

The UV spectra showed a maximum around $284 \mathrm{~nm}$, which is in a good agreement with the results obtained by Francoleon et al. who reported a maximum around $280 \mathrm{~nm} .{ }^{166}$ In the next step, the $\mathrm{pH}$ of the solution was changed to 9 using sodium hydroxide to generate the conjugate base (GSS) of GSSH resulting in a shift in 
absorbance wavelength. The peak at $284 \mathrm{~nm}$ gradually decreased and a new peak around $335 \mathrm{~nm}$ showed up. This value is also in good agreement with the previously reported value of $340 \mathrm{~nm}$ for $\mathrm{GSS}^{-}$and $335 \mathrm{~nm}$ for $\mathrm{CysS}^{-}$(conjugate base of cysteine persulfide). ${ }^{166,167}$

\subsubsection{Instrumentation and Chromatographic Conditions}

A Perkin Elmer Series 200 HPLC system equipped with a temperature controlled column compartment was coupled to a Perkin Elmer Elan DRC-e ICP-MS (dynamic reaction cell inductively coupled mass spectrometer). The ICP-MS was equipped with a cyclonic spray chamber and a Meinhard nebulizer and was used in the standard mode. ICP-MS signal at $\mathrm{m} / \mathrm{z} 75$ for ${ }^{75} \mathrm{As}$ was monitored. Instrument performance was checked daily against a tuning solution recommended by the manufacturer and if necessary nebulizer gas flow and composition adjustments were made manually for maximum sensitivity. List of instrument parameters for ICP-MS are listed in Table 5.3 and the HPLC gradient elution program is provided in Table 5.4. Waters Spherisorb $5 \mu \mathrm{m} \mathrm{C8,} 4.0$ x 250 mm (Part No. PSS845281) column was employed for the separation of species and the column was kept at $10^{\circ} \mathrm{C}$. Data was collected and processed using Elan v. 3.4 and Chromera v. 1.2 software (Perkin Elmer, USA).

A Thermo Finnigan Surveyor HPLC system equipped with an autosampler and column compartment was coupled with an LCQ Deca XP MAX (Thermo Finnigan, USA) MS. Data was collected and treated using Xcalibar software (Thermo, USA). The instrumental parameters were optimized using the flow injection mode with a $5 \mu \mathrm{g} \mathrm{mL} \mathrm{m}^{-1}$ caffeine standard. 
Proton NMR spectrum was recorded at $25{ }^{\circ} \mathrm{C}$ on a Bruker 400 FT NMR spectrometer operating at a proton frequency of $400 \mathrm{MHz}$. Samples were dissolved in $\mathrm{D}_{2} \mathrm{O}$ : Acetone-D6 1:4 v/v mix. The samples were transferred to the NMR tubes and capped with rubber septa immediately. NMR spectra were collected within ten minutes of sample preparation. The chemical shift values were referenced to acetone-D6.

Perkin Elmer Spectrum 100 Fourier Transform Infrared Spectrometer (FT-IR) with Perkin Elmer Spectrum software version 10.01.00 was employed to acquire infrared spectrums. Varian Cary 100 Bio UV-Visible Spectrophotometer with Cary 300 software was used to collect UV data.

Table 5.3 ICP-MS parameters employed

\begin{tabular}{|c|c|}
\hline Parameter (unit) & Typical value \\
\hline Nebulizer Ar Gas Flow (L/min) & $0.94-0.96$ \\
\hline Auxiliary Gas Flow (L/min) & 1 \\
\hline Plasma Gas Flow (L/min) & 15 \\
\hline Nebulizer Oxygen Gas Flow (L/min) & 0.2 \\
\hline Lens voltage & 9 \\
\hline ICP RF Power (W) & 1350 \\
\hline Analog Stage Voltage & -1525 \\
\hline Pulse Stage Voltage & 950 \\
\hline $\mathrm{QRO}^{1}$ & -2 \\
\hline $\mathrm{CRO}^{2}$ & -7 \\
\hline Discriminator Threshold & 40 \\
\hline $\mathrm{CPV}^{3}$ & -20 \\
\hline
\end{tabular}

${ }^{1}$ QRO stands for Quadrupole Rod Offset Std

${ }^{2}$ CRO stands for Cell Rod Offset Std

${ }^{3} \mathrm{CPV}$ stands for Cell Path Voltage Std 
Table 5.4 HPLC gradient program

\begin{tabular}{|c|c|c|c|c|c|c||}
\hline Step & Step type & $\begin{array}{c}\text { Step time } \\
(\mathbf{m i n})\end{array}$ & $\begin{array}{c}\text { Flow } \\
(\mathbf{m L} / \mathbf{m i n})\end{array}$ & $\begin{array}{c}\mathbf{0 . 0 5 \%} \\
\mathbf{T F A}\end{array}$ & ACN \% & Curve \\
\hline 0 & Equilibration & 7.0 & 1.0 & 99 & 1 & N/A \\
\hline 1 & Run & 5.5 & 0.4 & 99 & 1 & 0.0 \\
\hline 2 & Run & 3.5 & 0.5 & 87 & 13 & 1.0 \\
\hline 3 & Run & 11.0 & 0.5 & 80 & 20 & 0.0 \\
\hline 4 & Run & 10.0 & 0.5 & 95 & 5 & 0.0 \\
\hline
\end{tabular}

\subsubsection{Experimental Procedures}

5.4.6.1 Determination of the Source and the Form of Sulfur Used for the Formation of Thiolated Arsenicals

The slow hydrogen sulfide releaser (GYY4137) was used to react with $\mathrm{DMA}^{\mathrm{III}}(\mathrm{GS})$ in addition to NaHS and $\mathrm{Na}_{2} \mathrm{~S}$ at $\mathrm{pH} 7.4,6.0$, and 3.0 in $50 \mathrm{mM}$ HEPES, MES, and formate buffers respectively in addition to double deionized water with no $\mathrm{pH}$ control at 1 to 5 As to $\mathrm{S}$ ratio and the formation of DMMTA ${ }^{\mathrm{V}}$ and DMDTA ${ }^{\mathrm{V}}$ were monitored over 24 hours. Furthermore, to determine the possibility of DMMTA ${ }^{\mathrm{V}}$ and DMDTA ${ }^{\mathrm{V}}$ formation from sulfane sulfur, DMA ${ }^{\mathrm{V}}$ was reacted with GSSH in the mol ratio of 1 to 2 respectively. The samples were stirred for 15 minutes and to half of the samples GSH was added in 1 to 1 mol ratio of GSSH to GSH. The samples with no added GSH were used as controls. The final mol ratio of DMA ${ }^{\mathrm{V}}$ :GSSH:GSH was 1:2:2. Both the controls and the samples were monitored over time to observe if thiolated arsenicals can be produced from sulfane sulfur. 
5.4.6.2 The Effect of $\mathrm{pH}$, Sulfide and GSH Concentrations on the Formation of Thiolated Arsenical from DMA ${ }^{\mathrm{III}}(\mathrm{GS})$ and $\mathrm{DMA}^{\mathrm{V}}$; Mechanism of Formation of Thiolated Arsenicals

I previously proposed that the formation of DMMTA ${ }^{\mathrm{V}}$, and ultimately the formation of $\operatorname{DMMTA}^{\mathrm{V}}(\mathrm{GS})$ from DMA ${ }^{\mathrm{III}}(\mathrm{GS})$ may go through either the formation of $\mathrm{DMA}^{\mathrm{V}}\left(\mathrm{DMA}^{\mathrm{V}}\right.$ pathway \#1) and/or a dimer (dimerization pathway \#2). The updated proposed pathways are depicted in Figure 5.7.

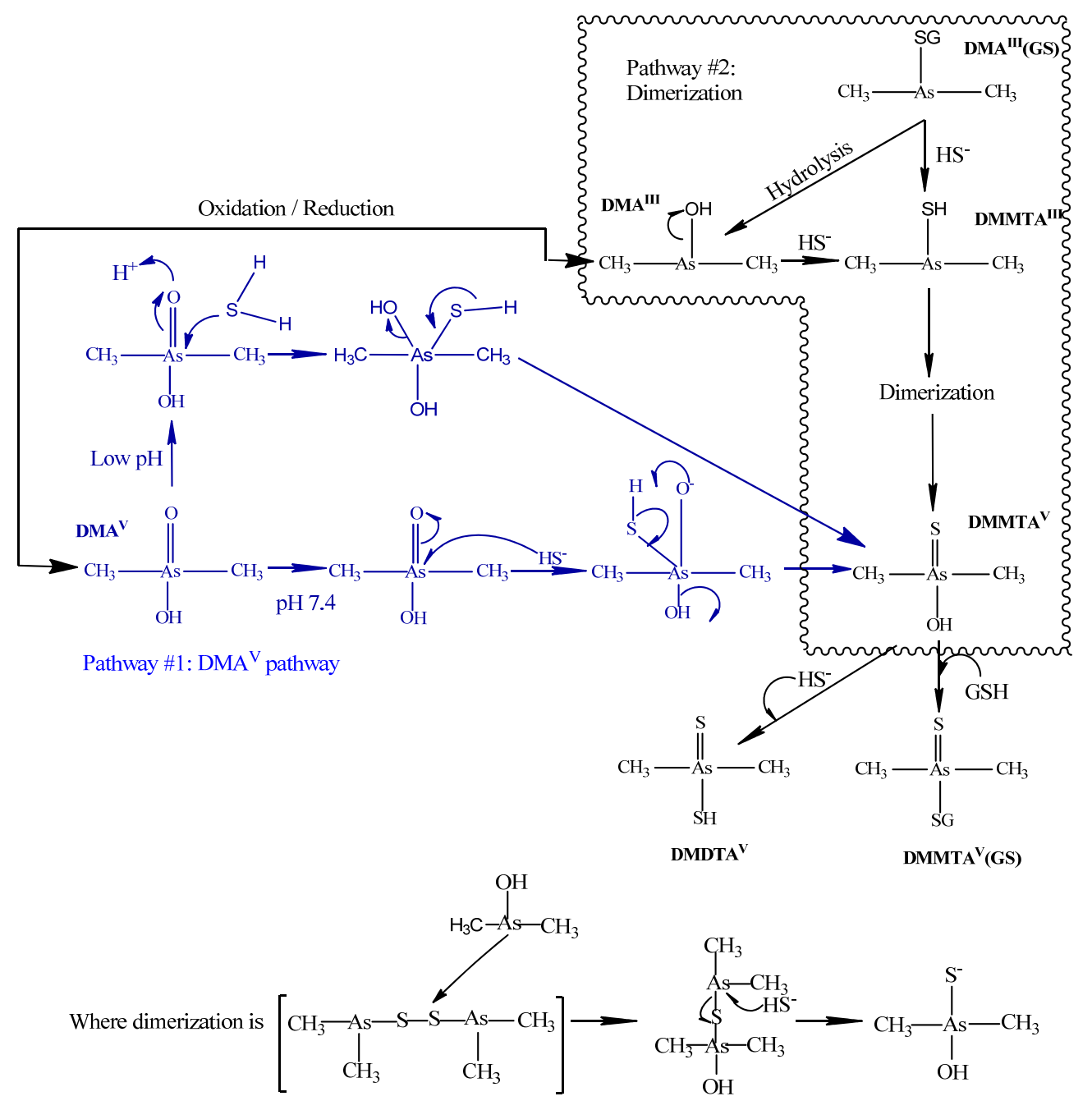

Figure 5.7 Proposed mechanism of formation of thiolated arsenicals 
For every sample, $\mathrm{DMA}^{\mathrm{V}}$ and $\mathrm{DMA}^{\mathrm{III}}(\mathrm{GS})$ were separately prepared at the exact same As concentrations (to enable me to compare peak areas) for incubation with $\mathrm{Na}_{2} \mathrm{~S}$ at mol ratios of As:S 1:1, 1:2, 1:5, and 1:80 in $50 \mathrm{mM}$ pH 3.0 (formate), 6.0 (MES), and 7.4 (phosphate) buffers to determine the effect of $\mathrm{pH}$ on the formation of thiolated arsenic metabolites and the effect of excess sulfide on species distribution. No GSH was added to these samples. To study the effect of GSH on the formation of thiolated and GSH-conjugated species (all species distribution) I incubated DMA ${ }^{\mathrm{III}}(\mathrm{GS})$ with $\mathrm{Na}_{2} \mathrm{~S}$ in the mol ratio of As:S 1:1, 1:2, and 1:5 at $\mathrm{pH} 7.4,6.0$, and 3.0 with $2.5 \mathrm{mM}$ and $5.0 \mathrm{mM} \mathrm{GSH}$ present in the initial reaction medium in addition to samples containing no added GSH. In order to study the effect of GSH on the formation of DMMTA ${ }^{\mathrm{V}}(\mathrm{GS})$ directly from already synthesized DMMTA ${ }^{\mathrm{V}}$, I also incubated $\mathrm{DMA}^{\mathrm{III}}(\mathrm{GS})$ with $\mathrm{Na}_{2} \mathrm{~S}$ in the mol ratio of As:S 1:2 at $\mathrm{pH} 7.4,6.0$, and 3.0 and let the samples stand for 90 minutes (to allow the formation of $\mathrm{DMMTA}^{\mathrm{v}}$ ) and then added GSH to the reaction medium to yield final concentrations of $0,2.5$, and $5.0 \mathrm{mM} \mathrm{GSH}$ at each tested $\mathrm{pH}$. The amount of $\operatorname{DMMTA}^{\mathrm{V}}(\mathrm{GS})$ that formed as a function of $\mathrm{pH}$, sulfide and GSH concentration levels was determined. Moreover, these experiments were used to examine if thiolated arsenicals form via different pathways from trivalent $\left(\mathrm{DMA}^{\mathrm{III}}(\mathrm{GS})\right)$ and pentavalent $\left(\mathrm{DMA}^{\mathrm{V}}\right)$ arsenicals

5.4.6.3 Enzymatic Reactions for the Identification of Enzymes Responsible for the Catalysis of DMMTA ${ }^{\mathrm{V}}(\mathrm{GS})$ Formation from DMMTA ${ }^{\mathrm{V}}$

Human pi GST and also a mixture of human microsomal and cytosolic GSTs extracted from human placenta were tested to determine if they catalyze the formation of DMMTA ${ }^{\mathrm{V}}(\mathrm{GS})$ via the conjugation of GSH to DMMTA ${ }^{\mathrm{V}}$. The enzymes 
were separately added to the mixture of $\mathrm{DMA}^{\mathrm{III}}(\mathrm{GS})$ and $\mathrm{Na}_{2} \mathrm{~S}$ (1:2 mol ratios respectively) and the formation of $\operatorname{DMMTA}^{\mathrm{V}}(\mathrm{GS})$ was monitored and compared to the controls that were prepared the same way, but without the addition of enzyme. The experiment with pi GST was performed at pH 7.4 in 50 mM HEPES buffer containing $2.5 \mathrm{mM} \mathrm{GSH}$ and the experiment involving the mixture of cytosolic and microsomal GSTs was performed in $100 \mathrm{mM}$ potassium phosphate buffer (pH 6.5) with $100 \mathrm{mM}$ EDTA, as recommended by the manufacturer, and in 50 mM HEPES buffer at $\mathrm{pH}$ 7.4. Both buffers contained $2.5 \mathrm{mM} \mathrm{GSH}$. All experiments were carried out at $37^{\circ} \mathrm{C}$.

\subsubsection{Identification of Unknown Chromatographic Peaks}

During the course of experiments with $\mathrm{DMA}^{\mathrm{III}}(\mathrm{GS})$ and $\mathrm{Na}_{2} \mathrm{~S}$, unknown peaks showed up in the chromatograms acquired on the HPLC-ICP-MS. I suspected that one of the peaks was dimethylmonothioarsinous acid (DMMTA ${ }^{\mathrm{III}}$ ) as I hypothesized that DMMTA ${ }^{\mathrm{V}}$ forms from $\mathrm{DMA}^{\mathrm{III}}(\mathrm{GS})$ via $\mathrm{DMMTA}^{\mathrm{III}}$ as depicted in Figure 5.7 (dimerization pathway). As the synthesis of this highly unstable and oxidation prone compound has not been published to my knowledge, I attempted to produce DMMTA $^{\text {III }}$ by reacting DMA ${ }^{\text {III }}(\mathrm{GS})$ with $\mathrm{Na}_{2} \mathrm{~S}$ in an completely oxygen free environment to try to stop the formation of dimers and other products (such as DMMTA ${ }^{\mathrm{V}}$ and DMDTA $^{\mathrm{V}}$ ) that are all formed by oxidation and retard the reaction at the formation of DMMTA $^{\text {III }}$. The samples were then analyzed on the HPLC-ICP-MS and the retention time of the produced compound was compared to the retention times of the unknown peaks to determine if the peak produced by DMMTA ${ }^{\mathrm{III}}$ matches one of the unknown peaks. Then the sample was exposed to air and reanalyzed periodically to monitor the change in species distribution compared to the initial results. 


\subsection{Results}

5.5.1 Comparison of the Abilities of $\mathrm{S}^{2-}, \mathrm{HS}^{-}$, and $\mathrm{H}_{2} \mathrm{~S}$ to Produce DMMTA ${ }^{\mathrm{V}}$

GYY4137, NaHS, and $\mathrm{Na}_{2} \mathrm{~S}$ in $50 \mathrm{mM}$ pH 7.4 HEPES, pH 6.0 MES, pH 3.0 formate buffers, and in double deionized water were able to produce DMMTA ${ }^{\mathrm{V}}$. Results for $\mathrm{pH} 7.4$ and 6.0 are presented in Figures 5.8 A and B respectively.
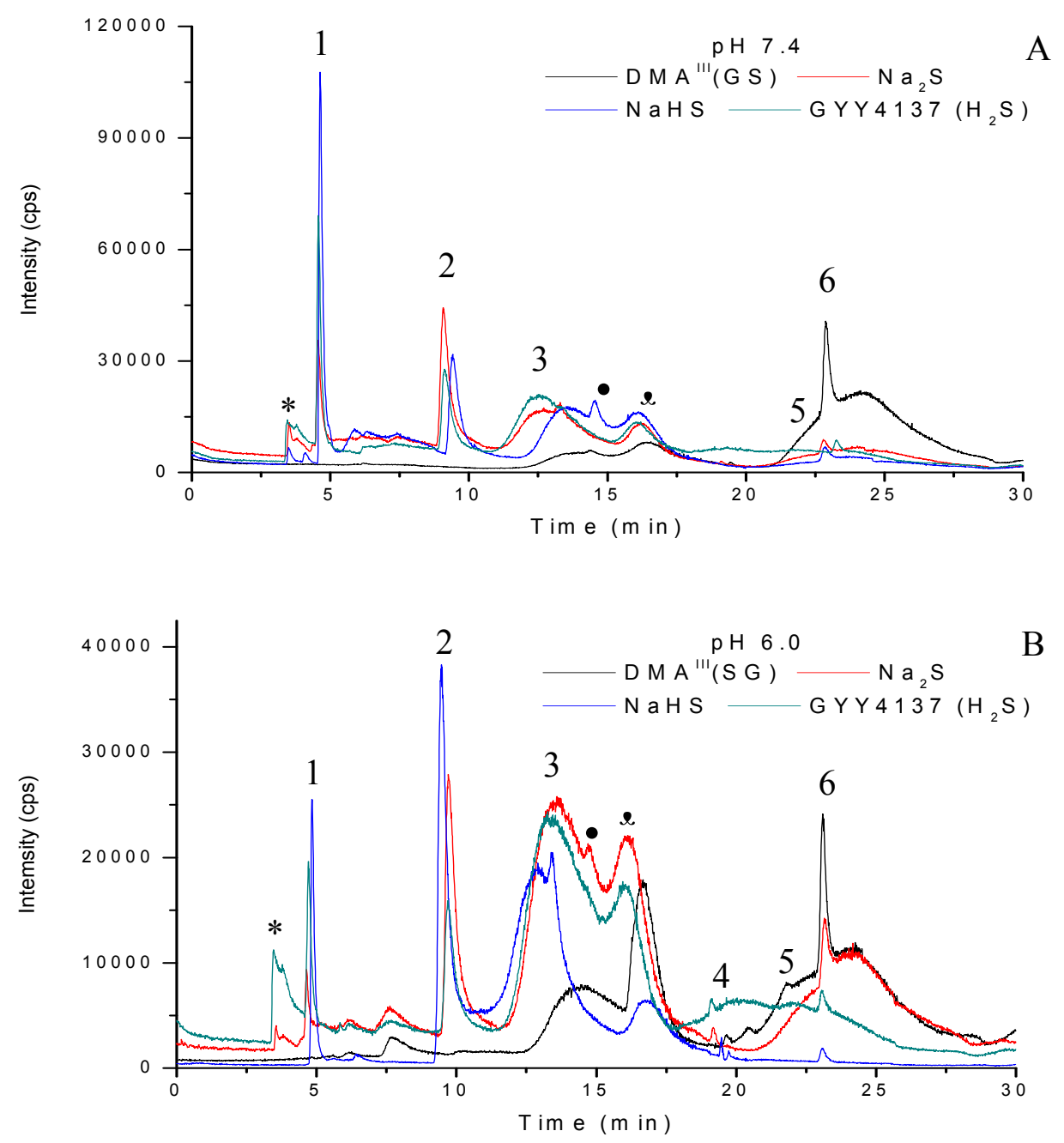

Figure 5.8 Reactions between $\mathrm{DMA}^{\mathrm{III}}(\mathrm{GS})$ and GYY4137, NaHS, and $\mathrm{Na}_{2} \mathrm{~S}$ at (A) $\mathrm{pH} 7.4$ and (B) $\mathrm{pH}$ 6.0. Full names of peaks, their abbreviation, structure, and peak numbers are displayed in Table 5.5. 
Table 5.5 Names, abbreviations, structures and peak numbers

\begin{tabular}{|c|c|c|c|}
\hline \multicolumn{2}{|c|}{ Most common } & \multirow{2}{*}{ Structure } & \multirow{2}{*}{ Peak \# } \\
\hline Names & Abbreviations & & \\
\hline $\begin{array}{l}\text { Dimethylmonothioarsinous } \\
\text { acid }\end{array}$ & DMMTA $^{\text {III }}$ & $\mathrm{CH}_{3}-\mathrm{As}-\mathrm{CH}_{3}$ & $\bullet(?)$ \\
\hline \multicolumn{3}{|l|}{ Unknown peaks } & $*$ and $\bullet$ \\
\hline \multicolumn{3}{|c|}{ Baseline disturbance resulting from the gradient program } & e \\
\hline $\begin{array}{l}\text { Dimethyldithioarsinic acid } \\
\text { Dimethylarsinodithioic acid }\end{array}$ & DMDTA $^{\mathrm{V}}$ & $\mathrm{CH}_{3}-\mathrm{As}-\mathrm{CH}_{3}$ & 1 \\
\hline $\begin{array}{l}\text { Dimethylmonothioarsinic acid, } \\
\text { Dimethylarsinothioic acid, } \\
\text { Thio-dimethylarsinate }\end{array}$ & $\begin{array}{l}\text { DMMTA }^{\mathrm{V}} \\
\text { Thio-DMA }^{\text {DMAS }}\end{array}$ & $\mathrm{CH}_{3}-{ }_{\mathrm{As}}-\mathrm{CH}_{3}$ & 2 \\
\hline $\begin{array}{l}\text { Dimethylarsinic acid, } \\
\text { Dimethylarsinate }\end{array}$ & $\begin{array}{l}\text { DMA }^{\mathrm{V}} \\
\text { DMAs }^{\mathrm{V}}\end{array}$ & $\mathrm{CH}_{3}-\mathrm{As}-\mathrm{CH}_{3}$ & 3 \\
\hline $\begin{array}{l}\text { Dimethylarsinothioyl } \\
\text { glutathione }\end{array}$ & $\begin{array}{l}\text { DMMTA }^{\mathrm{V}}-\mathrm{GS} \\
\text { DMATG } \\
\text { DMAS }^{\mathrm{V}}-\mathrm{GS} \\
\text { DMMTA }^{\mathrm{V}}(\mathrm{GS})\end{array}$ & $\|_{\mathrm{SG}}^{\mathrm{S}}$ & 4 \\
\hline $\begin{array}{l}\text { Dimethylarsinous acid, } \\
\text { Dimethylarsinite }\end{array}$ & $\begin{array}{l}\text { DMA }^{\text {III }} \\
\text { DMAs }^{\text {III }}\end{array}$ & $\mathrm{CH}_{3}-\mathrm{As}-\mathrm{CH}_{3}$ & 5 \\
\hline $\begin{array}{l}\text { Dimethylarsinic glutathione, } \\
\text { Dimethylarsinous glutathione, } \\
\text { Dimethylarsino-glutathione, } \\
\text { DAR, ZIO-101, Darinaparsin, }\end{array}$ & $\begin{array}{l}\text { DMA }^{\mathrm{III}}(\mathrm{GS}) \\
\text { DAR, DMAG } \\
\text { DMAs }{ }^{\mathrm{III}} \mathrm{GS}\end{array}$ & $\left.\right|_{\mathrm{SG}} ^{\mathrm{CH}_{3}-\mathrm{As}-\mathrm{CH}_{3}}$ & 6 \\
\hline
\end{tabular}

The results showed that from all starting compounds DMMTA ${ }^{\mathrm{V}}$ could be formed at every tested $\mathrm{pH}$ value. The formation of significant amounts of $\mathrm{DMDTA}^{\mathrm{V}}$ was also observed with the highest amount at $\mathrm{pH} 7.4$ but almost no DMDTA ${ }^{\mathrm{V}}$ formed at $\mathrm{pH}$ 3.0. Very small amount of DMMTA ${ }^{\mathrm{V}}(\mathrm{GS})$ formation was observed at $\mathrm{pH} 7.4$, while with decreasing $\mathrm{pH}$, its amount increased. 
5.5.2 Evaluation of the Ability of Glutathione Persulfide (GSSH), a Model Compound of Protein Persulfides, to Produce DMMTA ${ }^{\mathrm{V}}$ at Physiological $\mathrm{pH}$ When $\mathrm{DMA}^{\mathrm{V}}$ was reacted with only GSSH (control) at $\mathrm{pH} 7.4$, almost no DMMTA $^{\mathrm{V}}$ formation was observed (Fig. 5.9). After the addition of GSH (to reduce the disulfide bond in GSSH to liberate ${ }^{-} \mathrm{SH}$ ), the sample was reanalyzed periodically over a day. The initial chromatograms obtained 10 minutes after the addition of GSH showed the quick formation of DMMTA ${ }^{\mathrm{V}}$ in addition to DMDTA ${ }^{\mathrm{V}}$ and a very small amount of $\operatorname{DMMTA}^{\mathrm{V}}(\mathrm{GS})$ as shown in Figure 5.9.

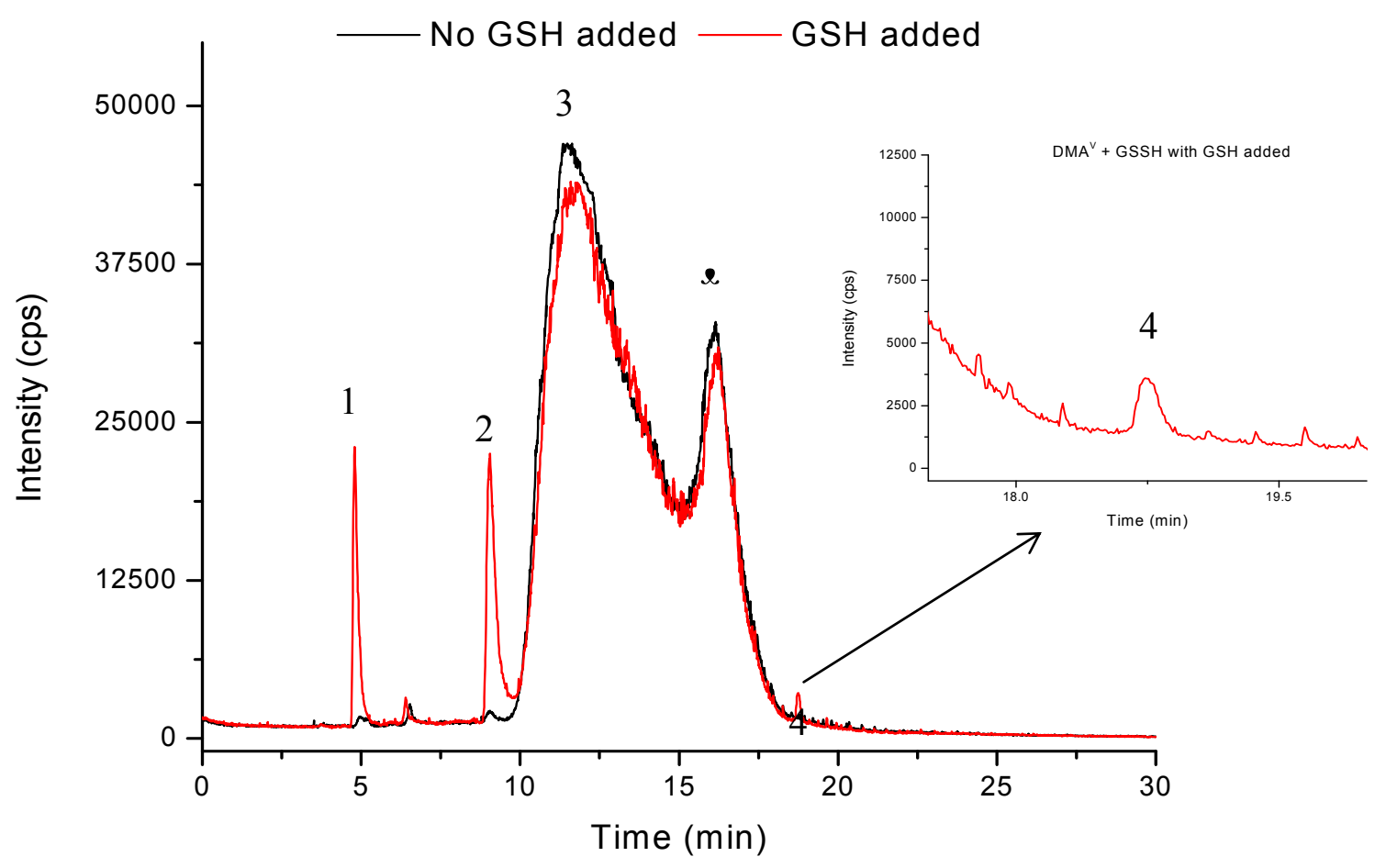

Figure 5.9. Reaction between $\mathrm{DMA}^{\mathrm{V}}$ and GSSH at $\mathrm{pH} 7.4$ in the presence and absence of added GSH. See Table 5.5 for peak identification. The control (black) only contained GSSH and DMA ${ }^{\mathrm{V}}$, while to the sample (red) GSH was added 10 minutes after mixing GSSH and DMA ${ }^{\mathrm{V}}$. 


\subsubsection{Formation of DMMTA ${ }^{\mathrm{V}}$ from $\mathrm{DMA}^{\mathrm{V}}$}

$\mathrm{DMA}^{\mathrm{V}}$ was reacted with $\mathrm{Na}_{2} \mathrm{~S}$ at $\mathrm{pH}$ 7.4, 6.0, and 3.0 in the mol ratios of As:S $1: 1,1: 2,1: 5$, and 1:80 and the formation of $\mathrm{DMMTA}^{\mathrm{V}}$ was monitored over time. All samples were prepared at the same As concentration to enable me to compare peak areas. The results showed that at all tested $\mathrm{pH}$ values DMMTA ${ }^{\mathrm{V}}$ formed from DMA ${ }^{\mathrm{v}}$. The highest amount of DMMTA ${ }^{\mathrm{V}}$ formed at $\mathrm{pH}$ 7.4, and the more sulfide was present, the faster it formed and in larger amounts. Interestingly, more $\mathrm{DMMTA}^{\mathrm{V}}$ was observed at $\mathrm{pH}$ 3.0 than at 6.0. The $\mathrm{pH}$ dependence of DMMTA ${ }^{\mathrm{V}}$ formation is depicted in Figure 5.10. Additionally, the formation of DMDTA ${ }^{\mathrm{V}}$ was observed. DMDTA ${ }^{\mathrm{V}}$ had the highest ability to form at $\mathrm{pH} 7.4$ and to lesser extent at $\mathrm{pH}$ 6.0. Almost no $\mathrm{DMDTA}^{\mathrm{V}}$ formed at $\mathrm{pH}$ 3.0. (For information on the $\mathrm{pH}$ dependence of $\mathrm{DMDTA}^{\mathrm{V}}$ formation from $\mathrm{DMA}^{\mathrm{III}}(\mathrm{GS})$, refer to Figure 5.12.)

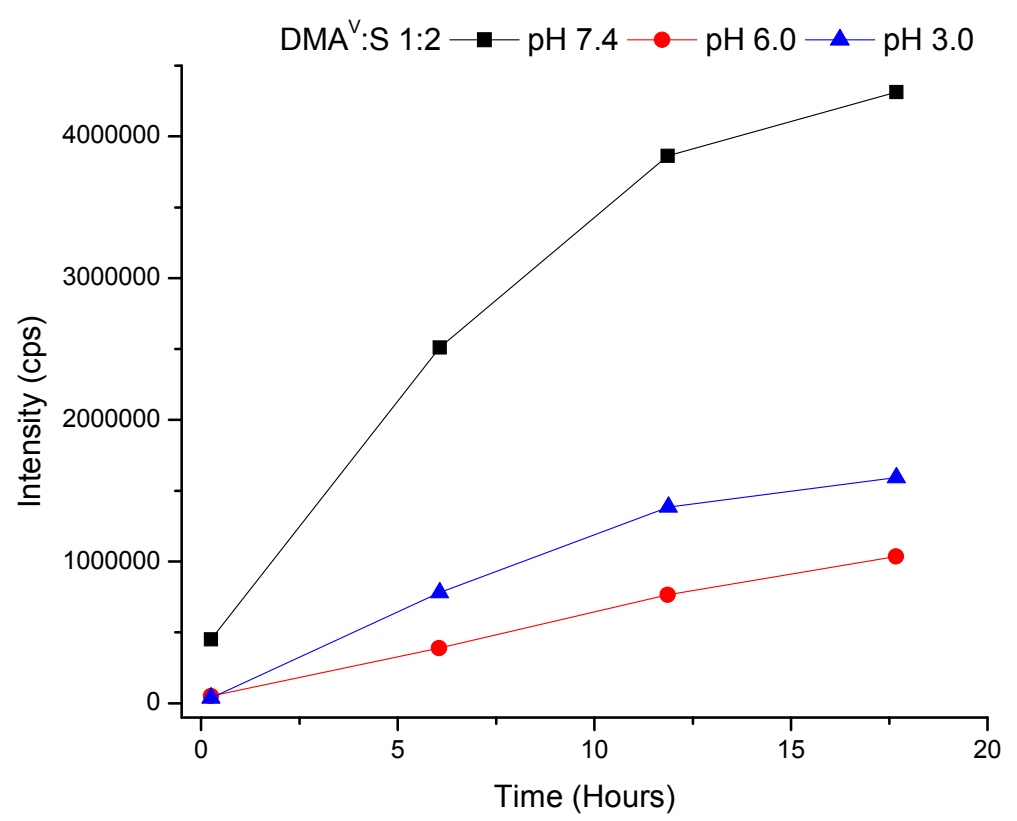

Figure 5.10 Formation of DMMTA ${ }^{\mathrm{v}}$ from $\mathrm{DMA}^{\mathrm{v}}$ at $\mathrm{pH}$ 7.4, 6.0 and 3.0 at As:S mol ratio of $1: 2$ over time 


\subsubsection{Formation of Thiolated Arsenicals from $\mathrm{DMA}^{\mathrm{III}}(\mathrm{GS})$}

The results showed that while DMMTA $^{\mathrm{V}}$ formed very easily from $\mathrm{DMA}^{\mathrm{III}}(\mathrm{GS})$ at physiological $\mathrm{pH}$, as the GSH concentration increased, the amount of DMMTA $^{\mathrm{V}}$ decreased (Fig. 5.11). As far as the $\mathrm{pH}$ dependence of DMMTA ${ }^{\mathrm{V}}$ formation goes, at a specific GSH concentration, the highest amount formed at $\mathrm{pH} 7.4$ and lesser amounts at 6.0 and 3.0. Interestingly, at all the tested GSH concentrations, slightly more DMMTA $^{\mathrm{V}}$ was present at $\mathrm{pH} 3.0$ than 6.0 , same as when $\mathrm{DMMTA}^{\mathrm{V}}$ formed from DMA ${ }^{\mathrm{V}}$. Not surprisingly, under the same conditions, as the concentration of sulfide increased, the peak distribution shifted to DMDTA ${ }^{\mathrm{v}}$ from DMMTA ${ }^{\mathrm{V}}$. The formation of $\mathrm{DMDTA}^{\mathrm{V}}$ was

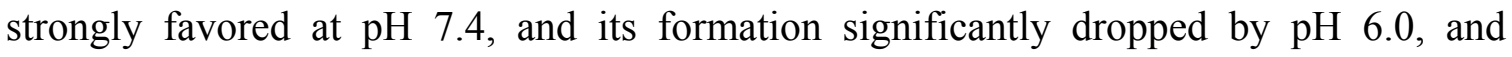
minimal amounts formed at $\mathrm{pH} 3.0$ (Fig. 5.12). At one specific $\mathrm{pH}$, such as $\mathrm{pH} 7.4$, the higher the GSH concentration, the more favored the formation of this dithiolated species is. In summary:

i) At $\mathrm{pH} 7.4$ and 6.0, the higher the concentration of GSH, the more favorable the formation of DMDTA ${ }^{\mathrm{V}}$ and less favorable the formation of DMMTA ${ }^{\mathrm{V}}$

ii) At $\mathrm{pH} 7.4$ and 6.0, the higher the sulfide concentration, the more favorable the formation of DMDTA ${ }^{\mathrm{V}}$ and less favorable the formation of DMMTA ${ }^{\mathrm{V}}$

iii) The formation of both $\mathrm{DMMTA}^{\mathrm{V}}$ and DMDTA ${ }^{\mathrm{v}}$ is the most favorable at $\mathrm{pH} 7.4$ 


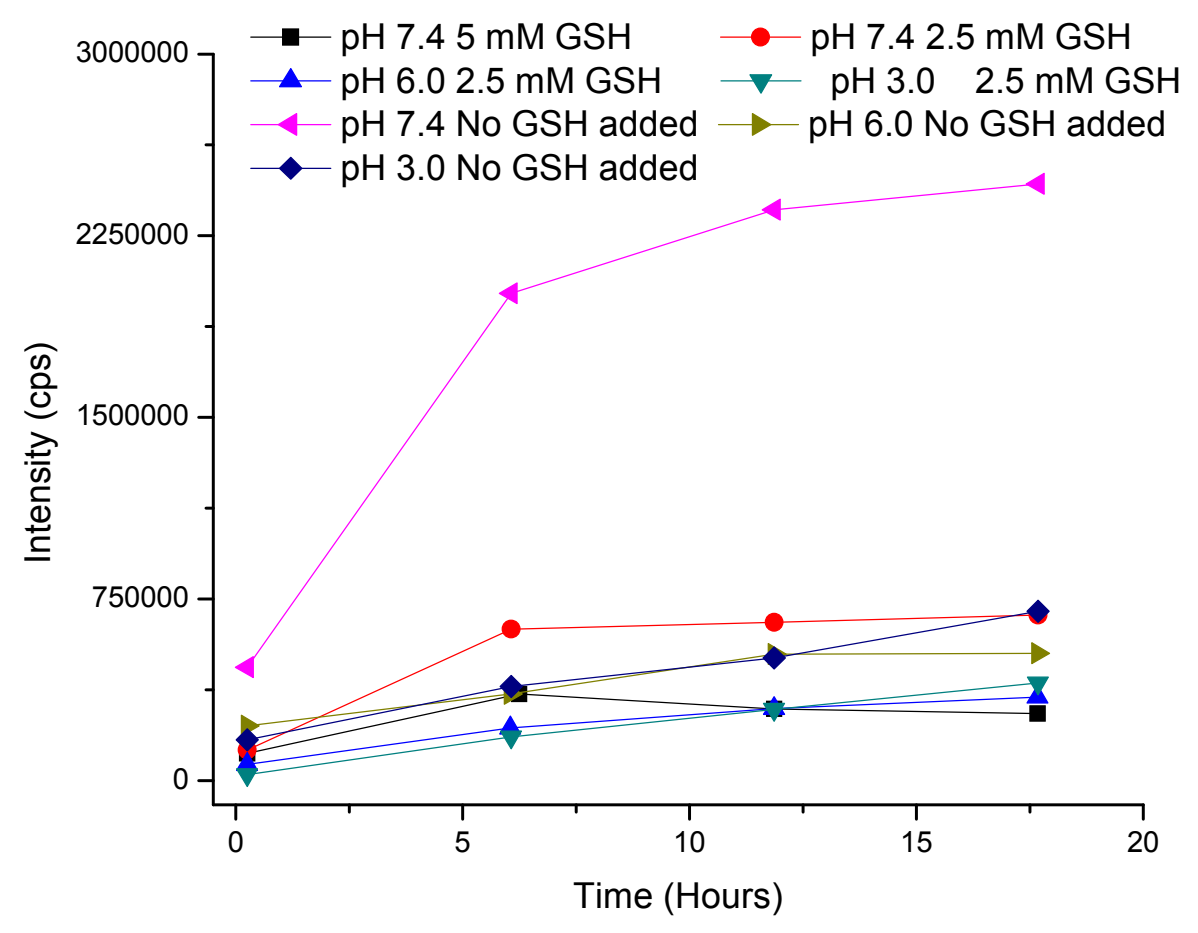

Figure 5.11 Formation of DMMTA ${ }^{\mathrm{V}}$ from $\mathrm{DMA}^{\mathrm{III}}(\mathrm{GS})$ at $\mathrm{pH} 7.4,6.0$, and 3.0 with As:S mol ratios of 1:2 at different GSH concentrations

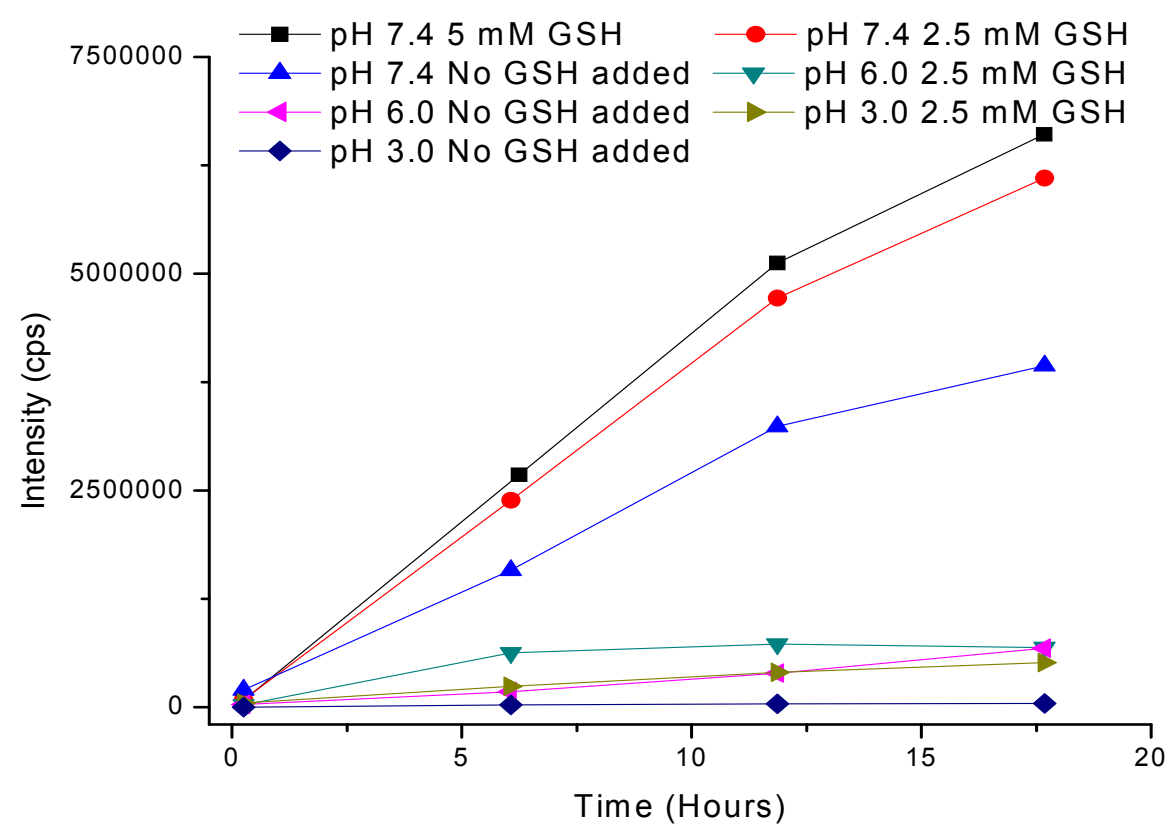

Figure 5.12 Formation of DMDTA ${ }^{\mathrm{V}}$ from $\mathrm{DMA}^{\mathrm{III}}(\mathrm{GS})$ at $\mathrm{pH}$ 7.4, 6.0, and 3.0 with As:S mol ratios of 1:2 at different GSH concentrations 
$\mathrm{DMA}^{\mathrm{III}}(\mathrm{GS})$ levels quickly decreased under all tested conditions (Fig. 5.13). The lower the $\mathrm{pH}$, the higher the stability of this species is. At one specific $\mathrm{pH}$ value, the higher the GSH concentration, the higher the stability of $\mathrm{DMA}^{\mathrm{III}}(\mathrm{GS})$. The results indicated that while high GSH concentration is needed to conserve species identity, $\mathrm{pH}$ is also a very important factor in maintaining the identity of DMA ${ }^{\mathrm{III}}(\mathrm{GS})$.

DMA $^{\text {III }}$, just like DMA ${ }^{\text {III }}(G S)$ was observed to be present in higher amounts at $\mathrm{pH}$ 3.0, than at higher $\mathrm{pH}$ (Fig. 5.14). Moreover, just like $\mathrm{DMA}^{\mathrm{III}}(\mathrm{GS})$, at one specific $\mathrm{pH}$, the higher the GSH concentration, the higher the amount of DMA ${ }^{\mathrm{III}}$. Basically, DMA $^{\mathrm{III}}$ mirrored the tendencies observed for $\mathrm{DMA}^{\mathrm{III}}(\mathrm{GS})$ On an important note, I suspect, that most of the DMA ${ }^{\mathrm{III}}$ present comes from the hydrolysis of DMA ${ }^{\mathrm{III}}(\mathrm{GS})$ during HPLC separation, and is not present in the sample. (See Discussion for explanation.)

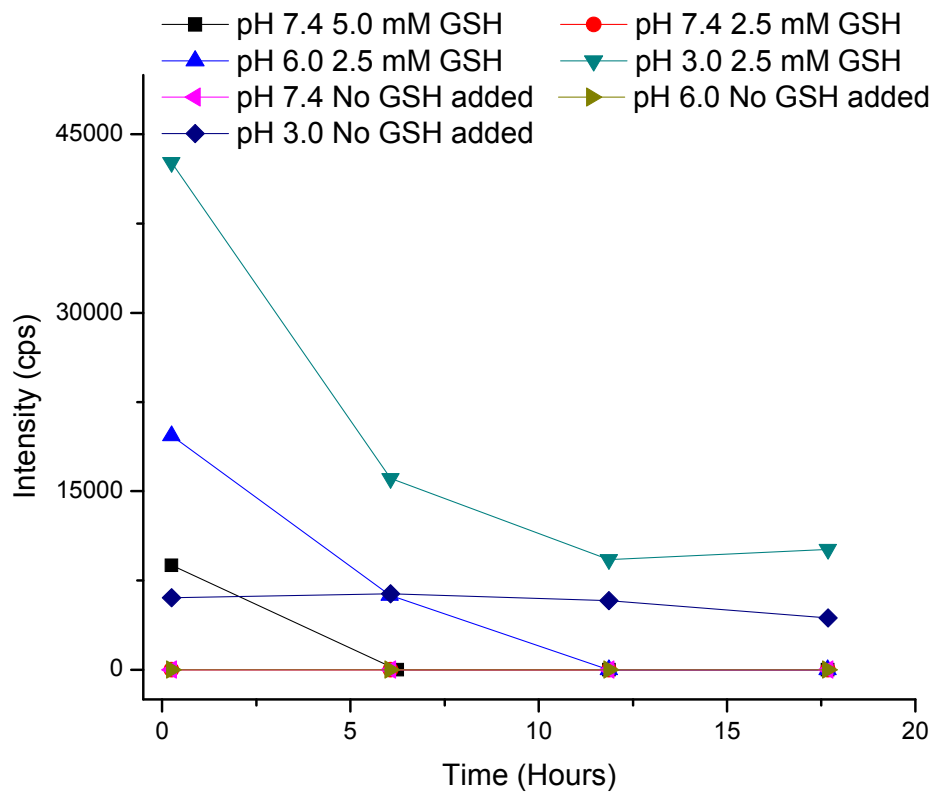

Figure 5.13 Formation of $\mathrm{DMA}^{\mathrm{III}}(\mathrm{GS})$ from $\mathrm{DMA}^{\mathrm{III}}(\mathrm{GS})$ at $\mathrm{pH}$ 7.4, 6.0, and 3.0 with As:S mol ratios of 1:2 at different GSH concentrations 


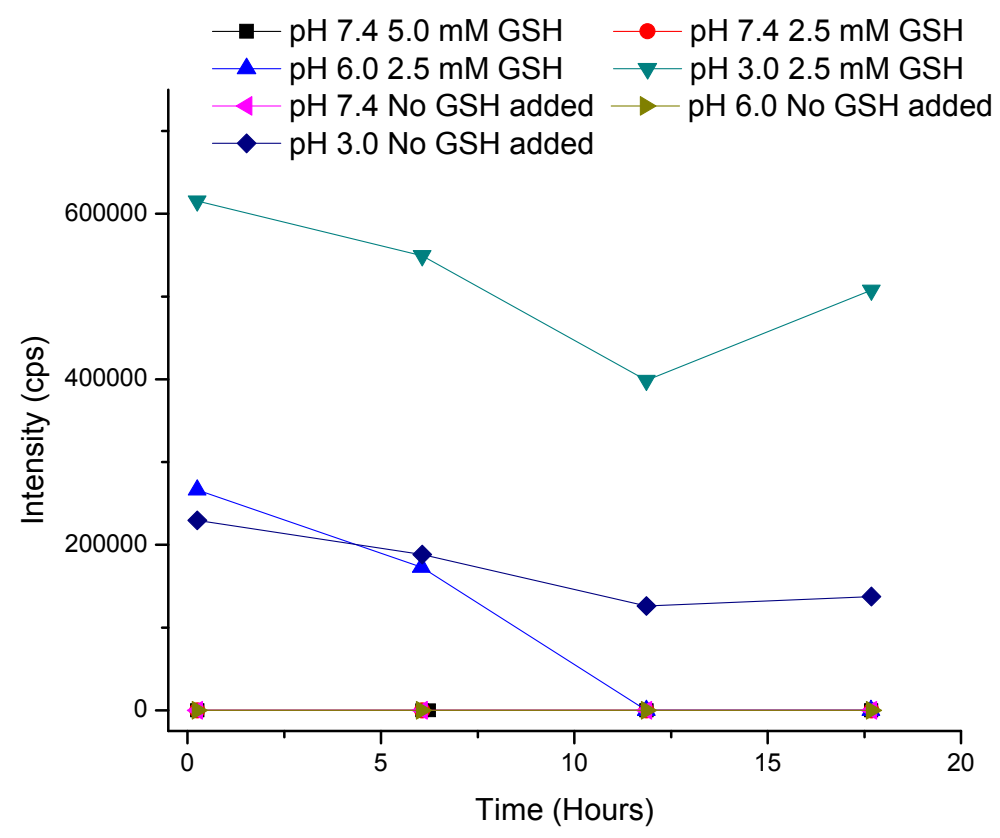

Figure 5.14 Formation of DMA ${ }^{\mathrm{III}}$ from $\mathrm{DMA}^{\mathrm{III}}(\mathrm{GS})$ at $\mathrm{pH} 7.4,6.0$, and 3.0 with As:S mol ratios of 1:2 at different GSH concentrations. (Most of the DMA ${ }^{\mathrm{III}}$ present is suspected to originate from the hydrolysis of DMA ${ }^{\mathrm{III}}(\mathrm{GS})$ to DMA ${ }^{\mathrm{III}}$ during HPLC separation.)

The formation of DMMTA ${ }^{\mathrm{V}}(\mathrm{GS})$, just like the formation of DMA ${ }^{\mathrm{III}}(\mathrm{GS})$ was preferred at lower $\mathrm{pH}$ and at higher GSH concentrations at a specific $\mathrm{pH}$. I observed the formation of DMMTA ${ }^{\mathrm{V}}(\mathrm{GS})$ at $\mathrm{pH}$ 7.4, although only to a very small extent (Fig. 5.15), in the presence of 2.5 and $5.0 \mathrm{mM} \mathrm{GSH}$, but not in the absence of it. These results are not in agreement with those presented by Naranmandura and Suzuki who reported that $\operatorname{DMMTA}^{\mathrm{V}}(\mathrm{GS})$ only forms under $\mathrm{pH}$ 7. ${ }^{111,135}$

Comparable amounts of $\mathrm{DMMTA}^{\mathrm{V}}$ were formed from $\mathrm{DMA}^{\mathrm{V}}$ and $\mathrm{DMA}^{\mathrm{III}}(\mathrm{GS})$ at a specific $\mathrm{pH}$ (Fig. 5.16). The chromatograms obtained using DMA ${ }^{\mathrm{III}}(\mathrm{GS})$ as the starting material showed two unidentified peaks, one eluting before DMDTA ${ }^{\mathrm{V}}$, and 
the other eluting after the DMA ${ }^{\mathrm{V}}$ peak (Fig. 5.17). These unidentified peaks did not show up in the chromatograms where $\mathrm{DMA}^{\mathrm{V}}$ was the starting compound. No DMA ${ }^{\mathrm{III}}$ peaks were observed in the chromatograms using $\mathrm{DMA}^{\mathrm{V}}$ as the starting material.

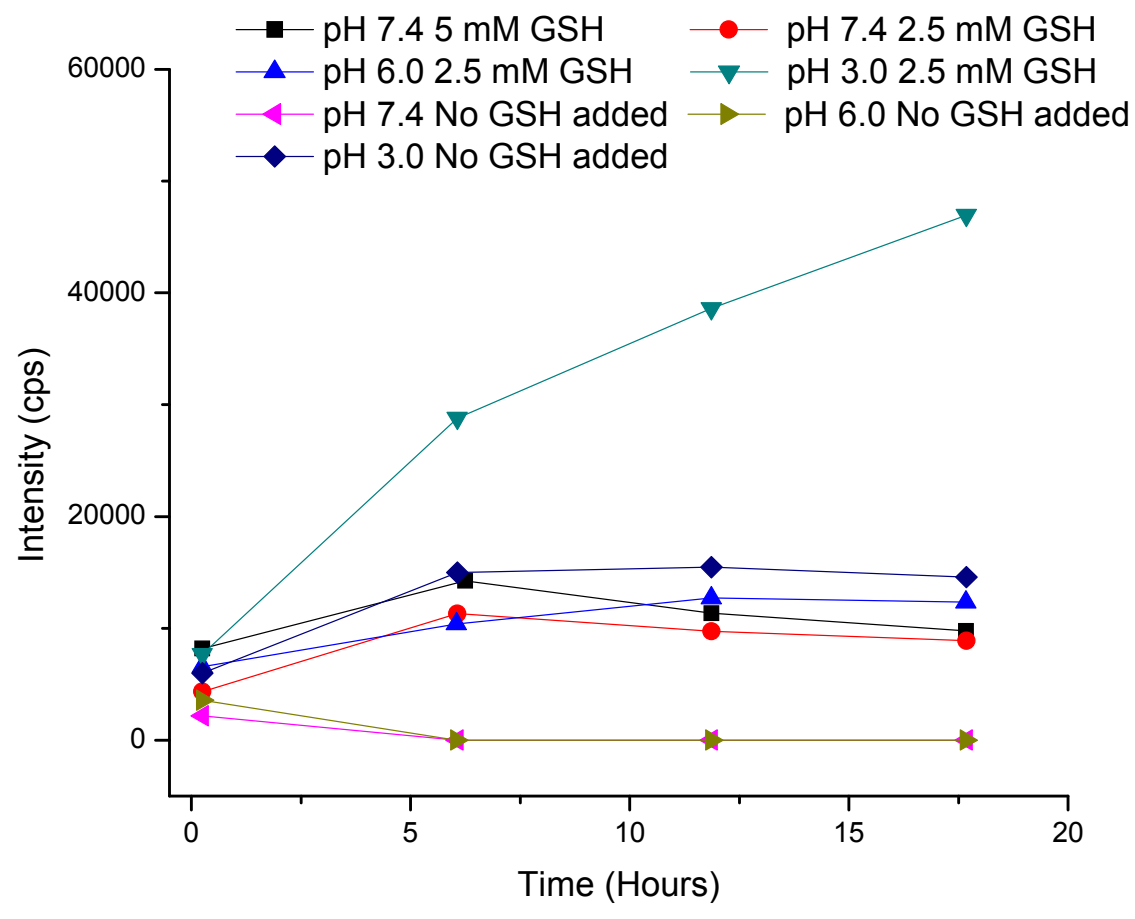

Figure 5.15 Formation of $\mathrm{DMMTA}^{\mathrm{V}}(\mathrm{GS})$ from $\mathrm{DMA}^{\mathrm{III}}(\mathrm{GS})$ at $\mathrm{pH}$ 7.4, 6.0, and 3.0 with As:S mol ratios of 1:2 at different GSH concentrations 


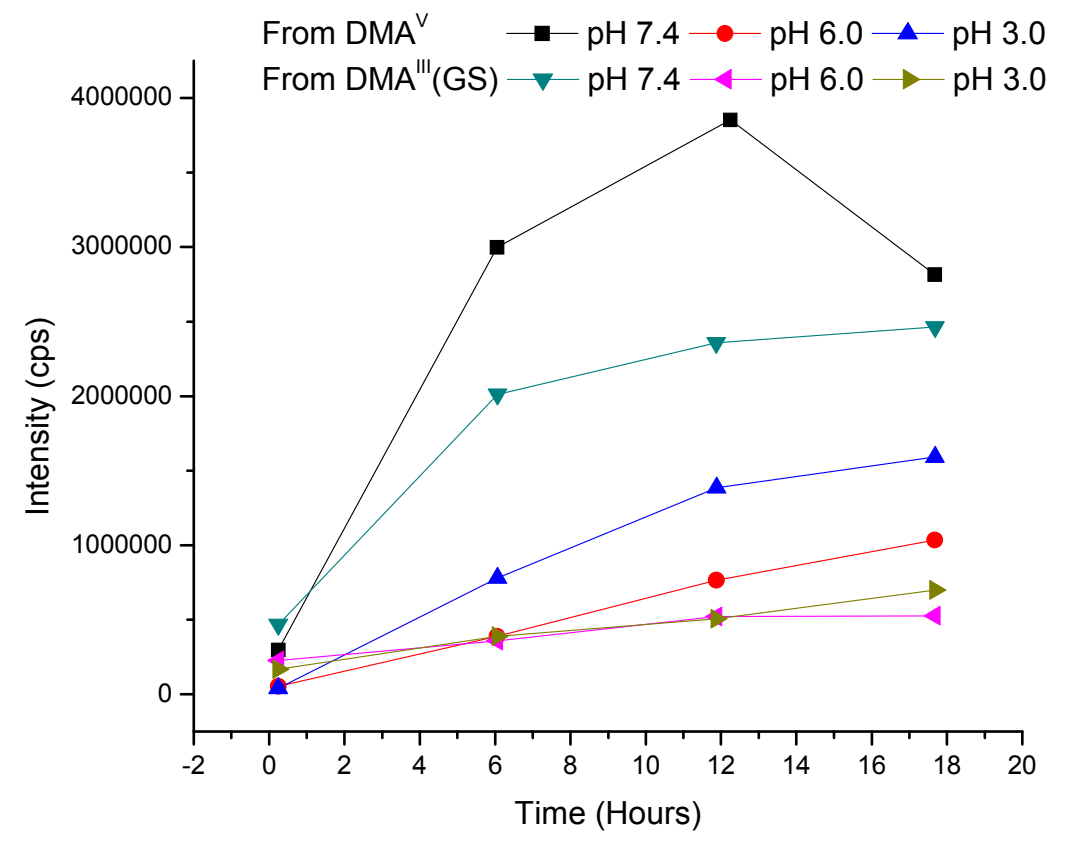

Figure 5.16 Comparison of formation of $\mathrm{DMMTA}^{\mathrm{V}}$ from $\mathrm{DMA}^{\mathrm{V}}$ and $\mathrm{DMA}^{\mathrm{III}}(\mathrm{GS})$ at $\mathrm{pH}$ 3.0, 6.0, and 7.4. The mol ratio of As:S was 1:2. (No GSH was added.)

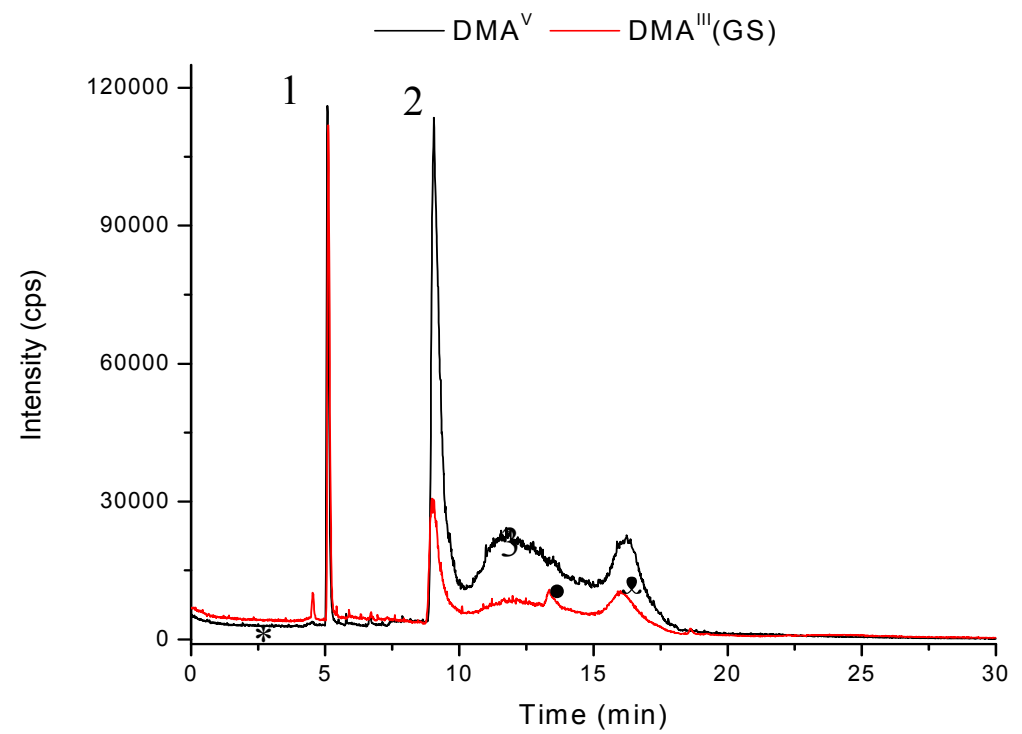

Figure 5.17 Overlay of chromatograms to show the presence of unknown peaks for chromatograms with $\mathrm{DMA}^{\mathrm{III}}(\mathrm{GS})$ as a starting material and the absence of these peaks for experiments where the starting compound was $\mathrm{DMA}^{\mathrm{V}}$. See Table 5.5 for peak identification. 


\subsubsection{Identification of Unknown Peaks}

The major peak produced by the reaction of $\mathrm{DMA}^{\mathrm{III}}(\mathrm{GS})$ with $\mathrm{Na}_{2} \mathrm{~S}$ in the absence of oxygen (assumed to be DMMTA ${ }^{\mathrm{III}}$ ) eluted in between the $\mathrm{DMA}^{\mathrm{V}}$ and the ghost peaks produced by the gradient elution program (Fig. 5.18 A). Once the sample was exposed to air, in less than 5 minutes increase in DMMTA ${ }^{\mathrm{V}}$, DMDTA ${ }^{\mathrm{V}}$, and DMA ${ }^{\mathrm{V}}$ peak areas was observed. To compensate for this, a very quick decrease in the peak area of the compound assumed to be DMMTA ${ }^{\mathrm{III}}$ was observed. The DMMTA ${ }^{\mathrm{III}}$ peak was very large and broad and originally eluted at a slightly longer retention time and partially coeluted with the ghost peak (Fig. 5.18 B). Once the sample was exposed to air, the peak gradually shifted to the retention time of the second unknown peak as the amounts of $\mathrm{DMA}^{\mathrm{v}}$, DMMTA ${ }^{\mathrm{v}}$ and DMDTA ${ }^{\mathrm{v}}$ increased. Additionally, the other unknown peak that elutes right before DMDTA ${ }^{\mathrm{V}}$, though much smaller than the later eluting unknown assumed to be DMMTA ${ }^{\mathrm{III}}$, was observed (Fig. $5.18 \mathrm{C}$ ). Changes in this peak were observed over time. Initially, this unknown and DMDTA ${ }^{\mathrm{V}}$ produced one broad peak that visibly consisted out of two peaks and did not separate well. As the sample was exposed to air, the peak areas of both increased and the presence of two peaks eluting close to each other became apparent. As additional time passed, the unknown peak area decreased and the counts for DMDTA ${ }^{\mathrm{v}}$ increased. 

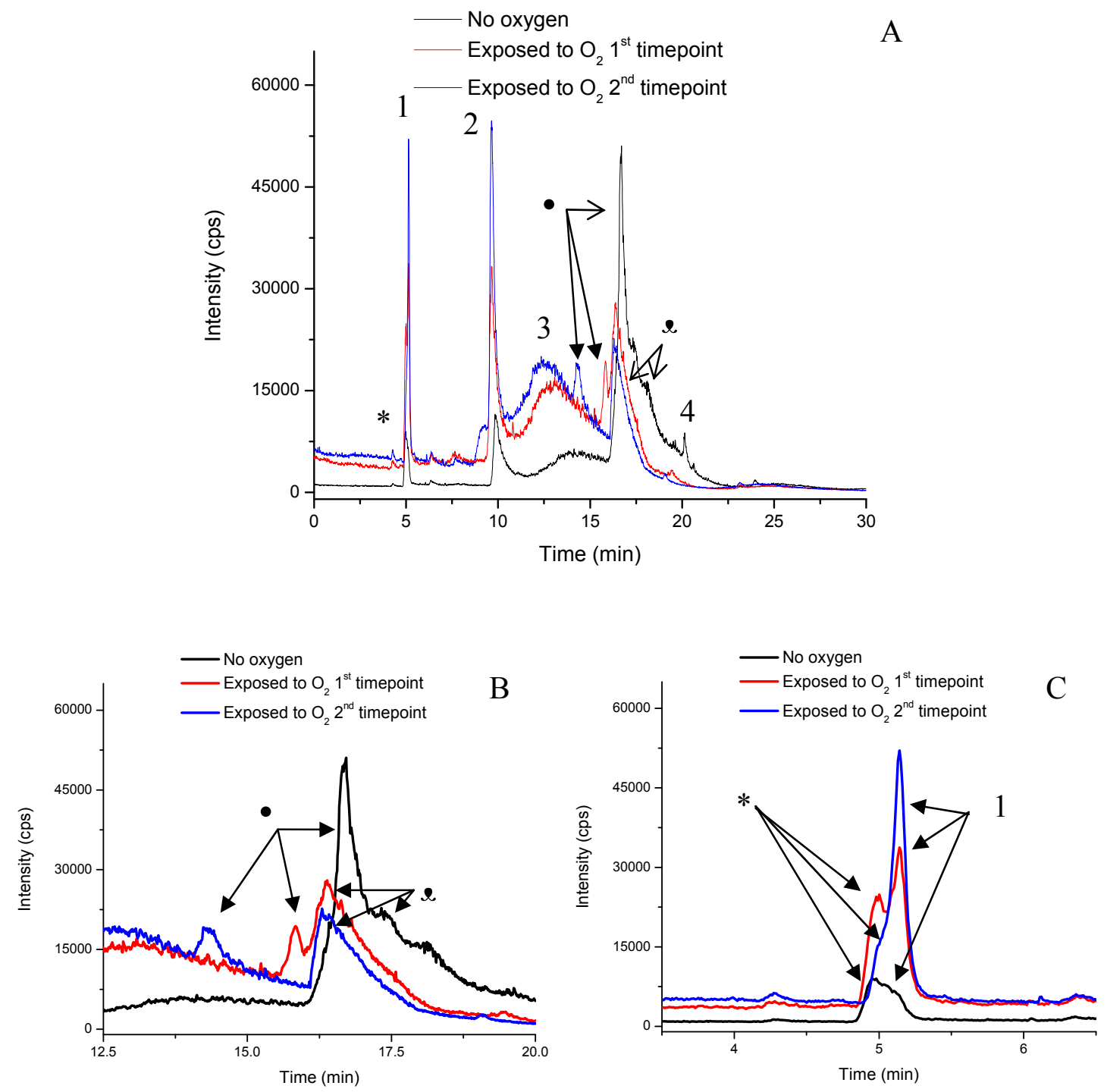

Figure 5.18. (A) Overlay of chromatograms to show changes in peak distribution when a sample produced under anaerobic conditions is gradually exposed to air. To prepare the sample DMA ${ }^{\mathrm{III}}(\mathrm{GS})$ was reacted with $\mathrm{Na} 2 \mathrm{~S}$ in the absence of oxygen, immediately analyzed and then exposed to air and re-analyzed periodically. Chromatograms B) and C) show how the unknown peaks changed in size over time once exposed to air. See Table 5.5 for peak identification. $\left(1^{\text {st }}\right.$ time point: 5 minutes after exposure to air, $2^{\text {nd }}$ time point: 45 minutes after exposure to air.) 


\subsubsection{Enzymatic Reactions}

The amount of DMMTA ${ }^{\mathrm{V}}(\mathrm{GS})$ produced in control samples containing no enzymes were the same as in samples that contained human pi GST or the mixture of human microsomal and cytosolic GSTs extracted from human placenta.

\subsection{Discussion}

Currently it is not known what form or forms of sulfur $\left(\mathrm{H}_{2} \mathrm{~S}, \mathrm{HS}^{-}\right.$, or $\left.\mathrm{S}^{2-}\right)$ are responsible for the formation of DMMTA ${ }^{\mathrm{V}}$. The $\mathrm{pK}_{\mathrm{a} 1}$ of $\mathrm{H}_{2} \mathrm{~S}$ is 7.02 and $\mathrm{pK}_{\mathrm{a} 2}$ is 12.0. As the $\mathrm{pK}_{\mathrm{a} 2}$ is large (the $\mathrm{K}_{\mathrm{a}}$ is so small), as soon as $\mathrm{Na}_{2} \mathrm{~S}$ is dissolved in water, it reacts with water to form $\mathrm{HS}^{-}$and ${ }^{-} \mathrm{OH}$. The resulting solution is very basic. As depicted in Figure 5.19, sulfide $\left(\mathrm{S}^{2-}\right)$ does not exist in appreciable amounts below $\mathrm{pH} 10$.

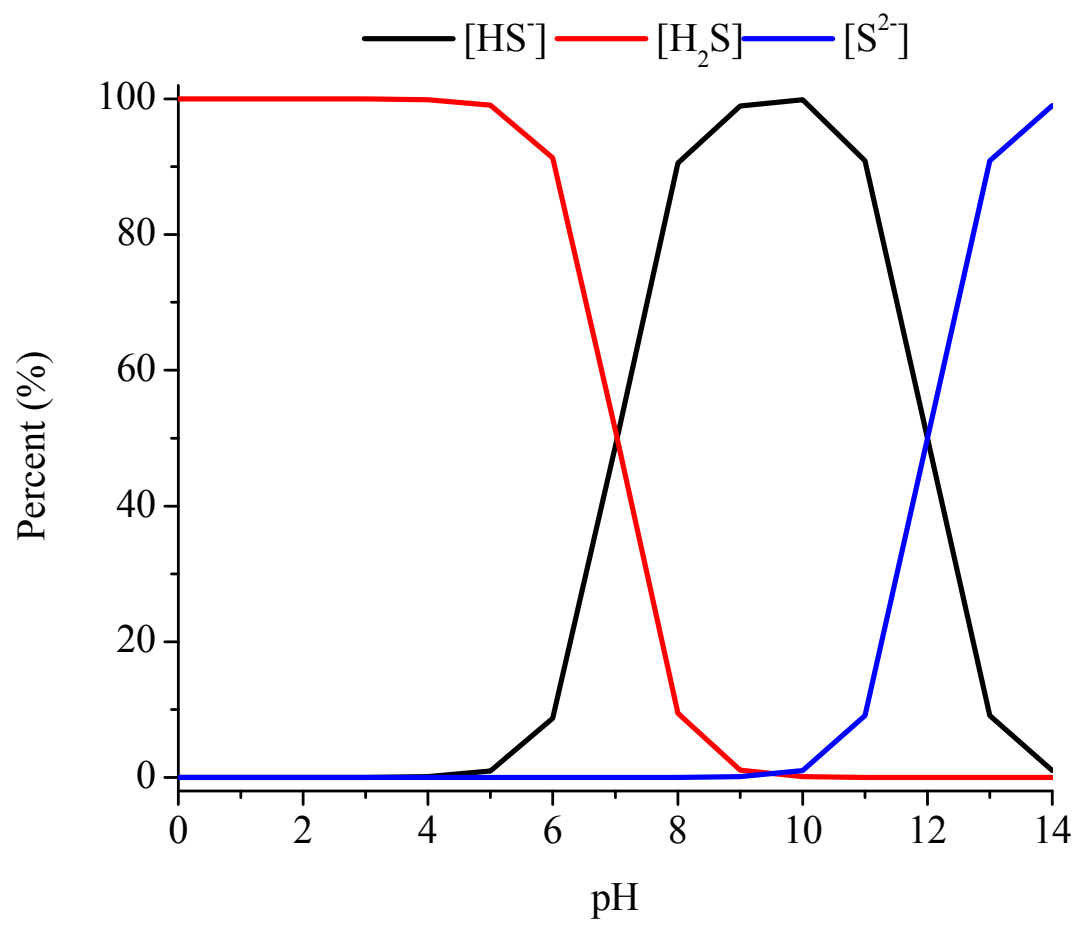

Figure 5.19 Distribution diagram for $\mathrm{H}_{2} \mathrm{~S}$ 
At $\mathrm{pH} 7.4$ almost $3 / 4^{\text {th }}$ of sulfide is present as $\mathrm{HS}^{-}$and the rest as $\mathrm{H}_{2} \mathrm{~S}$. As the $\mathrm{pH}$ drops, the fraction of $\mathrm{H}_{2} \mathrm{~S}$ increases while the portion of $\mathrm{HS}^{-}$decreases. At $\mathrm{pH} 6.0$, over $90 \%$ of the sulfur species is present as $\mathrm{H}_{2} \mathrm{~S}$ and this percentage increases to $99.99 \%$ at $\mathrm{pH}$ 3.0. As I have observed the formation of $\mathrm{DMMTA}^{\mathrm{V}}$ from $\mathrm{DMA}^{\mathrm{V}}$ under $\mathrm{pH}$ conditions where $\mathrm{H}_{2} \mathrm{~S}$ was the major species ( $\mathrm{pH}$ 3.0) and where $\mathrm{HS}^{-}$was the major species (pH 7.4), it is reasonable that both of these species can react with arsenic to form thiolated arsenicals. Larger amounts have formed at $\mathrm{pH} 7.4$, thus I theorize, that depending on the $\mathrm{pH}$ (and thus the form of sulfur present $\left(\mathrm{HS}^{-}\right.$or $\mathrm{H}_{2} \mathrm{~S}$ ) DMMTA ${ }^{\mathrm{V}}$ may form from $\mathrm{DMA}^{\mathrm{V}}$ by different mechanisms. At higher $\mathrm{pH}$, including the physiologically relevant $\mathrm{pH}$ of 7.4, where the major species is $\mathrm{HS}^{-}, \mathrm{DMMTA}^{\mathrm{V}}$ forms by nucleophilic attack of $\mathrm{HS}^{-}$on $\mathrm{DMA}^{\mathrm{V}}$, and no prior reduction of $\mathrm{DMA}^{\mathrm{V}}$ to $\mathrm{DMA}^{\mathrm{III}}$ is required to form $\mathrm{DMMTA}^{\mathrm{V}}$ (Fig. 5.7). On the other hand, at lower $\mathrm{pH}$ values where almost $100 \%$ of sulfide is present in the form of $\mathrm{H}_{2} \mathrm{~S}$ (known reducing agent) or at physiological $\mathrm{pH}$ in a reducing environment maintained by high intracellular GSH levels, the formation of DMMTA ${ }^{\mathrm{V}}$ from $\mathrm{DMA}^{\mathrm{V}}$ is through a different mechanism that may involve the prior reduction of $\mathrm{DMA}^{\mathrm{V}}$ to $\mathrm{DMA}^{\mathrm{III}}$ or $\mathrm{DMA}^{\mathrm{III}}(\mathrm{GS})$ enzymatically or non-enzymatically. While I did not observe DMA ${ }^{\mathrm{III}}$ peaks on the chromatograms where $\mathrm{DMA}^{\mathrm{V}}$ was the starting material, it may have been the result of the fast transformation of $\mathrm{DMA}^{\mathrm{III}}$ to DMMTA ${ }^{\mathrm{III}}$ and ultimately to DMMTA ${ }^{\mathrm{V}}$. Moreover, it is also possible that $\mathrm{DMA}^{\mathrm{V}}$ reacts with $\mathrm{H}_{2} \mathrm{~S}$ to form $\mathrm{DMMTA}^{\mathrm{V}}$ without the prior reduction of $\mathrm{DMA}^{\mathrm{V}}$ to $\mathrm{DMA}^{\mathrm{III}}$ (Fig. 5.7). Considering the faster transformation of $\mathrm{DMA}^{\mathrm{III}}(\mathrm{GS})$ to thiolated arsenicals at physiological $\mathrm{pH}$ compared to lower $\mathrm{pH}$, it seems that the major species responsible for the formation of the As-S compounds is $\mathrm{HS}^{-}$. It is unlikely that under physiological $\mathrm{pH}$ and reducing conditions $\mathrm{S}^{2-}$ 
plays a role in the formation of DMMTA ${ }^{\mathrm{V}}$. Consequently, it is possible that DMMTA ${ }^{\mathrm{V}}$ may form from $\mathrm{H}_{2} \mathrm{~S}$ generated in enzymatic processes in cells in the form of $\mathrm{H}_{2} \mathrm{~S}$ or $\mathrm{HS}^{-}$. As a consequence of the highly debated concentration level of hydrogen sulfide in human cells, its contribution to the formation of thiolated arsenicals cannot be assessed at this point.

It has also been proposed that the source of sulfur for the formation of DMMTA ${ }^{\mathrm{V}}$ may come from sulfane sulfur compounds. When $\mathrm{DMA}^{\mathrm{V}}$ was reacted with only the persulfide GSSH (control) at $\mathrm{pH} 7.4$, almost no DMMTA ${ }^{\mathrm{V}}$ formation was observed but upon the addition of GSH after 10 minutes (to reduce the disulfide bond in GSSH to liberate ${ }^{-} \mathrm{SH}$ ), quick formation of DMMTA ${ }^{\mathrm{V}}$ was observed. It is plausible, that during this reaction DMMTA ${ }^{\mathrm{V}}$ formed from $\mathrm{DMA}^{\mathrm{V}}$ via a reduction step to $\mathrm{DMA}^{\mathrm{III}}$ or $\mathrm{DMA}^{\mathrm{III}}(\mathrm{GS})$ resulting from the addition of GSH or via a non-reductive nucleophilic attach by $\mathrm{HS}^{-}$ (liberated from GSSH with the help of GSH) on DMA ${ }^{\mathrm{V}}$. The prior reduction of the $\mathrm{DMA}^{\mathrm{V}}$ to $\mathrm{DMA}^{\mathrm{III}}$ or $\mathrm{DMA}^{\mathrm{III}}(\mathrm{GS})$ after the addition of GSH is unlikely as the amount of GSH added was very small and the formation of DMA ${ }^{\mathrm{III}}(\mathrm{GS})$ is very slow and takes place to a minimal extent in the absence of excess GSH at $\mathrm{pH} 7.4$, while the formation of $\mathrm{DMMTA}^{\mathrm{V}}$ was very fast. Moreover, no $\mathrm{DMA}^{\mathrm{III}}(\mathrm{GS})$ peak was observed though this compound is more stable than DMA $\mathrm{DII}^{\mathrm{III}}$ and should have appeared on the chromatograms. Thus I suspect that the major reaction was a nucleophilic attack by HS, liberated from GSSH with the help of GSH, on DMA ${ }^{\mathrm{v}}$ without the prior reduction of $\mathrm{DMA}^{\mathrm{V}}$. The experiment involving GSSH, a model compound for protein persulfides, indicates that in the reducing environment of cells, it is indeed possible that the thiolated As species form from $\mathrm{HS}^{-}$released from protein or other persulfides with the help of GSH, Cys, or other 
biomolecules capable of reducing disulfide bonds. According to a recent report, the formation of persulfides in cells is prevalent; approximately $10-25 \%$ of many hepatic proteins are sulfhydrated under physiological conditions. ${ }^{162}$ Depending on the intracellular level of GSH and other reductants, ${ }^{-} \mathrm{SH}$ can be liberated from persulfides and directly utilized for the formation of thiolated arsenicals. It is also a possibility that in the first step arsenic directly reacts with the terminal S atom of $\mathrm{R}_{-} \mathrm{S}-\mathrm{S}^{-}$and forms a complex and then the disulfide gets reduced and two compounds, a thiolated arsenical and a reduced R-SH or R-S forms. As sulfuration (attachment of ${ }^{-} \mathrm{SH}$ to thiols of biomolecules forming persulfide popularly, but incorrectly referred to as sulfhydration) alters protein function (may hyperactivate or deactivate it), the loss of ${ }^{-} \mathrm{SH}$ to form thiolated arsenicals may significantly affect protein function and in turn, the survival of the cell. On an important note, it was shown that cystathionine beta synthase (CBS) and cystathionine gamma lyase (CSE), responsible for the generation of $\mathrm{H}_{2} \mathrm{~S}$ in the presence of L-cysteine, are also partially responsible for donating the hydrogen sulfide needed for the generation of protein persulfides. In the liver of $\mathrm{CSE}^{-/ /}$knockout mice (no working CSE present), it was shown that endogenous sulfhydration was abolished indicating that proteins are physiologically sulfhydrated through CSE activity. ${ }^{162}$ Thus it is reasonable that not only the direct destruction of these protein persulfides during thiolated arsenic metabolite formation may be responsible for the toxicity of arsenic (in addition to other known mechanisms), but by utilizing the $\mathrm{H}_{2} \mathrm{~S}$ needed for the synthesis of these protein persulfides for thiolated arsenic species production, these important post translational protein modifications cannot take place, or to a smaller extent, and such their enzymatic capabilities diminishes contributing to As toxicity indirectly. 
Formation studies revealed that while DMMTA $^{\mathrm{V}}$ very easily formed from $\mathrm{DMA}^{\mathrm{III}}(\mathrm{GS})$ at physiological $\mathrm{pH}$, as the GSH concentration increased, the amount of DMMTA $^{\mathrm{V}}$ decreased. The reason for this is that as the GSH concentration increased at $\mathrm{pH}$ 7.4, the DMDTA ${ }^{\mathrm{V}}$ concentration increased. As far as the $\mathrm{pH}$ dependence of DMMTA $^{\mathrm{v}}$ formation is concerned, at a specific GSH concentration, the highest amount formed at $\mathrm{pH} 7.4$ and lesser amounts at 6.0 and 3.0. Interestingly, at all the tested GSH concentrations, slightly more $\mathrm{DMMTA}^{\mathrm{V}}$ was present at $\mathrm{pH} 3.0$ than 6.0. The reason for the unusually high DMMTA ${ }^{\mathrm{V}}$ concentration at $\mathrm{pH} 3.0$ is that at this $\mathrm{pH}$ the formation of DMDTA $^{\mathrm{V}}$ is not favored, and most of the thiolated species are in the form of DMMTA ${ }^{\mathrm{V}}$. The reason for this probably lies in the fact that almost all sulfur is in the form of $\mathrm{H}_{2} \mathrm{~S}$ at $\mathrm{pH}$ 3.0. As seen in Figure 5.7, under strongly acidic conditions, $\mathrm{DMMTA}^{\mathrm{V}}$ can form from DMA $^{\mathrm{V}}$ with the help of $\mathrm{H}_{2} \mathrm{~S}$, but the formation of DMDTA ${ }^{\mathrm{V}}$ from DMMTA ${ }^{\mathrm{V}}$ requires the presence of $\mathrm{HS}^{-}$and cannot form from $\mathrm{H}_{2} \mathrm{~S}$. As expected, at the same $\mathrm{pH}$, as the concentration of sulfide increased, the peak distribution shifted to DMDTA ${ }^{\mathrm{V}}$ from DMMTA $^{\mathrm{V}}$, except at $\mathrm{pH} 3.0$ where the formation of DMDTA ${ }^{\mathrm{V}}$ was not favored.

On the basis of prior stability testing in our lab, it was not surprising that $\mathrm{DMA}^{\mathrm{III}}(\mathrm{GS})$ was found to be unstable at physiological $\mathrm{pH}$, and quickly transformed to other species. ${ }^{34}$, 115 The formation of $\mathrm{DMA}^{\mathrm{III}}(\mathrm{GS})$ was preferred at lower $\mathrm{pH}$ and at higher GSH concentrations at a specific $\mathrm{pH}$. DMA ${ }^{\mathrm{III}}$ almost completely mirrored the tendency of $\mathrm{DMA}^{\mathrm{III}}(\mathrm{GS})$ formation under different conditions, thus I suspect that probably most of the DMA ${ }^{\mathrm{III}}$ observed originates from the hydrolysis of $\mathrm{DMA}^{\mathrm{III}}(\mathrm{GS})$ on the LC column to DMA $^{\mathrm{III}}$ and GSH during HPLC separation. 
The formation of DMMTA ${ }^{\mathrm{V}}(\mathrm{GS})$ was also preferred at lower $\mathrm{pH}$ and at higher GSH concentrations at a specific $\mathrm{pH}$. Though only to a very small extent, I did observe the formation of $\operatorname{DMMTA}^{\mathrm{V}}(\mathrm{GS})$ at $\mathrm{pH} 7.4$ in the presence of 2.5 and $5.0 \mathrm{mM} \mathrm{GSH}$, but not in the absence of it. These results are in contrast with those reported by Suzuki and Naranmandura who found that $\operatorname{DMMTA}^{\mathrm{V}}(\mathrm{GS})$ forms only below $\mathrm{pH} 7{ }^{111,135}$ It is possible that the method used by them was either not sensitive enough to detect $\operatorname{DMMTA}^{\mathrm{V}}(\mathrm{GS})$ at a very low concentration or it hydrolyzed on the column during separation. Additionally, care must be taken to maintain the native GSH concentration of cells during sample preparation prior to analysis to minimalize the hydrolysis of $\operatorname{DMMTA}^{\mathrm{V}}(\mathrm{GS})$ and other GSH conjugated species. In my experiments, the sample GSH concentrations were maintained at all tested (2.5 and $5.0 \mathrm{mM}) \mathrm{GSH}$ levels at all times. These results showed, that it may be possible that $\operatorname{DMMTA}^{\mathrm{V}}(\mathrm{GS})$ indeed forms to a very small extent at $\mathrm{pH} 7.4$ in cells with high GSH concentration non-enzymatically. Our previous experiments in heat deactivated cells (Chapter 3) did not show the presence of this compound at $\mathrm{pH}$ 7.4. It is likely, that in the presence of cells, due to matrix effects, this small amount of DMMTA ${ }^{\mathrm{V}}(\mathrm{GS})$ may not be detectable.

The chromatograms obtained with DMA ${ }^{\mathrm{III}}(\mathrm{GS})$ as the starting compound showed two unidentified peaks, one eluting before DMDTA ${ }^{\mathrm{V}}$, and one eluting after the $\mathrm{DMA}^{\mathrm{V}}$ peak. These peaks did not show up in the chromatograms where $\mathrm{DMA}^{\mathrm{V}}$ was the starting compound. Moreover, no $\mathrm{DMA}^{\mathrm{III}}$ peak was observed in the $\mathrm{DMA}^{\mathrm{V}}$ chromatograms. These results indicate that the formation of $\mathrm{DMMTA}^{\mathrm{V}}$ from $\mathrm{DMA}^{\mathrm{V}}$ and $\mathrm{DMA}^{\mathrm{III}}(\mathrm{GS})$ are likely through different pathways and the reduction of $\mathrm{DMA}^{\mathrm{V}}$ to $\mathrm{DMA}^{\mathrm{III}}$ and the oxidation of $\mathrm{DMA}^{\mathrm{III}}(\mathrm{GS})$ to $\mathrm{DMA}^{\mathrm{V}}$ are not needed prior to the formation of DMMTA ${ }^{\mathrm{V}}$. 
As comparable amounts of DMMTA ${ }^{\mathrm{V}}$ formed from both $\mathrm{DMA}^{\mathrm{V}}$ and $\mathrm{DMA}^{\mathrm{III}}(\mathrm{GS})$ at $\mathrm{pH}$ 7.4 (Fig. 5.16), the formation of DMMTA ${ }^{\mathrm{V}}$ is possible under physiological $\mathrm{pH}$ via both the $\mathrm{DMA}^{\mathrm{V}}$ and the dimerization pathways (Fig. 5.7).

In order to decipher the mechanism of DMMTA ${ }^{\mathrm{V}}$ formation from $\mathrm{DMA}^{\mathrm{III}}(\mathrm{GS})$ via the dimerization pathway, I attempted to identify the unknown peaks observed in the chromatograms where the starting material was $\mathrm{DMA}^{\mathrm{III}}(\mathrm{GS})$. According to the dimerization pathway, DMMTA ${ }^{\mathrm{III}}$ is an important intermediate in this route, thus I attempted to determine if one of the unknown peaks is DMMTA ${ }^{\mathrm{III}}$. Unfortunately, no description of the synthesis of this very highly oxidation prone compound is available in the literature to my knowledge. Experiments carried out to synthesize DMMTA ${ }^{\mathrm{III}}$ yielded a peak with a retention time close to the second unknown peak. The chromatogram in Figure 5.18 clearly showed as the peak area of the DMA ${ }^{\mathrm{V}}$ (always eluting as a broad peak) increases, its retention time (RT) decreases (along with the RT of the unknown peak) and such exhibits a Langmuir type of behavior. This type of behavior of peaks presents when solute-stationary phase interactions are strong and solute-solute interactions are relatively weak, as arises in cases when the stationary phase has sites capable of hydrogen bonding with the compound producing the peak. ${ }^{168-171}$ This type of behavior of $\mathrm{DMA}^{\mathrm{V}}$ affects the retention time of the later eluting peaks including the peak assumed to be DMMTA ${ }^{\mathrm{III}}$. Consequently, DMMTA ${ }^{\mathrm{III}}$ elutes earlier when $\mathrm{DMA}^{\mathrm{V}}$ is present in larger concentrations. At lower $\mathrm{DMA}^{\mathrm{V}}$ concentrations, the retention time of the DMMTA $^{\text {III }}$ increases and the peak is pushed closer to the later eluting ghost peak produced by the gradient program. Moreover, at high DMMTA ${ }^{\mathrm{III}}$ concentrations a broad peak is produced and makes it hard to separate it from the ghost peak. On the basis of 
these results, though not unequivocally, I can make the assumption that the second unknown is probably the highly unstable and oxidation prone DMMTA ${ }^{\mathrm{III}}$. Though presently I have no evidence, I assume that the peak eluting before DMDTA ${ }^{\mathrm{V}}$ is produced by one of the dimers or a mix of these dimers. These dimers we expect to be far less stable than DMMTA ${ }^{\mathrm{III}}$, and such they present with much smaller peak areas resulting from their fast transformation into other species.

Human microsomal and cytosolic GSTs did not seem to catalyze the formation of $\operatorname{DMMTA}^{\mathrm{V}}(\mathrm{GS})$. Further experiments are needed to find the biomolecule responsible for the enzymatic catalysis of this species in biological systems. As the results showed, it is also possible that to a small extent $\operatorname{DMMTA}^{\mathrm{V}}(\mathrm{GS})$ forms at $\mathrm{pH} 7.4$ non-enzymatically, thus some of the DMMTA ${ }^{\mathrm{V}}(\mathrm{GS})$ seen in cells may have formed non-enzymatically, though considering the large amounts observed within a short period of time, its formation must be mainly enzymatically catalyzed in cells. Moreover, it is possible that in intact cells DMMTA ${ }^{\mathrm{V}}(\mathrm{GS})$ forms in acidic organelles. 


\section{CHAPTER 6}

Stabilization of Arsenic Metabolites in Biological Samples: The Chapter of Negative

Results 


\subsection{Introduction}

In order to correctly assess the toxicity of arsenic-containing compounds in biological samples, the true metabolic speciation profile of the arsenical must be obtained. Unfortunately, many of the human As metabolites are highly unstable and during storage, sample preparation, and analysis transform to other species possessing different toxicities than the original species present. Arsenite (As ${ }^{\mathrm{III}}$ ), monomethylarsonous acid $\left(\mathrm{MMA}^{\mathrm{III}}\right)$, and especially dimethylarsinous acid $\left(\mathrm{DMA}^{\mathrm{III}}\right)$ are prone to oxidation to their much less toxic pentavalent counterparts arsenate $\left(\mathrm{As}^{\mathrm{V}}\right)$, monomethylarsonic acid $\left(\mathrm{MMA}^{\mathrm{V}}\right)$, and dimethylarsinic acid $\left(\mathrm{DMA}^{\mathrm{V}}\right)$. Arsino-glutathione $\left(\mathrm{As}^{\mathrm{III}}(\mathrm{GS})_{3}\right)$, monomethylarsino-glutathione $\left(\mathrm{MMA}^{\mathrm{III}}(\mathrm{GS})_{2}\right)$, and dimethylarsinoglutathione $\left(\mathrm{DMA}^{\mathrm{III}}(\mathrm{GS})\right)$ can easily and quickly hydrolyze to their non-GSH conjugated trivalent counterparts $\left(\mathrm{As}^{\mathrm{III}}, \mathrm{MMA}^{\mathrm{III}}\right.$, and $\left.\mathrm{DMA}^{\mathrm{III}}\right)$ once the native $\mathrm{GSH}$ concentration of the cells is diluted during sample preparation prior to speciation analysis. These non-GSH conjugated trivalent species (especially $\mathrm{DMA}^{\mathrm{III}}$ ) then are easily oxidized to their less toxic pentavalent counterparts.

Consequently, great care must be taken with sample storage and preparation to conserve species identities to enable us to obtain the true speciation profile of arsenic metabolites in human cells. Colder temperature (especially freezing) was shown to retard the oxidation of the trivalent species. ${ }^{118,172} \mathrm{pH}$ was shown to help conserve species identities as well. The highly toxic and oxidation prone $\mathrm{DMA}^{\mathrm{III}}$ was shown to have a much higher stability at $\mathrm{pH} 6.0$ than at $\mathrm{pH} 3.2 .{ }^{151}$ Dimethyldithioarsinic acid $\left(\mathrm{DMDTA}^{\mathrm{V}}\right)$ displays higher stability at the physiological $\mathrm{pH}$ of 7.4 but then its stability significantly drops below $\mathrm{pH}$ 6.0. ${ }^{135}$ The newly found human arsenic metabolite dimethylarsinothioyl 
glutathione $\left(\operatorname{DMMTA}^{\mathrm{V}}(\mathrm{GS})\right)$ was found to be more stable at $\mathrm{pH} 6.0$ than at 7.4 or at lower $\mathrm{pH}$ values upon extraction. ${ }^{34}$ On the other hand, trivalent GSH complexes, $\mathrm{As}^{\mathrm{III}}(\mathrm{GS}) 3, \mathrm{MMA}^{\mathrm{III}}(\mathrm{GS})_{2}$, and $\left.\mathrm{DMA}^{\mathrm{III}}(\mathrm{GS})\right)$ displayed the opposite trend; namely, at lower $\mathrm{pH}$ (such as $\mathrm{pH} 2.0$ ) these complexes had a much longer half-life than at $\mathrm{pH}$ 7.4. ${ }^{115}$ In summary, arsenicals display significantly different stabilities at different $\mathrm{pH}$ values, thus when a mixture of these compounds is potentially present in biological samples, $\mathrm{pH}$ cannot be used alone to preserve species identities. It was shown that maintaining GSH concentrations helps preserve the identities of trivalent GSH complexes. The native GSH concentration of the cells is between $1-10 \mathrm{mM}$ providing a reducing environment necessary for the life of the cell. During sample preparation, the extraction solvent significantly dilutes the GSH concentration of the sample thus promotes the hydrolyzation of GSH complexes and changes the redox environment of these oxidation prone species to favor oxidation.

In order to conserve species identities during storage, sample preparation, and extraction, I performed experiments to find a compound that can

a) stabilize and prevent the hydrolysis and oxidation of the trivalent GSH complexes to their less toxic pentavalent counterparts and

b) prevent the transformation of the other oxidation prone trivalent arsenicals to pentavalent arsenicals displaying much lower toxicities and

c) conserve trivalent species without the reduction of the pentavalent species to their more toxic trivalent counterparts. 


\subsection{Experimental Procedures and Results}

As mentioned above, on the basis of prior studies $\mathrm{pH}$ control alone was determined not to be suitable for the stabilization of all possible human As metabolites as a consequence of their varying stability as a function of $\mathrm{pH}$. Thus, I examined if it was possible to chemically stabilize these species without altering species identities. Numerous compounds were evaluated for this purpose. They were selected on the basis of their potential ability to stabilize trivalent arsenicals either by complexing them thus preventing their oxidation or by acting as oxygen scavengers to retard the oxidation of trivalent species. A summary of some of the agents explored for the stabilization of trivalent species is displayed in Table 6.1. These agents were added to solutions of trivalent arsenicals at different $\mathrm{pH}$ values (between 2.0-7.4) and different As:chemical mol ratios. The samples were monitored over time to determine if the oxidation states of all species were maintained.

\subsection{Discussion}

\subsubsection{Oxygen Scavengers}

Oxygen scavengers such as ascorbic acid, to a small degree were able to slow down the oxidation of trivalent arsenicals without the reduction of pentavalent arsenicals. Unfortunately, not only they were unable to significantly retard the oxidation of trivalent species, but when these chemicals were added to biological samples, they altered the

original $\mathrm{pH}$ of the sample and diluted the native GSH concentration, thus had a negative effect on the stability of GSH complexes and potentially other species. Oxygen scavengers were found to be unable to conserve As species identities and maintain their stabilities as a result. 
Table 6.1 Agents explored for the stabilization of labile arsenicals

\begin{tabular}{|c|c|c|c|}
\hline Name & Structure & On the basis of & Results \\
\hline $\begin{array}{l}\mathbf{N H}_{2} \mathbf{O H} \cdot \mathbf{H C l} \\
\text { (hydroxylamine } \\
\text { hydrochloride) }\end{array}$ & & $\begin{array}{c}\text { Can provide a mild } \\
\text { reducing environment } \\
\text { and act as a sacrificial } \\
\text { oxidant. Previously } \\
\text { shown to help preserve } \\
\text { As }{ }^{\text {III }} \text { in soil and } \\
\text { sediments. }{ }^{173,174}\end{array}$ & $\begin{array}{l}\text { Did not retard the oxidation } \\
\text { of } \mathrm{DMA}^{\mathrm{III}} \text {. }\end{array}$ \\
\hline Ascorbic acid & & $\begin{array}{l}\text { As an antioxidant was } \\
\text { previously reported to } \\
\text { help the stabilization of } \\
\text { some arsenicals. }{ }^{175}\end{array}$ & $\begin{array}{l}\text { Did not retard the oxidation } \\
\text { of } \mathrm{DMA}^{\mathrm{III}} \text {. }\end{array}$ \\
\hline $\begin{array}{c}\text { DMSA } \\
\text { (meso-2,3- } \\
\text { dimercaptosuccinic } \\
\text { acid) }\end{array}$ & & Complexing agent. & $\begin{array}{l}\text { Fast and effective reducer of } \\
\text { pentavalent species. }\end{array}$ \\
\hline $\begin{array}{c}\text { DMPS } \\
(2,3-\text { Dimercapto-1- } \\
\text { propanesulfonic acid) }\end{array}$ & & Complexing agent. & $\begin{array}{l}\text { Was found to reduce } \\
\text { pentavalent species. }\end{array}$ \\
\hline $\begin{array}{c}\text { APDC } \\
\text { (pyrrolidine } \\
\text { dithiocarbamate } \\
\text { ammonium salt) } \\
\end{array}$ & & $\begin{array}{l}\text { Complexing agent for } \\
\text { the extraction of } \\
\text { arsenicals. }{ }^{176,177}\end{array}$ & $\begin{array}{l}\text { Was found to reduce } \\
\text { pentavalens species. }\end{array}$ \\
\hline $\begin{array}{c}\text { NaDDC } \\
\text { (Sodium } \\
\text { diethyldithiocarbamate) }\end{array}$ & & $\begin{array}{l}\text { Complexing agent that } \\
\text { was shown to stabilize } \\
\text { As }^{\text {III }} \text { in soil. }{ }^{173}\end{array}$ & $\begin{array}{l}\text { Reduction of some } \\
\text { pentavalent arsenical was } \\
\text { observed in addition to the } \\
\text { appearance of complexation } \\
\text { products. It was found to } \\
\text { destroy DMA(GS). }\end{array}$ \\
\hline $\begin{array}{c}\text { TGA or MAA } \\
\text { (thioglycolic acid, } \\
\text { mercaptoacetic acid) } \\
\end{array}$ & & $\begin{array}{l}\text { Monothiol, complexes } \\
\text { with metals. }\end{array}$ & $\begin{array}{l}\text { Was found to reduce } \\
\text { pentavalens species. }\end{array}$ \\
\hline $\begin{array}{l}\text { DTPA (diethylene } \\
\text { triamine pentaacetic } \\
\text { acid) }\end{array}$ & & $\begin{array}{l}\text { Used for intracellular } \\
\text { chelation. }\end{array}$ & $\begin{array}{c}\text { Resulted in very complex } \\
\text { ESI spectrum and did not } \\
\text { prevent the oxidation of } \\
\text { DMA }\end{array}$ \\
\hline Glycine & $\mathrm{NH}_{2}$ & $\begin{array}{c}\text { Was shown to help } \\
\text { preserve the oxidation } \\
\text { state of GSAO, a } \\
\text { trivalent arsenical at pH } \\
7 \text { over time } \\
\end{array}$ & $\begin{array}{l}\text { Was found not to retard the } \\
\text { oxidation of trivalent species } \\
\text { over time }\end{array}$ \\
\hline
\end{tabular}




\subsubsection{Non-thiol-containing Chelators}

Non-thiol-containing chelators such as EDTA and DTPE were unable to prevent the oxidation of trivalent arsenicals. Additionally, during the addition of chelators, the native GSH concentration was diluted as well negatively affecting the stability of GSH complexes.

\subsubsection{Glycine}

Glycine was shown not to help retard the oxidation of the trivalent species.

\subsubsection{Thiol-containing Agents}

Thiol-containing chemicals are routinely used to complex arsenicals. ${ }^{62,} 178$ Unfortunately, while they provide a reducing environment to maintain the oxidation state of the trivalent species, they reduce pentavalent arsenicals to their more toxic trivalent counterparts with various extents. Moreover, as $\mathrm{As}^{\mathrm{V}}, \mathrm{MMA}^{\mathrm{V}}$, and $\mathrm{DMA}^{\mathrm{V}}$ have different affinities for reduction by the same species, the extent of reduction is also arsenic species dependent. These agents have also shown the ability to replace GSH on the trivalent GSH complexes making it impossible to evaluate the amounts of trivalent non-GSH conjugated arsenicals (As ${ }^{\mathrm{III}}, \mathrm{MMA}^{\mathrm{III}}$, and DMA ${ }^{\mathrm{III}}$ ) and their GSH complexes (AsIII(GS) ${ }_{3}$, $\mathrm{MMA}^{\mathrm{III}}(\mathrm{GS})_{2}$, and $\left.\mathrm{DMA}^{\mathrm{III}}(\mathrm{GS})\right)$ that were present in the original sample.

As an example, when NaDDC was evaluated for the stabilization of trivalent species, it was found to destroy the glutathione complex of DMA ${ }^{\mathrm{III}}$ (Fig. 6.1), thus $\mathrm{DMA}^{\mathrm{III}}$ and $\mathrm{DMA}^{\mathrm{III}}(\mathrm{GS})$ both appeared on the chromatogram as a mix of DMA ${ }^{\mathrm{III}}$ and $\mathrm{DMA}^{\mathrm{V}}$. As previous experiments have shown, GSH was found to be the only species capable of maintaining the identity of DMA ${ }^{\mathrm{III}}(\mathrm{GS})$ over extended periods of time (Fig. $6.1)$. 


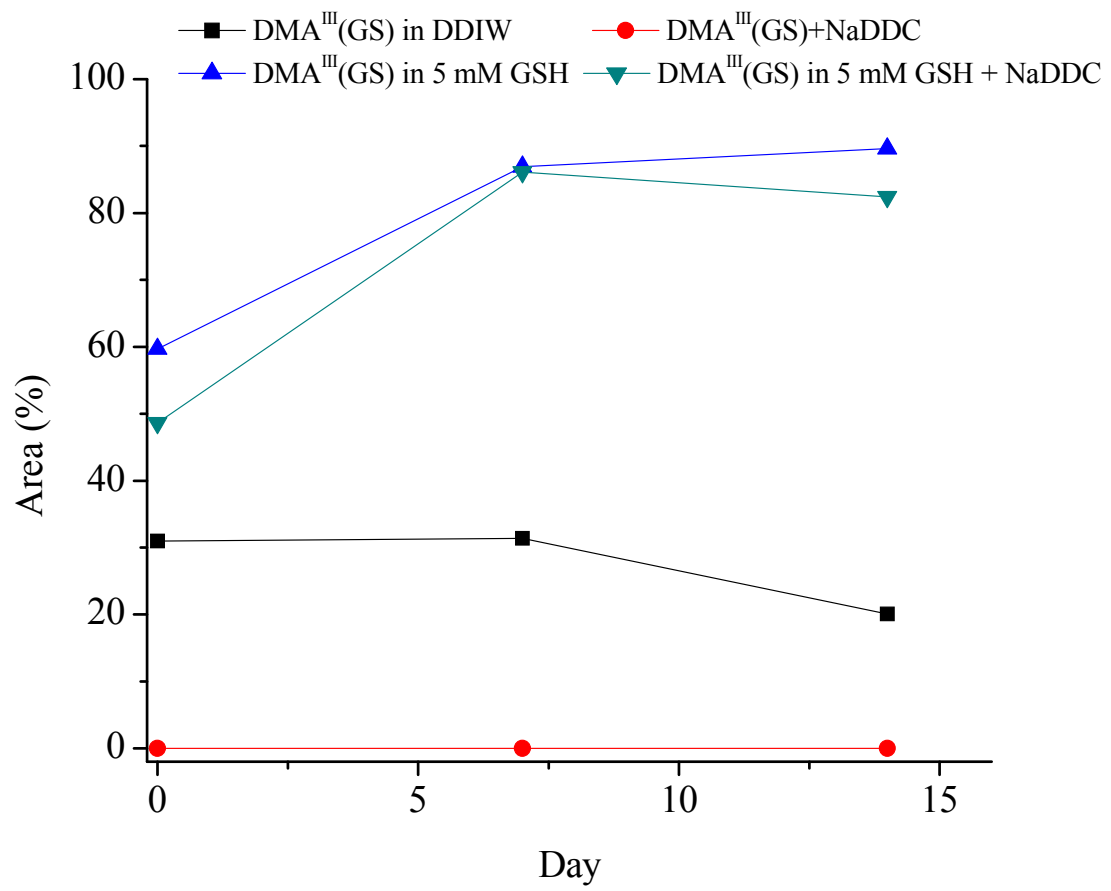

Figure 6.1 Stability of DMA ${ }^{\mathrm{III}}(\mathrm{GS})$ in the presence of NaDDC and/or GSH. The mol ratio of As:NaDDC was $1: 2$ and the samples were kept at $-4 \mathrm{C}^{\circ}$ in the freezer and were periodically reanalyzed to monitor DMA ${ }^{\mathrm{III}}(\mathrm{GS})$ stability.

\subsection{Conclusions}

On the basis of my results and an extensive review of the literature, it is my opinion, that there is no single compound that can preserve the species identities of all possible arsenic metabolites in biological samples. It is my recommendation, that in order to maintain true species distribution, the following procedures should be observed for sample storage and preparation prior to analysis:

1) The sample should be kept frozen until analysis. 
2) If possible, the sample should be processed in an oxygen free environment, such as a glove box filled with an inert gas, to avoid the oxidation of highly labile and toxic species such as DMA ${ }^{\mathrm{III}}$ and dimethylmonothioarsinous acid (DMMTA ${ }^{\mathrm{III}}$ ).

3) Extraction solvent: The $\mathrm{pH}$ and the redox environment of the cells should be maintained throughout sample processing. The usage of buffer mimicking physiological $\mathrm{pH}$ or double deionized water is recommended for sample preparation. The native GSH concentration of the biological sample should be measured prior to analysis and this GSH concentration should be maintained during sample dilution.

4) Samples should be analyzed immediately after preparation. 


\section{CHAPTER 7}

Summary, Significance, and Future Research Directions 


\subsection{Summary}

\subsubsection{Dimethylarsinothioyl Glutathione}

The formation of the newly discovered human metabolite dimethylarsinothioyl glutathione (DMMTA ${ }^{\mathrm{V}}(\mathrm{GS})$ ) was confirmed in human multiple myeloma and identified for the first time in lymphoma cell lines employing high performance liquid chromatography inductively coupled mass spectrometry (HPLC-ICPMS) and high performance liquid chromatography electrospray ionization tandem mass spectrometry (HPLC-ESI-MS/MS). The $\mathrm{pH}$ range of formation of $\mathrm{DMMTA}^{\mathrm{V}}(\mathrm{GS})$ was evaluated. Dimethylarsinothioyl glutathione (DMMTA ${ }^{\mathrm{V}}(\mathrm{GS})$ ) was found to form at the tested $\mathrm{pH}$ range of 3.0 to 7.4. Its formation was the most favorable at low $\mathrm{pH}$ and at higher GSH concentrations. Dimethylarsinothioyl glutathione was also found to form non-enzymatically at $\mathrm{pH} 7.4$ in the presence of 2.5 and $5.0 \mathrm{mM}$ GSH to a very small extent. At pH 7.4 in the presence of cells, significant amounts of DMMTA $(\mathrm{V}$ (G) formed in a short period of time indicating that it is probably mostly forms via an enzymatically catalyzed reaction under physiological conditions. Attempts to find the enzyme that may catalyze its formation in human cells were carried out. I examined if human microsomal and cytosolic GSTs may catalyze the formation of $\operatorname{DMMTA}^{\mathrm{V}}(\mathrm{GS})$, and in particular human cytosolic class pi GST. The enzymes studied did not catalyze the formation of $\operatorname{DMMTA}^{\mathrm{V}}(\mathrm{GS})$ from DMMTA ${ }^{\mathrm{V}}$. While the enzyme(s) responsible for the formation of $\operatorname{DMMTA}^{\mathrm{V}}(\mathrm{GS})$ remained elusive, I provided further proof that it is mostly enzymatically catalyzed in human cells. Moreover, it is also plausible that $\operatorname{DMMTA}^{\mathrm{V}}(\mathrm{GS})$ forms in acidic organelles in intact cells. 
In order to understand the toxicological importance of the formation of $\operatorname{DMMTA}^{\mathrm{V}}(\mathrm{GS})$, its toxicity and uptake by cancer cells was evaluated along with the toxicities and uptakes of Darinaparsin (dimethylarsinous glutathione, DMA ${ }^{\mathrm{III}}(\mathrm{GS})$ ) and dimethylmonothioarsinic acid (DMMTA ${ }^{\mathrm{V}}$ ). When assessing the toxicity by exposing multiple myeloma cells to arsenicals externally, $\operatorname{DMMTA}^{\mathrm{V}}(\mathrm{GS})$ was much less toxic than DMA $^{\mathrm{III}}(\mathrm{GS})$ and DMMTA ${ }^{\mathrm{V}}$, probably as a result of its very limited uptake (less than $10 \%$ and $16 \%$ of $\mathrm{DMA}^{\mathrm{III}}(\mathrm{GS})$ and $\mathrm{DMMTA}^{\mathrm{V}}$ respectively). However, the toxicity of this compound was evaluated by exposing the cells to DMMTA ${ }^{\mathrm{V}}(\mathrm{GS})$ externally, hence the observed low toxicity attributable to very limited uptake, might not be able to reflect the actual toxicity of this compound intracellularly. During the metabolism of Darinaparsin, this species forms inside the cells along with other metabolites, and could exhibit a higher toxicity. Bearing in mind that glutathione conjugation is generally a detoxification process and it flags the molecule for elimination from cells, the formation of this metabolite should be considered a detoxification process.

\subsubsection{Analytical Method Development}

During the metabolism of different arsenic-containing compounds in human, a variety of metabolites are produced with significantly varying toxicities. Currently available analytical methods could only detect a limited number of human metabolites in biological samples during one run as a result of their diverse characteristics. In addition, with most detection techniques co-elution of species is unnoticeable leading to inaccurate metabolic profiles and assessment of toxicity. I successfully developed a high performance liquid identify fourteen common arsenic metabolites possibly present in human in one run to ensure that no co-elution of these species occur. The 14 species 
separated by the method are arsenite $\left(\mathrm{As}^{\mathrm{III}}\right)$, arsino-glutathione $\left(\mathrm{As}(\mathrm{GS})_{3}\right)$, arsenate $\left(\mathrm{As}^{\mathrm{V}}\right)$, monomethylarsonous acid (MMA $\left.{ }^{\mathrm{III}}\right)$, monomethylarsino-glutathione (MMA $\left.{ }^{\mathrm{III}}(\mathrm{GS})_{2}\right)$, monomethylarsonic acid $\left(\mathrm{MMA}^{\mathrm{V}}\right)$, dimethylarsinous acid (DMA ${ }^{\mathrm{III}}$ (from DMA $\left.{ }^{\mathrm{III}} \mathrm{I}\right)$ ), S(dimethylarsinic)cysteine $\left(\mathrm{DMA}^{\mathrm{III}}(\mathrm{Cys})\right)$, dimethylarsino-glutathione $\left(\mathrm{DMA}^{\mathrm{III}}(\mathrm{GS})\right)$, dimethylarsinic acid $\left(\mathrm{DMA}^{\mathrm{V}}\right)$, dimethylmonothioarsinic acid $\left(\mathrm{DMMTA}^{\mathrm{V}}\right)$, dimethyldithioarsinic acid $\left(\right.$ DMDTA $\left.^{\mathrm{V}}\right), \quad$ dimethylarsinothioyl glutathione $\left(\operatorname{DMMTA}^{\mathrm{V}}(\mathrm{GS})\right)$, and the later added dimethylmonothioarsinous acid (DMMTA $\left.{ }^{\mathrm{III}}\right)$. A potential method to synthesize dimethylmonothioarsinous acid (DMMTA ${ }^{\mathrm{III}}$ ) was also offered for the first time.

An extensive study was carried out to examine the effects of ICP nebulizer flow rate and composition on ICP-MS signal intensity and its importance to minimalize baseline disturbance that was present as a result of high acetonitrile concentration in the mobile phase. Moreover, the effect of composition of nebulizer flow on carbon deposits inside the ICP-MS was evaluated. An inexpensive method, employing a T connector, was introduced to augment the nebulizer flow with oxygen to protect the instrument and stabilize the ICP plasma during analysis. The developed method was also found to be compatible with the high performance liquid chromatograph electrospray ionization tandem mass spectrometer (HPLC-ESI-MS/MS) providing an additional tool to identify unknown peaks.

I applied this method to the analysis of cancer cells that were incubated with Darinaparsin to demonstrate the ability of the method for the analysis of arsenic metabolites in human cells. Moreover, I employed this method to try to decipher the mechanisms and the conditions of formation of thiolated arsenic metabolites. 


\subsubsection{Mechanistic Study of Thiolated Arsenical Formation}

In the course of my research I investigated the possible mechanisms and conditions of formation of dimethylmonothioarsinic acid (DMMTA ${ }^{\mathrm{V}}$ ), dimethyldithioarsinic acid (DMDTA $\left.{ }^{\mathrm{V}}\right)$, dimethylarsinous glutathione (DMA ${ }^{\mathrm{III}}(\mathrm{GS})$ ), and dimethylarsinothioyl glutathione (DMMTA ${ }^{\mathrm{V}}(\mathrm{GS})$ ) from dimethylarsinic acid (DMA ${ }^{\mathrm{V}}$ ) and Darinaparsin $\left(\mathrm{DMA}^{\mathrm{III}}(\mathrm{GS})\right)$ and the form $\left(\mathrm{H}_{2} \mathrm{~S}, \mathrm{HS}^{-}\right.$, or $\left.\mathrm{S}^{2-}\right)$ and the source of sulfur involved in the generation of thioarsenicals (sulfane sulfur (protein persulfides in particular) or $\mathrm{H}_{2} \mathrm{~S}$ produced during metabolism). In this study, I successfully synthesized and used a recently reported slow $\mathrm{H}_{2} \mathrm{~S}$ releaser GYY4137 (morpholin-4-ium 4 methoxphenyl (morpholino) phosphinodithionate), which has been shown to slowly release $\mathrm{H}_{2} \mathrm{~S}$ both in vitro and in vivo to produce $\mathrm{H}_{2} \mathrm{~S}$ creating a reaction environment milder and more closely relevant to physiological conditions. I provided additional information to enable others to unequivocally identify GYY4137. I found that DMMTA ${ }^{\mathrm{V}}$ can form from $\mathrm{DMA}^{\mathrm{V}}$ utilizing both $\mathrm{H}_{2} \mathrm{~S}$ and $\mathrm{HS}^{-}$via different pathways, while DMDTA $^{\mathrm{V}}$ can only form utilizing $\mathrm{HS}^{-}$. Additionally, it was shown that the reduction of $\mathrm{DMA}^{\mathrm{V}}$ to $\mathrm{DMA}^{\mathrm{III}}$ is not necessary for the formation of DMMTA ${ }^{\mathrm{V}}$. My research also showed that DMMTA ${ }^{\mathrm{V}}$ can form from $\mathrm{DMA}^{\mathrm{III}}(\mathrm{GS})$ in the presence of $\mathrm{HS}^{-}$without the need for the oxidation of $\mathrm{DMA}^{\mathrm{III}}(\mathrm{GS})$ to $\mathrm{DMA}^{\mathrm{V}}$. It was proposed, for the first time, that the formation of DMMTA ${ }^{\mathrm{V}}$ from $\mathrm{DMA}^{\mathrm{III}}(\mathrm{GS})$ is via the formation of DMMTA ${ }^{\mathrm{III}}$ and highly unstable dimers. While the exact mechanism of the proposed dimerization pathway could not be elucidated, proof to support it was provided.

In order to investigate the ability of arsenic to react with protein persulfides to form thiolated arsenicals, I employed glutathione persulfide (GSSH) as a simple model 
molecule for protein persulfides. GSSH when reacted with $\mathrm{DMA}^{\mathrm{V}}$ formed very small amounts of DMMTA ${ }^{\mathrm{V}}$. Once GSH was added to the reaction media, it liberated $\mathrm{HS}^{-}$from GSSH, and the very fast formation of thiolated arsenicals was observed. The experiment showed that protein persulfides may provide the sulfide needed for the formation of sulfur-containing arsenicals in the reducing environment of the cells. It was suggested in this work for the first time, that utilizing the sulfur of protein persulfides for the formation of thiolated arsenicals, may be an important contributor to arsenic induced toxicity (directly) as the loss of persulfide from proteins alters their enzymatic abilities. It was also proposed for the first time, that some of the (indirect) toxicity of arsenicals may be attributable to their interference with protein persulfide synthesis (an important post translational modification of proteins to increase their activity) by utilizing the $\mathrm{H}_{2} \mathrm{~S}$ generated in enzymatic reactions that is used for the synthesis of protein persulfides.

\subsection{Significance and Implications of the Work Done}

\subsubsection{Analytical Method Development}

In order to understand the metabolic pathways of As, the mode of action of As toxicity, and the mechanisms underlying As chemotherapy, scientists must have an analytical method that is capable of unequivocally identifying the arsenicals formed during the metabolism of environmental As exposure or therapeutic As administration. Speciation analysis of arsenic metabolites is very important, because each arsenic species possesses varying toxicities. This work is unique, since it is the first to report a validated analytical testing method that can simultaneously detect 14 human arsenic metabolites in one liquid chromatographic run. The development of such method was required as the 
analytical methods available prior to this technique could only detect a limited number of human metabolites in biological samples during one chromatographic run. The previously reported methods could not meet the need of "full-spectrum" analysis of As metabolites. In addition, with employing inductively coupled mass spectroscopy (ICPMS) as the ionization and detection technique co-elution of species is unnoticeable leading to inaccurate metabolic profiles and assessment of toxicity, thus care had to be taken to separate all confirmed and potential human arsenic metabolites.

The developed method was successfully applied to the analysis of human cancer cells incubated with Darinaparsin for the determination of arsenic speciation profile during the metabolism of this promising antineoplastic agent. Moreover, the method proved to be an indispensable tool for the mechanistic study of thiolated arsenic species formation.

\subsubsection{Thiolated Arsenicals}

Sulfur-containing pentavalent arsenic metabolites such as MMMTA ${ }^{\mathrm{V}}$, DMMTA $^{\mathrm{V}}, \operatorname{DMDTA}^{\mathrm{v}}$, and $\operatorname{DMMTA}^{\mathrm{V}}(\mathrm{GS})$ are important mammalian arsenic metabolites, though rarely detected in humans up until now. ${ }^{10,11,14,25,35,36,114,155}$ The toxicity of most thiolated arsenicals in humans is unknown. Interestingly, while in general trivalent arsenic compounds are more toxic than their pentavalent counterparts, DMMTA $^{\mathrm{V}}$ has been shown to be unusually highly toxic for a pentavalent species. ${ }^{10-13,98}$ Consequently, it was very important to understand and evaluate the toxicity of these species and to measure the ability of cells to take them up. These objectives were accomplished by incubating human cancer cells with $\left.\mathrm{DMA}^{\mathrm{III}}(\mathrm{GS})\right)$, DMMTA ${ }^{\mathrm{V}}$, and $\operatorname{DMMTA}^{\mathrm{V}}(\mathrm{GS})$. DMMTA ${ }^{\mathrm{V}}(\mathrm{GS})$ was found to be much less toxic than DMA ${ }^{\mathrm{III}}(\mathrm{GS})$ and 
DMMTA $^{\mathrm{V}}$, probably as a result of its very limited uptake (less than $10 \%$ and $16 \%$ of $\mathrm{DMA}^{\mathrm{III}}(\mathrm{GS})$ and DMMTA ${ }^{\mathrm{V}}$ respectively). However, the toxicity of this compound was evaluated by exposing the cells to DMMTA (GS) externally, hence the observed low toxicity attributable to very limited uptake, might not be able to reflect the actual toxicity of this compound intracellularly.

It was also pertinent to understand the formation and the conditions of formation of all thiolated arsenicals and to examine if their mechanism of formation contributes to arsenic toxicity in addition to the unusually high reactivity of DMMTA ${ }^{\mathrm{V}}$ with thiol compounds. Up until now, the form and the source of sulfur utilized for the formation of DMMTA ${ }^{\mathrm{V}}$ and DMDTA ${ }^{\mathrm{V}}$ in human and animal cells remained unclear. One possible source of sulfide was suggested to be hydrogen sulfide enzymatically generated in the body with the help of cystathionine beta synthase (CBS) and cystathionine gamma lyase (CSE) from the metabolism of cysteine and homocysteine along with other enzymatic processes. Another possible source of sulfur was proposed to be sulfane sulfur of proteins (protein persulfides). I found that under physiological conditions ( $\mathrm{pH}$ and GSH concentrations) all these thiolated As species form extensively from hydrogen sulfide (utilizing $\mathrm{H}_{2} \mathrm{~S}$ and $\mathrm{HS}^{-}$), expect for $\operatorname{DMMTA}^{\mathrm{V}}(\mathrm{GS})$ that was observed to form only to a limited degree in the absence of cellular material providing further proof that its formation in cells is mostly enzymatically catalyzed. For the first time evidence was provided to demonstrate that different pathways may be responsible for the formation of DMMTA $^{\mathrm{V}}$. Evidence was provided for the first time to show that the toxicity of these arsenical may be attributed not only to the fact that they interact with protein persulfides, but they are indeed capable of utilizing the $\mathrm{HS}^{-}$of protein persulfides for their formation 
in the reducing environment of the cells. This was accomplished by employing glutathione persulfide as a model for protein persulfides. Moreover, it was proposed for the first time, that a contributing factor to the toxicity of the thiolated arsenicals may be a result of them utilizing the $\mathrm{H}_{2} \mathrm{~S}$ generated during enzymatic processes. As hydrogen sulfide is an important messenger in cells affecting various physiological functions, the processes requiring signaling by $\mathrm{H}_{2} \mathrm{~S}$, cannot take place or to a lesser extent. Moreover, $\mathrm{H}_{2} \mathrm{~S}$ is thought to be important in the synthesis of protein persulfides, a crucial post translational modification of proteins to increase their activities, and by the arsenic metabolism incorporating the $\mathrm{H}_{2} \mathrm{~S}$ produced by enzymatic reactions to form thiolated arsenicals, the formation of these species may result in the decrease or complete halt of the production of protein persulfides.

\subsubsection{Summary}

In summary, this study is of great analytical, biological, and medical importance and provides significant results to help us further understand the toxicity and uptake of some human arsenic metabolites and the mechanism of their formation. Moreover, this work provides a tool (in the form of an advanced analytical separation technique) that enables us to make further progress in evaluating arsenic induced toxicity and to speciate arsenicals in biological samples to correctly assess their toxicity and decipher their metabolism. 


\subsection{Future Research Directions}

\subsubsection{Further Analytical Method Development}

The analytical separation method reported in this dissertation was developed for the speciation of most human arsenic metabolites using both ICP-MS and ESIMS/MS as detectors. Unfortunately, while these species are separated during the HPLC run, in the electrospray stage some have very low ionization efficiencies and/or they oxidize resulting in changes of species identities. In order to increase ionization efficiencies and prevent the oxidation of species, post column derivatization could provide an answer. Employing ESI detection, the amount of organic solvent significantly affects ionization efficiency. In order to achieve adequate or very high ionization, the presence of large amounts of organic solvents, such as methanol, is needed. Unfortunately, as the HPLC separation method is also used with ICP-MS detector, the usage of large percentage of organic solvent during separation is not possible as the plasma of the ICP can only tolerate small amounts of organic solvents before it extinguishes. When using ESI-MS as detector, organic solvent could be added to the HPLC effluent post column to increase ionization efficiency and thus sensitivity. The eluent from the HPLC column could be supplemented with the organic solvent post column using a $\mathrm{T}$ connector. Moreover, a compound containing easily ionizable group(s) with high affinity to arsenic could be added to the post column makeup flow to help complex/derivatize the easily oxidizable species without the reduction and complexation of the pentavalent arsenicals in order to enable us to distinguish species that may oxidize in the electrospray stage from their pentavalent counterparts and to increase their ionization efficiencies. Furthermore, $\mathrm{pH}$ modifiers can also be added to the post column 
makeup flow containing the organic solvent and the derivatizing agent to further help the ionization of some species. The organic solvent, the derivatizing agent, and the $\mathrm{pH}$ modifier must be carefully chosen and their amounts cautiously adjusted to achieve the most sensitive and specific detection of all species on ESI-MS detectors.

\subsubsection{Synthesis of DMMTA ${ }^{\mathrm{III}}$}

During formation studies of DMMTA ${ }^{\mathrm{V}}$, two unknown peaks were observed in the chromatograms where the starting material was $\mathrm{DMA}^{\mathrm{III}}(\mathrm{GS})$, but not in the chromatograms with $\mathrm{DMA}^{\mathrm{V}}$ as the initial compound. This, along with other data, indicated that $\mathrm{DMMTA}^{\mathrm{V}}$ forms through distinct mechanisms from $\mathrm{DMA}^{\mathrm{V}}$ and $\mathrm{DMA}^{\mathrm{III}}(\mathrm{GS})$. It is important to identify these unknown species to fully decipher the mechanism of metabolism of Darinaparsin and to understand the possible pathways of DMMTA $^{\mathrm{V}}$ formation. I suspected that these unknown species may be one or more of the proposed dimer intermediates and/or dimethylmonothioarsinous acid (DMMTA ${ }^{\mathrm{III}}$ ). As no information in the literature is currently available on how to synthesize DMMTA ${ }^{\mathrm{III}}$, I attempted to produce this compound by the reaction of $\mathrm{DMA}^{\mathrm{III}}(\mathrm{GS})$ and $\mathrm{Na}_{2} \mathrm{~S}$ in an oxygen free environment. Theoretically, the only product that may form in this reaction is DMMTA $^{\mathrm{III}}$, as the formation of any of the dimers, DMMTA ${ }^{\mathrm{V}}$, DMDTA ${ }^{\mathrm{V}}$, and DMMTA $^{\mathrm{V}}(\mathrm{GS})$ requires oxidation. The peak produced showed that one of the unknown peaks, between DMA ${ }^{\mathrm{V}}$ and the ghost peak produced by the gradient elution program, is probably DMMTA ${ }^{\mathrm{III}}$ based on retention time. In order to unequivocally state that this unknown is indeed DMMTA ${ }^{\text {III }}$, further experiments need to be carried out. First, the synthesis of relatively stable DMMTA ${ }^{\mathrm{III}}$ needs to be resolved. This may be accomplished by the addition of oxygen scavengers (such as ascorbic acid) to the reaction media that do 
not react with $\mathrm{HS}^{-}, \mathrm{DMA}^{\mathrm{III}}(\mathrm{GS})$, and $\mathrm{DMMTA}^{\mathrm{III}}$, they merely retard the oxidation of DMMTA $^{\text {III }}$ to improve stability for further characterization and verification of the identity of this species. Additionally, as the synthesis of stable relatively pure DMMTA ${ }^{\mathrm{V}}$ is resolved, a method may be developed to reduce $\mathrm{DMMTA}^{\mathrm{V}}$ to $\mathrm{DMMTA}^{\mathrm{III}}$ employing reductants that do not form stable complexes with arsenic. Moreover, enzymatic reduction of DMMTA ${ }^{\mathrm{V}}$ to DMMTA ${ }^{\mathrm{III}}$ may be explored.

7.3.3 Finding the Biomolecules Responsible for Catalyzing the Formation of $\operatorname{DMMTA}^{\mathrm{V}}(\mathrm{GS})$ and DMMTA ${ }^{\mathrm{V}}$

The direct precursor of the formation of $\operatorname{DMMTA}^{\mathrm{V}}(\mathrm{GS})$ is $\mathrm{DMMTA}^{\mathrm{V}}$. Theoretical calculations indicate that the conjugation of DMMTA ${ }^{\mathrm{V}}$ with GSH is probably exothermal, but these calculations did not take the $\mathrm{pH}$ effect into calculation and used methanethiol instead of GSH to shorten calculation time. Results obtained by Suzuki indicated that no DMMTA $^{\mathrm{V}}(\mathrm{GS})$ forms from $\mathrm{DMMTA}^{\mathrm{V}}$ in the absence of cellular material above $\mathrm{pH}$ 7. Metabolic studies of Darinaparsin conducted in our lab in human cancer cells showed the presence of this metabolite even at $\mathrm{pH} 7.4$ and its stability upon extraction between $\mathrm{pH} 3$ to 7.4. Heat deactivation of the enzymes prevented its formation indicating the possibility that at physiological $\mathrm{pH}$ it forms in an enzymatic reaction. Later experiments showed that while its formation is indeed favored under acidic conditions, I did observed the formation of a very small amount of $\operatorname{DMMTA}^{\mathrm{V}}(\mathrm{GS})$ at $\mathrm{pH} 7.4$ in the presence of 2.5 and $5.0 \mathrm{mM}$ GSH and $\mathrm{Na}_{2} \mathrm{~S}$ from $\mathrm{DMA}^{\mathrm{III}}(\mathrm{GS})$ non-enzymatically without the presence of cellular material. It is possible that in the reaction media where heatdeactivated cells were present, this small amount of DMMTA ${ }^{\mathrm{V}}(\mathrm{GS})$ was not detectable as a consequence of matrix effects. As our previous results showed the formation of 
substantial amounts of this metabolite within ten minutes in cells, it further confirms that this reaction is probably mostly enzymatically catalyzed. It is also important to note, that it may also form in acidic organelles non-enzymatically in intact cells. The enzyme suspected to help its formation is glutathione S-transferase (GST). GSTs form three superfamilies: the cytosolic, mitochondrial, and microsomal GSTs that are further divided into classes on the basis of their structures. GSTs have the ability to inactivate toxic compounds thus play important roles in the detoxification of noxious chemicals that are cytotoxic and genotoxic. Moreover, glutathione conjugation flags the molecule for removal. While the ability of GSTs to aid in the removal of toxic chemicals is beneficial to the organism, in cancer therapy in the tumor cells, it is a potential problem to the host. Tumors may overexpress GSTs and increase their ability to conjugate GST significantly resulting in acquired resistance to chemotherapeutic agents. On the other hand, while xenobiotics may initially be detoxified by conjugation with GSH with the help of GSTs, the initial toxic compound can be regenerated spontaneously. I examined if human microsomal and cytosolic GSTs may catalyze the formation of $\operatorname{DMMTA}^{\mathrm{V}}(\mathrm{GS})$, but did not looked at mitochondrial GSTs or other enzymes or proteins at this time. Human cytosolic class pi GST, widely distributed in tissues, was tested individually to examine if it can catalyze the conjugation of GSH to DMMTA ${ }^{\mathrm{V}}$. My results showed that these enzymes do not catalyze the reaction, thus further experiments are needed to identify the biomolecule responsible for aiding the formation of $\operatorname{DMMTA}^{\mathrm{V}}(\mathrm{GS})$. This could be done by preparing subcellular fractions and examine if in the presence of a specific fraction the rate of DMMTA ${ }^{\mathrm{V}}(\mathrm{GS})$ synthesis is increased in order to identify if microsomal, cytosolic, or mitochondrial enzymes (in general, not just GSTs) are responsible for the formation of 
this species. Once the fraction responsible for the catalysis of the reaction is identified, further work can be done in order to identify the specific biomolecule(s) responsible for the catalytic activity of the formation of this metabolite.

In order to accomplish this, tissue must be acquired (such as fragments of liver, hepatocytes, etc.) and then homogenized prior to use. This will break up the endoplasmic reticulum (ER) into small spheres called microsomes. The diluted tissue homogenate containing the microsomes is centrifuged to remove debris, nuclei, and mitochondria. The resulting supernatant containing the microsomes and cytoplasm contains most of the drug-metabolizing enzymes present in tissue. Using ultracentrifugation the supernatant can be further separated into the cytosol and the microsomes. Furthermore, the fraction containing the mitochondria can be further separated and isolated. The fractions then can be used with the necessary cofactors and incubated with the substrate $\left(\mathrm{DMMTA}^{\mathrm{V}}\right)$ to see if they catalyze the formation of $\operatorname{DMMTA}^{\mathrm{V}}(\mathrm{GS})$.

It is also possible that the formation of $\mathrm{DMMTA}^{\mathrm{V}}$ is catalyzed enzymatically as well from $\mathrm{DMA}^{\mathrm{V}}$ or $\mathrm{DMA}^{\mathrm{III}}(\mathrm{GS})$ despite of the fact that its formation can happen easily under non-enzymatic conditions at physiological $\mathrm{pH}$ in the presence of $\mathrm{HS}^{-}$. The amount of freely available $\mathrm{HS}^{-}$in the cells is not known and it is possible that enzymes donating $\mathrm{HS}^{-}$may be, to an unknown extent, responsible for its formation. The subcellular fractions used for studies of $\operatorname{DMMTA}^{\mathrm{V}}(\mathrm{GS})$ formation could also be employed to examine if enzymes may be involved in the catalysis of $\mathrm{DMMTA}^{\mathrm{V}}$ formation. 


\subsubsection{DMA $^{\text {III }}(\mathrm{GS})$ Uptake as DMA ${ }^{\mathrm{III}}(\mathrm{Cys})$}

According to a the latest research, $\mathrm{DMA}^{\mathrm{III}}(\mathrm{GS})$ may be uptaken as DMA $^{\text {III }}(\mathrm{Cys})$ by cells. ${ }^{94}$ In order to provide further prove that this is indeed the case, human cells could be incubated with Darinaparsin, but instead of waiting at least 10-15 minutes prior to analysis during which time $\mathrm{DMA}^{\mathrm{III}}(\mathrm{Cys})$ can be further metabolized, the samples should be analyzed within a short period of time such as within 0.5 minute after treatment with Darinaparsin started to see if the presence of $\mathrm{DMA}^{\mathrm{III}}(\mathrm{Cys})$ can be confirmed. Moreover, cells could be tested every minute after that to see how fast $\mathrm{DMA}^{\mathrm{III}}(\mathrm{GS})$ is converted to $\mathrm{DMA}^{\mathrm{III}}(\mathrm{Cys})$. Additionally, cells incubated with $\operatorname{DMMTA}^{\mathrm{V}}(\mathrm{GS})$ could also be examined via the same protocol to see if DMMTA $^{\mathrm{V}}(\mathrm{Cys})$ forms enzymatically prior to uptake. For these reactions, $\operatorname{DMMTA}^{\mathrm{V}}(\mathrm{Cys})$ will have to be synthesized to establish the retention time of this compound with the newly developed method. The synthesis of DMMTA ${ }^{\mathrm{V}}(\mathrm{Cys})$ is probably easily achievable at low $\mathrm{pH}$ in the presence of excess cysteine.

7.3.5 Assessment of the Contribution of $\mathrm{H}_{2} \mathrm{~S}$ Formed in Metabolic Processes to the Formation of Thiolated Arsenic Metabolites

I proposed that $\mathrm{H}_{2} \mathrm{~S}$ generated from enzymatic reactions in the body with the help of cystathionine beta synthase (CBS) and cystathionine gamma lyase (CSE) from the metabolism of cysteine and homocysteine may be responsible partially for the formation of thiolated arsenic metabolites. While $\mathrm{H}_{2} \mathrm{~S}$ may be generated in other enzymatic reactions, its production with the help of CBS and CSE is the most mayor source of endogenous hydrogen sulfide. The true concentration level of $\mathrm{H}_{2} \mathrm{~S}$ in cells is highly debated and varies over a $10^{5}$-fold concentration range in different reports, and such its 
importance for the production of $\mathrm{DMMTA}^{\mathrm{V}}$ and other sulfur-containing compounds could not be accurately estimated up until now. In order to assess the contribution of $\mathrm{H}_{2} \mathrm{~S}$ formed in metabolic processes to the formation of thiolated As-metabolites, the amounts of combined DMMTA ${ }^{\mathrm{V}}$, DMDTA ${ }^{\mathrm{V}}$, and $\operatorname{DMMTA}^{\mathrm{V}}(\mathrm{GS})$ present in cell lines could be compared in cells in which CBS and CSE (individually and combined) are inhibited selectively to those cells where the enzyme function of CBS and CSE is preserved. On the basis of the differences in the amount of total thiolated arsenic species formation, the contribution of $\mathrm{H}_{2} \mathrm{~S}$ released in metabolic processes could be determined. Unfortunately, while some reported that both CSE and CBS can be selectively inhibited, most current research shows that only CSE can be selectively inhibited and no selective pharmacological inhibitor is currently available for CBS. While the selective inhibition of CBS is not possible, by selectively inhibiting CSE and then both of the enzymes, the relative contribution of CBS to thiolated arsenical formation can be estimated as well.

\subsubsection{Interactions of DMMTA ${ }^{\mathrm{V}}$ with Protein Persulfides}

My research showed that DMMTA $^{\mathrm{V}}$ can form from GSSH (glutathione persulfide) if GSH (glutathione) is added to the reaction media to break up the disulfide bond in GSSH and liberate HS- This was an important find, as protein persulfides are known to be prevalent in cells and thus they may supply the sulfide needed for the synthesis of thiolated arsenic metabolites. It is estimated that approximately $10-25 \%$ of many hepatic proteins are sulfhydrated under physiological conditions and sulfhydration appears to be a common physiologic posttranslational modification of proteins. Consequently, it is very plausible that the sulfur comes from persulfides of biomolecules in the presence of reducing agents, such as GSH, that can liberate HS- from protein 
persulfides. It is also a possibility that in the first step arsenic directly reacts with the terminal S atom of R-S-S- and forms a complex and then the disulfide gets reduced and the original reduced $\mathrm{R}-\mathrm{SH}$ or $\mathrm{R}-\mathrm{S}^{-}$leaves. As sulfuration alters protein function (may hyperactivate or deactivate it), the permanent loss of $-\mathrm{SH}$ to form thiolated arsenicals may significantly affect protein function and in turn, the survival of the cell. If this is the prevalent pathway of formation of these species, it is possible that this may be one of the important reasons how arsenic compounds exert toxicity in addition to protein binding and ROS (reactive oxygen species) generation. On an important note, it was shown that CBS and CSE responsible for the generation of $\mathrm{H}_{2} \mathrm{~S}$ in the presence of L-cysteine, are also partially responsible for donating the hydrogen sulfide needed for the generation of protein persulfides. In the liver of CSE-/- knockout mice (no working CSE present), it was shown that endogenous sulfhydration was abolished indicating that proteins are physiologically sulfhydrated through CSE activity. Thus it is reasonable that not only the direct destruction of these protein persulfides during thiolated arsenic metabolite formation may be responsible for the toxicity of arsenic (in addition to other known mechanisms), but by utilizing the $\mathrm{H}_{2} \mathrm{~S}$ needed for the synthesis of these protein persulfides for thiolated arsenic species production, these important post translational protein modifications cannot take place and such their enzymatic capabilities diminishes contributing to As toxicity indirectly.

To examine if this may be one of the contributing reasons of toxicity, a few (1-2) small protein-persulfides with enzymatic properties resulting from their persulfides present should be chosen and then reacted with $\mathrm{DMA}^{\mathrm{V}}$ and $\mathrm{DMA}^{\mathrm{III}}(\mathrm{GS})$. After reaction, either GSH or a mild non-thiol containing disulfide bond reducing agent should be added 
to monitor if $\mathrm{DMMTA}^{\mathrm{V}}$ or other thiolated arsenicals form and if the protein loses its enzymatic function as a result. The loss of or the decrease in enzymatic function can easily be evaluated by using a known reaction that is catalyzed by that specific proteinpersulfide. If the loss of or decrease in enzymatic function is revealed, it can be shown that not only ROS generation and direct bonding can deactivate enzymes (thus cause toxicity), but also the loss of persulfides of enzymes. On the basis of the prevalence of these protein persulfides, its contribution to toxicity can be estimated.

One of the proteins that may be suitable for this experiment is glyceraldehyde3-phosphate dehydrogenase (GAPDH, $38 \mathrm{KDa}$ ). GAPDH is physiologically sulfhydrated uniquely at Cys150, the cysteine that is needed for its catalytic activity. At physiological L-cysteine concentrations in the presence of CSE approximately 50\% of GAPDH can be sulfhydrated. The presence of sulfhydrated GAPDH can easily be confirmed using liquid tandem mass spectrometry (LC-MS/MS) with the addition of DTT, as the presence of this reducing agent will abolish the mass spectrometric signal of this compound (by breaking up the disulfide bond and removing the terminal $\mathrm{HS}^{-}$). Once sulfhydrated, GAPDH can be reacted with DMAV in the presence of GSH or other non-thiol containing disulfide bond reducing agent and the formation of thiolated arsenicals can be monitored to further confirm that it is indeed possible that these protein persulfides can donate the sulfur needed for the formation of thiolated arsenicals. Moreover, post reaction, the activity of GAPDH should be reassessed to determine if its activity has changed. A decrease in activity would show that the destruction of these protein thiols modifies (retards) enzyme activity and thus may partially be a reason for the observed toxicity of arsenicals in addition to other already known ways. 


\section{REFERENCES}

(1) Mandal, B. (2002) Arsenic round the world: a review. Talanta 58, 201-235.

(2) Goldfrank, L., Flomenbaum, N. E., Lewin, N. E., Howland, M. A., Hoffman, R. S., Nelson, L. S. . (2002) Goldfrank's toxicologic emergencies. 7th ed., McGrawHill Medical Publishing Division, New York.

(3) Zhao, F. J., McGrath, S. P., and Meharg, A. A. (2010) Arsenic as a Food Chain Contaminant: Mechanisms of Plant Uptake and Metabolism and Mitigation Strategies. Annu. Rev. Plant. Biol. 61, 535-559.

(4) Evens, A. M., Tallman, M. S., and Gartenhaus, R. B. (2004) The potential of arsenic trioxide in the treatment of malignant disease: past, present, and future. Leukemia Res. 28, 891-900.

(5) Vahidnia, A. (2007) Arsenic neurotoxicity A review. Hum. and Exp. Toxicol. 26, 823-832.

(6) Tapio, S., and Grosche, B. (2006) Arsenic in the aetiology of cancer. Mutat. Res. $612,215-246$.

(7) Styblo, M., Del Razo, L. M., Vega, L., Germolec, D. R., LeCluyse, E. L., Hamilton, G. A., Reed, W., Wang, C., Cullen, W. R., and Thomas, D. J. (2000) Comparative toxicity of trivalent and pentavalent inorganic and methylated arsenicals in rat and human cells. Arch. Toxicol. 74, 289-299.

(8) Mass, M. J., Tennant, A., Roop, B. C., Cullen, W. R., Styblo, M., Thomas, D. J., and Kligerman, A. D. (2001) Methylated Trivalent Arsenic Species Are Genotoxic. Chem. Res. Toxicol. 14, 355-361.

(9) Hirano, S., Kobayashi, Y., Cui, X., Kanno, S., Hayakawa, T., and Shraim, A. (2004) The accumulation and toxicity of methylated arsenicals in endothelial cells: important roles of thiol compounds. Toxicol. Appl. Pharmacol. 198, 458467.

(10) Bu, N., Wang, H. Y., Hao, W. H., Liu, X., Xu, S., Wu, B., Anan, Y., Ogra, Y., Lou, Y. J., and Naranmandura, H. (2011) Generation of thioarsenicals is dependent on the enterohepatic circulation in rats. Metallomics 3, 1064-1073.

(11) Raml, R., Rumpler, A., Goessler, W., Vahter, M., Li, L., Ochi, T., and Francesconi, K. A. (2007) Thio-dimethylarsinate is a common metabolite in urine samples from arsenic-exposed women in Bangladesh. Toxicol. Appl. Pharmacol. $222,374-380$. 
(12) Suzuki, K. T., Iwata, K., Naranmandura, H., and Suzuki, N. (2007) Metabolic differences between two dimethylthioarsenicals in rats. Toxicol. Appl. Pharmacol. 218, 166-173.

(13) Naranmandura, H., Ibata, K., and Suzuki, K. T. (2007) Toxicity of dimethylmonothioarsinic acid toward human epidermoid carcinoma A431 cells. Chem. Res. Toxicol. 20, 1120-1125.

(14) Watanabe, T., and Hirano, S. (2012) Metabolism of arsenic and its toxicological relevance. Arch. Toxicol., 1-11.

(15) Bartel, M., Ebert, F., Leffers, L., Karst, U., and Schwerdtle, T. (2011) Toxicological Characterization of the Inorganic and Organic Arsenic Metabolite Thio-DMA ${ }^{\mathrm{V}}$ in Cultured Human Lung Cells. J. Toxicol. 2011.

(16) Leffers, L., Unterberg, M., Bartel, M., Hoppe, C., Pieper, I., Stertmann, J., Ebert, F., Humpf, H. U., and Schwerdtle, T. (2013) In vitro toxicological characterisation of the S-containing arsenic metabolites thio-dimethylarsinic acid and dimethylarsinic glutathione. Toxicology 305, 109-119.

(17) Sakurai, T., Kojima, C., Kobayashi, Y., Hirano, S., Sakurai, M. H., Waalkes, M. P., and Himeno, S. (2006) Toxicity of a trivalent organic arsenic compound, dimethylarsinous glutathione in a rat liver cell line (TRL 1215). Br. J. Pharmacol. 149, 888-897.

(18) Kojima, C., Sakurai, T., Waalkes, M. P., and Himeno, S. (2005) Cytolethality of Glutathione Conjugates with Monomethylarsenic or Dimethylarsenic Compounds. Biol. Pharm. Bull. 28, 1827-1832.

(19) Kitchin, K. T., and Wallace, K. (2008) The role of protein binding of trivalent arsenicals in arsenic carcinogenesis and toxicity. J. Inorg. Biochem. 102, 532-539.

(20) Prajapati, V., Kale, R. K., and Singh, R. P. (2011) Arsenic and its combinations in cancer therapeutics. Ther. Deliv. 2, 793-806.

(21) Rin, K., Kawaguchi, K., Yamanaka, K., Tezuka, M., Oku, N., and Okada, S. (1995) DNA-strand breaks induced by dimethylarsinic acid, a metabolite of inorganic arsenics, are strongly enhanced by superoxide anion radicals. Biol. Pharm. Bull. 18, 45-48.

(22) Hansen, J. M., Zhang, H., and Jones, D. P. (2006) Differential oxidation of thioredoxin-1, thioredoxin-2, and glutathione by metal ions*. Free Radical Biol. Med. 40, 138-145.

(23) Mizumura, A., Watanabe, T., Kobayashi, Y., and Hirano, S. (2010) Identification of arsenite-and arsenic diglutathione-binding proteins in human hepatocarcinoma cells. Toxicol. Appl. Pharmacol. 242, 119-125. 
(24) Le, X. C., Lu, X., Ma, M., Cullen, W. R., Aposhian, H. V., and Zheng, B. (2000) Speciation of Key Arsenic Metabolic Intermediates in Human Urine. Anal. Chem. $72,5172-5177$.

(25) Mandal, B. K., Ogra, Y., and Suzuki, K. T. (2001) Identification of Dimethylarsinous and Monomethylarsonous Acids in Human Urine of the Arsenic-Affected Areas in West Bengal, India. Chem. Res. Toxicol. 14, 371-378.

(26) Mandal, B., Ogra, Y., Anzai, K., and Suzuki, K. T. (2004) Speciation of arsenic in biological samples. Toxicol. Appl. Pharmacol. 198, 307-318.

(27) Wang, Z., Zhou, J., Lu, X., Gong, Z., and Le, X. C. (2004) Arsenic Speciation in Urine from Acute Promyelocytic Leukemia Patients undergoing Arsenic Trioxide Treatment. Chem. Res. Toxicol. 17, 95-103.

(28) Valenzuela, O. L., Borja-Aburto, V. H., Garcia-Vargas, G. G., Cruz-Gonzalez, M. B., Garcia-Montalvo, E. A., Calderon-Aranda, E. S., and Del Razo, L. M. (2004) Urinary Trivalent Methylated Arsenic Species in a Population Chronically Exposed to Inorganic Arsenic. Environ. Health Perspect. 113, 250-254.

(29) Yoshino, Y., Yuan, B., Miyashita, S.-i., Iriyama, N., Horikoshi, A., Shikino, O., Toyoda, H., and Kaise, T. (2009) Speciation of arsenic trioxide metabolites in blood cells and plasma of a patient with acute promyelocytic leukemia. Anal. Bioanal. Chem. 393, 689-697.

(30) Cui, X., Kobayashi, Y., Hayakawa, T., and Hirano, S. (2004) Arsenic speciation in bile and urine following oral and intravenous exposure to inorganic and organic arsenics in rats. Toxicol. Sci. 82, 478-487.

(31) Kala, S. V., Kala, G., Prater, C. I., Sartorelli, A. C., and Lieberman, M. W. (2004) Formation and urinary excretion of arsenic triglutathione and methylarsenic diglutathione. Chem. Res. Toxicol. 17, 243-249.

(32) Xie, R., Johnson, W., Spayd, S., Hall, G. S., and Buckley, B. (2006) Arsenic speciation analysis of human urine using ion exchange chromatography coupled to inductively coupled plasma mass spectrometry. Anal. Chim. Acta 578, 186-194.

(33) Devesa, V., Del Razo, L. M., Adair, B., Drobná, Z., Waters, S. B., Hughes, M. F., Stýblo, M., and Thomas, D. J. (2004) Comprehensive analysis of arsenic metabolites by $\mathrm{pH}$-specific hydride generation atomic absorption spectrometry. $J$. Anal. At. Spectrom. 19, 1460-1467.

(34) Yehiayan, L. (2010) Interactions of different arsenic species with thols: Chemical and biological implications, Ph. D. Dissertation, Florida International University, Miami, Florida, USA. 
(35) Naranmandura, H., and Suzuki, K. T. (2008) Formation of dimethylthioarsenicals in red blood cells. Toxicol. Appl. Pharmacol. 227, 390-399.

(36) Naranmandura, H., Suzuki, N., Iwata, K., Hirano, S., and Suzuki, K. T. (2007) Arsenic metabolism and thioarsenicals in hamsters and rats. Chem. Res. Toxicol. 20, 616-624.

(37) Le, X. C., and Ma, M. (1998) Short-Column Liquid Chromatography with Hydride Generation Atomic Fluorescence Detection for the Speciation of Arsenic. Anal. Chem. 70, 1926-1933.

(38) Suzuki, K. T., Mandal, B. K., and Ogra, Y. (2002) Speciation of arsenic in body fluids. Talanta (Oxford) 58, 111-119.

(39) Lu, M., Wang, H., Li, X. F., Lu, X., Cullen, W. R., Arnold, L. L., Cohen, S. M., and Le, X. C. (2004) Evidence of Hemoglobin Binding to Arsenic as a Basis for the Accumulation of Arsenic in Rat Blood. Chem. Res. Toxicol. 17, 1733-1742.

(40) Styblo, M., Serves, S. V., Cullen, W. R., and Thomas, D. J. (1997) Comparative inhibition of yeast glutathione reductase by arsenicals and arsenothiols. Chem. Res. Toxicol. 10, 27-33.

(41) Chouchane, S., and Snow, E. T. (2001) In vitro effect of arsenical compounds on glutathione-related enzymes. Chem. Res. Toxicol. 14, 517-522.

(42) Muller, S., Walter, R. D., and Fairlamb, A. H. (1995) Differential susceptibility of filarial and human erythrocyte glutathione reductase to inhibition by the trivalent organic arsenical melarsen oxide. Mol. Biochem. Parasitol. 71, 211-219.

(43) Wang, T. S., Shu, Y. F., Liu, Y. C., Jan, K. Y., and Huang, H. (1997) Glutathione peroxidase and catalase modulate the genotoxicity of arsenite. Toxicology 121, 229-237.

(44) Lin, S., Cullen, W. R., and Thomas, D. J. (1999) Methylarsenicals and Arsinothiols Are Potent Inhibitors of Mouse Liver Thioredoxin Reductase. Chem. Res. Toxicol. 12, 924-930.

(45) Lin, S., Del Razo, L. M., Styblo, M., Wang, C., Cullen, W. R., and Thomas, D. J. (2001) Arsenicals inhibit thioredoxin reductase in cultured rat hepatocytes. Chem. Res. Toxicol. 14, 305-311.

(46) Chang, K. N., Lee, T. C., Tam, M. F., Chen, Y. C., Lee, L. W., Lee, S. Y., Lin, P. J., and Huang, R. N. (2003) Identification of galectin I and thioredoxin peroxidase II as two arsenic-binding proteins in Chinese hamster ovary cells. Biochem. $J$. $371,495-503$. 
(47) Stevenson, K. J., Hale, G., and Perham, R. N. (1978) Inhibition of pyruvate dehydrogenase multienzyme complex from Escherichia coli with mono- and bifunctional arsenoxides. Biochemistry 17, 2189-2192.

(48) Li, J., and Pickart, C. M. (1995) Binding of phenylarsenoxide to Arg-tRNA protein transferase is independent of vicinal thiols. Biochemistry 34, 1582915837.

(49) Li, J., and Pickart, C. M. (1995) Inactivation of Arginyl-tRNA Protein Transferase by a Bifunctional Arsenoxide: Identification of Residues Proximal to the Arsenoxide Site. Biochemistry 34, 139-147.

(50) Petrick, J. S., Jagadish, B., Mash, E. A., and Aposhian, H. V. (2001) Monomethylarsonous Acid (MMAIII) and Arsenite: LD50in Hamsters and In Vitro Inhibition of Pyruvate Dehydrogenase. Chem. Res. Toxicol. 14, 651-656.

(51) Swindell, E. P., Hankins, P. L., Chen, H., Miodragović, Đ. U., and O’Halloran, T. V. (2013) Anticancer Activity of Small-Molecule and Nanoparticulate Arsenic (III) Complexes. Inorg. Chem. 52, 12292-12304.

(52) Larochette, N., Decaudin, D., Jacotot, E., Brenner, C., Marzo, I., Susin, S. A., Zamzami, N., Xie, Z., Reed, J., and Kroemer, G. (1999) Arsenite induces apoptosis via a direct effect on the mitochondrial permeability transition pore. Exp. Cell Res. 249, 413-421.

(53) Ling, Y.-H., Jiang, J.-D., Holland, J. F., and Perez-Soler, R. (2002) Arsenic trioxide produces polymerization of microtubules and mitotic arrest before apoptosis in human tumor cell lines. Mol. Pharmacol. 62, 529-538.

(54) Li, Y. M., and Broome, J. D. (1999) Arsenic targets tubulins to induce apoptosis in myeloid leukemia cells. Cancer Res. 59, 776-780.

(55) Ma, D. C., Sun, Y. H., Chang, K. Z., Ma, X. F., Huang, S. L., Bai, Y. H., Kang, J., Liu, Y. G., and Chu, J. J. (1998) Selective induction of apoptosis of NB4 cells from G2+ M phase by sodium arsenite at lower doses. Eur. J. Haematol. 61, 2735 .

(56) Perkins, C., Kim, C. N., Fang, G., and Bhalla, K. N. (2000) Arsenic induces apoptosis of multidrug-resistant human myeloid leukemia cells that express BcrAbl or overexpress MDR, MRP, Bcl-2, or Bcl-xL. Blood 95, 1014-1022.

(57) Zhang, X., Yang, F., Shim, J. Y., Kirk, K. L., Anderson, D. E., and Chen, X. (2007) Identification of arsenic-binding proteins in human breast cancer cells. Cancer Lett. 255, 95-106. 
(58) Vahter, M., Marafante, E., Lindgren, A., and Dencker, L. (1982) Tissue distribution and subcellular binding of arsenic in Marmoset monkeys after injection of 74As-Arsenite. Arch. Toxicol. 51, 65-77.

(59) Vahter, M., and Marafante, E. (1985) Reduction and binding of arsenate in marmoset monkeys. Arch. Toxicol. 57, 119 -124.

(60) Aposhian, H. V., and Aposhian, M. M. (2006) Arsenic Toxicology:Â Five Questions. Chem. Res. Toxicol. 19, 1-15.

(61) Katzung, B. (2009) Basic and Clinical Pharmacology, 11th Edition.

(62) Flora, S. J. S., and Pachauri, V. Chelation in Metal Intoxication. Int.J.environ.Res. $7,2745$.

(63) Waxman, S., and Anderson, K. C. (2001) History of the Development of Arsenic Derivatives in Cancer Therapy. Oncologist 6, 3-10.

(64) Balaz, P., and Sedlak, J. (2010) Arsenic in Cancer Treatment: Challenges for Application of Realgar Nanoparticles (A Minireview). Toxins 2, 1568-1581.

(65) Hazardous Substance Fact Sheet: Arsenic Disulfide.

(66) MSDS: Realgar.

(67) MSDS: Orpiment.

(68) Henke, K. (2009) Arsenic : environmental chemistry, health threats, and waste treatment. John Wiley \& Sons, United Kingdom.

(69) Konkola, K. (1992) More Than a Coincidence? The Arrival of Arsenic and the Disappearance of Plague in Early Modern Europe. J. Hist. Med. All. Sci. 47, 186209.

(70) Donovan's solution (AsHgI4) - Chembase - Chemical Compounds Database.

(71) Chemical of the Week -- Arsenic.

(72) Antman, K. H. (2001) Introduction: The History of Arsenic Trioxide in Cancer Therapy. Oncologist 6, 1-2.

(73) Gibaud, S., and Jaouen, G. (2010) Arsenic-based drugs: from Fowler's solution to modern anticancer chemotherapy, In Medicinal Organometallic Chemistry pp 120, Springer. 
(74) Bisser, S., N'Siesi, F.-X., Lejon, V., Preux, P.-M., Van Nieuwenhove, S., Bilenge, C. M. M., and Büscher, P. (2007) Equivalence trial of melarsoprol and nifurtimox monotherapy and combination therapy for the treatment of second-stage Trypanosoma brucei gambiense sleeping sickness. J. Infect. Dis. 195, 322-329.

(75) Lloyd, N. C., Morgan, H. W., Nicholson, B. K., and Ronimus, R. S. (2005) The Composition of Ehrlich's Salvarsan: Resolution of a Century-Old Debate. Angew. Chem. Int. Ed. 44, 941-944.

(76) Au, W.-Y., Kumana, C. R., Lee, H. K., Lin, S.-Y., Liu, H., Yeung, D. Y., Lau, J. S., and Kwong, Y.-L. (2011) Oral arsenic trioxide-based maintenance regimens for first complete remission of acute promyelocytic leukemia: a 10-year follow-up study. Blood 118, 6535-6543.

(77) Arsenic Trioxide Injection - PubMed Health.

(78) Trisenox (Arsenic Trioxide Injection) Drug Information: User Reviews, Side Effects, Drug Interactions and Dosage at RxList.

(79) Tsimberidou, A. M., Camacho, L. H., Verstovek, S., Ng, C., Hong, D. S., Uehara, C. K., Gutierrez, C., Daring, S., Stevens, J., Komarnitsky, P. B., Schwartz, B., and Kurzrock, R. (2009) A Phase I Clinical Trial of Darinaparsin in Patients with Refractory Solid Tumors. Clin. Cancer Res. 15, 4769-4776.

(80) Hermine, O., Dombret, H., Poupon, J., Arnulf, B., Lefre`re, F., Rousselot, P., Damaj, G., Delarue, R., Fermand, J. P., Brouet, J. C., Degos, L., Varet, B., de The $\hat{A}^{\prime}$, H., and Bazarbachi, A. (2004) Phase II trial of arsenic trioxide and alpha interferon in patients with relapsed/refractory adult T-cell leukemia/lymphoma. The hematology journal : the official journal of the European Haematology Association 5, 130-134.

(81) Altman, J. K., and Tallman, M. S. (2011) "Boldness be my friend"(Shakespeare; Cymbeline). Blood 118, 6477-6478.

(82) Chen, H., MacDonald, R. C., Li, S., Krett, N. L., Rosen, S. T., and O'Halloran, T. V. (2006) Lipid encapsulation of arsenic trioxide attenuates cytotoxicity and allows for controlled anticancer drug release. J. Am. Chem. Soc. 128, 1334813349 .

(83) Chen, H., Ahn, R., Van den Bossche, J., Thompson, D. H., and O'Halloran, T. V. (2009) Folate-mediated intracellular drug delivery increases the anticancer efficacy of nanoparticulate formulation of arsenic trioxide. Mol. Cancer Ther. 8, 1955-1963. 
(84) Chen, H., Pazicni, S., Krett, N. L., Ahn, R. W., Penner-Hahn, J. E., Rosen, S. T., and O'Halloran, T. V. (2009) Coencapsulation of Arsenic-and Platinum-based Drugs for Targeted Cancer Treatment. Angew. Chem. Int. Ed. 48, 9295-9299.

(85) Ahn, R. W., Chen, F., Chen, H., Stern, S. T., Clogston, J. D., Patri, A. K., Raja, M. R., Swindell, E. P., Parimi, V., and Cryns, V. L. (2010) A novel nanoparticulate formulation of arsenic trioxide with enhanced therapeutic efficacy in a murine model of breast cancer. Clin. Cancer Res. 16, 3607-3617.

(86) Ahn, R. W., Barrett, S. L., Raja, M. R., Jozefik, J. K., Spaho, L., Chen, H., Bally, M. B., Mazar, A. P., Avram, M. J., and Winter, J. N. (2013) Nano-Encapsulation of Arsenic Trioxide Enhances Efficacy against Murine Lymphoma Model while Minimizing Its Impact on Ovarian Reserve In Vitro and In Vivo. PloS one 8, e58491.

(87) Effects of realgar (tetra-arsenic tetra-sulfide) on malignant tumor cells. - ASCO.

(88) Elliott, M., Ford, S., Prasad, E., Dick, L., Farmer, H., Hogg, P., and Halbert, G. (2012) Pharmaceutical development of the novel arsenical based cancer therapeutic GSAO for Phase I clinical trial. Int. J. Pharm. 426, 67-75.

(89) Cadd, V. A., Hogg, P. J., Harris, A. L., and Feller, S. M. (2006) Molecular profiling of signalling proteins for effects induced by the anti-cancer compound GSAO with 400 antibodies. BMC cancer 6, 155.

(90) Park, D., Chiu, J., Perrone, G. G., Dilda, P. J., and Hogg, P. J. (2012) The tumour metabolism inhibitors GSAO and PENAO react with cysteines 57 and 257 of mitochondrial adenine nucleotide translocase. Cancer Cell Int 12, 11.

(91) Matulis, S. M., Morales, A. A., Yehiayan, L., Croutch, C., Gutman, D., Cai, Y., Lee, K. P., and Boise, L. H. (2009) Darinaparsin induces a unique cellular response and is active in an arsenic trioxide-resistant myeloma cell line. Mol. Cancer Ther. 8, 1197-1206.

(92) Kumagai, Y., and Sumi, D. (2007) Arsenic: Signal Transduction, Transcription Factor, and Biotransformation Involved in Cellular Response and Toxicity. Annu. rev. Pharmacol. Toxicol. 47, 243-262.

(93) Novel organic arsenic molecule darinaparsin: Development of IV and oral forms. - ASCO.

(94) Garnier, N., Redstone, G., Dahabieh, M. S., Nichol, J. N., Del Rincon, S. V., Gu, Y., Bohle, D. S., Sun, Y., Conklin, D. S., and Mann, K. K. (2014) The Novel Arsenical Darinaparsin is Transported by Cystine Importing Systems. Mol. Pharmacol. 85, 576-585. 
(95) Miodragović, Đ. U., Quentzel, J. A., Kurutz, J. W., Stern, C. L., Ahn, R. W., Kandela, I., Mazar, A., and O'Halloran, T. V. (2013) Robust Structure and Reactivity of Aqueous Arsenous Acid-Platinum (II) Anticancer Complexes. Angew. Chem. Int. Ed. 52, 10749-10752.

(96) Naranmandura, H., Iwata, K., Suzuki, K. T., and Ogra, Y. (2010) Distribution and metabolism of four different dimethylated arsenicals in hamsters. Toxicol. Appl. Pharmacol. 245, 67-75.

(97) Drobn $\tilde{A}_{i}$, Z., Walton, F. S., Harmon, A. W., Thomas, D. J., and Styblo, M. (2010) Interspecies differences in metabolism of arsenic by cultured primary hepatocytes. Toxicol. Appl. Pharmacol. 245, 47-56.

(98) Rehman, K., and Naranmandura, H. (2012) Arsenic metabolism and thioarsenicals. Metallomics 4, 881-892.

(99) Stamatelos, S., Brinkerhoff, C., Isukapalli, S., and Georgopoulos, P. (2011) Mathematical model of uptake and metabolism of arsenic (III) in human hepatocytes-Incorporation of cellular antioxidant response and thresholddependent behavior. BMC Syst. Biol. 5, 16.

(100) Leslie, E. M. (2012) Arsenic-glutathione conjugate transport by the human multidrug resistance proteins (MRPs/ABCCs). J. Inorg. Biochem. 108, 141-149.

(101) Leung, J., Pang, A., Yuen, W.-H., Kwong, Y.-L., and Eric, W. (2007) Relationship of expression of aquaglyceroporin 9 with arsenic uptake and sensitivity in leukemia cells. Blood 109, 740-746.

(102) Kobayashi, Y., Hayakawa, T., and Hirano, S. (2007) Expression and activity of arsenic methyltransferase Cyt19 in rat tissues. Environ. Toxicol. Phar. 23, 115120.

(103) Challenger, F. (1945) Biological methylation. Chem. Rev. 36, 315-361.

(104) Hayakawa, T., Kobayashi, Y., Cui, X., and Hirano, S. (2005) A new metabolic pathway of arsenite: arsenic-glutathione complexes are substrates for human arsenic methyltransferase Cyt19. Arch. Toxicol. 79, 183-191.

(105) Kala, S. V., Neely, M. W., Kala, G., Prater, C. I., Atwood, D. W., Rice, J. S., and Lieberman, M. W. (2000) The MRP2/cMOAT transporter and arsenic-glutathione complex formation are required for biliary excretion of arsenic. J. Biol. Chem. 275, 33404-33408.

(106) Sherratt, P. J., and Hayes, J. D. (2002) 9 Glutathione S-transferases. J. Wiley, New York. 
(107) Naranmandura, H., Suzuki, N., and Suzuki, K. T. (2006) Trivalent arsenicals are bound to proteins during reductive methylation. Chem. Res. Toxicol. 19, 10101018 .

(108) Suzuki, K. T., Katagiri, A., Sakuma, Y., Ogra, Y., and Ohmichi, M. (2004) Distributions and chemical forms of arsenic after intravenous administration of dimethylarsinic and monomethylarsonic acids to rats. Toxicol. Appl. Pharmacol. $198,336-344$.

(109) Bogdan, G. M., Sampayo-Reyes, A., and Vasken Aposhian, H. (1994) Arsenic binding proteins of mammalian systems: I. Isolation of three arsenite-binding proteins of rabbit liver. Toxicology 93, 175-193.

(110) Suzuki, K. T., Mandal, B. K., Katagiri, A., Sakuma, Y., Kawakami, A., Ogra, Y., Yamaguchi, K., Sei, Y., Yamanaka, K., Anzai, K., Ohmichi, M., Takayama, H., and Aimi, N. (2004) Dimethylthioarsenicals as Arsenic Metabolites and Their Chemical Preparations. Chem. Res. Toxicol. 17, 914-921.

(111) Naranmandura, H., Suzuki, N., and Suzuki, K. T. (2008) Reaction mechanism underlying the in vitro transformation of thioarsenicals. Toxicol. Appl. Pharmacol. 231, 328-335.

(112) Raab, A., Wright, S. H., Jaspars, M., Meharg, A. A., and Feldmann, J. (2007) Pentavalent Arsenic Can Bind to Biomolecules. Angew. Chem. Int. Ed. 46, 25942597.

(113) Brima, E. I., Haris, P. I., Jenkins, R. O., Polya, D. A., Gault, A. G., and Harrington, C. F. (2006) Understanding arsenic metabolism through a comparative study of arsenic levels in the urine, hair and fingernails of healthy volunteers from three unexposed ethnic groups in the United Kingdom. Toxicology and Applied Pharmacology 216, 122-130.

(114) Van de Wiele, T., Gallawa, C. M., Kubachk, K. M., Creed, J. T., Basta, N., Dayton, E. A., Whitacre, S., Du Laing, G., and Bradham, K. (2010) Arsenic metabolism by human gut microbiota upon in vitro digestion of contaminated soils. Environ. Health Perspect. 118, 1004.

(115) Yehiayan, L., Pattabiraman, M., Kavallieratos, K., Wang, X., Boise, L. H., and Cai, Y. (2009) Speciation, formation, stability and analytical challenges of human arsenic metabolites. J. Anal. At. Spectrom. 24, 1397-1405.

(116) Gong, Z., Lu, X., Cullen, W. R., and Le, X. C. (2001) Unstable trivalent arsenic metabolites, monomethylarsonous acid and dimethylarsinous acid. J. Anal. At. Spectrom. 16, 1409-1413. 
(117) Yehiayan, L., Membreno, N., Matulis, S., Boise, L. H., and Cai, Y. (2011) Extraction tool and matrix effects on arsenic speciation analysis in cell lines. Anal. Chim. Acta 699, 187-192.

(118) Raab, A., Meharg, A. A., Jaspars, M., Genney, D. R., and Feldmann, J. (2004) Arsenic-glutathione complexes: their stability in solution and during separation by different HPLC modes. J. Anal. At. Spectrom. 19, 183.

(119) Gong, Z., Lu, X., Ma, M., Watt, C., and Le, X. C. (2002) Arsenic speciation analysis. Talanta $58,77-96$.

(120) Chungang, Y., and Le, X. C. (2009) Arsenic Speciation Analysis. Prog. Chem. $21,467-473$.

(121) Hsu, K.-C., Sun, C.-C., and Huang, Y.-L. (2011) Arsenic speciation in biomedical sciences: Recent advances and applications. Kaohsiung J. Med. Sci. 27, 382-389.

(122) B'Hymer, C., and Caruso, J. A. (2004) Arsenic and its speciation analysis using high-performance liquid chromatography and inductively coupled plasma mass spectrometry. J. Chromatogr. A 1045, 1-13.

(123) Francesconi, K. A., and Kuehnelt, D. (2004) Determination of arsenic species: A critical review of methods and applications, 2000-2003. Analyst (London) 129, 373.

(124) Abernathy, C., and Morgan, A. (2001) Chapter 3: Exposure and Health Effects, United Nations Synthesis Report on Arsenic in Drinking Water, World Health Organization, Geneva, Switzerland.

(125) Campas, C., and Castaner, R. (2009) Darinaparsin. Organic arsenical, Apoptosis inducer, Oncolytic. Drug Future 34, 97-100.

(126) Wu, J., Henderson, C., Feun, L., Van Veldhuizen, P., Gold, P., Zheng, H., Ryan, T., Blaszkowsky, L. S., Chen, H., Costa, M., Rosenzweig, B., Nierodzik, M., Hochster, H., Muggia, F., Abbadessa, G., Lewis, J., and Zhu, A. X. (2010) Phase II study of darinaparsin in patients with advanced hepatocellular carcinoma. Invest. New Drugs 28, 670-676.

(127) Mason, T. A., Kolobova, E., Liu, J., Roland, J. T., Chiang, C., and Goldenring, J. R. (2011) Darinaparsin Is a Multivalent Chemotherapeutic Which Induces Incomplete Stress Response with Disruption of Microtubules and Shh Signaling. PLOS ONE 6, e27699.

(128) Diaz, Z., Mann, K. K., Marcoux, S., Kourelis, M., Colombo, M., Komarnitsky, P. B., and Miller, W. H. (2008) A novel arsenical has antitumor activity toward $\mathrm{As}_{2} \mathrm{O}_{3}$-resistant and MRP1/ABCC1-overexpressing cell lines. Leukemia 22, 18531863. 
(129) Mann, K. K., Wallner, B., Lossos, I. S., and Miller Jr, W. H. (2009) Darinaparsin: a novel organic arsenical with promising anticancer activity. Expert Opin. Investig. Drugs 18, 1727-1734.

(130) Petrick, J. S., Jagadish, B., Mash, E. A., and Aposhian, H. V. (2000) Monomethylarsonous Acid (MMAIII) Is More Toxic Than Arsenite in Chang Human Hepatocytes. Toxicol. Appl. Pharmacol. 163, 203-207.

(131) Hirano, S., and Kobayashi, Y. (2006) Cytotoxic effects of S-(dimethylarsino)glutathione: A putative intermediate metabolite of inorganic arsenicals. Toxicology 227, 45-52.

(132) Marapakala, K., Qin, J., and Rosen, B. P. (2012) Identification of catalytic residues in the As (III) S-adenosylmethionine methyltransferase. Biochemistry 51, 944-951.

(133) Naranmandura, H., Ogra, Y., Iwata, K., Lee, J., Suzuki, K. T., Weinfeld, M., and Le, X. C. (2009) Evidence for toxicity differences between inorganic arsenite and thioarsenicals in human bladder cancer cells. Toxicol. Appl. Pharmacol. 238, 133140 .

(134) Yehiayan, L., Pattabiraman, M., Kavallieratos, K., Wang, X., Boise, L. H., and Cai, Y. (2009) Speciation, formation, stability and analytical challenges of human arsenic metabolites. Journal of Analytical Atomic Spectrometry 24, 1397-1405.

(135) Suzuki, N., Naranmandura, H., Hirano, S., and Suzuki, K. T. (2008) Theoretical calculations and reaction analysis on the interaction of pentavalent thioarsenicals with biorelevant thiol compounds. Chem. Res. Toxicol. 21, 550-553.

(136) Smedley, P., and Kinniburgh, D. G. (2013) Arsenic in groundwater and the environment. Springer, Netherlands.

(137) Brammer, H., and Ravenscroft, P. (2009) Arsenic in groundwater: a threat to sustainable agriculture in South and South-east Asia. Environ. Int. 35, 647-654.

(138) Kile, M. L., Houseman, E. A., Breton, C. V., Smith, T., Quamruzzaman, Q., Rahman, M., Mahiuddin, G., and Christiani, D. C. (2007) Dietary arsenic exposure in Bangladesh. Environ. Health Perspect. 115, 889.

(139) Meharg, A. A., and Rahman, M. M. (2003) Arsenic contamination of Bangladesh paddy field soils: implications for rice contribution to arsenic consumption. Environ. Sci. Tech. 37, 229-234.

(140) Francesconi, K. A. (2010) Arsenic species in seafood: Origin and human health implications. Pure Appl. Chem. 82, 373-381. 
(141) Bhattacharjee, P., Chatterjee, D., Singh, K. K., and Giri, A. K. (2013) Systems biology approaches to evaluate arsenic toxicity and carcinogenicity: An overview. Int. J. Hyg. Envir. Heal.

(142) Banerjee, M., Bhattacharjee, P., and Giri, A. K. (2011) Arsenic-induced cancers: a review with special reference to gene, environment and their interaction. Gene Environ. 33, 128-140.

(143) Navas-Acien, A., Silbergeld, E. K., Pastor-Barriuso, R., and Guallar, E. (2008) Arsenic exposure and prevalence of type 2 diabetes in US adults. JAMA 300, 814822.

(144) Aronson, S. (1994) Arsenic and old myths. Rhode Island medicine 77, 233.

(145) Haller, J. S. (1975) Therapeutic mule: the use of arsenic in the nineteenth century materia medica. Pharmacy in History 17, 87-100.

(146) Liu, J.-X., Zhou, G.-B., Chen, S.-J., and Chen, Z. (2012) Arsenic compounds: revived ancient remedies in the fight against human malignancies. Curr. Opin. Chem. Biol. 16, 92-98.

(147) Shen, Z.-X., Chen, G.-Q., Ni, J.-H., Li, X.-S., Xiong, S.-M., Qiu, Q.-Y., Zhu, J., Tang, W., Sun, G.-L., and Yang, K.-Q. (1997) Use of arsenic trioxide (As2O3) in the treatment of acute promyelocytic leukemia (APL): II. Clinical efficacy and pharmacokinetics in relapsed patients. Blood 89, 3354-3360.

(148) Lossos, I., Craig, M., Tallman, R., Boccia, P., Conkling, C., Becerra, P., Komarnitsky, B., Hamilton Lewis, J., and Miller, W. (2009) Novel organic arsenic molecule darinaparsin: development of IV and oral forms. J. Clin. Onc., Proc. Am. Soc. Clin. Onc. 27, A\# 8501.

(149) Burrows, G. G. J. (1920) A new type of compound containing arsenic. J. Chem. Soc., Trans. 117, 1373.

(150) Spuches, A. M., Kruszyna, H. G., Rich, A. M., and Wilcox, D. E. (2005) Thermodynamics of the As(III)-Thiol Interaction: Arsenite and Monomethylarsenite Complexes with Glutathione, Dihydrolipoic Acid, and Other Thiol Ligands. Inorg. Chem. 44, 2964-2972.

(151) Nakayama, T., Edmonds, J. S., Shibata, Y., and Morita, M. (2006) The rate of oxidation of dimethylarsinous acid to dimethylarsinic acid is $\mathrm{pH}$ dependent: implications for the analysis and toxicology of arsenic metabolites in urine. $J$. Chem. Res. 2006, 185-187.

(152) Kazakevich, Y. V., and Lobrutto, R. (2007) HPLC for Pharmaceutical Scientists. John Wiley \& Sons, New York. 
(153) Kralj, P., and Veber, M. (2003) Investigations into nonspectroscopic effects of organic compounds in inductively coupled plasma mass spectrometry. Acta chimica slovenica 50, 633-644.

(154) Lam, J. W. H., and Horlick, G. (1990) A comparison of argon and mixed gas plasmas for inductively coupled plasma-mass spectrometry. Spectrochim. Acta B $45,1313-1325$.

(155) Yoshida, K., Kuroda, K., Zhou, X., Inoue, Y., Date, Y., Wanibuchi, H., Fukushima, S., and Endo, G. (2003) Urinary sulfur-containing metabolite produced by intestinal bacteria following oral administration of dimethylarsinic acid to rats. Chem. Res. Toxicol. 16, 1124-1129.

(156) Asimakopoulou, A., Panopoulos, P., Chasapis, C. T., Coletta, C., Zhou, Z., Cirino, G., Giannis, A., Szabo, C., Spyroulias, G. A., and Papapetropoulos, A. (2013) Selectivity of commonly used pharmacological inhibitors for cystathionine beta synthase (CBS) and cystathionine gamma lyase (CSE). Br. J. Pharmacol. 169.4, 922-932.

(157) Chiku, T., Padovani, D., Zhu, W., Singh, S., Vitvitsky, V., and Banerjee, R. (2009) $\mathrm{H}_{2} \mathrm{~S}$ biogenesis by human cystathionine $\gamma$-lyase leads to the novel sulfur metabolites lanthionine and homolanthionine and is responsive to the grade of hyperhomocysteinemia. J. Biol. Chem. 284, 11601-11612.

(158) Kabil, O., and Banerjee, R. (2010) Redox biochemistry of hydrogen sulfide. $J$. Biol. Chem. 285, 21903-21907.

(159) Singh, S., Padovani, D., Leslie, R. A., Chiku, T., and Banerjee, R. (2009) Relative contributions of cystathionine $\beta$-synthase and $\gamma$-cystathionase to $\mathrm{H}_{2} \mathrm{~S}$ biogenesis via alternative trans-sulfuration reactions. J. Biol. Chem. 284, 22457-22466.

(160) Toohey, J. I. (2011) Sulfur signaling: is the agent sulfide or sulfane? Anal. Biochem. 413, 1-7.

(161) Mueller, E. G. (2006) Trafficking in persulfides: delivering sulfur in biosynthetic pathways. Nat. Chem. Biol. 2, 185-194.

(162) Mustafa, A. K., Gadalla, M. M., Sen, N., Kim, S., Mu, W., Gazi, S. K., Barrow, R. K., Yang, G., Wang, R., and Snyder, S. H. (2009) $\mathrm{H}_{2} \mathrm{~S}$ signals through protein S-sulfhydration. Sci. Signal. 2, ra72.

(163) Paul, B. D., and Snyder, S. H. (2012) $\mathrm{H}_{2} \mathrm{~S}$ signalling through protein sulfhydration and beyond. Nat. Rev. Mol. Cell Bio. 13.8, 499-507.

(164) Ruzza, P., and Calderan, A. (2013) Glutathione Transferase (GST)-Activated Prodrugs. Pharmaceutics 5, 220-231. 
(165) Li, L., Whiteman, M., Guan, Y. Y., Neo, K. L., Cheng, Y., Lee, S. W., Zhao, Y., Baskar, R., Tan, C.-H., and Moore, P. K. (2008) Characterization of a Novel, Water-Soluble Hydrogen Sulfide-Releasing Molecule (GYY4137) New Insights Into the Biology of Hydrogen Sulfide. Circulation 117, 2351-2360.

(166) Francoleon, N. E., Carrington, S. J., and Fukuto, J. M. (2011) The reaction of $\mathrm{H}_{2} \mathrm{~S}$ with oxidized thiols: Generation of persulfides and implications to $\mathrm{H}_{2} \mathrm{~S}$ biology. Arch. Biochem. Biophys. 516, 146-153.

(167) Rao, S. G., Gorin, George. (1959) Reaction of Cysteine with Sodium Sulfide in Sodium Hydroxide Solution. J. Org. Chem. 24, 749-753.

(168) Wenzel, T. Fundamental Aspects of Chromatography.

(169) Gritti, F., Piatkowski, W., and Guiochon, G. (2002) Comparison of the adsorption equilibrium of a few low-molecular mass compounds on a monolithic and a packed column in reversed-phase liquid chromatography. J. Chromatogr. A 978, 81-107.

(170) Mazzotti, M. (2006) Equilibrium theory based design of simulated moving bed processes for a generalized Langmuir isotherm. J. Chromatogr. A 1126, 311-322.

(171) Mazzotti, M. (2006) Local equilibrium theory for the binary chromatography of species subject to a generalized Langmuir isotherm. J. Ind. Eng. Chem. 45, 53325350 .

(172) Feldmann, J., Lai, V. W., Cullen, W. R., Ma, M., Lu, X., and Le, X. C. (1999) Sample preparation and storage can change arsenic speciation in human urine. Clin. Chem. 45, 1988-1997.

(173) Georgiadis, M., Cai, Y., and Solo-Gabriele, H. M. (2006) Extraction of arsenate and arsenite species from soils and sediments. Environ. Pollut. 141, 22-29.

(174) Ellwood, M. J., and Maher, W. A. (2003) Anal. Chim. Acta 447, 279.

(175) Feldman, C. (1979) Improvements in the arsine accumulation-helium glow detector procedure for determining traces of arsenic. Anal. Chem. 51, 664-669.

(176) Soylak, M., Elci, L., and Doğan, M. (1993) Determinations of some trace metals in dialysis solutions by atomic absorption spectrometry after preconcentration. Anal. Lett. 26, 1997-2007.

(177) Palágyi, S., Braun, T., Alfassi, Z., and Wai, C. (1992) Separation and preconcentration of trace elements and inorganic species on solid polyurethane foam sorbents, In Preconcentration Techniques for Trace Elements pp 363-400, CRC Press, Boca Raton. 
(178) Srivastava, S., and Goyal, P. (2010) Detoxification of Metals-Biochelation, In Novel Biomaterials pp 11-20, Springer. 
VITA

\section{SZABINA STICE}

2004-2005 A.S., Chemistry

Kingsborough College of the City University of New York

Brooklyn, New York

2005-2006 B.A., Chemistry

Brooklyn College of the City University of New York

Brooklyn, New York

2006 Sylvia Smolensky Chemistry Award

Brooklyn College

Brooklyn, New York

2006-2008 Senior Analyst

Swisscaps

Miramar, Florida

2007 Graduate Certificate in Forensic Drug Chemistry

University of Florida

Gainesville, Florida

2008-2009 M.S., Pharmacy and Pharmaceutical Sciences

University of Florida

Gainesville, Florida

2008-2010 Analytical Scientist III

Aveva Drug Delivery Systems

Miramar, Florida

2010-2014 PhD, Chemistry

Florida International University,

Miami, Florida

2012-2014 FIU MBRS RISE Fellow

2012-2014 Graduate Certificate in Pharmaceutical Chemistry

University of Florida

Gainesville, Florida

2014-current Adjunct Chemistry Faculty

Miami Dade College

Miami, Florida 


\section{PUBLICATIONS AND PRESENTATIONS:}

Dimethylarsinothioyl glutathione as a metabolite in human multiple myeloma cell lines upon exposure to Darinaparsin. Published in the journal of Chemical Research in Toxicology, 03/2014.

Simultaneous determination of multiple human arsenic metabolites employing high performance liquid chromatograph inductively coupled plasma mass spectrometer. (Submitted to the journal of Analytical and Bioanalytical Chemistry)

Mechanistic study on the formation of dimethylarsinothioyl glutathione and other sulfur containing arsenic metabolites. (Submitted to the journal of Chemical Research in Toxicology)

MARC U*STAR \& MBRS RISE Biomedical Symposium, 10/2013, Miami, FL (oral)

$9^{\text {th }}$ International Symposium on Persistent Toxic Substances, 10/2012, Miami, FL (poster)

MARC U*STAR \& MBRS RISE Biomedical Symposium, 10/2012, Miami, FL (oral) 